JUAN MARCELO ROJAS ARANGO

REFINO DE GRÃO DAS LIGAS DO SISTEMA COBRE-ESTANHO

São Paulo

2016 
JUAN MARCELO ROJAS ARANGO

REFINO DE GRÃO DAS LIGAS DO SISTEMA COBRE-ESTANHO

Tese de doutoramento apresentada à Escola Politécnica da Universidade de São Paulo para obtenção do título de Doutor em Ciências.

São Paulo 
JUAN MARCELO ROJAS ARANGO

\section{REFINO DE GRÃO DAS LIGAS DO SISTEMA COBRE-ESTANHO}

Tese de doutoramento apresentada à Escola Politécnica da Universidade de São Paulo para obtenção do título de Doutor em Ciências.

Área de concentração: Engenharia Metalúrgica.

Orientador: Prof. Dr. Marcelo de Aquino Martorano.

São Paulo

2016 
Este exemplar foi revisado e corrigido em relação à versão original, sob responsabilidade única do autor e com a anuência de seu orientador.

São Paulo, de de

Assinatura do autor:

Assinatura do orientador:

Arango, Juan Marcelo Rojas Arango

Refino de grão das ligas do sistema cobre-estanho / J. M. R. A. Arango -versão corr. -- São Paulo, 2016.

$130 \mathrm{p}$.

Tese (Doutorado) - Escola Politécnica da Universidade de São Paulo. Departamento de Engenharia Metalúrgica e de Materiais.

1.Refino de grão 2.Inoculação 3.Ligas de cobre 4.Solidificação 5.Microscopia de transmissão I.Universidade de São Paulo. Escola Politécnica. Departamento de Engenharia Metalúrgica e de Materiais II.t. 
Dedicado a mi familia, gracias por haberme educado así. 


\section{AGRADECIMENTOS}

À Eline Alves de Souza Barreto, minha esposa amada, pela paciência, pelas palavras e por estar sempre ao meu lado durante este caminho que juntos decidimos percorrer.

Ao meu orientador, Professor Marcelo de Aquino Martorano, pela acolhida, a paciência e o seu profissionalismo que me incentiva com seu exemplo a continuar em frente.

Um muito obrigado ao Prof. Dr. Angelo Fernando Padilha, pela cooperação com o projeto de pesquisa e pela ajuda com as discussões e sugestões em os momentos da elaboração deste trabalho.

Aos funcionários e professores do Departamento de Engenharia Metalúrgica e de Materiais da Escola Politécnica da USP: Gilberto Martins, Clélia dos Santos, Lívio da Silva Nunes, Veríssimo S. dos Santos, Danilo Augusto de Almeida, Rubens B. do Carvalho, Rafael Maia, Suellen Cardozo, Vera Lúcia dos Santos, Patrícia dos Santos, Prof. Dr. André Paulo Tschiptschin, Prof. Dr. Hélio Goldenstein, Prof. Dr. Guilherme Lenz, Prof. Dr. Marcelo Breda Mourão; que com sua ajuda essencial, facilitaram o desenvolvimento deste trabalho.

Aos meus grandes amigos, Anderson Ariza e Juliana Gomez, Dany Centeno e Leidy Hernández, Alan Barros, Mario Gonzáles, Arthur Seiji Nishikawa, Ana Cecília Rodrigues, Thiago Nagasima, Luis Varela, Felipe Jaime, Ygor Regados, Marcelo Tirelli e Pablo Correa, pela amizade, pelas palavras de ânimo, pela paciência e pelas discussões científicas nos corredores do PMT.

À Ricardo Aristizábal S. pela amizade de todos estes anos e sua ajuda incondicional.

À CAPES pela bolsa de estudos concedida e ao suporte financeiro da FAPESP (processo no. 2013/08723-1).

Às empresas Termomecânica S.A. e a Paranapanema S. A. pelo fornecimento das ligas especiais.

À senhora Marycel Cotrim do Centro de Química e Meio Ambiente - CQMA Ipen e ao Laboratório de análises químicas- Cquim no IPT, pelas análises químicas. 
Ao Laboratório de Fenômenos de Superfície (LFS) pela execução das análises no MEV.

Ao Laboratório de Caracterização Estrutural (LCE) do Departamento de Engenharia de Materiais (DEMa) da Universidade Federal de São Carlos (UFSCar) e o Centro de Microscopia da Universidade Federal de Minas Gerais, Belo Horizonte, MG, pela execução das análises no microscópio eletrônico de transmissão. 


\section{RESUMO}

As ligas de cobre têm grande importância na fabricação de produtos metálicos que necessitam de boa resistência à corrosão e/ou alta condutividade térmica e elétrica. A sua estrutura de grãos bruta de solidificação define diversas propriedades requeridas em serviço/processamento e o refino desta estrutura pode ser realizado a partir da inoculação do banho metálico antes do início da solidificação, aumentando o número de núcleos sólidos formados. A inoculação e os mecanismos de refino de grão em ligas de cobre foram pouco investigados e não são entendidos suficientemente para permitir o projeto de inoculantes. O presente trabalho tem como principal objetivo identificar os mecanismos fundamentais de inoculação e refino de grão das ligas do sistema Cu-Sn a partir de adições de $\mathrm{Zr}$ aos banhos líquidos antes da solidificação. Amostras cilíndricas foram produzidas a partir da solidificação das ligas a uma taxa de resfriamento de $\sim 0,8{ }^{\circ} \mathrm{C} / \mathrm{s}$. Estas amostras foram analisadas por diferentes técnicas: (a) observação da macroestrutura de grãos; (b) análise térmica das curvas de resfriamento obtidas durante a solidificação; (c) análise química; (d) exame da microestrutura em microscopia óptica, microscopia eletrônica de varredura (MEV) com emissão de campo (FEG), microscopia eletrônica de transmissão (MET) com e sem o feixe de íons (FIB) e (e) microanálise por espectroscopia de energia dispersiva (EDS). Observa-se que adições de $\mathrm{Zr}$ na faixa de 0,04 a $0,4 \%$ a banhos da liga $\mathrm{Cu}-8 \% \mathrm{Sn}$ com cobertura de pó de grafita reduzem o tamanho médio de grão em até $90 \%$, mas não causam efeito significativo sem a cobertura de grafita. Este efeito da diminuição do tamanho de grão com a adição de $Z r$ torna-se significativo somente para teores de $S n \geq 4 \%$. Esta redução de tamanho médio de grão é acompanhada do aparecimento de partículas facetadas na microestrutura, identificadas como $\mathrm{ZrC}$ a partir de padrões de difração de elétrons e microanálises EDS. Uma análise teórica mostra desajustes entre os reticulados do ZrC e do Cua tão pequenos quanto 1,9\%, indicando que estas partículas podem funcionar como centros efetivos para a nucleação heterogênea e causar o refino de grão em ligas de $\mathrm{Cu}$. Parâmetros extraídos da recalescência das curvas de resfriamento, como a diferença entre as temperaturas mínima e máxima da recalescência, apresentaram boa correlação com o tamanho médio de grão final, indicando a possibilidade do controle do tamanho de grão em ligas $\mathrm{Cu}$-Sn com adições de $Z r$ a partir da análise térmica.

Palavras chave: Refino de grão, inoculação, ligas de cobre. 


\begin{abstract}
Copper alloys are important to the production of metallic parts with good corrosion resistance and high thermal and electrical conductivity. The as-cast grain structures of these alloys are closely related to the properties required in service or during processing. The refining of the grain structure can be achieved by inoculation of the metallic melt, before the beginning of solidification, increasing the number of solid nuclei. The inoculantion and grain refining of copper alloys have been poorly investigated and are not sufficiently understood to enable the design of inoculants. The objective of the present work is to identify the fundamental mechanisms underlying the inoculation and grain refining of $\mathrm{Cu}-\mathrm{Sn}$ alloys by additions of $\mathrm{Zr}$ to the melt prior to solidification. Cylindrical samples of these alloys were cast at a cooling rate of $\sim 0,8$ ${ }^{\circ} \mathrm{C} / \mathrm{s}$. These samples were analyzed using different techniques: (a) observation of the grain macrostructure; (b) thermal analysis of the cooling curves collected during solidification; (c) chemical analysis; (d) observation of the microstructure in the optical microscope, scanning electron microscope (SEM) with field emission gun (FEG), trasmission electron microscope (TEM) with and without the focused ion beam (FIB) for sample preparation and (e) energy dispersive spectroscopy (EDS) microanalysis. The results show that additions of $Z r$ in the range between 0,04 and $0,4 \%$ to melts of a $\mathrm{Cu}-8 \% \mathrm{Sn}$ alloy with a graphite powder cover decrease the average grain size by up to $90 \%$, but have no effect without the graphite cover. The decrease in grain size obtained with $\mathrm{Zr}$ additions become significant only for alloys with \%Sn $\geq 4$ and is followed by the appearance of faceted particles in the microstructure, identified as $\mathrm{ZrC}$ after examining electron difraction patterns and EDS microanalyses of the particles. A theoretical analysis of the disregistry parameters between the lattices of $\mathrm{ZrC}$ and $\mathrm{Cu} \alpha$ indicated values as low as 1,9\%, which is an indication that the $\mathrm{ZrC}$ particles can work as effective centers for heterogeneous nucleation and can cause the refining of grains in $\mathrm{Cu}$ alloys. Parameters calculated from the recalescence of the cooling curves measured during solidification correlated well with the everage grain size, suggesting the possibility of grain size control of $\mathrm{Cu}-\mathrm{Sn}$ alloys with $\mathrm{Zr}$ addition using thermal analysis.
\end{abstract}

Keywords: Grain refinement, inoculation, copper alloys. 


\section{LISTA DE ILUSTRAÇÕES}

Figura 1 - Estrutura: a) não facetada; b) facetada. (KURZ; FISHER, 1989).

Figura 2 - Variação da energia livre de um aglomerado esférico de sólido em função do raio do aglomerado (PEREPEZKO, 1998a).

Figura 3 - Variação da taxa de nucleação em metais com o super-resfriamento $\Delta \boldsymbol{T}$, onde $\Delta T C$ é o super-resfriamento crítico para a nucleação (GARCIA, 2001).

Figura 4 - Sistema de forças interfaciais existentes na nucleação heterogênea (PEREPEZKO, 1998a).

Figura 5 - Variação do fator de forma ou $\Delta \operatorname{GHet}(\boldsymbol{r}) / \Delta \operatorname{GHom}(\boldsymbol{r})$ e tamanho relativo da calota esférica, $\mathrm{h} / \mathrm{r}$, como uma função do ângulo de contato, $\theta$ (PEREPEZKO, 1998a).

Figura 6 - Variação da taxa de nucleação em metais com o super-resfriamento $\Delta \boldsymbol{T}$, para a nucleação homogênea e nucleação heterogênea, (FLEMINGS, 1974).

Figura 7 - Seção transversal e longitudinal da estrutura bruta de solidificação de lingotes a) estrutura coquilhada (equiaxial) nas paredes do molde e estrutura colunar em direção ao centro. b) estrutura coquilhada nas paredes, seguida de estrutura colunar e estrutura equiaxial no centro do lingote. c) estrutura totalmente equiaxial. Modificado de: (KALPAKJIAN, 2006).

Figura 8 - (a) Crescimento equiaxial, (b) crescimento direcional, (c) campos de composição e temperatura ao longo do eixo da dendrita. (TRIVEDI; KURZ, 1994).. 13

Figura 9 - Representação esquemática da estrutura equiaxial dendrítica e a variação da composição. Adaptado do DANTZIG; RAPPAZ (2009).

Figura 10 - Nucleação de um cristal com formato esférico sobre um substrato de TiB2 apresentando o rádio mínimo de curvatura limitado pelo diâmetro da partícula, GREER et al. (2000). 
Figura 11 - Comparação da variação da velocidade da ponta da dendrita como função da concentração de valores teóricos e experimentais. a) valores experimentais socionitrilo-acetona, $\Delta T=0,5 \mathrm{~K}$. Triveri et al. (1994). b) valores simulados para ligas de Cu-Al, $\Delta \mathrm{T}=0,5 \mathrm{~K}$ e 1,5 K, DANTZIG; RAPPAZ (2009).

Figura 12 - Macroestrutura de grãos em uma liga de cobre (Cu-36\%Zn-1.5\%Pb0,4\%Al): a) sem adição de inoculante; b) com adição de 275 ppm de Fe e 15 ppm B (SADAYAPPAN et al., 2005).

Figura 13 - Seção transversal perpendicular ao plano (100) num reticulado cúbico simples mostrando as regiões locais com ajuste no reticulado entre núcleo e substrato. Adaptado de TURNBULL; VONNEGUT (1952).

Figura 14 - Relações de orientação (direções e planos cristalográficos paralelos nos dois reticulados) entre substratos de $\mathrm{TiAl}_{3}$ e $\mathrm{ZrAl}_{3}$ com o alumínio (Al) e posicionamento relativo dos átomos em cada reticulado. A linha tracejada delineia o parâmetro de rede, a ordem de aparecimento do valor do parâmetro de rede é primeiro o do nucleante e segundo o do alumínio. Adaptado de (MARCANTO; MONDOLFO, 1970).

Figura 15 - Parte do diagrama de fases AI-Ti (EASTON; STJOHN, 1999). .25

Figura 16 - Diagrama de fase $\mathrm{Cu}-\mathrm{Fe}$ na região rica em cobre. (PATCHETT; ABBASCHIAN, 1985) .26

Figura 17 - Histórico térmico da solidificação dendrítica equiaxial: a) curva de resfriamento; b) curva de fração de solido; c) curvas da taxa de nucleação (I), velocidade de crescimento dos grãos $(\mathrm{V})$, (Tf) Temperatura de nucleação e número de grãos (N) (KURZ; FISHER, 1989).

Figura 18 - Curva de resfriamento da liga Al-6,5\% Si (356) e a sua respectiva derivada (BARLOW; STEFANESCU, 1997). As siglas $T_{1}, T_{e}$ e $T_{f}$ representam as temperaturas do líquido, do eutético e de final da solidificação, respectivamente. 29

Figura 19- Definição da temperatura e tempo de nucleação nas curvas de resfriamento e na primeira derivada destas curvas: $T_{n}$ e $t_{n}$ são a temperatura e o instante de início de nucleação segundo Apelian et al., (APELIAN et al., 1984), Schetky et al., 
(SCHETKY et al., 1983), Bäckerud et al. (BACKERUD et al., 1986) e Charbonnier (CHARBONNIER, 1984).

Figura 20 - Ampliação da curva de resfriamento na região da recalescência mostrando: (a) Parâmetros de temperatura: super-resfriamento da recalescência ( $\Delta T_{R}$ -

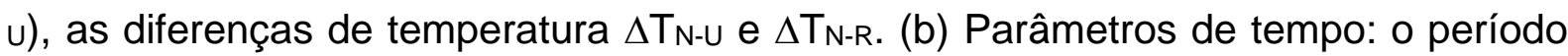
da recalescência $(\boldsymbol{t} 1)$, o período do estágio da nucleação $(\boldsymbol{t} 2)$, o período entre a nucleação e 0 final da recalescência $t 3$ e a temperatura de líquido $T_{L}$ (CHARBONNIER, 1984), (IBARRA, 1999). 30

Figura 21 - Ampliação da curva de resfriamento $(T)$ e de taxa de resfriamento (dT/dt) na região da recalescência (IBARRA, 1999) apresentando a integral da taxa de resfriamento $(\mathrm{dT} / \mathrm{dt})$ 31

Figura 22 - Definição da temperatura $\left(T_{f}\right)$ e instante $\left(t_{f}\right)$ do final da solidificação nas curvas de resfriamento e na primeira derivada desta curva (BACKERUD et al., 1986).

Figura 23 - Diagrama de fases Cu-Sn (ASM-HANDBOOK, 1998). .32

Figura 24 - Diagrama de fases Cu- Fe (ASM-HANDBOOK, 1998). .33

Figura 25 - Diagrama esquemático do forno de resistências utilizado para realizar as fusões das ligas. .38

Figura 26- Ferramentas para a adição dos elementos de liga ao banho líquido: (a) pacotes contendo Cu50\%Zr; (b) pacote fixado na barra de grafite. 40

Figura 27 - Sistema de solidificação: (a) sensor descartável posicionado sobre a base do pedestal; (b) representação esquemática do sensor descartável e o termopar. Medidas em $\mathrm{mm}$.

Figura 28 - Fotografia da montagem experimental utilizada para a obtenção das curvas de resfriamento: (a) copo de areia shell e pedestal; (b) sistema de aquisição de dados.

Figura 29 - Desenho esquemático do sistema de solidificação e o sistema de aquisição de dados. 
Figura 30 - Curva de resfriamento e primeira derivada do experimento Cu8Sn0,08Zr. (a) curvas originais sem suavizar, (b) curvas filtradas segundo o filtro de transformada rápida de Fourier (FFT).

Figura 31 - (a) Lingote da liga Cu8\%Sn obtido experimentalmente; (b) diagrama dos cortes utilizados para obtenção das amostras para análise macro e microestrutural. A linha tracejada em vermelho indica a área utilizada para a medição do tamanho médio de grão.

Figura 32 - a) Corte dos lingotes solidificados no molde metálico. b) desenho esquemático do molde para obter amostras de composição química. Medidas em milímetros.

Figura 33 - Fotomicrografia obtida em microscópio eletrônico de varredura FEG do experimento $\mathrm{EN}_{2}$-Inoc após o experimento potenciodinâmico: a) e b) diluída com Ácido fosfórico $65 \%$. c) e d) diluída com Acetato de amônio $4 \mathrm{M}$ + amônia 2,5M.

Figura 34 - Fotografias dos estágios de deposição do filme de carbono no evaporador por arco: a) e b) evaporador de carbono e posicionamento das amostras dentro do equipamento; c) amostra imersa no reagente para a extração do filme de carbono indicando em vermelho os cortes feitos com bisturi; d) filmes no sistema de filtragem com bomba de vácuo.

Figura 35- Fotomicrografias obtida em microscópio eletrônico de varredura FEG do experimento Cu8Sn0,16Zr, apresentando a sequência de corte e preparação da amostra para microscopia de transmissão: a) região selecionada para corte; a seta vermelha mostra o precipitado escolhido; b) região retangular para deposição de Pt; c) deposição de Pt; d) cortes laterais; e) corte em U na lâmina; f) manipulação da amostra com agulha de Pt; g) amostra soldada no porta amostras; h) amostra desbastada.

Figura 36- Macroestruturas da seção longitudinal dos lingotes dos experimentos da liga Cu0\%Sn com fonte de carbono: a) e b) com adição de P; b) e c) sem adição de $\mathrm{P}$, degaseificado com $\mathrm{N}_{2}$ (2 NI/min); ambos, sem e com adição de 0,08\%Zr. Reagente: Etanol 500ml, $\mathrm{FeCl} 325 \mathrm{~g}, \mathrm{HCl} 15 \mathrm{ml}$. 60 
Figura 37- Macroestruturas da seção longitudinal dos lingotes dos experimentos da liga Cu2\%Sn com fonte de carbono: a) e b) com adição de P; b) e c) sem adição de P; ambos, sem e com adição de 0,08\%Zr. Reagente: Etanol 500ml, FeCl3 25g, HCl $15 \mathrm{ml}$.

Figura 38- Macroestruturas da seção longitudinal dos lingotes dos experimentos da liga Cu8\%Sn com fonte de carbono: a) e b) com adição de P; (b) e c) sem adição de $\mathrm{P}$, degaseificado com Argônio (2 NI/min); Reagente: Etanol 500ml, FeCl3 25g, $\mathrm{HCl}$ $15 \mathrm{ml}$.

Figura 39- Macroestruturas da seção longitudinal dos lingotes dos experimentos da liga Cu8\%Sn: (a) e (b) sem fontes de carbono; (c) e (d) com fonte de carbono. Reagente: Etanol 500ml, FeCl3 25g, $\mathrm{HCl} 15 \mathrm{ml}$.

Figura 40- Fotomicrografia obtida por MEV com elétrons retroespalhados e espectros de energia dispersiva de raios-X (EDS) na posição assinalada com seta dos precipitados encontrados na microestrutura dos lingotes dos experimentos Cu8Sn0Zr0C e Cu8Sn0,08Zr0C. Polimento até $0,05 \mu \mathrm{m}$ com sílica, sem ataque químico.

Figura 41- Fotomicrografia obtida por MEV com elétrons retroespalhados e espectros de energia dispersiva de raios-X (EDS) na posição assinalada com seta, dos precipitados encontrados na microestrutura dos lingotes do experimento Cu8Sn0,08Zr. Polimento até $0,05 \mu \mathrm{m}$ com sílica, sem ataque químico. 66

Figura 42- Variação da energia livre padrão $\left(\Delta \boldsymbol{G}^{\circ}=\Delta \boldsymbol{H}^{\circ}+\boldsymbol{T} \Delta \boldsymbol{S}^{\circ}\right)$ em função da temperatura, calculada para a formação dos compostos $\mathrm{ZrC}, \mathrm{ZrN}$ e $\mathrm{ZrO}_{2}$ 67

Figura 43- Macroestruturas da seção longitudinal da série dos experimentos com adição de fósforo, zircônio e carbono: a) Cu8Sn0Zr, (b) Cu8Sn0,04Zr, (c) Cu8Sn0,08Zr, (d) Cu8Sn0,12Zr, (e) Cu8Sn0,16Zr, (f) Cu8Sn0,24Zr, (g) Cu8Sn0,32Zr e (h) Cu8Sn0,4Zr. Reagente: Etanol 500ml, FeCl3 25g, HCl 15ml. 70

Figura 44- Curva de tamanho de grão médio com diferentes adições nominais de $\mathrm{Zr}$ para a série da liga $\mathrm{Cu}-8 \% \mathrm{Sn}-0,025 \% \mathrm{P}$, com fonte de carbono. 
Figura 45- Fotomicrografia obtida por MEV com elétrons retroespalhados e espectros de energia dispersiva de raios- $X$ (EDS) na posição assinalada com seta, do experimento Cu8Sn0,4Zr. Polimento até $0,05 \mu \mathrm{m}$ com sílica, sem ataque químico.. 71

Figura 46- Macroestruturas da seção longitudinal das amostras dos experimentos da série variando o teor de Sn e Zr: a) Cu0Sn0Zr, (b) Cu0Sn0,08Zr, (c) Cu2Sn0Zr, (d) Cu2Sn0,08Zr, (e) Cu4Sn0Zr, (f) Cu4Sn0,08Zr, (g) Cu8Sn0Zr, (h) Cu8Sn0,08Zr, (i) Cu12Sn0Zr e (j) Cu12Sn0,08Zr. Reagente: Etanol 500ml, $\mathrm{FeCl}_{3} 25 \mathrm{~g}, \mathrm{HCl} 15 \mathrm{ml} . . . .74$

Figura 47 - Efeito do tamanho de grão médio com diferentes adições de Sn com e sem adição de Zr: (a) com adição de $\mathrm{P}$ e (b) Superposição da curva (a) com P (azul) e a curva sem adição de $P$ (preta).

Figura 48 - Efeito de adições crescentes de Sn: (a) variação de tamanho de grão médio e (b) aumento da densidade de número de grãos causados pela adição de $0,08 \% \mathrm{Zr}$. .76

Figura 49 - Curvas de resfriamento (filtradas em relação ao ruído) da série experimental onde adições crescentes de $\mathrm{Zr}$ foram realizadas à liga $\mathrm{Cu}-8 \% \mathrm{Sn}$.......78

Figura 50- (Superior) Curvas de resfriamento $(T)$ e de taxa de resfriamento (dT/dt) do experimento Cu8Sn0,16Zr. (Inf. esquerda) Aumento do trecho inicial das curvas mostrando a determinação da temperatura de início da solidificação $\left(T_{N}=1115^{\circ} \mathrm{C}\right)$. (Inf. direita) Aumento do trecho final das curvas mostrando a possível temperatura de final da solidificação $\left(\mathrm{Tf}=759^{\circ} \mathrm{C}\right)$.

Figura 51 - Curvas de resfriamento $(\mathrm{T})$ sobreposta à curva de taxa de resfriamento (dT/dt) do experimento $r$ : a) estágios de solidificação apresentados por Barlow e Stefanescu (BARLOW; STEFANESCU, 1997), b) aumento do trecho inicial das curvas mostrando em detalhe os estágios de solidificação. .80

Figura 52 - Curvas de resfriamento (filtradas em relação ao ruído) na região da recalescência da série Efeitos do $\mathrm{Zr}$ e C, com adição de fósforo incremento o teor de inoculante.

Figura 53- Ampliação da curva de resfriamento (filtrada em relação ao ruído) na região da recalescência do experimento desoxidados com fósforo sem adição de inoculante 
(Cu8Sn0Zr), mostrando o super-resfriamento da recalescência $\left(\Delta T_{R-U}\right)$, as diferenças de temperatura $\Delta \mathrm{T}_{\mathrm{N}-\mathrm{u}}$ e $\Delta \mathrm{T}_{\mathrm{N}-\mathrm{R}}$, o período da recalescência $(\boldsymbol{t} \mathbf{1})$, o período do estágio da nucleação ( $t 2$ ), o período entre a nucleação e o final da recalescência $t 3$ e a temperatura de líquido $T L$ 82

Figura 54- Curva de resfriamento (filtradas em relação ao ruído) e de taxa de resfriamento (dT/dt) do experimento Cu8Sn0Zr mostrando a medição do parâmetro $\mathrm{PL}$ .82

Figura 55- Parâmetros de temperatura e de tempo extraídos das curvas de resfriamento em função do teor de $\mathrm{Zr}$ nominal.

Figura 56- Tamanho médio de grão em função dos parâmetros de temperatura e tempo extraídos da região da recalescência das curvas de resfriamento.

Figura 57- Curvas de resfriamento dos experimentos com adições crescentes de Sn sem adição de $\mathrm{Zr}$

Figura 58 - Curvas de resfriamento dos experimentos com adições crescentes de $\mathrm{Sn}$ com adição de $0,08 \% Z$ r.

Figura 59- Ampliação das curvas de resfriamento na região da recalescência dos experimentos com adições crescentes de $\mathrm{Sn}$ sem adição de $\mathrm{Zr}$.

Figura 60 - Ampliação das curvas de resfriamento na região da recalescência dos experimentos com adições crescentes de Sn e com adição de $0,08 \% Z$ r.

Figura 61 - Parâmetros de temperatura e de tempo extraídos das curvas de resfriamento em função do teor de Sn, sem ou com a adição de $0,08 \% \operatorname{Zr}(\operatorname{Inoc})$.....88

Figura 62 - Tamanho médio de grão em função dos parâmetros de temperatura e tempo extraídos da região da recalescência das curvas de resfriamento nos experimentos com adições crescente de $\mathrm{Sn}$, sem e com a adição de $0,08 \% \mathrm{Zr}$ (Inoc).

Figura 63 - Microestruturas das seções transversais dos lingotes dos experimentos: a); b) Cu8Sn0Zr; c) e d) Cu8Sn0,08Zr. Reagentes: $\mathrm{NH} 4 \mathrm{OH} 20 \mathrm{ml}$, H2O2 10ml e Etanol $500 \mathrm{ml}, \mathrm{FeCl} 325 \mathrm{~g}, \mathrm{HCl} 15 \mathrm{ml} .2$ 
Figura 64 - Microestrutura obtida em microscópio eletrônico de varredura FEG das seções transversais dos lingotes do experimento Cu8Sn0,08Zr. Polimento até 0,05 $\mu \mathrm{m}$ com sílica, sem ataque químico.

Figura 65 - a) Fotomicrografia obtida por MEV FEG da microestrutura dos lingotes do experimento Cu8Sn, b) e c) espectros de energia dispersiva de raios-X (EDS) na posição assinalada com setas. Polimento até $0,05 \mu \mathrm{m}$ com sílica, sem ataque químico.

Figura 66 - Fotomicrografias obtidas por MEV FEG da microestrutura da liga Cu50\%Zr utilizada como inoculante: (a) e (b) imagem de elétrons retroespalhados; (1), (2) e (3) espectros de energia dispersiva de raios-X (EDS) na posição assinalada com setas. Polimento até $0,05 \mu \mathrm{m}$ com sílica, sem ataque químico.

Figura 67 - Fotomicrografia obtida por MEV FEG da microestrutura dos lingotes do experimento Cu8Sn0Zr: (a) e (c) precipitados ricos em S; b) precipitado rico em $\mathrm{Pb}$. Espectros de energia dispersiva de raios-X (EDS) na posição assinalada com seta vermelha. Polimento até $0,05 \mu \mathrm{m}$ com sílica, sem ataque químico. .96

Figura 68 - Fotomicrografias eletrônicas no modo de elétrons retroespalhados e espectros de energia dispersiva de raios-X (EDS) na posição assinalada com setas, da série do experimento com adição de fósforo, zircônio e carbono: (a) Cu8Sn0,04Zr, (b) Cu8Sn0,08Zr, (c) Cu8Sn0,16Zr, (d) Cu8Sn0,24Zr, (e) Cu8Sn0,4Zr. Polimento até $0,05 \mu \mathrm{m}$ com sílica, sem ataque químico.

Figura 69 - Diagrama de fases Cu-Zr. Adaptado: (ARIAS; ABRIATA, 1990) .98

Figura 70 - Diagrama de fases Zr-C. (JACKSON; LEE, 2012) .98

Figura 71 - Fotomicrografia obtida por MEV FEG dos precipitados na liga Cu8Sn0,08Zr. Polimento até $0,05 \mu \mathrm{m}$ com sílica, sem ataque químico (esquerda). Espectros de energia dispersiva de raios-X (EDS) na posição assinalada com a seta.

Figura 72 - Fotomicrografia obtida por MEV FEG do precipitado do experimento Cu8Sn0,08Zr. Polimento até $0,05 \mu \mathrm{m}$ com sílica, sem ataque químico (esquerda). 
Espectros de energia dispersiva de raios-X (EDS) na posição assinalada com a seta.

Figura 73 - Sequencia de aumentos na superfície do filtro: a) resíduo depositado no filtro, Imagens obtida por MEV FEG energia dispersiva de raios-X (EDS) na posição assinalada com a seta. Experimento Cu8Sn0,08Zr. 100

Figura 74 - Precipitados sobre a superfície do filme de carbono extraído por réplica. Imagem obtida por MEV-FEG. Experimento Cu8Sn0,08Zr. 101

Figura 75 - Precipitados na superfície do filme de carbono. Imagem eletrônica e espectro de energia dispersiva de raios-X (EDS). Experimento Cu8Sn0,08Zr. ......102

Figura 76 - Precipitados extraídos por réplica do experimento Cu8Sn0,16Zr. Imagem em campo claro e espectro de energia dispersiva de raios-X (EDS), na posição assinalada com a seta, obtida no MET Tecnai G2-20 - SuperTwin FEI - 200 kV....103

Figura 77- (a) Fotomicrografia em elétrons secundários obtida em microscópio eletrônico de varredura FEG da amostra (A) do experimento Cu8Sn0,16Zr contendo o precipitado e a matriz, (b) espectro de EDS na região 1 (precipitado), (c) espectro de EDS na região 2 (matriz). Espectros de EDS obtidos no MET Tecnai G2-20 SuperTwin FEI - $200 \mathrm{kV}$. 105

Figura 78- (a) Fotomicrografia em elétrons secundários obtida no microscópio eletrônico de varredura FEG da amostra (B) extraída com MEV-FEG-FIB do experimento Cu8Sn0,16Zr contendo o precipitado e a matriz, (b) espectro de EDS na região 1 (precipitado), (c) espectro de EDS na região 2 (matriz). Espectros de EDS obtidos no MET Tecnai G2-20 - SuperTwin FEl - 200 kV. 106

Figura 79- Padrões de difração indexados do precipitado da lâmina (A): a) imagem em campo claro, o círculo vermelho marca a área de coleta das difrações; b) eixo de zona

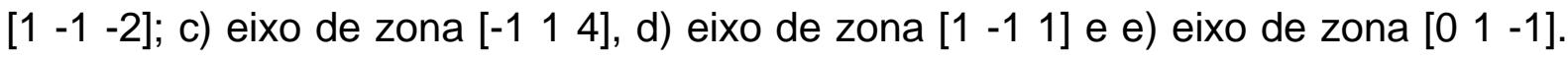
Imagens obtidas no MET Tecnai G2-20 - SuperTwin FEl - 200 kV. 108

Figura 80- Padrões de difração indexados da matriz da lâmina (A): a) imagem em campo claro, o círculo vermelho marca a área de coleta das difrações; b) eixo de zona [1 -1 -2]; c) eixo de zona [-1 -1 2], d) eixo de zona [1 -1 1] e e) interface com eixo de 
zona [1 -1 1], na posição da interface. Imagens obtidas no MET Tecnai G2-20 SuperTwin FEI - 200 kV.

Figura 81- Padrões de difração indexados do precipitado da lâmina (B): a) imagem em campo claro, o círculo amarelo marca a área de coleta das difrações; b) eixo de zona [ $\left.\begin{array}{lll}1 & -1 & -4\end{array}\right]$; c) eixo de zona [ $\left[\begin{array}{lll}0 & 1 & 1\end{array}\right]$ e d) eixo de zona [ 0 - 1 -1]. Imagens obtidas no MET Tecnai G2-20 - SuperTwin FEI - 200 kV.

Figura 82- - Padrões de difração indexados da matriz da lâmina (B): a) imagem em campo claro, o círculo amarelo marca a área de coleta das difrações; b) eixo de zona

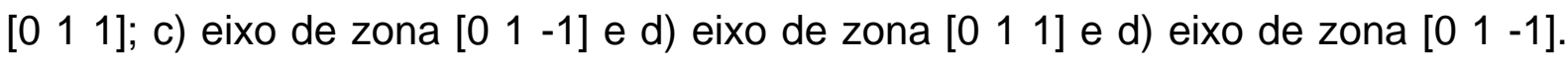
Imagens obtidas no MET Tecnai G2-20 - SuperTwin FEI - 200 kV.

Figura 83 - Representação esquemática das relações cristalográficas das interfases dos planos (100) do ZrC (linhas tracejadas) e os planos (100),(110) e (111) do Cu-a (linhas cheias).

Figura 84 - Representação esquemática das relações cristalográficas das interfases dos planos (111) do ZrC (linhas tracejadas) e os planos (100), (110) e (111) do Cu-a (linhas cheias)

Figura 85 - Representação esquemática das relações cristalográficas das interfases dos planos (110) do ZrC (linhas tracejadas) e os planos (100), (110) e (111) do Cu-a (linhas cheias).

Figura 86- Superposição dos padrões de difração indexados [1-1 1]Cu- $\alpha$ II [1-1-2]ZrC 119

Figura 87- Representação esquemática das relações cristalográficas das interfases do plano (2-22) do ZrC (linhas tracejadas) e o plano (022) do Cu- $\alpha$ (linhas cheias).

Figura 88- Imagens de alta resolução da interface matriz precipitado da lâmina (A): (a) e (b) regiões da interface apresentando coerência entre os reticulados da matriz e precipitado; (c) e (d) regiões da interface sem coerência aparente entre os reticulados. 
Figura 89- Microestruturas das seções transversais do lingote do experimento Cu8Sn0,16Zr. Cu- $\alpha$ com cor azul, as setas vermelhas marcam a posição dos precipitados facetados nos contornos e na região rica em Sn. Reagentes: Klem III.

Figura 90 - Microestruturas do experimento Cu8Sn0,08Zr, ambas as imagens ( $a$ e b) apresentam partículas hexagonais na região rica em estanho. Imagem obtida no MEV com contraste de elétron retroespalhados. Polimento até $0,05 \mu \mathrm{m}$ com sílica, sem ataque químico.

Figura 91- Microestruturas das seções transversais do lingote do experimento Cu8Sn0,16Zr. Cu- $\alpha$ com cor azul, as setas vermelhas marcam a posição dos precipitados facetados no interior da fase primaria. Reagentes: Klem III. 123

Figura 92 - Imagens obtidas no MEV-FEG de amostras do experimento Cu8Sn0,08Zr mostrando partículas no formato de disco no interior do grão. Polimento até $0,05 \mu \mathrm{m}$ com sílica, sem ataque químico.

Figura 93 - Microestruturas de grãos do experimento Cu8Sn0,08Zr mostrando uma partícula no interior do grão, longe dos contornos e da região interdendrítica, e uma partícula na região interdendrítica. Imagem obtida no MEV-FEG com elétrons secundários. Reagentes Polimento até $0,05 \mu \mathrm{m}$ com sílica, sem ataque químico...124 


\section{LISTA DE TABELAS}

Tabela 1 - Valores de super-resfriamento máximos em metais líquidos obtidos experimentalmente (FLEMINGS, 1974; GARCIA, 2001).

Tabela 2 - Correspondência entre os parâmetros de rede, estrutura cristalina e o efeito inoculante de alguns compostos utilizados para inocular alumínio. 20

Tabela 3 - Resumo dos nucleantes para ligas de cobre com detecção de refinamento de grão, apresentando o super resfriamento para a nucleação $(\Delta T)$ e as relações de orientação (OR), refinamento de grão (RG) reportadas por MONDOLFO (1982)....21

Tabela 4- Desajuste de diferentes compostos nucleantes para ligas base cobre (CIBULA, 1954).

Tabela 5 - Capacidade de segregação de alguns elementos de soluto no alumínio (EASTON; STJOHN, 1999).

Tabela 6 - Fatores de restrição ao crescimento de grão $(P, Q)$ para diversos elementos dissolvidos em cobre líquido e parâmetros utilizados no cálculo destes fatores: inclinação da linha líquidos do diagrama binário $(m)$, coeficiente de partição de soluto e composição média ( $\left.\mathrm{C}_{0}\right)$.

Tabela 7 Condições das séries de experimentos com as respectivas siglas de identificação. Os teores nominais (\% massa) de Sn, Zr, P e a adição ou não de cobertura de grafite (+ ou -) também estão indicados.

Tabela 8 - Composição química (\% massa) fornecida pelos fabricantes das ligas utilizadas no presente trabalho: cobre eletrolítico (Cu-CP), estanho eletrolítico (SnGA), adição de zircônio (Cu-50\%Zr) e desoxidante (Cu-15\%P)

Tabela 9 - Técnicas utilizadas para a análise de composição química das amostras e os laboratórios fornecedores dos resultados.

Tabela 10- Procedimentos metalográficos para analise estrutural

Tabela 11 - Resultados das análises químicas dos lingotes obtidos nos experimentos. A incorporação de $\mathrm{Zr}$ ao banho também está indicada (Ef). 
Tabela 12- Tamanho de grão medido (TG) e desvio padrão de medida para os lingotes de $\mathrm{Cu}$. O número de campos $(\mathrm{N})$ medidos também está indicado. .60

Tabela 13- Tamanho de grão medido (TG) e desvio padrão de medida para os lingotes da liga Cu2\%Sn. O número de campos $(\mathrm{N})$ medidos também está indicado. .61

Tabela 14- Tamanho de grão medido (TG) e desvio padrão de medida para os lingotes da liga Cu8\%Sn. O número de campos $(\mathrm{N})$ medidos também está indicado. 62

Tabela 15- Tamanho de grão medido (TG) e desvio padrão de medida para os lingotes da liga Cu8\%Sn. O número de campos $(\mathrm{N})$ medidos também está indicado. .64

Tabela 16- Valores das variações de entalpia padrão e de entropia padrão no intervalo de temperatura para as reações (EVANS, 1982).

Tabela 17 - Tamanho de grão medido (TG) e desvio padrão de medida para os lingotes obtidos na série com adição de $\mathrm{Zr}, \mathrm{P}$ e carbono. $\mathrm{O}$ número de campos $(\mathrm{N})$ medidos também está indicado.

Tabela 18- Tamanho de grão medido (TG) e desvio padrão de medida para os lingotes obtidos na série variando o teor de Sn e Zr. O número de campos $(\mathrm{N})$ medidos também está indicado.

Tabela 19 - Parâmetros extraídos da ampliação das curvas de resfriamento e de sua derivada obtidas nos experimentos de adições crescentes de $\mathrm{Zr}$ à liga $\mathrm{Cu}$-8\%Sn. ..78

Tabela 20 - Parâmetros extraídos das curvas de resfriamento e de sua derivada obtidas nos experimentos com adições crescentes de Sn sem e com a presença do teor nominal de $0,08 \% Z r$. .88

Tabela 21- Distancias interplanares medidas dos padrões de difração da Figura 79, comparadas com o cartão padrão do ZrC (ICSD: Inorganic Crystal Structure Database, código: 159874) *. 108

Tabela 22- Distancias interplanares medidas nos padrões de difração Figura 80, comparadas com o cartão padrão do Cu-a (ICSD: Inorganic Crystal Structure Database, código: 03-065-682) * 109 
Tabela 23- Distancias interplanares medidas dos padrões de difração da Figura 81, comparadas com o cartão padrão do ZrC (ICSD: Inorganic Crystal Structure Database, código: 159874$)^{\star}$.

Tabela 24- Distancias interplanares medidas nos padrões de difração da Figura 82, comparadas com o cartão padrão do Cu- $\alpha$ (ICSD: Inorganic Crystal Structure Database, código: 03-065-682) *

Tabela 25 - Parâmetros estruturais da fase Cua e das possíveis partículas sólidas presentes no banho líquido e o parâmetro de desajuste entre reticulados $\delta$. 113

Tabela 26- Cálculo do desajuste planar $\boldsymbol{\delta}$ segundo bramfit para de fase $\mathrm{Cu}-\alpha$ e as possíveis partículas inoculantes de $\mathrm{ZrC}$

Tabela 27- Cálculo do desajuste planar $\boldsymbol{\delta}$ segundo bramfit para os planos (2-22) do ZrC e (022) do Cu-a paralelos 120 


\section{LISTA DE SÍMBOLOS}

\begin{tabular}{|c|c|}
\hline$A$ & Área $\left(\mathrm{m}^{2}\right)$ \\
\hline$A_{S L}$ & Área da interface sólido - líquido $\left(\mathrm{m}^{2}\right)$ \\
\hline$a$ & Espaçamento entre dois átomos do líquido $(\mathrm{m})$ \\
\hline$a_{S}$ & Parâmetro de rede cristalina do núcleo sólido $(\AA ̊)$ \\
\hline$a_{T}$ & Parâmetro de rede cristalina do substrato inoculante $(\AA ̊)$ \\
\hline$C_{l}$ & Composição do líquido, (\%peso) \\
\hline$C_{p}$ & Calor específico do metal, (J/kg.K) \\
\hline$C_{s}$ & Composição do sólido, (\%peso) \\
\hline$C_{p_{l}}$ & Calor específico do metal líquido, (J/kg.K) \\
\hline$C_{p_{s}}$ & Calor específico do metal sólido, (J/kg.K) \\
\hline$D_{L}$ & Coeficiente de difusão no líquido, $\left(\mathrm{m}^{2} / \mathrm{s}\right)$ \\
\hline$E$ & Potencial elétrico, (mV) \\
\hline$E_{r}$ & Potencial elétrico de referência, $(\mathrm{mV})$ \\
\hline$F_{\text {corte }}$ & Freqüência de corte, $(\mathrm{Hz})$ \\
\hline$f_{s}$ & Fração de sólido \\
\hline$f(\theta)$ & Fator de forma para a nucleação heterogênea \\
\hline$G_{L}$ & Energia livre por unidade de volume da fase líquida, $\left(\mathrm{J} / \mathrm{m}^{3}\right)$ \\
\hline$G_{S}$ & Energia livre por unidade de volume da fase sólida, $\left(\mathrm{J} / \mathrm{m}^{3}\right)$ \\
\hline GRF & Fator de restrição de crescimento, $(\mathrm{K})$ \\
\hline$I$ & Taxa de nucleação, $\left(\mathrm{mol} / \mathrm{m}^{3} . \mathrm{s}\right)$ \\
\hline$L_{f}$ & Calor latente de solidificação por unidade de volume, $\left(\mathrm{J} / \mathrm{m}^{3}\right)$ \\
\hline$k$ & Coeficiente de partição de soluto \\
\hline$m$ & Inclinação da linha de líquido, (K/\%peso) \\
\hline$N$ & Número de grãos \\
\hline$n$ & Numero de dados \\
\hline$P$ & Parâmetro de restrição ao crescimento \\
\hline
\end{tabular}


$P L \quad$ Parâmetro área do pico do líquido, $\left({ }^{\circ} \mathrm{C} . \mathrm{s}\right)$

$Q \quad$ Parâmetro de restrição ao crescimento

$r \quad$ Raio do embrião esférico, (m)

$r^{*} \quad$ Raio crítico do embrião esférico, $(\mathrm{m})$

$R_{L} \quad$ Taxa de resfriamento até temperatura líquidus, $\left({ }^{\circ} \mathrm{C} / \mathrm{s}\right)$

$R_{m} \quad$ Taxa de resfriamento média, $\left({ }^{\circ} \mathrm{C} / \mathrm{s}\right)$

$T$ Temperatura, $\left({ }^{\circ} \mathrm{C}\right)$

$T_{E 1} \quad$ Temperatura do eutétoide, $\left({ }^{\circ} \mathrm{C}\right)$

$T_{E 2} \quad$ Temperatura do eutétoide, $\left({ }^{\circ} \mathrm{C}\right)$

$T_{p} \quad$ Temperatura do peritético, $\left({ }^{\circ} \mathrm{C}\right)$

$T_{f} \quad$ Temperatura de final de solidificação, $\left({ }^{\circ} \mathrm{C}\right)$

$T_{f} \quad$ Temperatura de fusão, $\left({ }^{\circ} \mathrm{C}\right)$

$T_{N} \quad$ Temperatura de inicio da nucleação, (s)

$T_{L} \quad$ Temperatura liquidus, $\left({ }^{\circ} \mathrm{C}\right)$

$T_{R} \quad$ Temperaturas máxima durante a recalescência, $\left({ }^{\circ} \mathrm{C}\right)$

$T_{U} \quad$ Temperaturas mínima durante a recalescência, $\left({ }^{\circ} \mathrm{C}\right)$

$T_{\infty} \quad$ Temperatura ambiente, $\left({ }^{\circ} \mathrm{C}\right)$

$T_{1} \quad$ Temperatura mínima durante a recalescência, $\left({ }^{\circ} \mathrm{C}\right)$

$T_{2}$ Temperatura máxima durante a recalescência, $\left({ }^{\circ} \mathrm{C}\right)$

$t$ Tempo, (s)

$t_{f} \quad$ Tempo final durante a solidificação, (s)

$t_{n} \quad$ Tempo inicial durante a solidificação, (s)

$t_{1} \quad$ Período de tempo de super-resfriamento, (s)

$V \quad$ Volume, $\left(\mathrm{m}^{3}\right)$

$V \quad$ Velocidade de crescimento de grão, $(\mathrm{m} / \mathrm{s})$

$V_{S} \quad$ Volume do aglomerado sólido $\left(\mathrm{m}^{3}\right)$

$\alpha \quad$ Difusividade térmica, $\left(\mathrm{m}^{2} / \mathrm{s}\right)$

$\alpha \quad$ Fase primária 


$\begin{array}{cl}\Delta n & \text { Número de grãos, }\left(\mathrm{m}^{3}\right) \\ \Delta G & \text { Variação da energia livre do embrião esférico, }(\mathrm{J}) \\ \Delta G_{H e t} & \text { Variação da energia livre na nucleação heterogênea, }(\mathrm{J}) \\ \Delta G_{H o m} & \text { Variação da energia livre na nucleação homogênea, }(\mathrm{J}) \\ \Delta G_{v} & \text { Diferença de energia livre entre as fases sólida e líquida, }\left(\mathrm{J} / \mathrm{m}^{3}\right) \\ \sigma_{L T} & \text { Energia de interface líquido/substrato por unidade de área, }\left(\mathrm{J} / \mathrm{m}^{2}\right) \\ \sigma_{S L} & \text { Energia de interface sólido/líquido por unidade de área, }\left(\mathrm{J} / \mathrm{m}^{2}\right) \\ \sigma_{S T} & \text { Energia de interface sólido/substrato por unidade de área, }\left(\mathrm{J} / \mathrm{m}^{2}\right) \\ \Delta E & \text { Diferencia de potencial elétrico, (mV) } \\ \Delta T & \text { Super-resfriamento aparente, }\left({ }^{\circ} \mathrm{C}\right) \\ \Delta T_{C} & \text { Super-resfriamento crítico, }\left({ }^{\circ} \mathrm{C}\right) \\ \theta T_{R-U} & \text { Diferença entre as temperaturas mínima e máxima durante a } \\ \left(\Delta T_{R-U}\right) & \text { recalescência, }\left({ }^{\circ} \mathrm{C}\right) \\ \delta & \text { Super-resfriamento da recalescência, }\left({ }^{\circ} \mathrm{C}\right) \\ \delta & \text { Desajuste do parâmetro de rede do inoculante e o núcleo sólido, }(\mathrm{A}) \\ \delta_{1} e \delta_{3} & \begin{array}{l}\text { Desajustes calculados ao longo de três direções de baixo índice } \\ \theta\end{array}\end{array}$




\section{SUMÁRIO}

1 INTRODUÇÃO .......................................................................................... 1

2 OBJETIVO ..............................................................................................

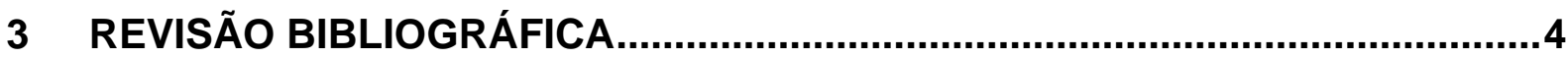

3.1 TEORIA DA NUCLEAÇÃO. (KURZ; FISHER, 1989) .................................4

3.1.1 Nucleação homogênea. (PEREPEZKO, 1998a) ............................................. 5

3.1.2 Nucleação Heterogênea. (PEREPEZKO, 1998a).......................................... 8

3.2 CRESCIMENTO DE GRÃOS NA SOLIDIFICAÇÃO (KURZ; FISHER, 1989) 11

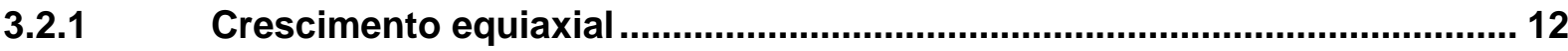

3.3 REFINO DE GRÃO NA ESTRUTURA BRUTA DE SOLIDIFICAÇÃO ...........15

3.3.1 Efeito da relação de orientação entre núcleo e substrato ….......................... 17

3.3.2 Restrição do Crescimento dos grãos .......................................................... 22

3.3.3 Teoria do peritético (CROSSLEY; MONDOLFO, 1951) ................................. 24

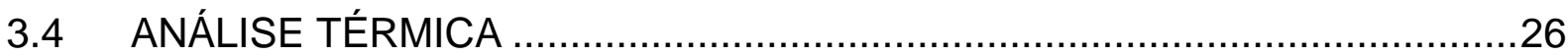

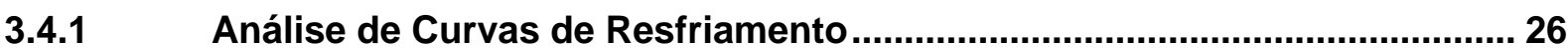

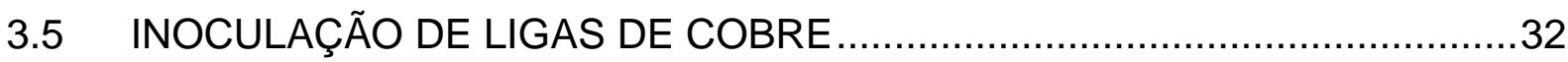

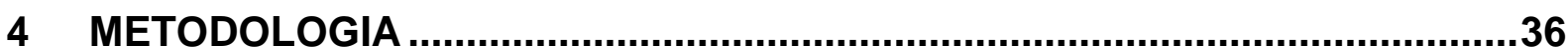

4.1 SISTEMA DE SOLIDIFICAÇÃO E OBTENÇÃO DAS AMOSTRAS ................37

4.1.1 Fusão e Tratamento do Metal Líquido …..................................................... 37

4.1.2 Sistema de Solidificação ........................................................................... 40

4.1.3 Coleta das Curvas de Resfriamento.......................................................... 41

4.1.4 Tratamento das curvas de resfriamento .................................................... 42

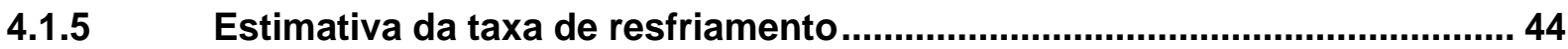

4.2 CARACTERIZAÇÃO QUÍMICA E MACRO-MICROESTRUTURAL ...............45

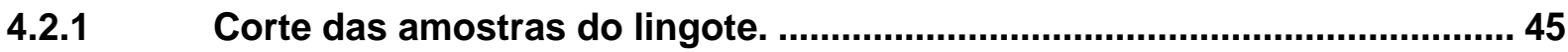

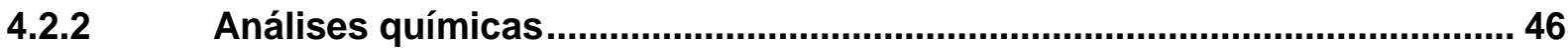

4.2.3 Medida do Tamanho Médio de Grão …........................................................... 47

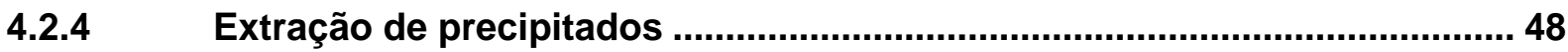

5 RESULTADOS E DISCUSSÃO .................................................................54

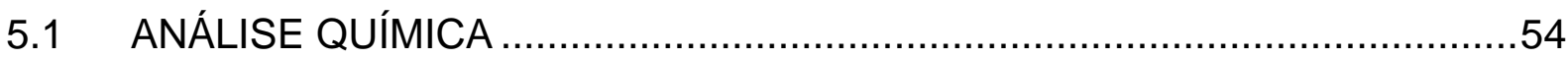

5.2 EFEITO DAS ADIÇÕES AO BANHO NA MACROESTRUTURA DE GRÃOS57

5.2.1 Efeito geral das adições de $\mathrm{P}, \mathrm{C}$ e Zr na macroestrutura de grãos 
5.2.2 Efeito geral das adições de Zr e C na macroestrutura de grãos ................... 63

5.2.3 Efeito das adições de $\mathrm{Zr}$ na macroestrutura de grãos do $\mathrm{Cu}-8 \% \mathrm{Sn}$............68

5.2.4 Efeito das adições de Sn e Zr macroestrutura de grãos .............................. 71

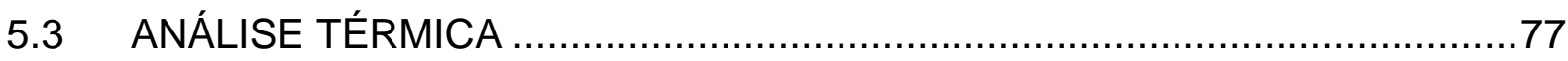

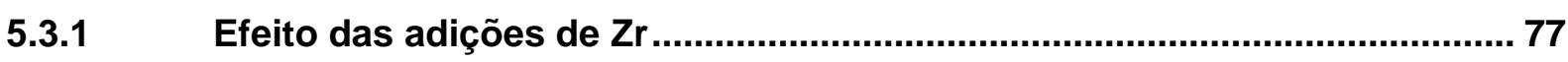

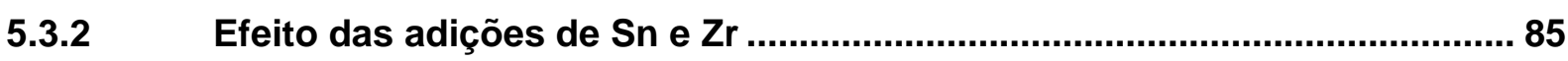

5.4 ANÁLISE MICROESTRUTURAL - IDENTIFICAÇÃO DAS FASES E

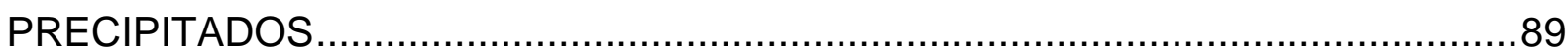

5.4.1 Análise microestrutural da liga Cu8\%Sn ................................................... 90

5.4.2 Análise microestrutural da liga Cu50\%Zr .............................................. 93

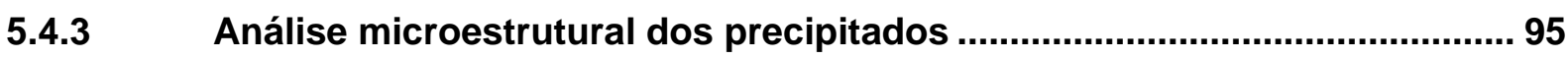

5.4.4 Análise Cristalográfica dos precipitados ............................................... 107

5.5 EVIDÊNCIAS DA NUCLEAÇÃO HETEROGÊNEA SOBRE OS

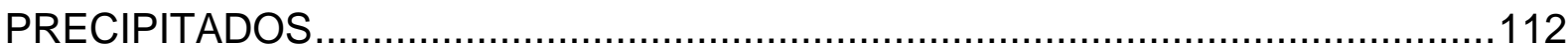

5.5.1 Análise do Desajuste entre Reticulados ................................................ 113

Observações do posicionamento relativo dos precipitados ..................... 121

6 CONCLUSÕES ........................................................................................125

7 REFERÊNCIAS BIBLIOGRÁFICAS........................................................127 


\section{INTRODUÇÃO}

As ligas de cobre são utilizadas intensamente pela indústria na construção de dispositivos como válvulas, estruturas de bombas hidráulicas, componentes elétricos e de transferência de calor. As propriedades finais das ligas de cobre são controladas pela sua composição e pela manipulação de aspectos de sua estrutura metalúrgica (REIF; WEBER, 1987b), como por exemplo, a distribuição dos constituintes, a quantidade de inclusões e o tamanho dos grãos. Tamanhos de grão menores geralmente resultam na melhoria de diversas propriedades e podem ser obtidos, por exemplo, através do tratamento de inoculação do banho metálico.

O objetivo principal do tratamento de inoculação de metais líquidos é aumentar o número de núcleos de grãos no interior do líquido para, consequentemente, diminuir ou refinar o tamanho de grão final (MAXWELL; HELLAWELL, 1975). Este processo transforma grãos grosseiros, com tamanhos da ordem de centímetros, até grãos equiaxiais refinados, com tamanhos da ordem de $100 \mu \mathrm{m}$. Esta transformação resulta, entre outros, em uma maior reprodutibilidade nos processos de fundição, na melhoria e maior controle das propriedades mecânicas, no melhor acabamento superficial e em outros benefícios (CIBULA; RUDDLE, 1949; MONDOLFO, 1982).

Um outro benefício importante do tratamento de inoculação é a melhoria da plasticidade durante a conformação mecânica de lingotes, como por exemplo os das ligas $\mathrm{Cu}-6 \% \mathrm{Sn}$ obtidos por lingotamento continuo, que são posteriormente laminados a quente. Estas ligas $\mathrm{Cu}-6 \% \mathrm{Sn}$ caracterizam-se por terem uma deformabilidade a quente limitada pelas fraturas intergranulares que ocorrem durante os processos de conformação. Uma melhora da fragilidade intergranular e da plasticidade deste material ocorre com a adição de teores de 0,03 a 0,05\%Zr, principalmente quando há uma conteúdo mínimo de contaminantes (Pb, S, As, O) (OZGOWICZ, 2007).

As propriedades de fundição e de serviço das ligas de cobre, particularmente do sistema Cu-Sn-Zn, são melhoradas através da inoculação do banho líquido. Entre os efeitos benéficos está o desaparecimento das trincas a quente, produto da contração das ligas durante a solidificação, por meio da adição de 0,04\%Zr. Observam-se 
também um aumento da fluidez e redução do tamanho de grão quando estas ligas solidificam em moldes metálicos (SADAYAPPAN et al., 2002).

Os mecanismos através dos quais o refino de grão da estrutura bruta de solidificação ocorre após a inoculação estão bem estabelecidos para ligas de alumínio (SPITTLE, 2006). Desde a década de 1940, muitos pesquisadores realizaram trabalhos para entender os mecanismos de refino de grão em ligas de alumínio a partir da adição de ligas-mãe ao banho líquido. A seguinte sequência de eventos compõe estes mecanismos: um grande número de potentes sítios (substratos) para nucleação heterogênea é disperso no metal fundido e uma quantidade destes sítios converte-se em centros ativos durante a solidificação para promover a nucleação heterogênea do sólido. No entanto, apesar de existirem várias ligas-mãe desenvolvidas e disponíveis comercialmente para realizar o tratamento de inoculação em ligas de Al, a disponibilidade de refinadores comerciais para ligas de Cu é incipiente. Além disso, estudos fundamentais para a identificação dos mecanismos de refino de grão em ligas de cobre praticamente inexistem. Os poucos trabalhos científicos existentes são, na sua maioria, de caráter tecnológico, onde várias adições de elementos são realizadas muitas vezes simultaneamente, e a ocorrência ou não do refino de grão verificada, sem uma investigação mais profunda para esclarecer os mecanismos de refino operantes. Em muitos casos existem ainda resultados controversos.

No entanto, Martorano e Capocchi (2000) mostraram experimentos exploratórios de refinamento durante a solidificação direcional da liga $\mathrm{Cu}-8 \% \mathrm{Sn}$, adicionando $\mathrm{Cu}$ $50 \% \mathrm{Zr}$ e uma cobertura de grafite para proteção do metal fundido. Os autores corroboram um efeito semelhante ao observado por Cibula (1954), alterando a estrutura colunar para uma estrutura inteiramente equiaxial de grãos refinados após a adição de $0,08 \% Z r$. O mecanismo gerador do refino de grão para esta liga não foi investigado, contudo, este estudo apresenta evidências de refinamentos importantes os quais serviram como base para o estudo do mecanismo de refinamento de grão nas ligas cobre-estanho do presente trabalho de pesquisa. 


\section{OBJETIVO}

Este trabalho tem como objetivo principal investigar os mecanismos fundamentais responsáveis pelo refino de grão da estrutura bruta de solidificação em ligas do sistema cobre-estanho a partir do tratamento de inoculação do banho líquido por meio de diferentes adições de elementos como estanho, zircônio, carbono e fósforo. Pretende-se ainda verificar a eficiência das adições destes elementos em promover o refino de grão de ligas de cobre. 


\section{REVISÃO BIBLIOGRÁFICA}

\subsection{Teoria da nucleação. (KURZ; FISHER, 1989)}

A solidificação dos metais compreende os processos de formação e crescimento dos primeiros aglomerados estáveis de átomos com estrutura do sólido no interior do líquido. Para que isso ocorra, é necessário o estabelecimento de condições termodinâmicas favoráveis para promover a instabilidade do líquido, causando a sua alteração para o estado sólido. (KURZ; FISHER, 1989).

Durante o estado líquido, os átomos do metal movimentam-se aleatoriamente. Esta movimentação aleatória pode criar pequenas regiões (embriões) onde a estrutura do líquido se parece com a estrutura do sólido. Quando a temperatura é diminuída, os embriões formados adquirem maior estabilidade termodinâmica e podem acabar formando uma estrutura de sólido estável, resultando no processo conhecido como nucleação da fase sólida.

Após a nucleação, o crescimento da fase sólida ocorrerá a partir da transferência de átomos da fase líquida para a fase sólida através da interface sólido-líquido. Durante este processo, a interface sólido/líquido forma uma estrutura específica de crescimento, que pode ser não facetada, típica dos metais, ou facetada, típica dos materiais não metálicos e compostos intermetálicos. Esses modos são apresentados na Figura 1.

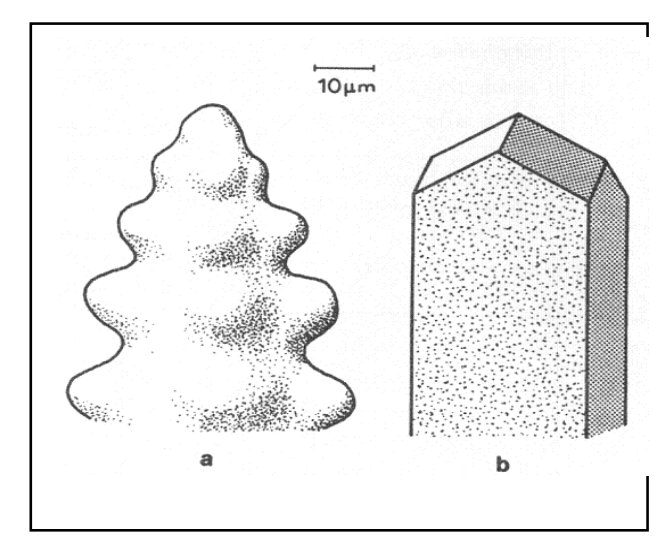

Figura 1 - Estrutura: a) não facetada; b) facetada. (KURZ; FISHER, 1989). 


\subsubsection{Nucleação homogênea. (PEREPEZKO, 1998a)}

A criação de pequenos cristais de sólido isolados no líquido sem o auxílio de interfaces existentes neste líquido é denominada de nucleação homogênea. A diferença de energia livre entre as fases sólida e líquida é dada por $\Delta G_{v}=G_{S}-G_{L}$, onde $G_{S}$ e $G_{L}$ são, respectivamente, as energias livres do sólido e do líquido por unidade de volume. Quando um único aglomerado ("cluster") de átomos com estrutura do sólido se forma no interior do líquido, na realização de um balanço energético devese também considerar a energia despendida na criação da interface sólido-líquido. Desta forma, a variação da energia livre total do processo de nucleação homogênea será:

$$
\Delta G_{H o m}=V_{S} \Delta G_{v}+A_{S L} \sigma_{S L}
$$

onde $V_{S}$ é o volume do aglomerado com estrutura do sólido, $A_{S L}$ é a área da interface sólido/líquido e $\sigma_{S L}$ é a energia de interface sólido/líquido por unidade de área. Assumindo-se um aglomerado esférico de raio $r$, a variação de energia livre para a nucleação homogênea pode ser expressa como:

$$
\Delta G_{\text {Hom }}(r)=\left(\frac{4 \pi r^{3}}{3} \Delta G_{v}+4 \pi r^{2} \sigma_{S L}\right)
$$

Esta variação de energia livre para a formação de um aglomerado esférico em função do raio $r$ é mostrada na Figura 2. Observe que, devido ao crescimento do embrião, a superfície cresce e a variação da energia livre alcança um valor máximo para o raio $r^{*}$, chamado de raio crítico, a partir do qual o crescimento do aglomerado diminui a energia livre do sistema. Dessa forma, para $r>r^{\star}$, o aglomerado é estável, resultando na formação de um núcleo solido. 


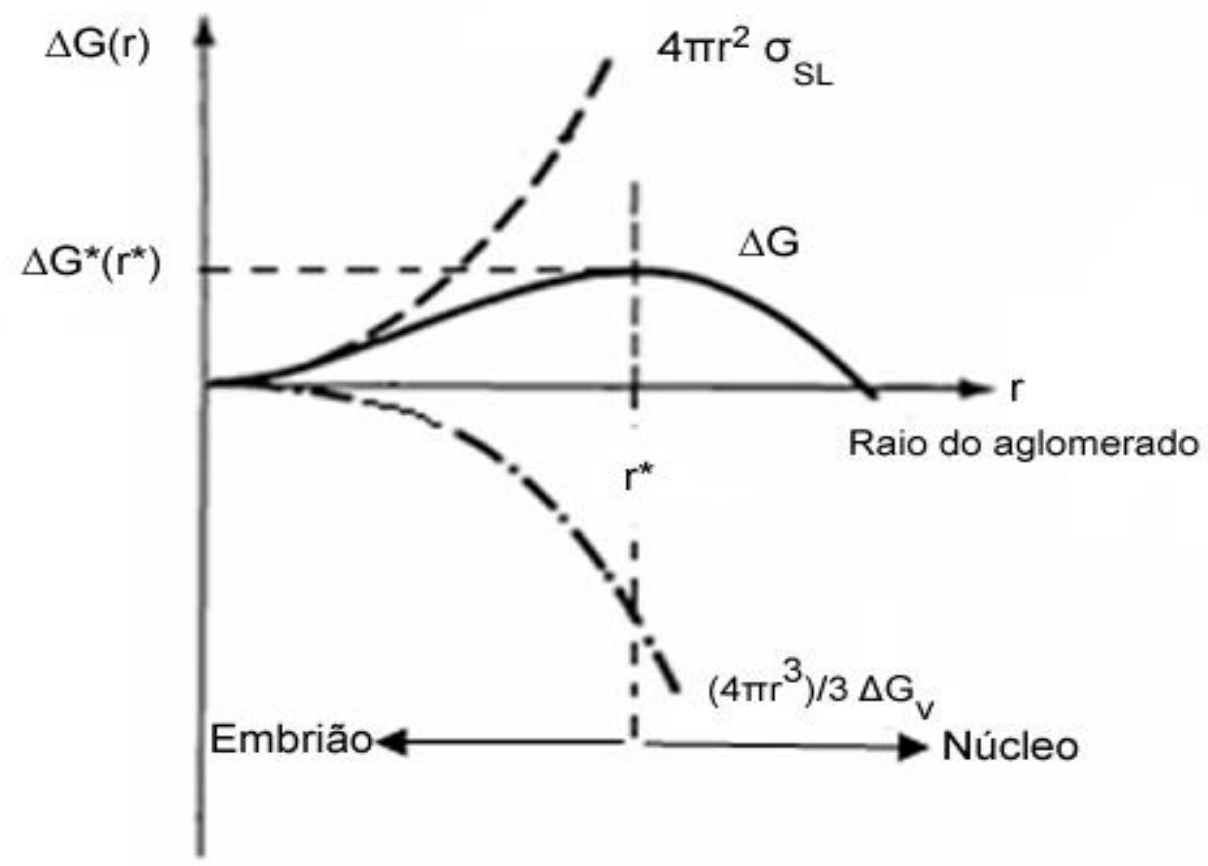

Figura 2 - Variação da energia livre de um aglomerado esférico de sólido em função do raio do aglomerado (PEREPEZKO, 1998a).

Fazendo:

$$
\left[\frac{\mathrm{d}\left(\Delta G_{H o m}(r)\right)}{\mathrm{dr}}\right]_{r=r^{*}}=0
$$

Pode-se determinar o raio critico $r^{*}$ como:

$$
r^{*}=\left(\frac{2 \sigma_{S L}}{\Delta G_{v}}\right)
$$

A expressão que define a taxa de nucleação homogênea com o tempo por unidade de volume, denominada I, foi determinada por Turnbull e Fisher (TURNBULL; FISHER, 1949) como: 


$$
\mathrm{I}=n_{L}\left(\frac{D_{L}}{a^{2}}\right)\left(\frac{4 \pi r^{* 2}}{a^{2}}\right) \exp \left(-\frac{16 \pi \sigma_{S L}^{3} T_{f}^{2}}{3 L^{2} \Delta T^{2} k T}\right)
$$

onde I é a taxa de nucleação, $a$ é o espaçamento entre dois átomos do líquido, $D_{L}$ é o coeficiente de difusão no líquido, $k$ é a constante de Boltzmann e $T$ é a temperatura. Esta equação mostra que a taxa de nucleação varia significativamente com o superresfriamento, $\Delta T=T_{f}-T$ (onde $T_{f}$ é a temperatura de fusão), devido ao termo ao quadrado dentro da exponencial.

É importante notar que a taxa de nucleação é muito sensível à magnitude do super-resfriamento $\Delta T$. O valor de I permanece reduzido até que um valor crítico de super-resfriamento $\Delta T_{C}$ seja alcançado, crescendo rapidamente, como se apresenta na Figura 3. A Tabela 1 mostra alguns valores de super-resfriamento críticos para alguns metais, obtidos experimentalmente.

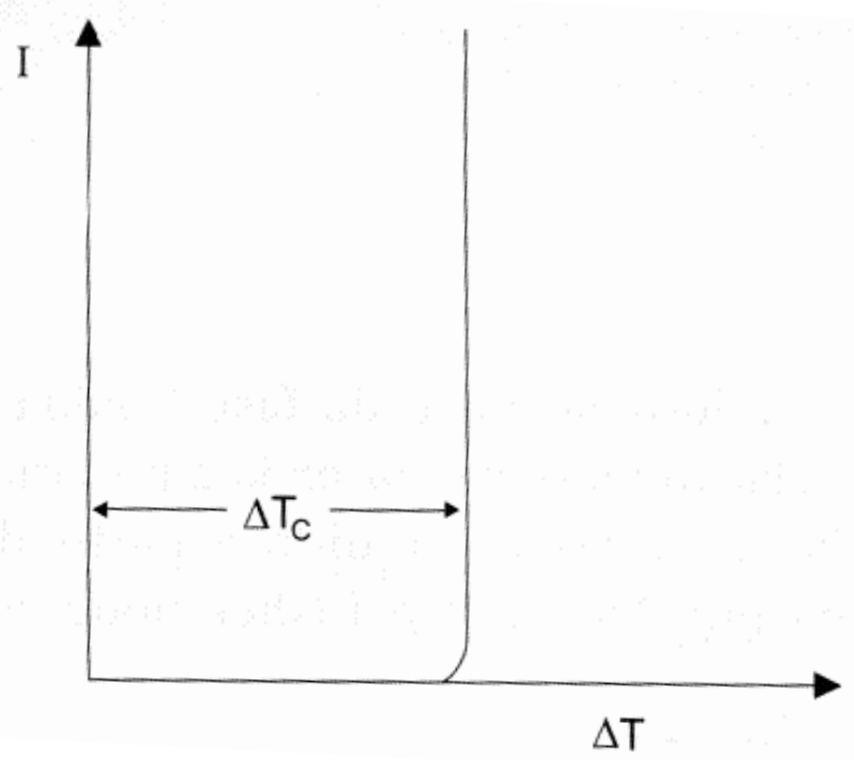

Figura 3 - Variação da taxa de nucleação em metais com o super-resfriamento $\Delta T$, onde $\Delta T_{C}$ é o superresfriamento crítico para a nucleação (GARCIA, 2001). 
Tabela 1 - Valores de super-resfriamento máximos em metais líquidos obtidos experimentalmente (FLEMINGS, 1974; GARCIA, 2001).

\begin{tabular}{cccc}
\hline Metal & $\begin{array}{c}\text { Ponto de Fusão } \mathbf{T}_{\mathbf{f}} \\
(\mathbf{K})\end{array}$ & $\mathbf{\Delta T}_{\max }(\mathbf{K})$ & $\mathbf{\Delta} \mathbf{T}_{\max } / \mathbf{T}_{\mathbf{f}}$ \\
\hline Estanho & 505,7 & 118 & 0,233 \\
Chumbo & 600,7 & 80 & 0,133 \\
Alumínio & 933 & 195 & 0,209 \\
Prata & 1233,7 & 227 & 0,184 \\
Ouro & 1336 & 230 & 0,172 \\
Cobre & 1356 & 236 & 0,174 \\
Níquel & 1725 & 319 & 0,185 \\
Ferro & 1809 & 295 & 0,163 \\
\hline
\end{tabular}

\subsubsection{Nucleação Heterogênea. (PEREPEZKO, 1998a)}

Na nucleação heterogênea, o embrião sólido não se forma isoladamente no líquido, como descrito para a nucleação homogênea, mais sim, sobre uma interface sólido/líquido já existente. Estas interfaces podem ser originárias de inclusões e filmes de óxidos presentes no líquido ou resultarem do contato do líquido com as paredes do molde. A nucleação em uma interface permite uma economia de energia, acelerando a cinética do processo.

A Figura 4 apresenta as considerações geométricas que permitem visualizar as forças entre as três interfaces em contato no ponto triplo durante a nucleação heterogênea de um núcleo em forma de calota esférica na interface com um determinado substrato.

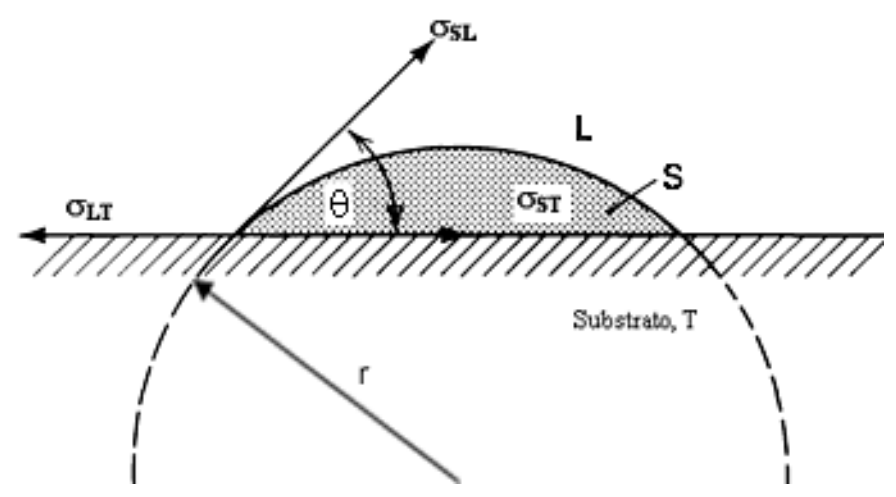

Figura 4 - Sistema de forças interfaciais existentes na nucleação heterogênea (PEREPEZKO, 1998a). 
O equilíbrio de forças interfaciais no ponto triplo é representado através da seguinte equação:

$$
\sigma_{L T}-\sigma_{S T}=\sigma_{S L} \cos \theta
$$

onde $\sigma_{L T}$ é a energia interfacial líquido/substrato por unidade de área; $\sigma_{S T}$ é a energia interfacial sólido/substrato por unidade de área, $\sigma_{S L}$ é a energia interfacial sólido/líquido por unidade de área e $\theta$ é o ângulo de contato ou de molhamento do substrato pelo embrião.

Através das considerações geométricas apresentadas na Figura 4, pode-se calcular a variação total da energia livre de Gibbs para a nucleação heterogênea de uma calota esférica de raio $r$ como:

$$
\begin{gathered}
\Delta G=\Delta G_{H e t}(r)=\left(\frac{4 \pi r^{3}}{3} \Delta G_{v}+4 \pi r^{2} \sigma_{S L}\right) f(\theta) \\
f(\theta)=\left[\frac{(2-\cos \theta)(1-\cos \theta)^{2}}{4}\right]
\end{gathered}
$$

onde $f(\theta)$ é chamado de fator de forma, pois está relacionado ao ângulo de molhamento e, portanto, ao formato da calota esférica. Deste modo, a variação das energias livres durante as nucleações heterogênea e homogênea estão relacionadas por:

$$
\Delta G_{H e t}(r)=\Delta G_{H o m}(r) f(\theta)
$$

Como consequência, para $\theta=180^{\circ}$ a variação de energia livre na formação de um núcleo esférico é igual nos dois casos (homogêneo e heterogêneo). No entanto, com o aumento da molhabilidade do substrato pelo sólido, $\theta$ diminui, decrescendo $o$ fator de forma e, portanto, a variação de energia livre do processo de nucleação (Figura 5). Quando o ângulo tende a zero, a barreira da nucleação é praticamente inexistente. 
De forma semelhante à nucleação homogênea, a taxa de nucleação heterogênea pode ser calculada por:

$$
\mathrm{I}=n_{L}\left(\frac{D_{L}}{a^{2}}\right)\left(\frac{4 \pi r^{* 2}(1-\cos \theta)}{a^{2}}\right) \exp \left(-\frac{16 \pi \sigma_{S L}^{3} T_{f}^{2}}{3 L^{2} \Delta T^{2} k T} f(\theta)\right)
$$

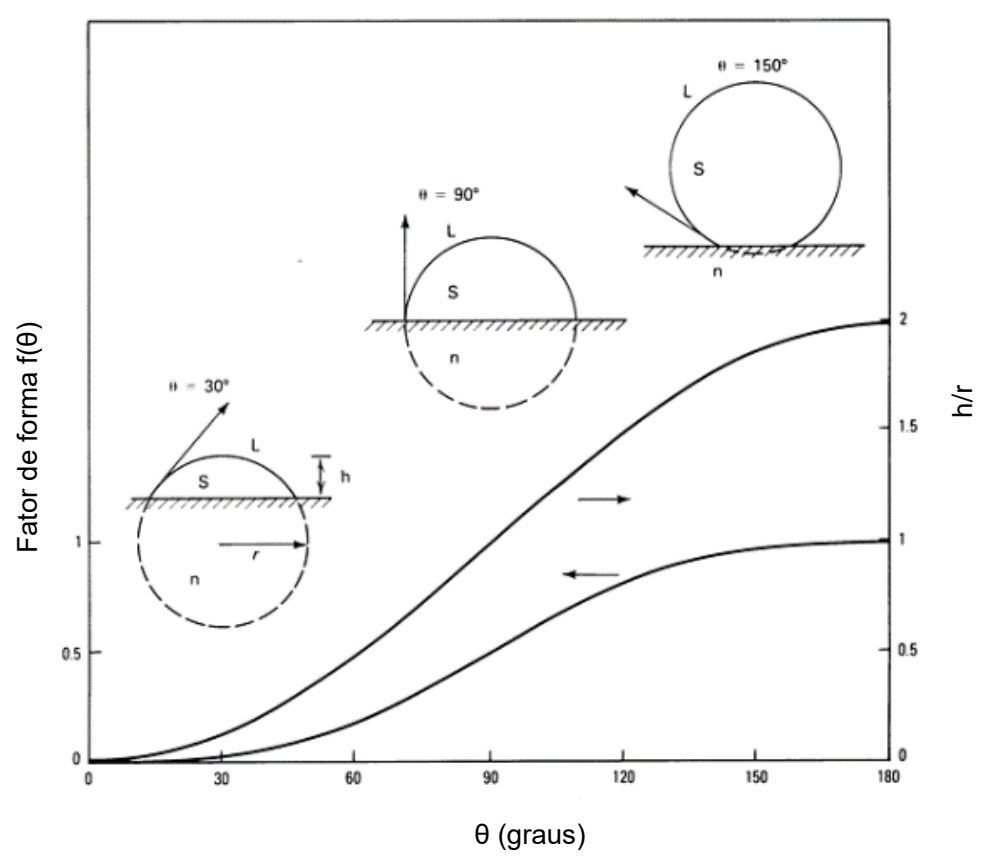

Figura 5 - Variação do fator de forma ou $\left[\Delta G_{H e t}(r) / \Delta G_{H o m}(r)\right]$ e tamanho relativo da calota esférica, $h / r$, como uma função do ângulo de contato, $\theta$ (PEREPEZKO, 1998a).

É importante ressaltar que a magnitude da taxa de nucleação heterogênea também é sensível à magnitude do super-resfriamento $\Delta T$, com valores menores, quando comparados com a nucleação homogênea, como se observa na Figura 6 . 


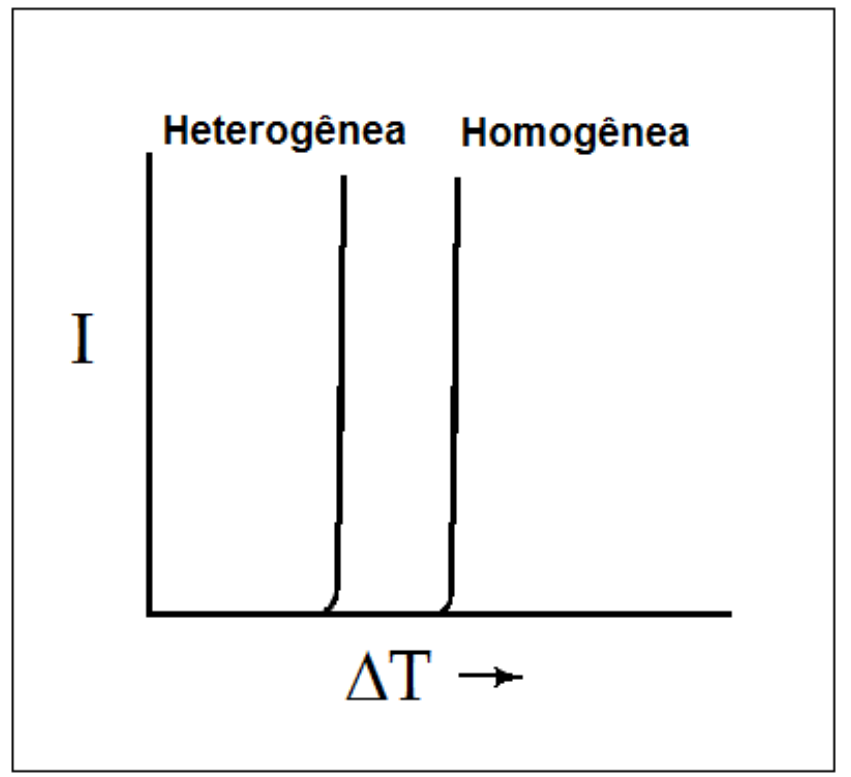

Figura 6 - Variação da taxa de nucleação em metais com o super-resfriamento $\Delta T$, para a nucleação homogênea e nucleação heterogênea, (FLEMINGS, 1974).

\subsection{Crescimento de grãos na solidificação (KURZ; FISHER, 1989)}

Depois de formado, o núcleo estável inicia a etapa de crescimento da estrutura. Esta etapa de crescimento distingue-se pelo aumento do tamanho do sólido esférico, que pode ou não evoluir para uma morfologia dendrítica característica. Cada uma destas estruturas de sólido é denominada de grão. Os grãos podem ser colunares ou equiaxiais, dependendo em grande parte das condições térmicas e químicas durante a solidificação.

A estrutura colunar caracteriza-se por ter uma direção de crescimento aproximadamente paralela à do fluxo de extração de calor, sendo comum em metais de maior pureza ou em ligas solidificadas direccionalmente. No entanto, a estrutura equiaxial forma-se a partir de um crescimento radial aproximadamente uniforme. $A$ morfologia dos grãos pode ser observa na macroestrutura bruta de solidificação de lingotes da Figura 7. Os lingotes mostram os dois tipos de grãos misturados ou não misturados. 

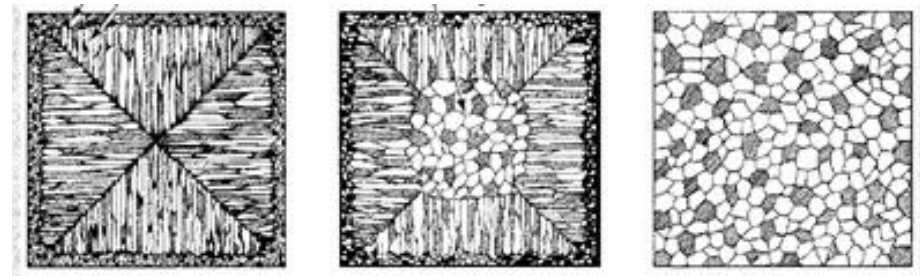

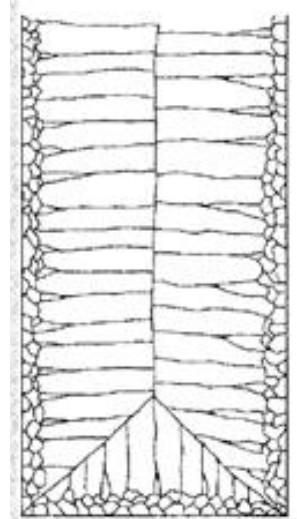

(a)

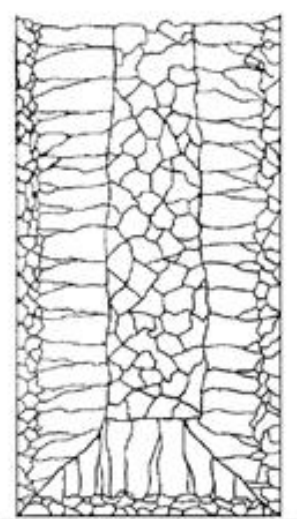

(b)

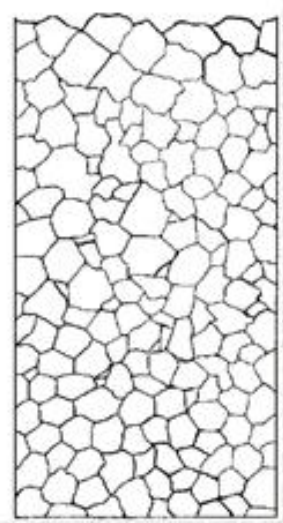

(c)

Figura 7 - Seção transversal e longitudinal da estrutura bruta de solidificação de lingotes a) estrutura coquilhada (equiaxial) nas paredes do molde e estrutura colunar em direção ao centro. b) estrutura coquilhada nas paredes, seguida de estrutura colunar e estrutura equiaxial no centro do lingote. c) estrutura totalmente equiaxial. Modificado de: (KALPAKJIAN, 2006).

\subsubsection{Crescimento equiaxial}

O crescimento dendrítico equiaxial em ligas metálicas, caracteriza-se pela formação do núcleo no interior do líquido super-resfriado, dissipando calor latente de fusão através deste líquido, na frente da interfase. Neste tipo de crescimento, o gradiente de temperatura do líquido na interface é negativo, enquanto que no sólido é perto de zero. Diferente do crescimento na solidificação direcional, que dissipa o calor latente de fusão através do sólido, com um gradiente de temperatura positivo imposto, como mostra a Figura 8.

A estrutura dendrítica equiaxial pode-se descrever como uma estrutura com segregação de soluto, composta por três regiões: a primeira um sólido de composição Co, com uma velocidade de avanço da ponta da dendrita $(v)$ ao alongo dos seus eixos; a segunda região é um líquido interdendrítico enriquecido em soluto, seguida pelo líquido extradendrítico, região que diminui sua composição à medida que se separa do sólido, como se apresenta na Figura 9. 


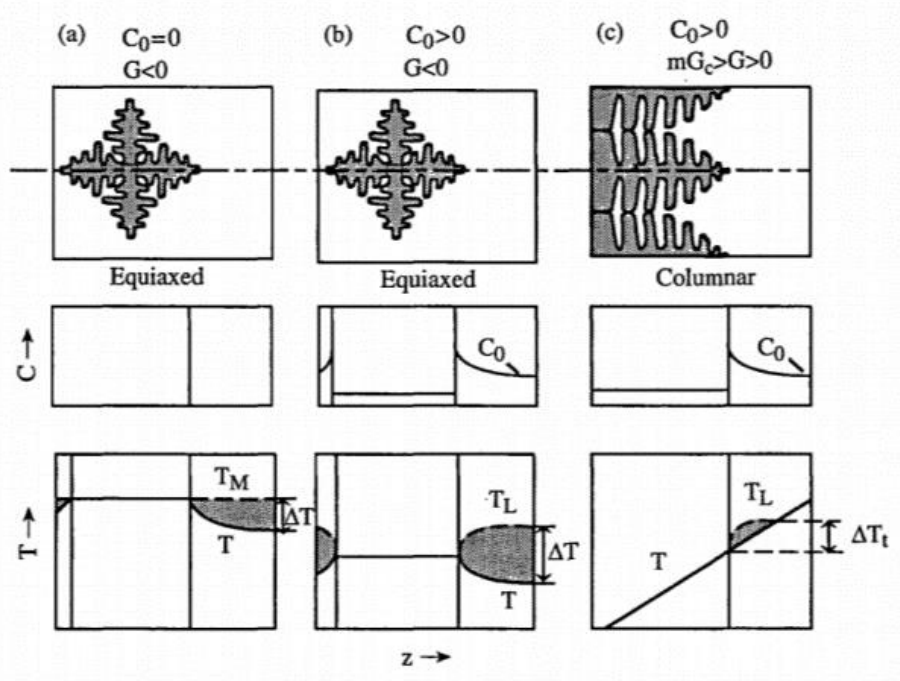

Figura 8 - (a) Crescimento equiaxial, (b) crescimento direcional, (c) campos de composição e temperatura ao longo do eixo da dendrita. (TRIVEDI; KURZ, 1994).

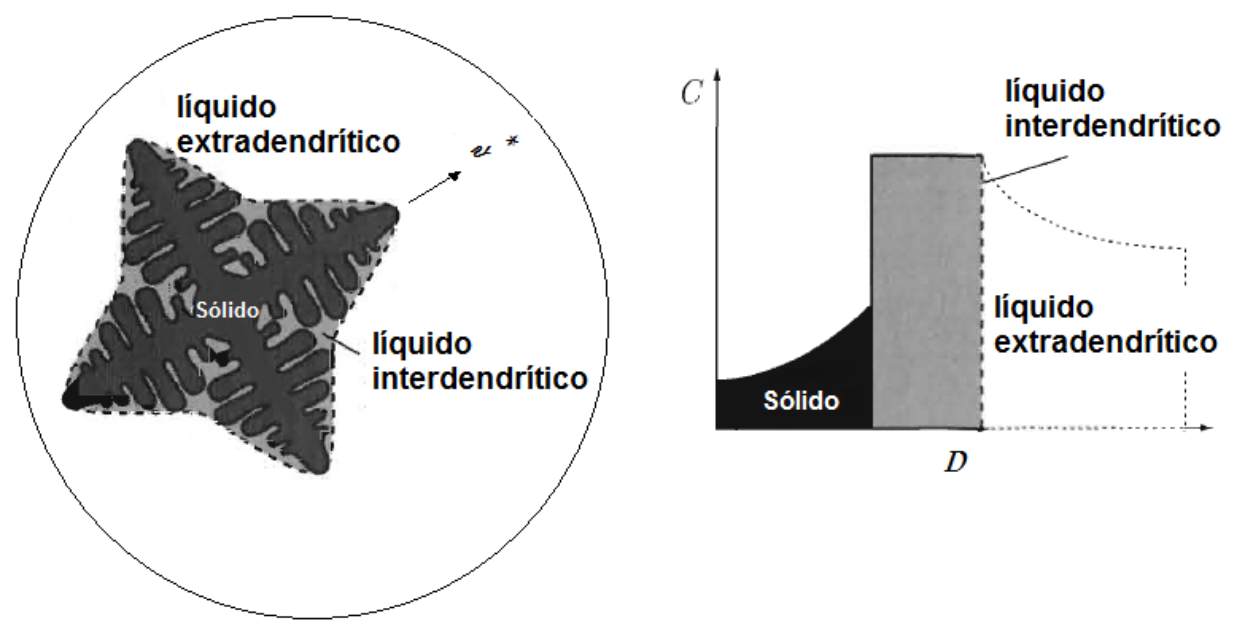

Figura 9 - Representação esquemática da estrutura equiaxial dendrítica e a variação da composição. Adaptado do DANTZIG; RAPPAZ (2009).

Assume-se que a formação de um grão equiaxial no interior do líquido está diretamente associado a um evento único de nucleação durante a solidificação, seja pela geração espontânea ou pela presença de um agente inoculante, que fornece substratos com baixos super-resfriamentos no interior do líquido. Neste sentido, GREER et al. (2000), propõe o modelo de livre crescimento na nucleação durante o refinamento (free growth), onde, a nucleação ocorre sob o substrato super-resfriado, formando uma calota esférica de baixo ângulo de contato que cresce com um rádio restrito, limitado pela superfície total do substrato como mostra a Figura 10. Para que o crescimento do substrato seja possível, o diâmetro da superfície do substrato deve 
ser $d=2 r^{*}$. O super-resfriamento para o crescimento livre $\Delta T_{f g}$ e o diâmetro da partícula nucleante $d$, estão relacionadas pela seguinte expressão:

$$
\Delta T_{f g}=\frac{4 \sigma}{\Delta S_{v} d}
$$

Onde $\sigma$ é a energia interfacial sólido-líquido, $\Delta S_{v}$ é a entropia de difusão por unidade de volume.

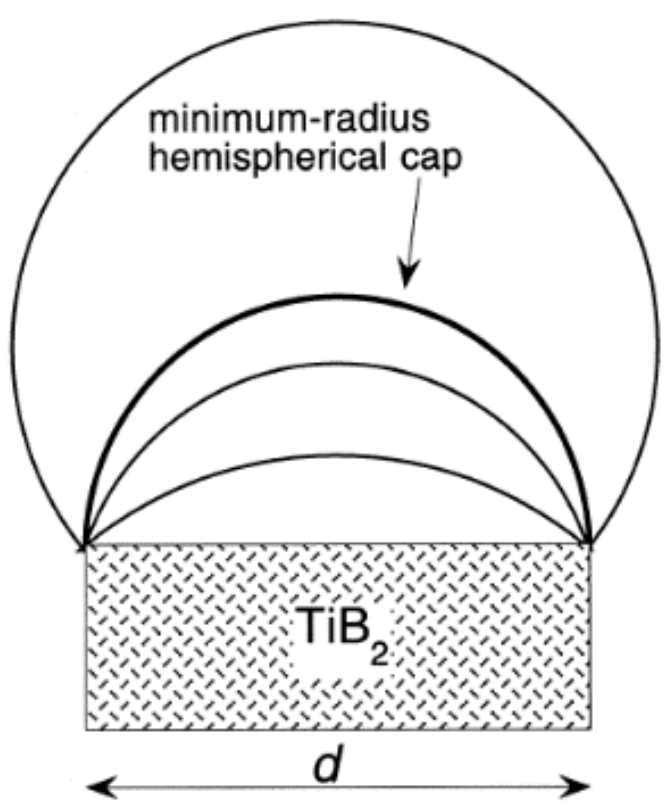

Figura 10 - Nucleação de um cristal com formato esférico sobre um substrato de TiB2 apresentando o rádio mínimo de curvatura limitado pelo diâmetro da partícula, GREER et al. (2000).

No crescimento dendrítico equiaxial, a composição do soluto $\left(C_{0}\right)$ e o superresfriamento $(\Delta \mathrm{T})$, controlam a taxa de crescimento ( $V$ ) na ponta das dendritas, como mostram os resultados experimentais da taxa de crescimento no sistema Socionitriloacetona comparados com os resultados de modelos de nucleação (Figura 11a.). Nesta figura, a variação da velocidade com a composição para um super-resfriamento fixo, mostra um valor máximo, que é atribuído segundo Triveri et al. (1994), à competição entre efeitos térmicos e de soluto, onde, pequenas quantidades de soluto desestabilizam a ponta da dendrita em crescimento, dissipando o calor latente mais facilmente, aumentando a velocidade (V). Assim, quando mais soluto é adicionado, a velocidade diminui, e desaparece com o incremento do super resfriamento $(\Delta T)$ Figura 11b.). 


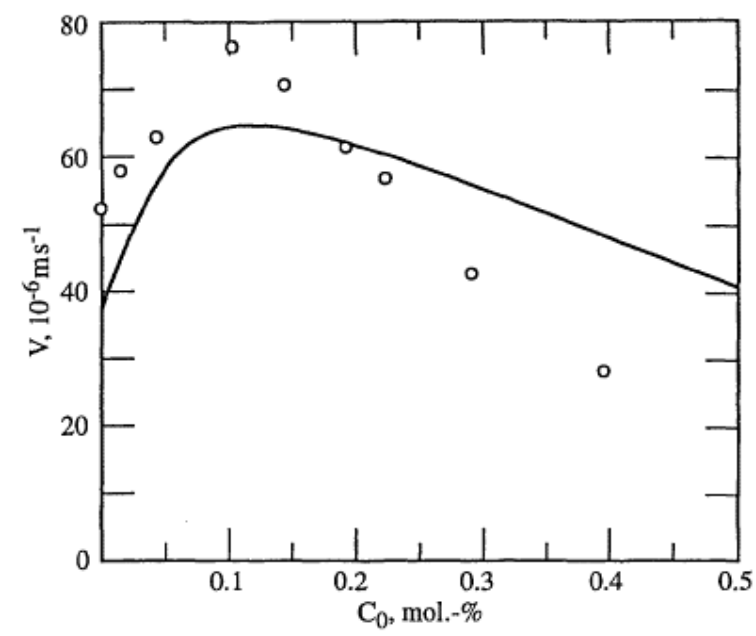

(a)

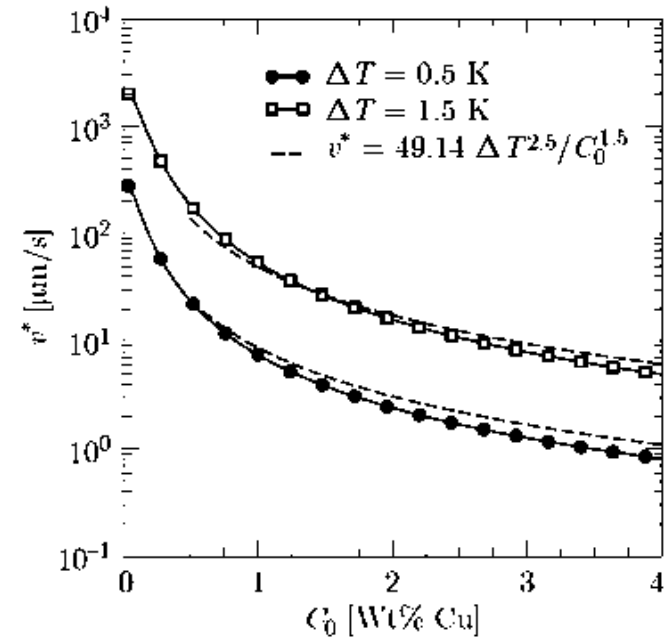

(b)

Figura 11 - Comparação da variação da velocidade da ponta da dendrita como função da concentração de valores teóricos e experimentais. a) valores experimentais socionitrilo-acetona, $\Delta \mathrm{T}=0,5 \mathrm{~K}$. Triveri et al. (1994). b) valores simulados para ligas de Cu-Al, $\Delta T=0,5 \mathrm{~K}$ e 1,5 K, DANTZIG; RAPPAZ (2009).

\subsection{Refino de Grão na estrutura bruta de solidificação}

A inoculação de banhos líquidos de metais e ligas é um dos processos de refino de grãos da estrutura bruta de solidificação. A inoculação consiste no tratamento do metal líquido mediante a adição de elementos inoculantes que, de alguma forma, resultam no aumento do número de núcleos sólidos formados no interior do líquido, resultando em maior número de grãos e, consequentemente, em um menor tamanho de grão médio (MAXWELL; HELLAWELL, 1975). Dessa forma, a estrutura bruta de solidificação é modificada para uma de morfologia equiaxial relativamente fina (Figura 12), que permite uma maior reprodutibilidade nos processos de fabricação e confere melhores propriedades mecânicas ao produto final (CIBULA; RUDDLE, 1949; MONDOLFO, 1982). 


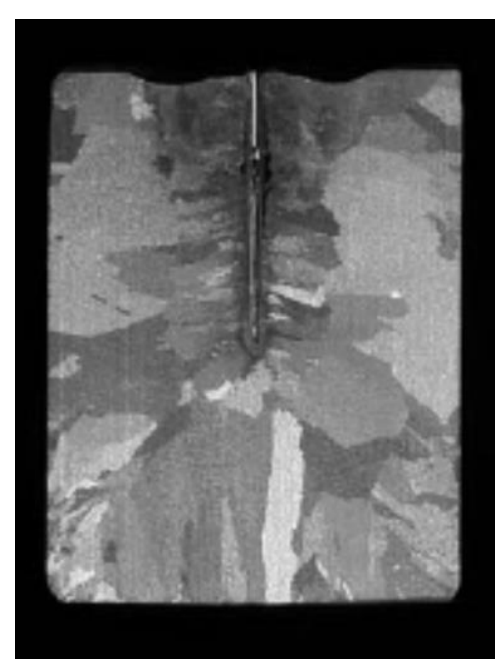

(a)

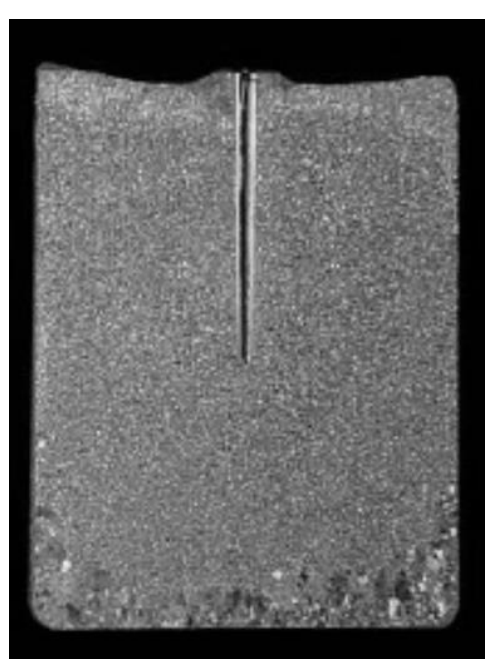

(b)

Figura 12 - Macroestrutura de grãos em uma liga de cobre (Cu-36\%Zn-1.5\%Pb-0,4\%Al): a) sem adição de inoculante; b) com adição de 275 ppm de Fe e 15 ppm B (SADAYAPPAN et al., 2005).

Para compreender melhor os mecanismos que governam a inoculação em ligas metálicas, vários estudos foram realizados com alumínio puro, ligas do sistema alumínio-silício (MOHANTY; GRUZLESKI, 1995), alumínio-cobre (KIM; CANTOR, 1994) e cobre-chumbo (KIM; CANTOR, 1992). Nestes estudos, examinaram-se: os efeitos dos tipos de substratos que causam a nucleação heterogênea; o superresfriamento crítico para a nucleação heterogênea (MARCANTO; MONDOLFO, 1970); e os efeitos das orientações cristalográficas relativas entre os reticulados do núcleo e do substrato e as energias interfaciais entre o núcleo e o substrato (CIBULA, 1949; BRAMFITT, 1970; DAVIES et al., 1970; MARASLI; HUNT, 1998). Nos próximos itens serão descritos os dois principais mecanismos utilizados para explicar a inoculação de banhos líquidos, o efeito da relação de orientação entre núcleo e substrato e a restrição do crescimento dos grãos. Em um terceiro item, a teoria do peritético, que aparentemente representa uma combinação entre os dois primeiros, será apresentada para explicar o efeito de inoculação observado na adição de elementos que causam uma reação peritética com o metal principal. 


\subsubsection{Efeito da relação de orientação entre núcleo e substrato}

Nos metais e ligas, a nucleação heterogênea da fase sólida sobre substratos sólidos presentes no interior do líquido têm sido investigada através de medidas relacionadas com a cristalografia do substrato e da fase sólida e de medidas do superresfriamento do líquido nos estágios iniciais da solidificação. Em seu estudo pioneiro, Turnbull e Vonnegut (Turbull e Vonnegut 1952) quantificaram a potencialidade dos substratos em promoverem a nucleação heterogênea por meio do parâmetro de desajuste cristalográfico $\delta$, definido a seguir como:

$$
\delta=\frac{a_{T}-a_{S}}{a_{S}}
$$

onde: $a_{T}$ é o parâmetro da rede cristalina do reticulado do substrato inoculante e $a_{S}$ o parâmetro da rede cristalina do núcleo sólido para os principais planos compactos obtido por difração de raios $x$.

A proposta do parâmetro $\delta$ está baseada na hipótese de que o cristal formado, tem uma relação de orientação cristalográfica estabelecida com o substrato sobre o qual se forma. Esta relação de orientação é definida com base nas direções e planos paralelos em ambos os cristais onde o arranjo atômico é semelhante. A Figura 13 apresenta a região de interface entre o núcleo sólido e o substrato, mostrando as pequenas regiões com reticulados semelhantes.

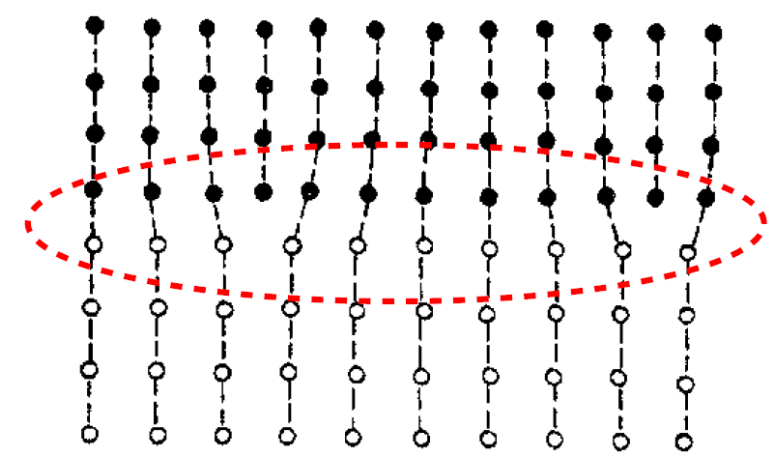

Figura 13 - Seção transversal perpendicular ao plano (100) num reticulado cúbico simples mostrando as regiões locais com ajuste no reticulado entre núcleo e substrato. Adaptado de TURNBULL; VONNEGUT (1952). 
MARCANTO; MONDOLFO (1970) Realizaram estudos pioneiros de inoculação em alumínio utilizando substratos de compostos intermetálicos. Estes pesquisadores encontraram compostos que causavam a nucleação heterogênea do alumínio sólido e mostraram que, para cada cristal sólido formado, existe pelo menos uma relação de orientação que proporciona baixos valores de desajuste $(\delta)$. A Figura 14 apresenta um desenho esquemático bidimensional do ajustamento das posições dos átomos nos reticulados tetragonais dos substratos de $\mathrm{TiAl}_{3}$ e $\mathrm{ZrAl}_{3}$ e do núcleo de alumínio CFC. Note-se que, para os três exemplos, existe pelo menos uma relação de orientação com baixo desajuste, significando que quando as direções e planos cristalográficos indicados para os dois reticulados forem paralelos, o desajuste é relativamente baixo. Nestes estudos, tanto o tipo de estrutura cristalina como os parâmetros de rede foram obtidos por difração de raios- $x$.

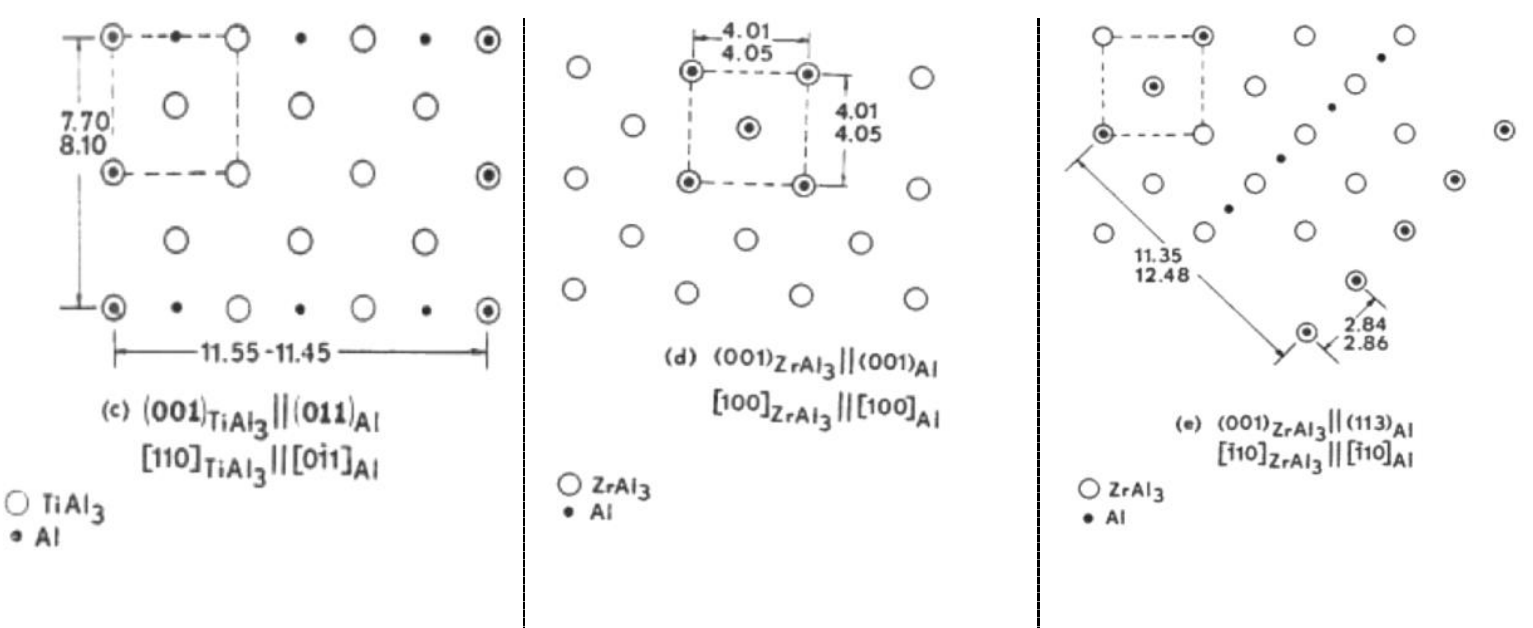

Figura 14 - Relações de orientação (direções e planos cristalográficos paralelos nos dois reticulados) entre substratos de $\mathrm{TiAl}_{3}$ e $\mathrm{ZrAl}_{3}$ com o alumínio (Al) e posicionamento relativo dos átomos em cada reticulado. A linha tracejada delineia o parâmetro de rede, a ordem de aparecimento do valor do parâmetro de rede é primeiro o do nucleante e segundo o do alumínio. Adaptado de (MARCANTO; MONDOLFO, 1970).

BRAMFITT (1970) Realizou estudos de correlação com o parâmetro de desajuste do potencial para a nucleação heterogênea do ferro mostrado por substratos de carbonetos e nitretos de silício, zircônio e tungstênio. Estes estudos mostraram uma limitação no cálculo do parâmetro de desajuste $(\delta)$ apresentado por TURNBULL; VONNEGUT (1952), permitindo propor um novo cálculo. Este cálculo pode ser utilizado não só para planos com arranjos atômicos similares, mas também 
para planos com arranjos atômicos que não se assemelham. $O$ autor apresentou o cálculo modificado deste parâmetro em duas formas. Uma forma geral, indicada como:

$$
\text { Forma geral: } \quad \delta=\frac{\delta_{1}+\delta_{2}+\delta_{3}}{3} \times 100
$$

onde $\delta_{1}, \delta_{2} e \delta_{3}$ são os desajustes calculados ao longo de três direções de baixo índice de Miller dentro de um quadrante de $90^{\circ}$ dos planos do sólido nucleado e o substrato, e uma forma específica dada por:

Forma específica: $\quad \delta_{(h k l)_{n}}^{(h k l)_{s}}=\sum_{i}^{3} \frac{\frac{\left[\left(d_{[u v w]_{s}^{i} \cos \theta}\right)-d_{[u v w]_{n}^{i}}\right]}{d_{[u v w]_{n}^{i}}}}{3}$

onde:

$>(h k l)_{s}=$ plano de baixo índice no substrato

$>[u v w]_{s}=$ direção de baixo índice no $(h k l)_{s}$

$>(h k l)_{n}=$ plano de baixo índice no sólido nucleado

$>[u v w]_{n}=$ direção de baixo índice no $(h k l)_{n}$

$>d[u v w]_{n}=$ espaçamento interatômico a longo da $[u v w]_{n}$

$>d[u v w]_{s}=$ espaçamento interatômico a longo da $[u v w]_{s}$

Cissé et al., (CISSÉ et al., 1971) realizaram estudos pioneiros de nucleação heterogênea durante a solidificação de alumínio em contato com peça maciça de TiC monocristalino ou policristalino e nucleação heterogênea de Al com TiC. Estes estudos evidenciaram a existência das relações de orientação $(001)_{A l} \|(001)_{T i C} \mathrm{e}$ $[001]_{A l} \|[001]_{T i C}$ na interface do Al/TiC, verificando que o TiC funciona como substrato para a nucleação. Consecutivamente (CISSÉ et al., 1974) corroboraram o efeito de nucleação de alumínio com compostos de AlTi e TiC apresentando evidências de centros de inoculação, obtidos variando as velocidades de resfriamento durante a solidificação. Os autores mostram que o papel do desajuste cristalográfico $\delta=6,5 \%$ entre o TiC e o Al, apesar de ser menor que o limite de $15 \%$, não é uma prova o suficientemente clara, para evidenciar o potencial de inoculação do TiC. No entanto, relações de orientação medidas diretamente nas amostras atacadas, utilizando a difração de raios-x nos grãos de $\mathrm{Al}$ ao redor das partículas de TiC no 
centro dos grãos, permitem corroborar o efeito inoculante. Contrário às observações da teoria do peritético proposta por Croosley, na qual a adição de carbono reduzia o efeito inoculante.

A similaridade nos parâmetros de rede entre o substrato para a nucleação e o núcleo sólido pode indicar a eficiência do refinamento de grão causado por este substrato. Quanto maior a similaridade, menor a energia interfacial entre o substrato e o núcleo e, segundo a Eq. (6), menor o ângulo de contato entre o núcleo e o substrato e menor o fator de forma, aumentando a taxa de nucleação (PEREPEZKO, 1998b). Como consequência, o parâmetro $\delta$, que indica a semelhança entre os reticulados do substrato e do núcleo, é utilizado para quantificar a eficiência de nucleação. É importante notar que $\delta<0.15$ indica um forte efeito inoculante, como está ilustrado na Tabela 2 para alguns compostos utilizados como inoculante em alumínio (MCCARTNEY, 1989).

Tabela 2 - Correspondência entre os parâmetros de rede, estrutura cristalina e o efeito inoculante de alguns compostos utilizados para inocular alumínio.

\begin{tabular}{lccc}
\multicolumn{1}{c}{ Composto } & Estrutura & $\boldsymbol{\delta}$ & Efeito inoculante \\
\hline $\mathbf{V C}$ & Cúbica & 0,014 & Forte \\
\hline $\mathrm{TiC}$ & Cúbica & 0,060 & Forte \\
\hline $\mathrm{TiB}_{\mathbf{2}}$ & Hexagonal & 0,048 & Forte \\
\hline $\mathbf{A l B} \mathbf{2}_{2}$ & Hexagonal & 0,038 & Forte \\
\hline $\mathbf{Z r C}$ & Cúbica & 0,145 & Forte \\
\hline $\mathbf{N b C}$ & Cúbica & 0,086 & Forte \\
\hline $\mathbf{W}_{\mathbf{2}} \mathbf{C}$ & Hexagonal & 0,035 & Forte \\
\hline $\mathbf{F e} \mathbf{C}$ & Ortorrômbica & 0,115 & Fraco \\
& & 0,255 & \\
\hline
\end{tabular}

A Tabela 3 apresenta um resumo do nucleantes reportados na literatura para ligas de cobre, a maioria deste nucleantes foram identificados pela detecção do efeito de refinamento de grãos, o autor menciona que a menos que seja definitivamente provado que o refinamento de grão é produzido pela nucleação heterogênea, e não por restrição ao crescimento ou por alguma impureza, qualquer relação derivada da desta tabela é uma questão em aberto. 
Tabela 3 - Resumo dos nucleantes para ligas de cobre com detecção de refinamento de grão, apresentando o super resfriamento para a nucleação $(\Delta T)$ e as relações de orientação (OR), refinamento de grão (RG) reportadas por MONDOLFO (1982).

\begin{tabular}{|c|c|c|c|}
\hline Nucleante & Detecção & $\Delta \mathrm{T}$ & OR \\
\hline $\mathrm{Ag}$ & - & 126 & - \\
\hline B & $R G$ & - & - \\
\hline $\mathrm{Be}$ & $R G$ & - & - \\
\hline Co & $R G$ & - & - \\
\hline $\mathrm{CoB}_{2}$ & $R G$ & - & - \\
\hline $\mathrm{Cr}$ & $R G$ & - & - \\
\hline $\mathrm{Fe}$ & $R G$ & 7 & $\begin{array}{c}(001)\|(001)[100]\|[110], \\
(211)\|(001),(111)\|(110), \\
(100) \|(100)\end{array}$ \\
\hline $\mathrm{Fe}+\mathrm{Mn}$ & $\mathrm{RG}$ & - & - \\
\hline $\mathrm{FeB}_{2}$ & RG & - & - \\
\hline Mo & $R G$ & - & $(111)\|(110)[-110]\|[11-1]$ \\
\hline $\mathbf{N b}$ & $R G$ & - & - \\
\hline $\mathbf{N i}$ & $R G$ & - & $(100) \Pi(100)$ \\
\hline Te & $R G$ & - & - \\
\hline $\mathrm{Ti}$ & $R G$ & - & $(111)\|(001)[110]\|[110]$ \\
\hline $\mathrm{Ti}+\mathrm{Be}+\mathrm{Cr}$ & $R G$ & - & - \\
\hline $\mathrm{TiB}_{2}$ & $R G$ & - & - \\
\hline $\mathbf{V}$ & $R G$ & - & - \\
\hline W & $R G$ & - & $\begin{array}{l}(111)\|(011)[112]\|[011], \\
(111)\|(011)[112]\|[120], \\
(111)\|(110)[-110]\|[11-1]\end{array}$ \\
\hline $\mathrm{Zr}$ & $R G$ & - & - \\
\hline $\mathrm{ZrB}_{2}$ & $R G$ & - & - \\
\hline
\end{tabular}

Na Tabela 4, CIBULA (1954) apresenta um compilado diferentes compostos nucleantes para ligas de cobre, o autor sugere que o refinador de grão deve ter similaridade estrutural com o metal base e dimensões do reticulado. Alguns autores admitem que um composto pode atuar como refinador desde que as dimensões do reticulado não difiram em mais que $20 \%$ com relação ao metal base. Outros admitem que isto e admissível mesmo quando está diferença atinge 30\%.

Tabela 4- Desajuste de diferentes compostos nucleantes para ligas base cobre (CIBULA, 1954).

\begin{tabular}{|c|c|c|c|c|c|c|c|c|c|}
\hline Formula & TiC & TiN & $\mathrm{TiB}_{2}$ & VC & VN & $\mathrm{VB}_{2}$ & $\mathrm{CrB}_{2}$ & FeB & MnB \\
\hline Desajuste \% & 20 & 17 & 19 & 15 & 14 & 18 & 16 & 18 & 18 \\
\hline Formula & ZrC & ZrN & $\mathrm{ZrB}_{2}$ & $\mathrm{NbC}$ & NbN & $\mathrm{NbB}_{2}$ & $\mathrm{Mo}_{2} \mathrm{C}$ & MoC & MoB $_{2.5}$ \\
\hline Desajuste \% & 30 & 28 & 24 & 23 & 21 & 21 & 17 & 13 & 18 \\
\hline Formula & WC & $\mathrm{W}_{2} \mathrm{C}$ & $\mathrm{WB}_{2.5}$ & $\mathrm{AlB}_{2}$ & & & & & \\
\hline Desajuste \% & 13 & 17 & 17 & 18 & & & & & \\
\hline
\end{tabular}




\subsubsection{Restrição do Crescimento dos grãos}

Johnson e Bäckerud (JOHNSSON; BACKERUD, 1996) sugeriram que a presença de elementos de liga em solução no líquido influencia o mecanismo de refinamento de grão. Durante a solidificação estes elementos são segregados pelo sólido para o líquido junto à interface sólido-líquido. Para que a solidificação tenha continuidade estes elementos devem difundir-se constantemente da interface para o interior do líquido. O processo de difusão depende de tempo para ocorrer e, portanto, acaba retardando o avanço da interface sólido-líquido. Quanto maior a quantidade destes elementos, maior é o efeito retardador. Quando o crescimento dos grãos é retardado e o sistema sólido-líquido está continuamente resfriando, o líquido remanescente torna-se cada vez mais super-resfriado antes de ser consumido pela solidificação dos grãos já existentes. Este maior super-resfriamento promove um aumento do número de substratos sobre os quais ocorre a nucleação heterogênea, aumentando o número de núcleos de sólido formados. Este efeito, que causa o refino de grão, é denominado de "efeito de restrição ao crescimento" e foi quantificado através de dois parâmetros, denominados $\boldsymbol{P}$ e $\boldsymbol{Q}$, definidos abaixo (TARSHIS et al., 1971; GREER et al., 2000)

$$
\begin{gathered}
P=\frac{m(k-1) C_{0}}{k} \\
Q=m(k-1) C_{0}=k P
\end{gathered}
$$

onde $m$ é a inclinação da linha de liquidus do diagrama de fases binário solventesoluto; $C_{0}$ é a concentração de soluto no líquido inicial e $k$ é o coeficiente de partição de soluto. Sabe-se que, em condições de equilíbrio, um sólido e um líquido podem apresentar composições distintas segundo o diagrama de fases. Dada as composições do sólido e do líquido em equilíbrio, $C_{s}$ e $C_{l}$ respectivamente, o coeficiente de partição de soluto é definido como:

$$
k=\frac{C_{s}}{C_{l}}
$$

O fator de restrição ao crescimento pode indicar entre os elementos que permanecem em solução no líquido aqueles mais efetivos para refinar o tamanho 
médio de grão. Os índices $\boldsymbol{P e} \boldsymbol{Q}$ mostram que os elementos mais efetivos apresentam valores de coeficiente de partição $(\boldsymbol{k})$ menores (para $\boldsymbol{k}<1$ ) e maior inclinação (em módulo) da linha liquidus $(\boldsymbol{m})$ do diagrama de fases binário.

O efeito de restrição ao crescimento para diferentes elementos no alumínio pode ser visto na Tabela 5 . Note que o valor de $m(k-1)$ para o Ti é muito maior que para os outros elementos, indicando que o efeito de restrição ao crescimento resultante da adição de Ti é maior que o da maioria dos outros elementos. Estes valores explicam a escolha do elemento Ti para fazer parte das ligas-mãe Al-Ti-B utilizadas para o refino de grão na indústria da fundição do alumínio.

Tabela 5 - Capacidade de segregação de alguns elementos de soluto no alumínio (EASTON; STJOHN, 1999).

\begin{tabular}{cccccc} 
Elemento & $\boldsymbol{k}$ & $\boldsymbol{m}$ & $(\boldsymbol{k}-\mathbf{1}) \boldsymbol{m}$ & Solubilidade $^{*}$ & Tipo de reação $^{\text {Peritético }}$ \\
\hline $\mathrm{Ti}$ & 7,8 & 33.3 & $\sim 220$ & 0,15 & Peritético \\
\hline $\mathrm{Ta}$ & 2,5 & 17 & 105 & 0,1 & Peritético \\
\hline $\mathrm{V}$ & 4,0 & 10 & 30 & $\sim 0,10$ & Peritético \\
\hline $\mathrm{Hg}$ & 2,4 & 8,0 & 11,2 & $\sim 0,50$ & Peritético \\
\hline $\mathrm{Mo}$ & 2,5 & 5,0 & 7,5 & $\sim 0,10$ & Peritético \\
\hline $\mathrm{Zr}$ & 2,5 & 4,5 & 6,8 & 0,11 & Peritético \\
\hline $\mathrm{Nb}$ & 1,5 & 13,3 & 6,6 & $\sim 0,15$ & Eutético \\
\hline $\mathrm{Si}$ & 0,11 & $-6,6$ & 5,9 & $\sim 12,6$ & Peritético \\
\hline $\mathrm{Cr}$ & 2,0 & 3,5 & 3,5 & $\sim 0,40$ & Eutético \\
\hline $\mathrm{Ni}$ & 0,007 & $-3,3$ & 3,3 & $\sim 6,0$ & Eutético \\
\hline $\mathrm{Mg}$ & 0,51 & $-6,2$ & 3,0 & $\sim 3,4$ & Eutético \\
\hline $\mathrm{Fe}$ & 0,02 & $-3,0$ & 2,9 & $\sim 1,8$ & Eutético \\
\hline $\mathrm{Cu}$ & 0,17 & $-3,4$ & 2,8 & 33,2 & Eutético \\
\hline $\mathrm{Mn}$ & 0,94 & $-1,6$ & 0,1 & 1,9 &
\end{tabular}

* Concentração máxima de alguns elementos de soluto no alumínio.

Uma redução da velocidade de crescimento dos grãos devido à adição de elementos de liga permite que o banho atinja super-resfriamentos mais elevados antes do final da solidificação e, portanto, aumenta o número de substratos efetivos para nucleação. O efeito de restrição quantificado a partir do cálculo dos parâmetros $\mathbf{P}$ e $\mathbf{Q}$ foram calculados para diversos elementos de liga no $\mathrm{Cu}$, principalmente para o $\mathrm{Sn}$ e $\mathrm{Zn}$, que parecem causar esta restrição. A Tabela 6 mostra os fatores de restrição, indicando que o Sn tem um maior efeito de restrição do que o $\mathrm{Zn}$ e que o $\mathrm{Pb}$ apresenta um fator muito elevado em vista de sua solubilidade quase nula no Cu-a. 
Tabela 6 - Fatores de restrição ao crescimento de grão $(P, Q)$ para diversos elementos dissolvidos em cobre líquido e parâmetros utilizados no cálculo destes fatores: inclinação da linha líquidos do diagrama binário $(\mathrm{m})$, coeficiente de partição de soluto e composição média $\left(C_{0}\right)$.

\begin{tabular}{|c|c|c|c|c|c|c|c|c|c|c|c|c|c|c|}
\hline $\begin{array}{l}\text { Elemento } \\
\text { de Soluto }\end{array}$ & $\underset{\left({ }^{\circ} \mathbf{C} / w t \%\right)}{m}$ & $\mathrm{~K}$ & $\begin{array}{c}\mathrm{C}_{0} \\
\text { (wt\%) }\end{array}$ & $\begin{array}{c}\mathrm{P} \\
\left({ }^{\circ} \mathrm{C}\right) \\
\end{array}$ & $\begin{array}{c}\mathrm{Q} \\
\left({ }^{\circ} \mathrm{C}\right) \\
\end{array}$ & $\begin{array}{c}\mathrm{C}_{0} \\
\text { (wt\%) }\end{array}$ & $\begin{array}{r}\mathbf{P} \\
\left({ }^{\circ} \mathrm{C}\right) \\
\end{array}$ & $\begin{array}{c}Q \\
\left({ }^{\circ} \mathbf{C}\right) \\
\end{array}$ & $\begin{array}{c}\mathrm{C}_{0} \\
(w t \%)\end{array}$ & $\begin{array}{r}\mathrm{P} \\
\left({ }^{\circ} \mathrm{C}\right) \\
\end{array}$ & $\begin{array}{c}Q \\
\left({ }^{\circ} \mathbf{C}\right) \\
\end{array}$ & $\begin{array}{c}\mathrm{C}_{0} \\
\text { (wt\%) }\end{array}$ & $\begin{array}{r}\mathbf{P} \\
\left({ }^{\circ} \mathrm{C}\right) \\
\end{array}$ & $\begin{array}{c}Q \\
\left({ }^{\circ} \mathbf{C}\right) \\
\end{array}$ \\
\hline Sn & $-11,3$ & 0,5 & 1,0 & 10,0 & 5,3 & 3,0 & 30,0 & 15,9 & 8,0 & 80,0 & 42,4 & 20,0 & 200,0 & 106 \\
\hline $\mathrm{Fe}$ & 3,6 & 1,3 & 0,3 & 0,2 & 0,3 & 0,5 & 0,4 & 0,6 & 1,0 & 0,9 & 1,1 & 2,0 & 1,7 & 2,3 \\
\hline Al & 3,3 & 0,9 & 1,0 & 0,3 & 0,3 & 3,0 & 1,0 & 0,9 & 6,0 & 2,1 & 1,9 & 8,0 & 2,8 & 2,5 \\
\hline $\mathrm{Zn}$ & $-4,9$ & 0,9 & 10,0 & 7,5 & 6,5 & 20,0 & 15,0 & 13,0 & 30,0 & 22,5 & 19,5 & 36,0 & 27,0 & 23,4 \\
\hline $\mathrm{Zr}$ & $-13,2$ & 0,0 & 0,08 & 62,1 & 1,0 & 0,2 & 116,5 & 1,9 & 0,4 & 310,7 & 5,2 & 0,8 & 621,5 & 10,4 \\
\hline $\mathrm{Ti}$ & $-10,7$ & 0,3 & 1,0 & 24,0 & 7,4 & 6,0 & 144 & 44,5 & 12,0 & 287,9 & 88,9 & 17,0 & 407,9 & 126 \\
\hline B & $-28,7$ & 0,0 & 0,0 & 28,2 & 0,6 & 0,1 & 70,4 & 1,4 & 1,0 & 1408 & 28,2 & 2,0 & 2817 & 56,3 \\
\hline $\mathrm{Pb}$ & $-3,5$ & 0,0 & 0,0 & 130 & 0,0 & 0,1 & 649,2 & 0,2 & 0,1 & 1298 & 0,3 & 0,5 & 6491 & 1,7 \\
\hline Mn & $-8,7$ & 0,7 & 1,0 & 4,4 & 2,9 & 2,0 & 8,9 & 5,9 & 3,0 & 13,3 & 8,8 & 4,0 & 17,7 & 11,7 \\
\hline $\mathrm{Cr}$ & 7,3 & 0,4 & 0,3 & 3,0 & 1,3 & 0,6 & 6,0 & 2,5 & 1,0 & 10,0 & 4,2 & 1,5 & 15,0 & 6,3 \\
\hline $\mathbf{P}$ & $-45,2$ & 0,2 & 0,3 & 51,2 & 10,7 & 1,0 & 170,8 & 35,7 & 2,0 & 341,7 & 71,5 & 3,0 & 512,5 & 107 \\
\hline S & $-23,5$ & 0,0 & 0,0 & 17,6 & 0,3 & 0,1 & 131,9 & 2,1 & 0,3 & 439,7 & 6,9 & 0,7 & 1026 & 16,2 \\
\hline
\end{tabular}

\subsubsection{Teoria do peritético (CROSSLEY; MONDOLFO, 1951)}

A teoria do diagrama de fases foi uma das primeiras tentativas em explicar 0 mecanismo de refinamento de grão em ligas de alumínio. Neste estudo foram analisados os efeitos da adição de $\mathrm{Cr}, \mathrm{Zr}, \mathrm{Ti}, \mathrm{Mo}$ e $\mathrm{W}$, que causam uma reação peritética com alumínio. No caso da adição de $\mathrm{Ti}$, a teoria sugere que o refinamento acontece porque partículas de $\mathrm{TiAl}_{3}$ estão presentes no Al líquido acima de sua temperatura de fusão, como mostra o diagrama de fases peritético do sistema Al-Ti, na região rica em Al (Figura 15). 


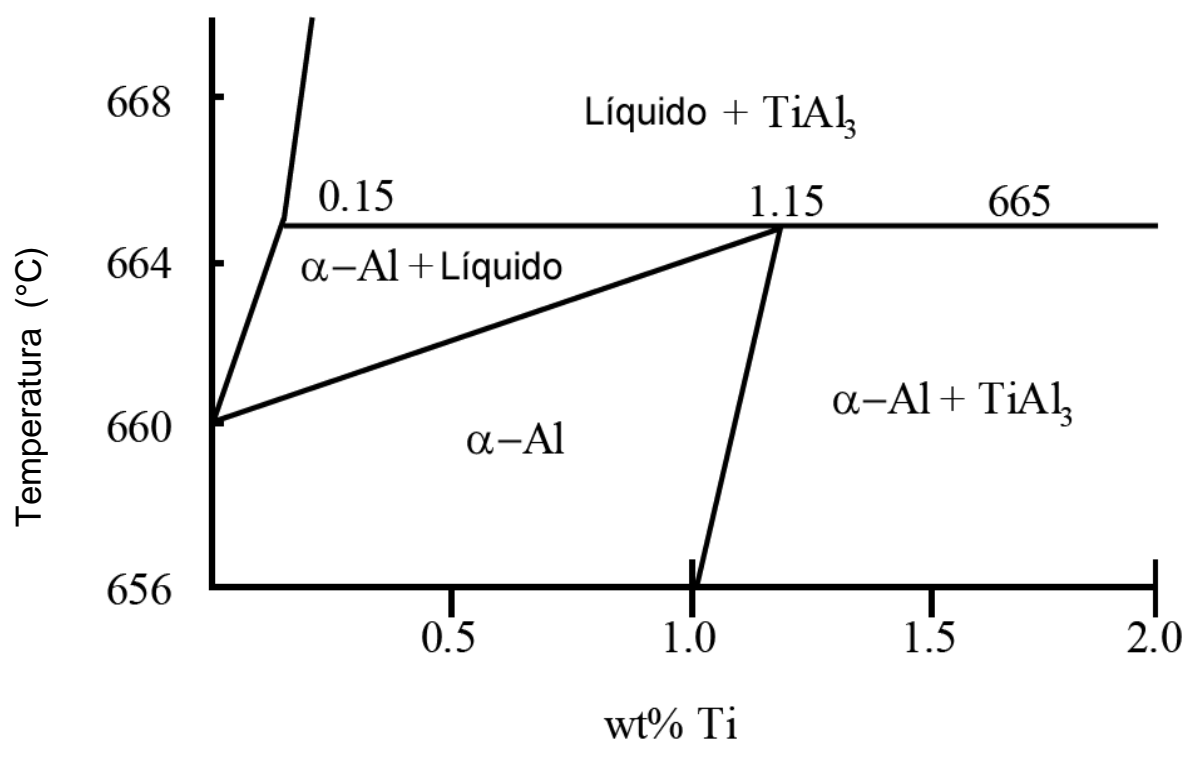

Figura 15 - Parte do diagrama de fases AI-Ti (EASTON; STJOHN, 1999).

Esta teoria está baseada na hipótese de que os cristais de $\mathrm{TiAl}_{3}$, que se formam no peritético, são nucleantes ativos, ou seja, apresentam um reticulado cristalino com desajuste cristalográfico relativamente pequeno em relação à fase primária (Al- $\alpha)$, apresentando-se como substratos efetivos para a nucleação heterogênea. Um outro aspecto que contribui para a potencialidade inoculante destes elementos é um coeficiente de partição de soluto relativamente baixo $(<1)$, causando também um efeito significativo de restrição ao crescimento de grão. No entanto, existem ainda controvérsias em relação ao fato de diversos elementos inoculantes efetivos formarem uma reação peritética com o metal principal (WANG et al., 2013).

De forma similar para o sistema Cu-Fe, na reação peritética $(\gamma(\mathrm{Fe})+\mathrm{L} \rightarrow \alpha(\mathrm{Cu}))$ ocorre a nucleação heterogênea da fase $\alpha(\mathrm{Cu})$ sobre a interface das fases $\gamma(\mathrm{Fe})$ e líquido $(L)$, na temperatura peritética $T p$, como se apresenta na Figura 16 para a região rica em cobre do diagrama de fase $\mathrm{Cu}-\mathrm{Fe}$. 


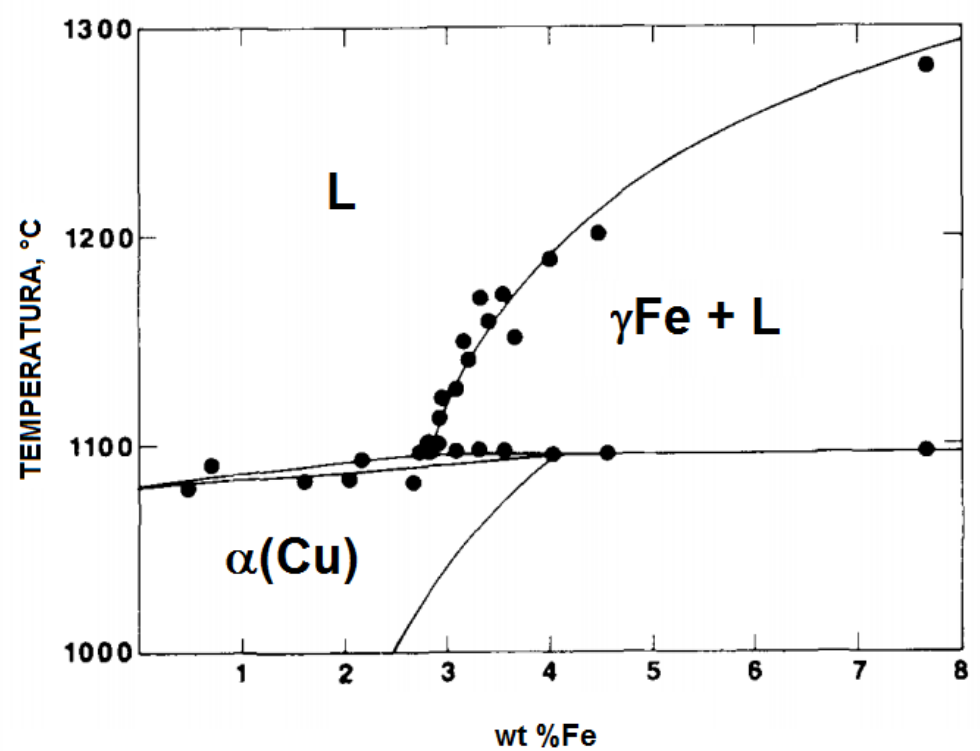

Figura 16 - Diagrama de fase Cu-Fe na região rica em cobre. (PATCHETT; ABBASCHIAN, 1985)

\subsection{Análise Térmica}

As reações químicas e muitas transições de fases estão associadas à liberação ou consumo de calor latente. Medições neste tipo de evento térmico podem ser realizadas durante a solidificação de ligas metálicas utilizando-se diferentes técnicas como: análise térmica diferencial (DTA - "Differential Thermal Analysis"); calorimetria diferencial exploratória (DSC - "Differential Scanning Calorimetry") e a técnica denominada no presente trabalho de "análise de curvas de resfriamento", que está descrita a seguir.

\subsubsection{Análise de Curvas de Resfriamento}

A análise das curvas de resfriamento durante a solidificação não-controlada é conduzida através do simples monitoramento da temperatura em função do tempo durante a solidificação livre de uma amostra submetida a um determinado ambiente de resfriamento. Durante este resfriamento, nem a temperatura e nem o fluxo de calor 
são controlados. As curvas obtidas, denominadas curvas de resfriamento, são medidas durante a solidificação a partir de termopares imersos no metal líquido.
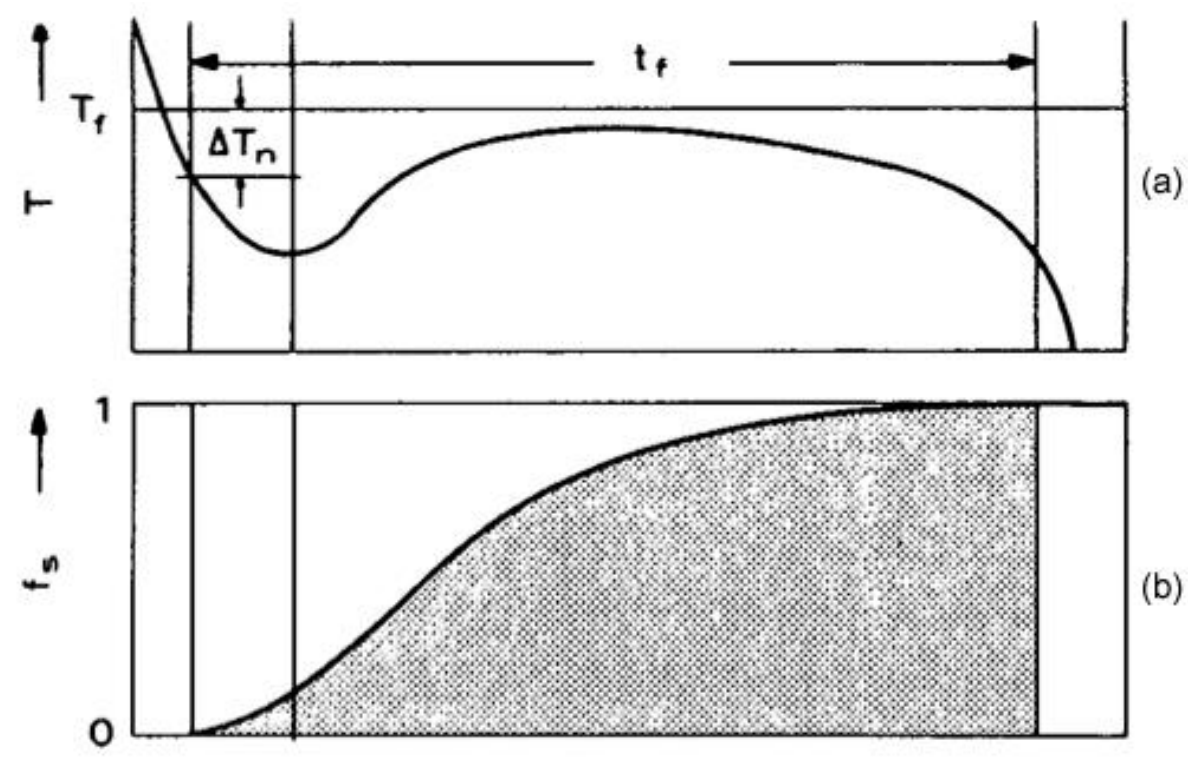

(b)

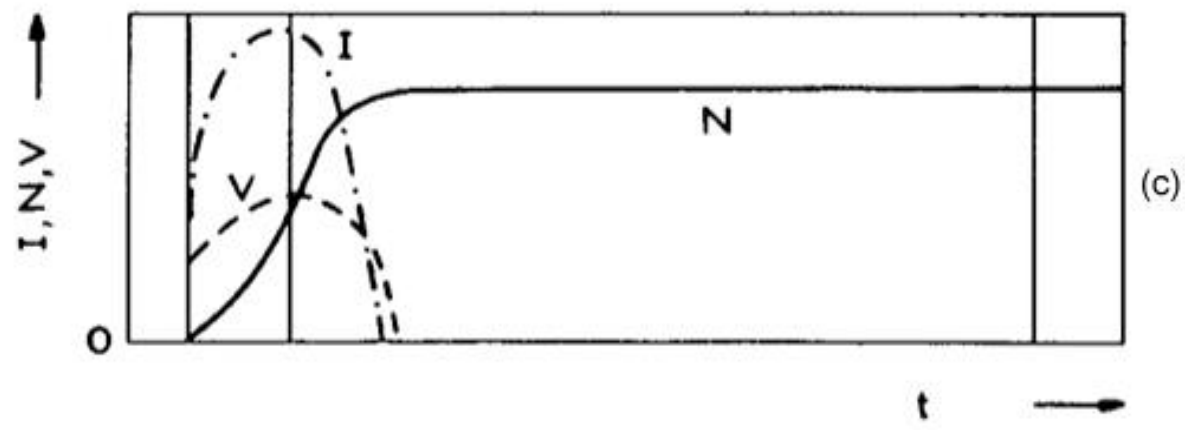

Figura 17 - Histórico térmico da solidificação dendrítica equiaxial: a) curva de resfriamento; b) curva de fração de solido; c) curvas da taxa de nucleação (I), velocidade de crescimento dos grãos (V), (Tf) Temperatura de nucleação e número de grãos (N) (KURZ; FISHER, 1989).

Nesta técnica utilizam-se conceitos matemáticos como as derivadas ou inflexões das curvas de resfriamento para interpretar os diferentes fenômenos que ocorrem durante a solidificação (BARLOW; STEFANESCU, 1997). Kurz e Fisher (KURZ; FISHER, 1989) correlacionaram de forma esquemática estes eventos com uma curva de resfriamento, como mostrado na Figura 17. O início da nucleação acontece quando a temperatura fica abaixo da temperatura de nucleação, $T_{f}-\Delta T_{N}$ (Figura 17(a)), coincidindo com o aumento da fração de sólido $f_{s}$ (Figura 17(b)) e também com o aumento da taxa de nucleação $I$ e velocidade de crescimento dos grãos $V$ (Figura 17(c)). É importante notar que $I$ e $V$ atingem um valor máximo conforme o superresfriamento aumenta. Com o aumento na temperatura originado pelo calor latente 
liberado devido à solidificação, ocorre um decréscimo na velocidade de crescimento e da taxa de nucleação.

As curvas de resfriamento nem sempre oferecem bons indicativos de todas as reações que acontecem durante a solidificação devido às reduzidas quantidades de calor latente liberadas. Logo, técnicas mais sensíveis, como aquelas que utilizam a primeira derivada da curva de resfriamento, foram exploradas por Bäckerud e Sigworth (BACKERUD; SIGWORTH, 1989). Estas técnicas tornam maiores os pequenos eventos térmicos da curva de resfriamento que antes não eram detectados. Um exemplo é a formação do eutético ternário Al-Mg2 Si-Si e a modificação do eutético por adição de diferentes elementos como o estrôncio (ARGYROPOULOS et al., 1983).

A Figura 18 apresenta uma curva de resfriamento típica da liga de AI 356 e a sua primeira derivada em relação ao tempo, chamada de curva de taxa de resfriamento, mostrando as diferentes regiões onde acontecem os eventos térmicos. Estes eventos foram definidos por diferentes autores como apresentado abaixo (BACKERUD et al., 1986; BACKERUD; SIGWORTH, 1989; SPARKMAN; KEARNEY, 1994; BARLOW; STEFANESCU, 1997):

- Região (1): Nucleação e crescimento inicial dos grãos de alumínio. No máximo valor da derivada (região da recalescência), tem-se uma rápida liberação de calor latente.

- Região (2): Crescimento da rede dendrítica da parede do molde em direção ao centro.

- Região (3): Espessamento dos braços de dendrita.

- Região (4): Nucleação do silício indicando o início da solidificação do eutético. Há um rápido aumento na derivada devido à repentina liberação de calor associada à formação dos cristais de Si.

- Região (5): Continuação do crescimento do silício e também do alumínio contido no eutético.

- Região (6): Nucleação e crescimento de uma nova fase, possivelmente $\mathrm{Mg}_{2} \mathrm{Si}$ da liga 356.

- Região (7): Término da solidificação; o calor produzido pela solidificação cessa rapidamente e há uma rápida diminuição do gradiente de temperatura. 


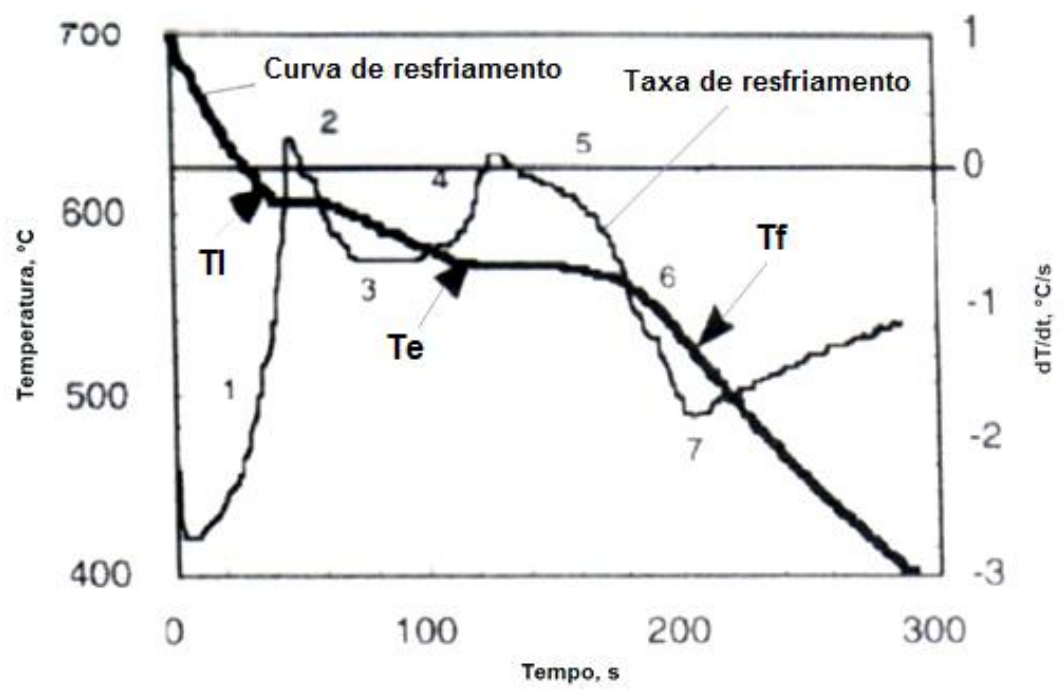

Figura 18 - Curva de resfriamento da liga Al-6,5\% Si (356) e a sua respectiva derivada (BARLOW; STEFANESCU, 1997). As siglas $T_{l}, T_{e}$ e $T_{f}$ representam as temperaturas do líquido, do eutético e de final da solidificação, respectivamente.

Schetky et al., (SCHETKY et al., 1983; APELIAN et al., 1984; CHARBONNIER, 1984; BACKERUD et al., 1986) argumentam que a temperatura e o tempo de início da nucleação ( $T_{N}$ e $t_{N}$, respectivamente) são indicados pela primeira mudança brusca na inclinação da curva de resfriamento (Figura 19). Para os autores este efeito na curva é causado pelo aumento de temperatura devido à liberação abrupta de calor latente durante o crescimento da rede dendrítica da fase primária. Esta temperatura e instante de tempo também foi definida por Bäckerud e Sigworth (BACKERUD; SIGWORTH, 1989) e Sparkman e Kearney (SPARKMAN; KEARNEY, 1994) como temperatura e instante da nucleação.

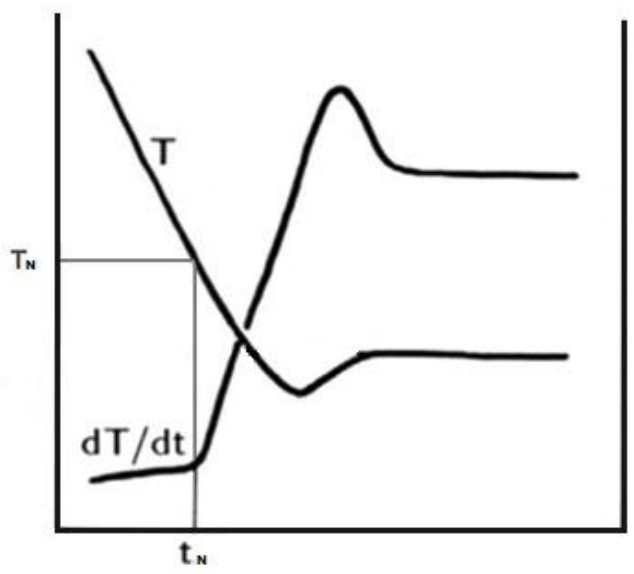

Figura 19- Definição da temperatura e tempo de nucleação nas curvas de resfriamento e na primeira derivada destas curvas: $T_{n}$ e $t_{n}$ são a temperatura e $o$ instante de início de nucleação segundo Apelian et al., (APELIAN et al., 1984), Schetky et al., (SCHETKY et al., 1983), Bäckerud et al. (BACKERUD et al., 1986) e Charbonnier (CHARBONNIER, 1984). 
Charbonnier (CHARBONNIER, 1984), (CROSSLEY; MONDOLFO, 1951) (IBARRA, 1999), observam que, nos primeiros estágios da solidificação dendrítica, a forma da curva de resfriamento oferece informação relacionada com o tamanho de grão. Quando se adiciona o inoculante, a curva de resfriamento aparece muitas vezes sem a recalescência. Nestas curvas, dois tipos de parâmetros podem ser extraídos, para serem correlacionados com o tamanho de grão, como representado na Figura 20. Os primeiros são os parâmetros térmicos como: o super-resfriamento da recalescência $\left(\Delta T_{R-U}=T_{R}-T_{U}\right)$, definido como a diferença entre as temperaturas mínima e máxima durante a recalescência. Outros parâmetros térmicos como $\Delta \mathrm{T}_{\mathrm{N}-U}$ $=T_{N}-T_{u}$ e $\Delta T_{N}-R=T_{N}-T_{R}$ definidos como a diferença entre a temperatura de nucleação e as temperaturas mínima e máxima durante a recalescência, respectivamente. O segundo tipo são os parâmetros de tempo como: o período de super-resfriamento $\left(t_{1}\right)$, ou seja, o tempo que separa a temperatura mínima e máxima e o período de superresfriamento $\left(t_{2}\right)$, definido como o tempo que separa a temperatura de nucleação e a temperatura mínima durante a recalescência.

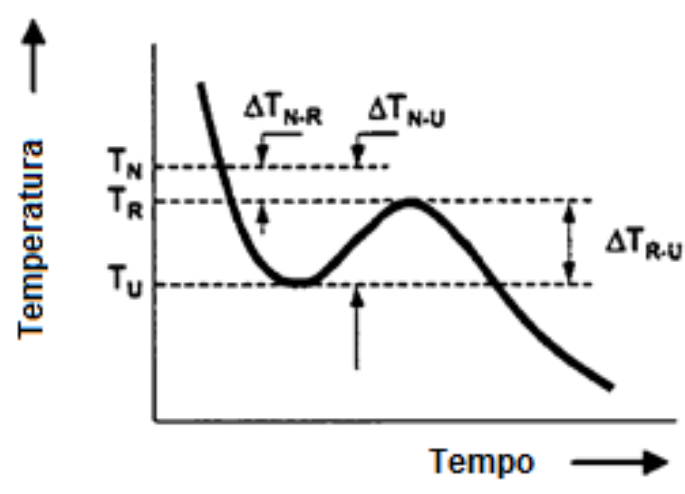

(a) Parâmetros de temperatura

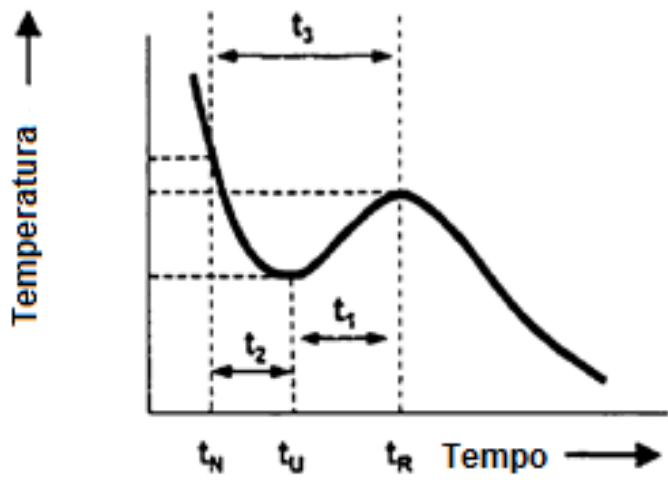

(b) Parâmetros de tempo

Figura 20 - Ampliação da curva de resfriamento na região da recalescência mostrando: (a) Parâmetros de

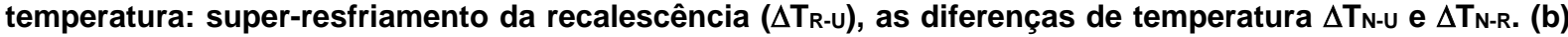
Parâmetros de tempo: o período da recalescência $\left(t_{1}\right)$, o período do estágio da nucleação $\left(t_{2}\right)$, o período entre a nucleação e o final da recalescência $\left(t_{3}\right)$ e a temperatura de líquido $T_{L}$ (CHARBONNIER, 1984), (IBARRA, 1999).

Um outro parâmetro que pode ser obtido é área do pico do líquido (PL), este é medido integrando a curva de taxa de resfriamento, gerando a área embaixo da curva no segmento positivo da curva da derivada, como apresentada na Figura 21. 


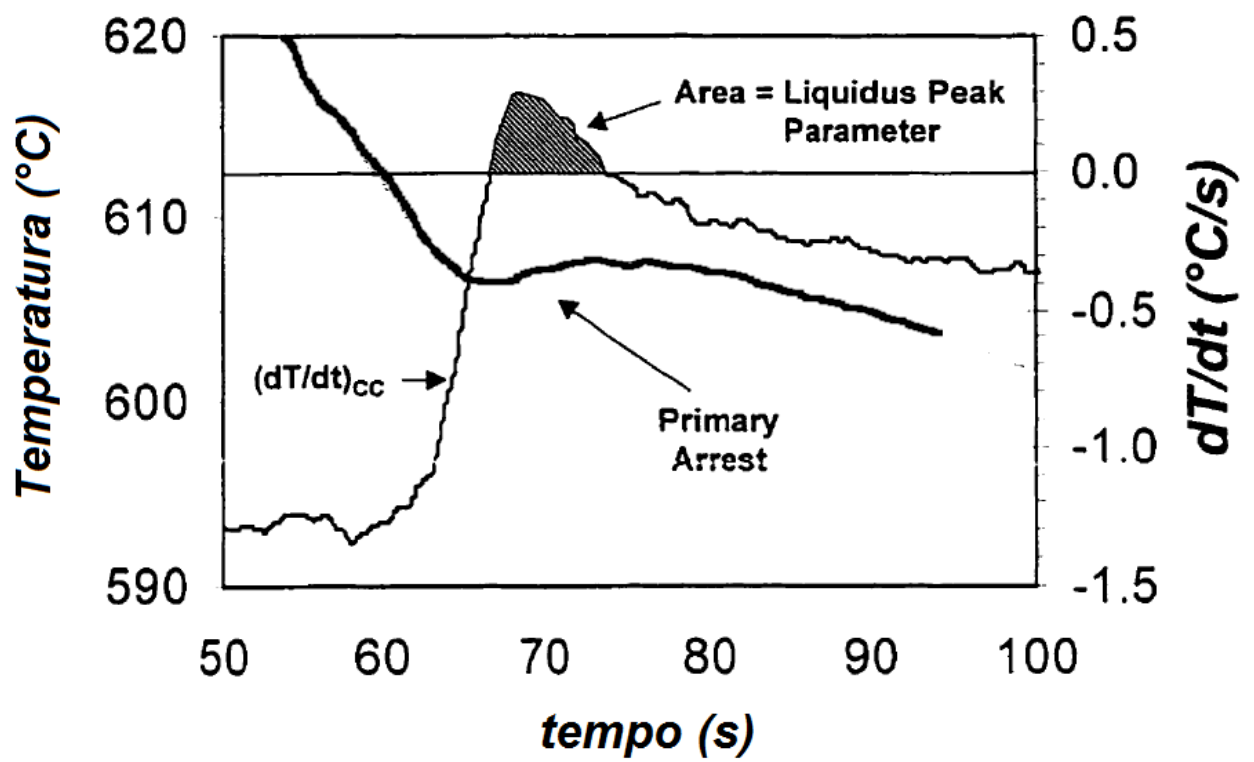

Figura 21 - Ampliação da curva de resfriamento (T) e de taxa de resfriamento (dT/dt) na região da recalescência (IBARRA, 1999) apresentando a integral da taxa de resfriamento (dT/dt).

Upadhya et al. (UPADHYA et al., 1989) e Bäckerud et al. (BACKERUD et al., 1986; BACKERUD; SIGWORTH, 1989) sugerem o uso da primeira derivada da curva de resfriamento também para definir o final da solidificação. O instante de tempo final da solidificação (tf) é detectado no último vale na curva da derivada, correspondente a um mínimo local. O instante tf pode ser obtido ao interceptar duas linhas tangentes no ultimo vale da curva de taxa de resfriamento, como mostra a Figura 22. Este evento é interpretado como a última variação térmica brusca, causada pela interrupção da liberação de calor latente.

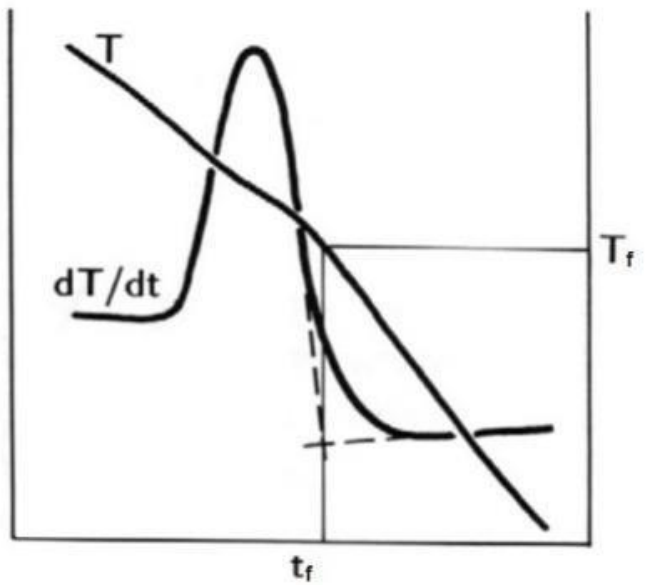

Figura 22 - Definição da temperatura $\left(T_{f}\right)$ e instante $\left(t_{f}\right)$ do final da solidificação nas curvas de resfriamento e na primeira derivada desta curva (BACKERUD et al., 1986). 


\subsection{Inoculação de Ligas de Cobre}

As teorias gerais que propõe explicações de mecanismos para a nucleação heterogênea de metais e ligas foram apresentadas nos itens anteriores. Existem inúmeros estudos e algumas revisões sobre detalhes dos mecanismos de inoculação de ligas de alumínio (MCCARTNEY, 1989; SPITTLE, 2006), porém no caso do cobre e de suas ligas, os estudos são escassos e muitas vezes inconclusivos. Na grande maioria destes estudos, utilizam-se ligas contendo os elementos principais das ligas de cobre comercias, como por exemplo o $\mathrm{Sn}$ e o $\mathrm{Zn}$, além de diversos outros que aparecem em menores teores. Nos próximos parágrafos, estes estudos serão apresentados e discutidos.

Cibula (CIBULA, 1954) estudou o efeito de adições de Sn no tamanho de grão do cobre puro, mostrando que para teores de Sn entre $10 \%$ a $15 \%$ em massa não houve variação significativa no tamanho do grão. O diagrama de fases do sistema CuSn está apresentado na Figura 23. Porém, algum refino foi observado quando também se adicionou 1\%(massa) de Al. Wallace e Kissling (WALLACE; KISSLING, 1963) não notaram um efeito significativo de refino com a adição de $\mathrm{Zn}$ em $\mathrm{Cu}$ de pureza comercial. Os autores não discutiram estes resultados com base nos mecanismos fundamentais de inoculação descritos anteriormente.

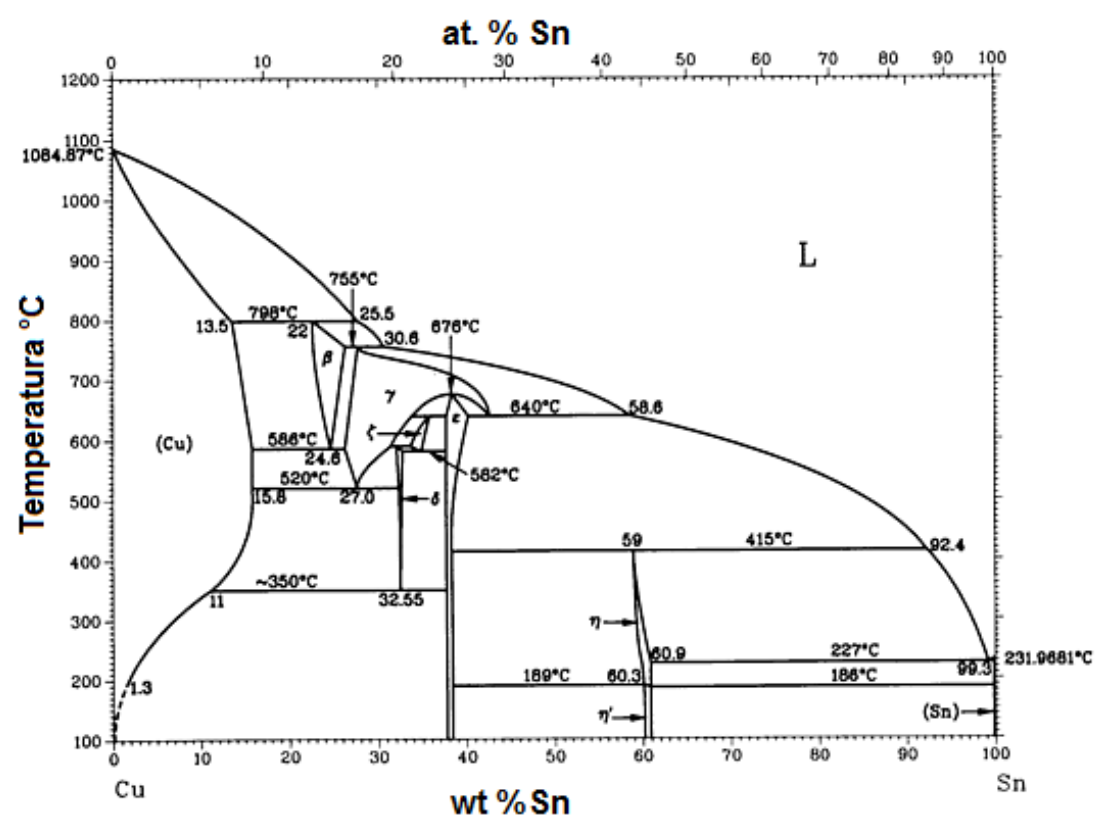

Figura 23 - Diagrama de fases Cu-Sn (ASM-HANDBOOK, 1998). 
Wallace e Kissling (WALLACE; KISSLING, 1963) adicionaram Fe em pequenos teores na faixa de $0,05 \%$ a $0,07 \%$ (massa) ao Cu puro e observaram um efeito moderado de refino de grão. Os autores relacionaram o efeito observado com a formação de precipitados por reações peritéticas (Figura 24). Gould (GOULD et al., 1960) também observaram um efeito de refino moderado após a adição de $0.02 \% \mathrm{Fe}$ na forma de partículas ao Cu puro líquido mantido em baixos superaquecimentos (< $50^{\circ} \mathrm{C}$ ). Com a elevação do superaquecimento, o refino foi inexistente. Os autores concluíram que a nucleação ocorreu sobre as partículas de Fe antes destas se dissolverem completamente no $\mathrm{Cu}$ líquido. $\mathrm{O}$ aumento do superaquecimento pode ter acelerado a dissolução, resultando no desaparecimento completo destas partículas antes da solidificação e impedindo o efeito de refino. Contudo, muito embora estas hipóteses tenham sido propostas para explicarem os resultados, elas não foram investigadas.

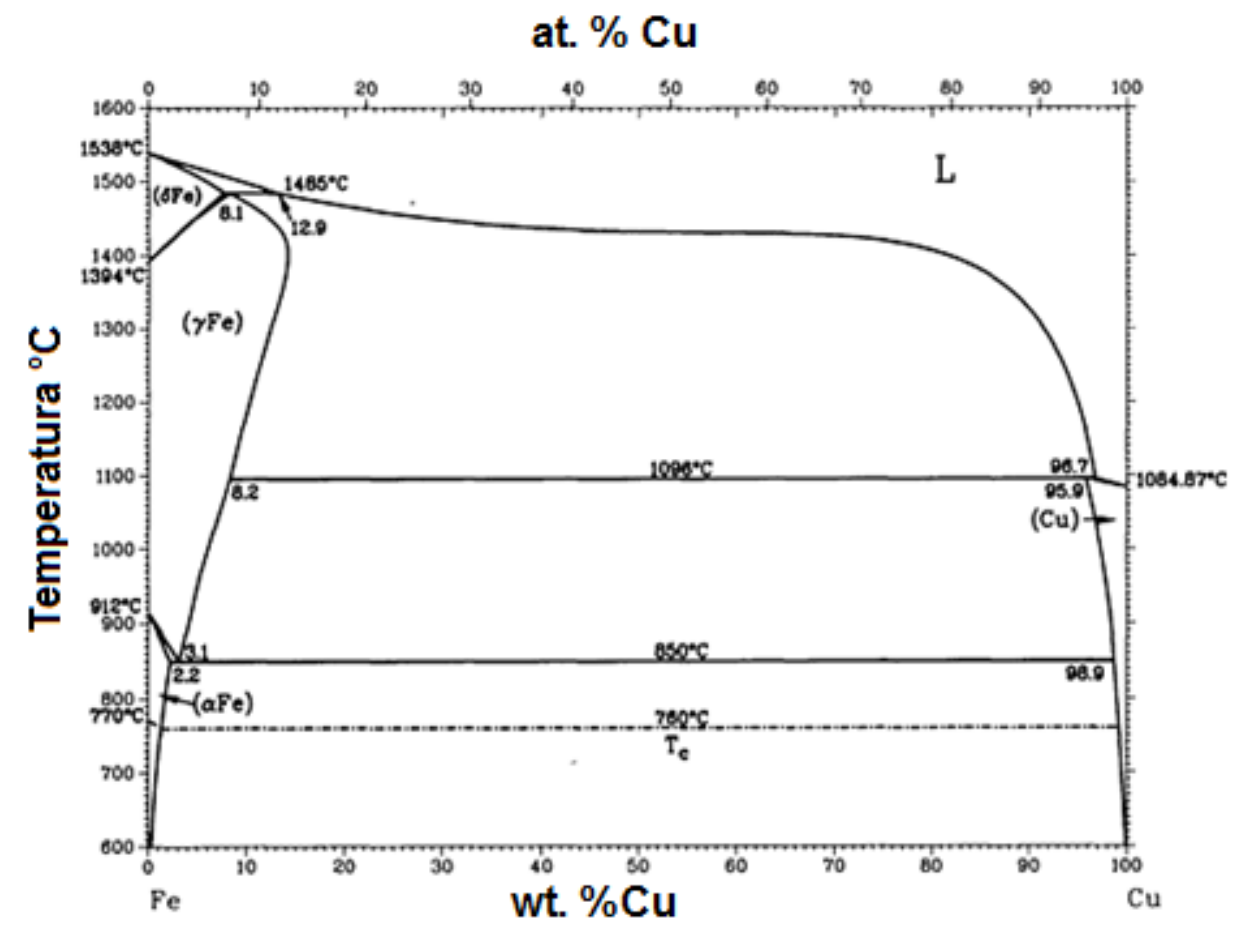

Figura 24 - Diagrama de fases Cu- Fe (ASM-HANDBOOK, 1998).

Patchett e Abbaschian (1985) estudaram o efeito da adição de Fe na faixa entre $0.57 \%$ a $7.5 \%$ (massa) a Cu de alta pureza. Nos experimentos, o líquido solidificou na forma de gotas levitando em uma atmosfera controlada e livre de oxigênio. O tamanho de grão decresceu de $300 \mu \mathrm{m}$ até cerca de $60 \mu \mathrm{m}$ para adições de até 
aproximadamente $2,8 \% \mathrm{Fe}$. Para teores de $\mathrm{Fe}$ acima deste valor, observa-se uma queda abrupta no tamanho de grão, que parece estar relacionada com a precipitação de partículas de Fe- $\alpha$ no interior do banho líquido e com a reação peritética $\mathrm{Cu}(\mathrm{L})+$ $\mathrm{Fe}_{\alpha} \rightarrow$ Cua. Entretanto, os autores não formularam mecanismos para explicar a diminuição do tamanho de grão.

Cibula (CIBULA, 1954) observou um efeito de refino de grão moderado após a adição de $\mathrm{Fe}$ em teores menores do que $1,6 \%$ a ligas $\mathrm{Cu}-10 \% \mathrm{Sn}$. Após a adição simultânea de $\mathrm{Zr}$ e B, o refino foi significativo, o que levou os autores a sugerirem que no segundo caso ocorreu a formação de partículas sólidas de $\mathrm{ZrB}_{2}$, sobre as quais a nucleação heterogênea ocorreu. Entretanto, a presença destas partículas na microestrutura da liga não foi identificada. No caso do refino moderado, observado com a adição apenas de $\mathrm{Fe}$ (sem B), nem ao menos uma proposta de mecanismo de refino foi sugerida. Couture e Edwards (COUTURE; EDWARDS, 1973), em um diferente estudo, mostraram apenas um fraco efeito de refino mesmo com a adição simultânea de $0.05 \% \mathrm{Fe}$ e $0.025 \% \mathrm{~B}$ a uma liga Cu-10\%Sn-2\%Zn, o que parece estar em contradição com o resultado de Cibula (1954).

Reif e Weber (REIF; WEBER, 1987a) também não observaram qualquer efeito de refino após a adição isolada de $\mathrm{B}$ ou simultânea de $\mathrm{B}$ e $\mathrm{Fe}$ a uma liga Cu-36\%Zn. Sadayappan et al. (SADAYAPPAN et al., 2004), no entanto, mostraram um refino de grão significativo ao adicionar $0,03 \%$ de $\mathrm{Fe}$ e $0,0035 \%$ de $\mathrm{B}$ a uma liga $\mathrm{Cu}-35 \% \mathrm{Zn}$ $0,3 \% \mathrm{Sn}-1 \% \mathrm{~Pb}$. Sadayappan et al. (SADAYAPPAN et al., 2004) notaram uma diminuição razoável de tamanho de grão com a adição de B em Cu-36\%Zn, na presença de $0,41 \%$ Sn. Este efeito do $B$ foi acentuado na presença de elementos como $\mathrm{Al}$ e $\mathrm{Pb}$. Os autores não formularam ou investigaram hipóteses para explicar o refino de grão observado.

Cibula (1954) adicionou $\mathrm{Zr}$ a ligas Cu-10\%Sn na presença de uma fonte de carbono. Este autor mostrou uma diminuição acentuada no tamanho de grão de $2 \mathrm{~mm}$ até valores de aproximadamente $200 \mu \mathrm{m}$ para teores de $\mathrm{Zr}$ da ordem de $0,01 \%$. Sugeriu-se que a nucleação ocorreu sobre partículas de ZrC formadas no interior do líquido a partir das adições. No entanto, quando $B$ também foi adicionado, houve refino de grão, mas o efeito foi menor. Desta forma, o autor concluiu que se formou $\mathrm{ZrB}_{2}$ preferencialmente a $\mathrm{ZrC}$ e que o $\mathrm{ZrB} 2$ não é um substrato tão efetivo para nucleação 
heterogênea da fase Cu- $\alpha$. Apesar das hipóteses sobre as partículas inoculantes, não houve uma investigação mais profunda. Martorano e Capocchi (2000) mostraram um efeito semelhante ao observado por Cibula (1954), ou seja, uma alteração brusca de uma estrutura colunar para uma estrutura completamente equiaxial de grãos refinados após a adição de 0,08\%Zr (massa) a um banho de Cu-8\%Sn. O mecanismo causador do refino de grão não foi investigado. Couture e Edwards (1973) adicionaram Zr (na forma de Cu-32\%Zr) às ligas Cu-10\%Sn-2\%Zn, Cu-10\%Sn-10\%Pb e Cu-5\%Sn$5 \% \mathrm{Zn}-5 \% \mathrm{~Pb}$, observando um efeito de refino. Também não houve uma investigação sobre os mecanismos que causaram a inoculação.

Sadayappan et al. (2005) observaram um efeito significativo de refino de grão após a adição de Zr em ligas Cu-14\%Zn-4.5\%Si. Novamente, neste estudo não foi investigado o tipo de mecanismo causador do refino de grão. Reif e Weber (1987) examinaram o efeito de adições de Cu-Zr-B às ligas Cu-30\%Zn e Cu-36\%Zn, não observando um refino de grão notável. Por outro lado, um efeito significativo ocorreu para adições crescentes de $\mathrm{Zr}$ quando os seguintes elementos foram também adicionados e mantidos nos teores indicados: $0.02 \% \mathrm{Mg}, 0.02 \% \mathrm{Fe}, 0.02 \% \mathrm{P}$ e $0.01 \% \mathrm{~B}$. Diante dos resultados, os autores propuseram uma composição de liga-mãe para refino contendo $\mathrm{Zr}-\mathrm{Mg}-\mathrm{Fe}-\mathrm{P}$, sem a presença de B. Nenhum mecanismo de refino foi proposto para explicar os resultados obtidos. 


\section{METODOLOGIA}

Neste item serão descritos os métodos e as condições adotadas na obtenção dos resultados experimentais. Estudos de refinamento de grão em ligas de cobre como o de Sadayappan et al. (SADAYAPPAN et al., 2005), onde as ligas estudadas são multicomponentes e com múltiplas adições de elementos, não permitem 0 entendimento dos efeitos individuais de cada elemento, dificultando o entendimento dos mecanismos de inoculação. Neste trabalho, foram estudados os efeitos de adições individuais e posteriormente combinadas a banhos de cobre eletrolítico e de ligas binárias $\mathrm{Cu}-\mathrm{Sn}$. Os elementos estudados detalhadamente foram o Zr e o Sn, que foram adicionados de forma isolada ou combinada. Porém, alguns ensaios foram conduzidos também para mostrar 0 efeito do $P$, adicionado com o objetivo de desoxidar o banho, e do $\mathrm{C}$, que se mostrou necessário para que as adições de $\mathrm{Zr}$ reduzissem o tamanho de grão final.

No item 4.1 serão apresentados os processos de fusão das ligas e de adição de elementos ao banho líquido, além do sistema de solidificação onde foram obtidas as amostras e as curvas de resfriamento. No item 4.2 serão apresentados os procedimentos de caracterização química, macro e microestrutural das amostras, e de medições do tamanho médio de grão. Posteriormente, no item 4.2.4, serão descritas as metodologias utilizadas na extração dos precipitados por via eletrolítica, extração por réplica com filme de carbono. A extração de precipitados utilizando técnicas eletrolíticas, a pesar de ter sido pouco eficiente para concentrar quantidades consideráveis de precipitados, permitiu coletar os parâmetros eletroquímicos para preparação superficial das amostras por extração por réplica. A preparação de amostras para microscopia de transmissão, foi realizada com ajuda do microscópio eletrônico de varredura com o sistema de nanofabricação, o que permitiu obter lâminas finas em regiões especificas da amostra. 


\subsection{Sistema de Solidificação e Obtenção das Amostras}

As condições experimentais das três séries de experimentos realizados neste trabalho estão apresentadas na Tabela 7. Nesta tabela estão indicadas a sigla que define o experimento, os teores nominais no banho após as adições de Sn, Zr e P, a utilização de uma cobertura de pó de grafita de alta pureza sobre o banho durante a fusão e algumas observações específicas a cada ensaio. A primeira série, nomeada de Efeito geral, tem como objetivo avaliar de forma geral os efeitos na estrutura de grãos das ligas Cu0\%Sn, Cu2\%Sn e Cu8\%Sn, da adição de fósforo, zircônio e carbono. A segunda série, Efeito do zircônio e Carbono, foi conduzida para mostrar o efeito de quantidades diferentes de adições de $\mathrm{Zr}$ para um teor fixo de estanho (Cu8\%Sn), ou seja, um bronze desoxidado com fósforo. A terceira série, Efeito do estanho, zircônio e carbono, tem como finalidade mostrar o efeito de adições crescentes de Sn (Cu0\%Sn, Cu2\%Sn, Cu4\%Sn, Cu8\%Sn e Cu12\%Sn) na presença ou não de Zr. É importante ressaltar que todos os experimentos foram realizados nas mesmas condições experimentais, exceto pelas diferentes adições.

\subsubsection{Fusão e Tratamento do Metal Líquido}

Em cada experimento, uma carga sólida de composição nominal definida na Tabela 7 foi produzida através de cobre eletrolítico (Cu-CP 99,90\%Cu) e estanho eletrolítico grau A (Sn-GA $99,92 \% \mathrm{Sn}$ ). A Tabela 8 mostra as composições químicas destes materiais e a Figura 23 apresenta o diagrama de fases binário do sistema CuSn. As cargas foram colocadas no interior de um cadinho de grafita com tampa de grafita e fundidas em um forno de resistência do tipo mufla com uma atmosfera protetora de argônio, como apresentado na Figura 25. Inicialmente fundiu-se o Cu-CP e posteriormente adicionou-se o Sn-GA e cobriu-se o banho com pó de grafite de alta pureza $(99,9 \%$ ) , como sugerido por Neff (NEFF, 1992) e Geskin (GESKIN et al., 1986), posteriormente agitando o banho vigorosamente com uma barra de grafita. Nos únicos dois experimentos sem fontes de carbono (Cu8Sn0Zr0C e Cu8Sn0,08Zr0C), o banho não foi coberto com o pó de grafita, foi utilizado um cadinho de grafita-argila para fusão e o banho foi agitado com um bastão de sílica vítrea. Após agitação, o 
banho foi mantido à temperatura de $1250^{\circ} \mathrm{C}$ por 5 minutos para garantir a completa dissolução do Sn-GA. Seguidamente, o metal foi desoxidado a partir da adição da liga Cu-15\%P para um teor nominal de 0,025 \%P no banho. O fósforo combina com o oxigênio dissolvido no líquido, retirando-o de solução. Em seis experimentos da série Efeito geral (Tabela 7), indicados com a sigla de final OP, o fósforo não foi adicionado, sendo substituído pelo borbulhamento de $\operatorname{Ar}$ ou $\mathrm{N}_{2}$ ultra puro dentro do banho líquido, utilizando uma lança de sílica vítrea, numa vazão de $2 \mathrm{NI} /$ min durante 60s (NEFF; SOLON, 1989). Em dois destes seis experimentos, não houve nem adição de $P$ e nem borbulhamento de gases (Cu2Sn0ZrOP e Cu2Sn0,08ZrOP).

$\mathrm{O}$ banho líquido à temperatura de $1250^{\circ} \mathrm{C}$ foi então parcialmente vazado no sistema de solidificação descrito no próximo item, permitindo a obtenção de um lingote cilíndrico e amostras para análise química e metalúrgica (Figura 31 e Figura 32). Ao restante deste banho mantido no cadinho, foi adicionada a liga Cu-50\%Zr em pó (Tabela 8) para se atingir o teor nominal de Zr desejado. Após a adição, o banho foi mantido no forno por $35 \mathrm{~min}$ até atingir novamente a temperatura de $1250^{\circ} \mathrm{C}$ e, finalmente, foi agitado vigorosamente e vazado no sistema de solidificação. É importante observar que a adição de Cu-50\%Zr foi feita em pequenos envoltórios de lâminas de cobre eletrolítico, fixados na ferramenta de manipulação (barra de grafite ou sílica vítrea), como se apresenta na Figura 26.

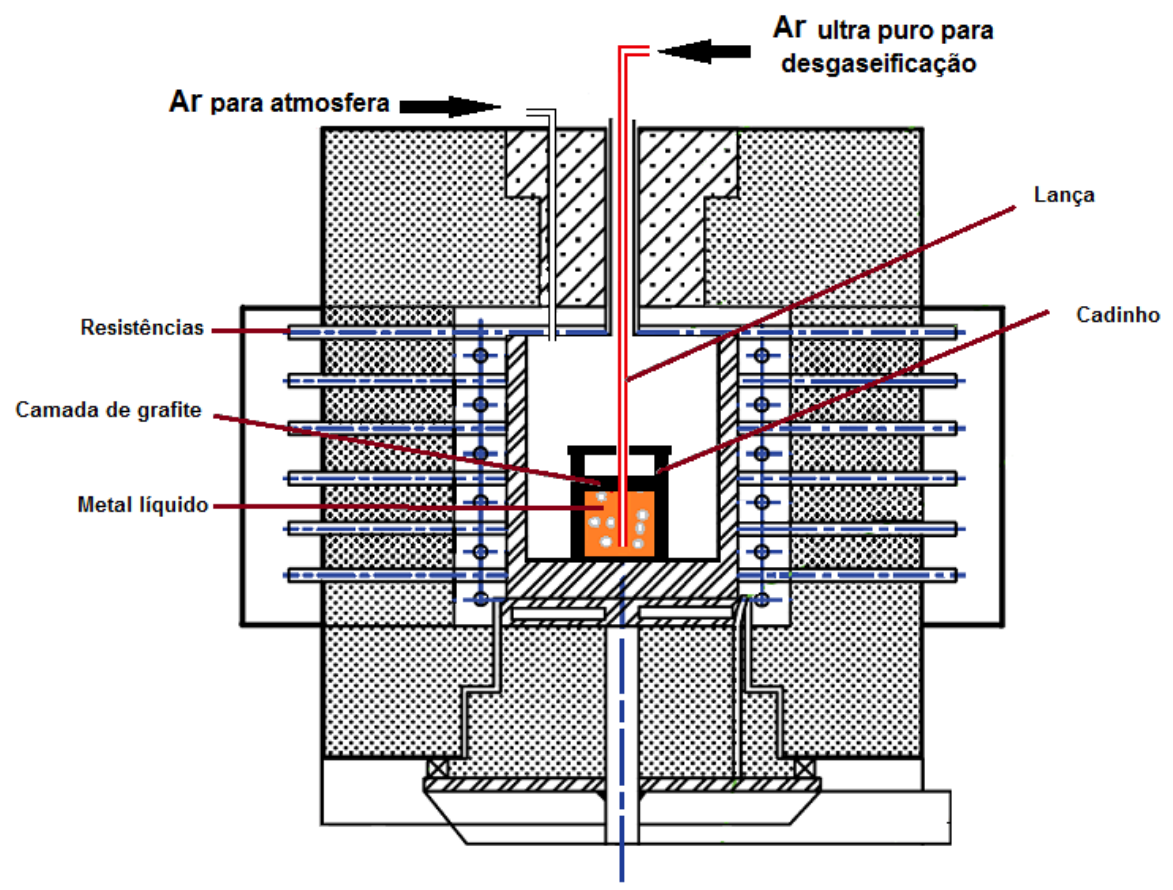

Figura 25 - Diagrama esquemático do forno de resistências utilizado para realizar as fusões das ligas. 
Tabela 7 Condições das séries de experimentos com as respectivas siglas de identificação. Os teores nominais (\% massa) de Sn, Zr, P e a adição ou não de cobertura de grafite (+ ou -) também estão indicados.

\begin{tabular}{|c|c|c|c|c|c|c|}
\hline Série & Sigla & $\%$ Sn & $\% \mathbf{Z r}$ & $\% \mathrm{P}$ & $\mathbf{C}_{\text {grafite }}$ & Observações \\
\hline \multirow{8}{*}{ Efeito geral } & Cu0Sn0ZrOP & - & - & - & + & Injeção de $\mathrm{N}_{2}: 2 \mathrm{NI} / \mathrm{min}$ \\
\hline & Cu0Sn0,08ZrOP & - & 0,08 & - & + & Injeção de $\mathrm{N}_{2}: 2 \mathrm{NI} / \mathrm{min}$ \\
\hline & Cu2Sn0Zr0P & 2 & - & - & + & \\
\hline & Cu2Sn0,08Zr0P & 2 & 0,08 & - & + & \\
\hline & Cu8Sn0Zr0C & 8 & - & 0,025 & - & Cadinho Argila-Grafita \\
\hline & Cu8Sn0,08Zr0C & 8 & 0,08 & 0,025 & - & Cadinho Argila-Grafita \\
\hline & Cu8Sn0Zr0P & 8 & - & - & + & Injeção de Ar: 2 NI/min \\
\hline & Cu8Sn0,08Zr0P & 8 & 0,08 & - & + & Injeção de Ar: 2 NI/min \\
\hline \multirow{8}{*}{ Efeito do Zr e C } & Cu8Sn0Zr & 8 & - & 0,025 & + & \\
\hline & Cu8Sn0,04Zr & 8 & 0,04 & 0,025 & + & \\
\hline & Cu8Sn0,08Zr & 8 & 0,08 & 0,025 & + & \\
\hline & Cu8Sn0,12Zr & 8 & 0,12 & 0,025 & + & \\
\hline & Cu8Sn0,16Zr & 8 & 0,16 & 0,025 & + & \\
\hline & Cu8Sn0,24Zr & 8 & 0,24 & 0,025 & + & \\
\hline & Cu8Sn0,32Zr & 8 & 0,32 & 0,025 & + & \\
\hline & Cu8Sn0,40Zr & 8 & 0,40 & 0,025 & + & \\
\hline \multirow{10}{*}{ Efeito do Sn, Zr e C } & CuOSn0Zr & 0 & - & 0,025 & + & \\
\hline & Cu0Sn0,08Zr & 0 & 0,08 & 0,025 & + & \\
\hline & Cu2Sn0Zr & 2 & - & 0,025 & + & \\
\hline & Cu2Sn0,08Zr & 2 & 0,08 & 0,025 & + & \\
\hline & Cu4Sn0Zr & 4 & - & 0,025 & + & \\
\hline & Cu4Sn0,08Zr & 4 & 0,08 & 0,025 & + & \\
\hline & Cu8Sn0Zr & 8 & - & 0,025 & + & \\
\hline & Cu8Sn0,08Zr & 8 & 0,08 & 0,025 & + & \\
\hline & Cu12Sn0Zr & 12 & - & 0,025 & + & \\
\hline & Cu12Sn0,08Zr & 12 & 0,08 & 0,025 & + & \\
\hline
\end{tabular}

Tabela 8 - Composição química (\% massa) fornecida pelos fabricantes das ligas utilizadas no presente trabalho: cobre eletrolítico (Cu-CP), estanho eletrolítico (SnGA), adição de zircônio (Cu-50\%Zr) e desoxidante (Cu-15\%P).

\begin{tabular}{lccccccccc}
\hline & $\% \mathrm{Cu}$ & $\% \mathrm{Sn}$ & $\% \mathrm{Zr}$ & $\% \mathrm{~S}$ & $\% \mathrm{Fe}$ & $\% \mathrm{Si}$ & $\% \mathrm{~Pb}$ & $\% \mathrm{P}$ & $\%$ Outros \\
\hline Cu-CP & 99,90 & 0,009 & - & - & 0,026 & 0,002 & - & 0,009 & 0,07 \\
\hline Sn-GA & 0,005 & 99,927 & - & 0,0005 & 0,0026 & - & 0,0412 & 0,0059 & 0,023 \\
\hline Cu-50\%Zr & 49,28 & 0,05 & 50,3 & - & 0,05 & 0,05 & 0,03 & - & 0,23 Max \\
\hline Cu-15\%P & 84,98 & - & - & - & 0,051 & - & - & 14,9 & 0,07 \\
\hline
\end{tabular}




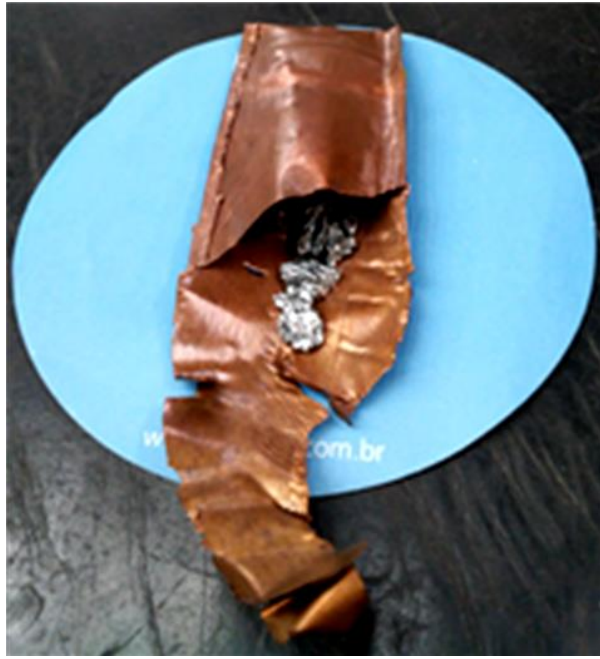

(a)

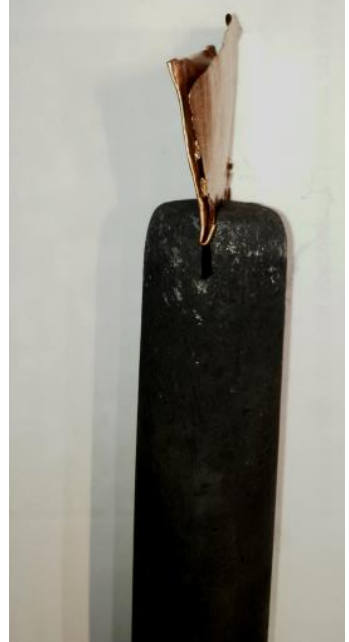

(b)

Figura 26- Ferramentas para a adição dos elementos de liga ao banho líquido: (a) pacotes contendo Cu50\%Zz; (b) pacote fixado na barra de grafite.

\subsubsection{Sistema de Solidificação}

A liga metálica líquida preparada como descrito no item anterior foi vazada em um sistema constituído de um copo cilíndrico descartável (Figura 27 (a)) produzido em areia-shell (Ecil - Carbontip K), contendo no seu interior dois termopares do tipo $\mathrm{K}$ (Cromel-Alumel) com isolação mineral e protegido por uma bainha de aço inox 310 de diâmetro externo igual a 1,5 mm (Figura 27 (b)). Os termopares foram protegidos com duas camadas de tinta refratária, inicialmente com tinta refratária Firit 5, seguida de uma camada de tinta de grafite Dycote 11, ambas produzidas pela Foseco. É importante ressaltar que foram utilizados os mesmos termopares para todos os experimentos com a finalidade de minimizar uma parte do erro experimental no cálculo de parâmetros extraídos das curvas de resfriamento. Os termopares foram conectados a um sistema de aquisição de dados por meio de um pedestal, como apresentado na Figura 28 (a). 


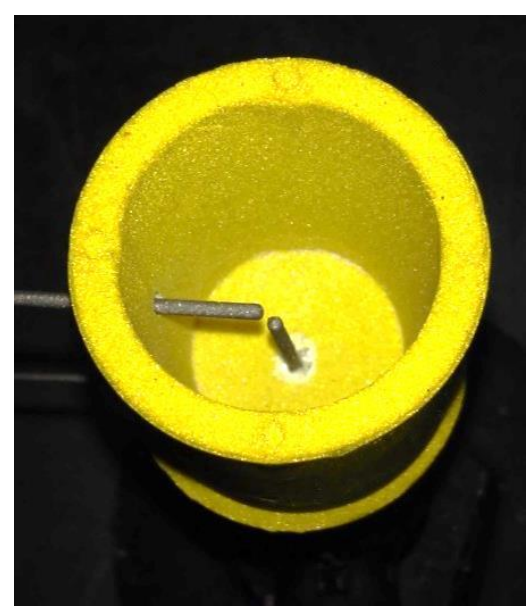

(a)

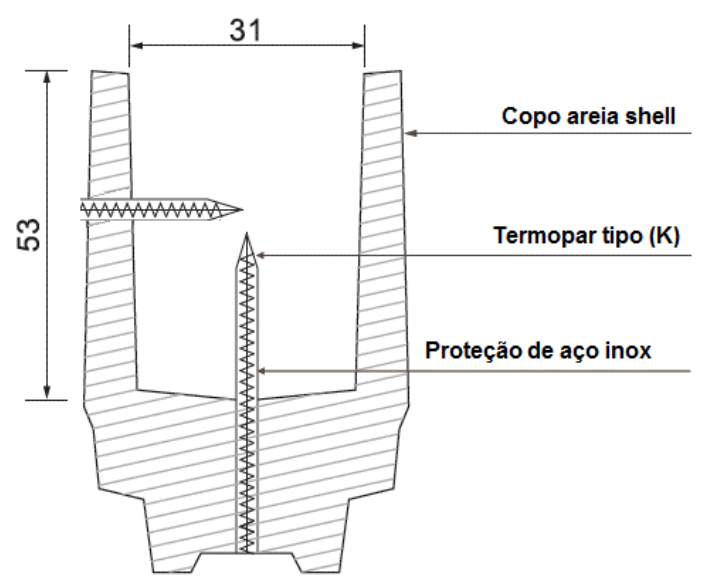

(b)

Figura 27 - Sistema de solidificação: (a) sensor descartável posicionado sobre a base do pedestal; (b) representação esquemática do sensor descartável e o termopar. Medidas em $\mathrm{mm}$.

\subsubsection{Coleta das Curvas de Resfriamento}

Os termopares inseridos no copo foram conectados por fios de compensação (blindados com trança metálica) até um sistema de aquisição de dados que consistiu de: um condicionador de sinais de marca National Instruments; uma placa de conversão analógico-digital com resolução de 16 bits também de marca National Instruments e o software LabView instalado em um microcomputador pessoal com processador Intel Pentium IV. Durante o período de solidificação, o sistema de aquisição de dados registrou o sinal de tensão emitido pelo termopar, convertendo-o para temperatura mediante a compensação de junta fria realizada a partir de um termistor instalado nas placas de condicionamento de sinal. O sistema de solidificação completo está apresentado nas Figura 28 e Figura 29. 


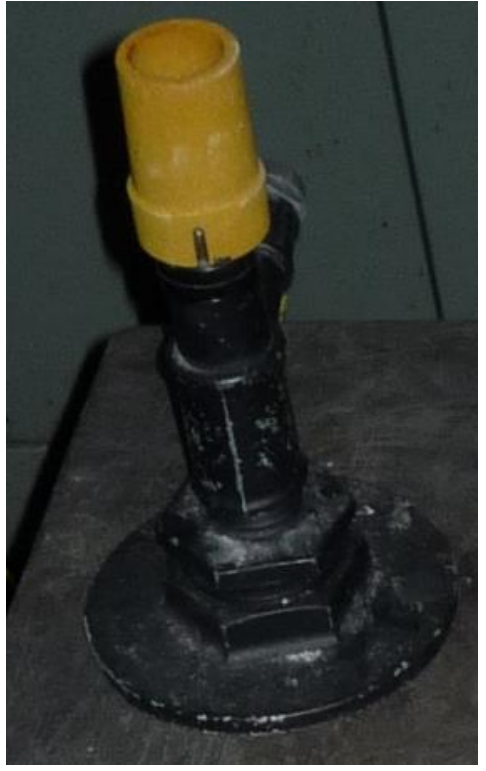

(a)

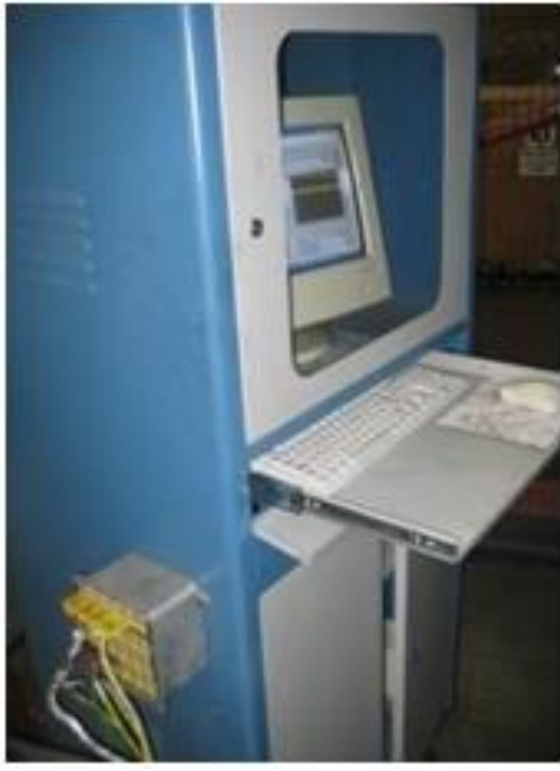

(b)

Figura 28 - Fotografia da montagem experimental utilizada para a obtenção das curvas de resfriamento: (a) copo de areia shell e pedestal; (b) sistema de aquisição de dados.

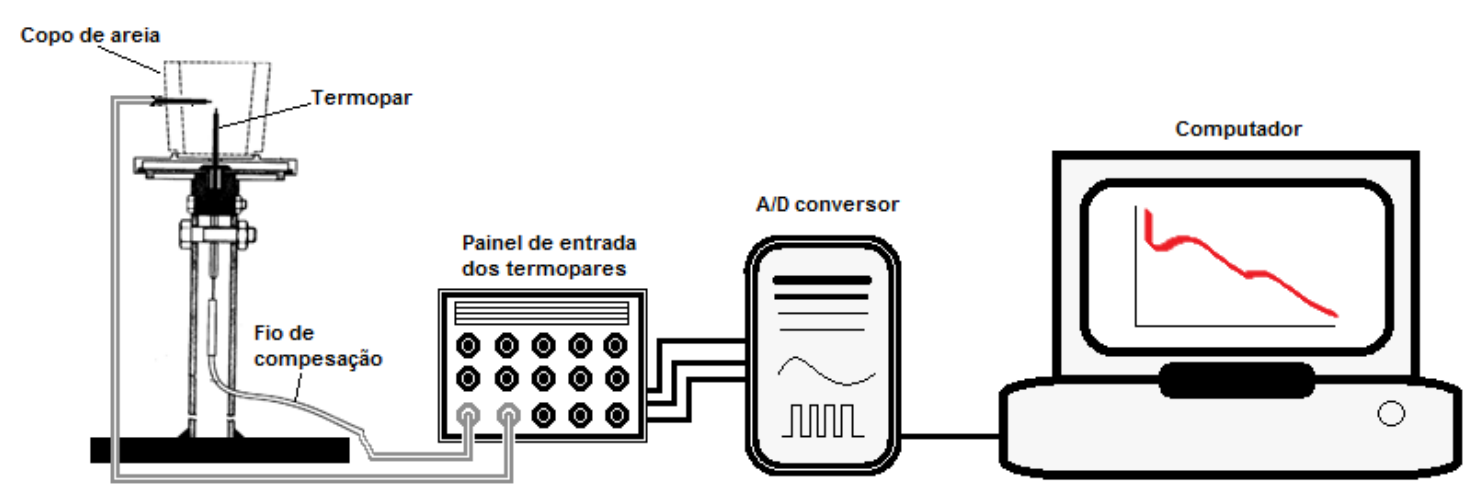

Figura 29 - Desenho esquemático do sistema de solidificação e o sistema de aquisição de dados.

\subsubsection{Tratamento das curvas de resfriamento}

Os sinais elétricos gerados pelos termopares foram captados pelo sistema de aquisição de dados em uma frequência de $10 \mathrm{~Hz}$ (10 medidas por segundo) e, após conversão para valores de temperatura, mostraram a presença de um ruído de fundo sobreposto ao sinal desejado. Este ruído é automaticamente amplificado quando as curvas são diferenciadas, impedindo alguns procedimentos importantes da análise térmica que utilizam as derivadas numérica das curvas de resfriamento. 
Segundo (CERQUEIRA et al., 2000) o tipo de ruído encontrado nestes sinais pode ser classificado como um ruído de frequência intermediária, apresentando-se como pequenos picos adicionados ao sinal original. Este ruído pode ser ocasionado pela proximidade da rede elétrica e de motores. Com a finalidade de minimizá-lo, foi conduzido um estudo onde as curvas de temperatura obtidas e a primeira derivada destas curvas em relação ao tempo foram filtradas por três tipos de filtros matemáticos: (1) média móvel; (2) Savitzky-Golay e (3) transformada rápida de Fourier.

O filtro "média móvel" divide o sinal em uma série de intervalos com a mesma quantidade de pontos. Posteriormente, substitui-se o valor do ponto central pelo valor médio dos pontos do intervalo (CERQUEIRA et al., 2000). Neste método não há controle sobre a frequência do sinal removido no processo. Savitzky e Golay (SAVITZKY; GOLAY, 1964) desenvolveram um filtro matemático baseado em uma regressão polinomial local, na qual os dados originais são substituídos por valores ajustados. Os valores ajustados devem ser calculados por um polinômio válido localmente, obtido através do método dos mínimos quadrados aplicado aos pontos experimentais em um pequeno intervalo de tempo (CERQUEIRA et al., 2000). Este filtro de suavização utiliza diretamente os sinais e não as frequências que compõem o mesmo. Portanto, o método é pouco seletivo em relação a frequência, podendo remover também informação útil contida no sinal. Um filtro mais elaborado é a Transformada Rápida de Fourier (FFT - "Fast Fourier Transform”). Segundo este filtro, um sinal qualquer, não necessariamente periódico, representado no domínio do tempo é transformado para o domínio da frequência através da transformada de Fourier, possibilitando identificar todas as frequências que o compõem. A transformada rápida de Fourier é um algoritmo que executa de forma rápida e eficiente a transformada de Fourier (JOAQUIM; SARTORI, 2003). As frequências mais elevadas, que normalmente compõem o ruído, são eliminadas. Aplica-se a transformada de Fourier inversa para se obter o sinal filtrado, sem os componentes de frequências maiores.

Em cada tipo de filtro adotado, deve-se escolher o tamanho dos intervalos em que a curva a ser filtrada será subdividida. Conforme o tamanho do intervalo aumenta, frequências menores do sinal, que podem conter também informações úteis, são eliminadas. Desta forma, deve-se escolher o menor intervalo que permita uma filtragem adequada. Após diversos testes, notou-se que as curvas de resfriamento 
seriam adequadamente filtradas utilizando um intervalo contendo 10 medidas de temperatura ( 1 s). Desta forma, os três tipos de filtros foram aplicados utilizando-se este intervalo com o auxílio do software Origin 9.0, produzido pela OriginLab Corporation. Após alguns testes, concluiu-se que a transformada rápida de Fourier forneceu a melhor diminuição de ruído, sem eliminar a informação importante do sinal. A curva de resfriamento filtrada com a transformada rápida de Fourier em um intervalo de 10 pontos foi derivada numericamente em relação ao tempo. A curva derivada apresentou também uma quantidade significativa de ruído; portanto, decidiu-se filtrála. Entretanto, observou-se que o intervalo de pontos mais adequado deveria ser 20. Um exemplo de curva de resfriamento e de derivada primeira sem e com a aplicação do filtro pode ser observado na Figura 30.

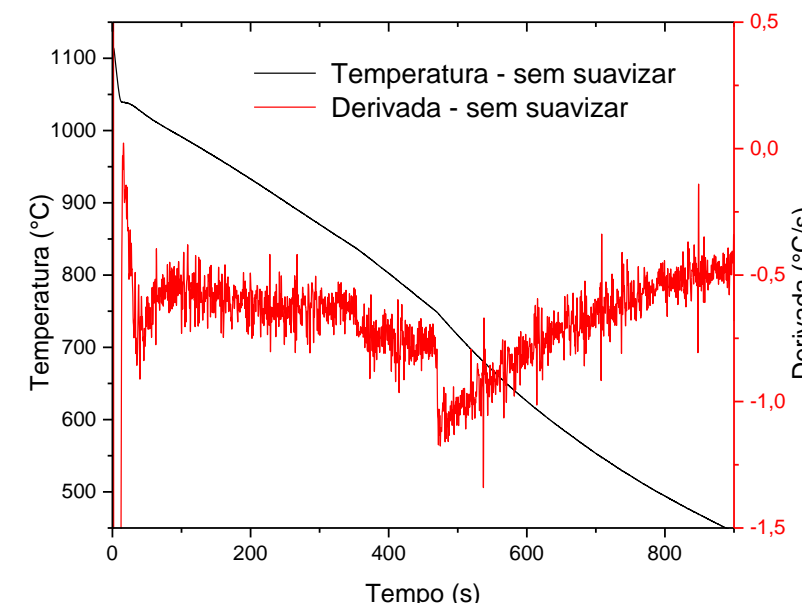

(a)

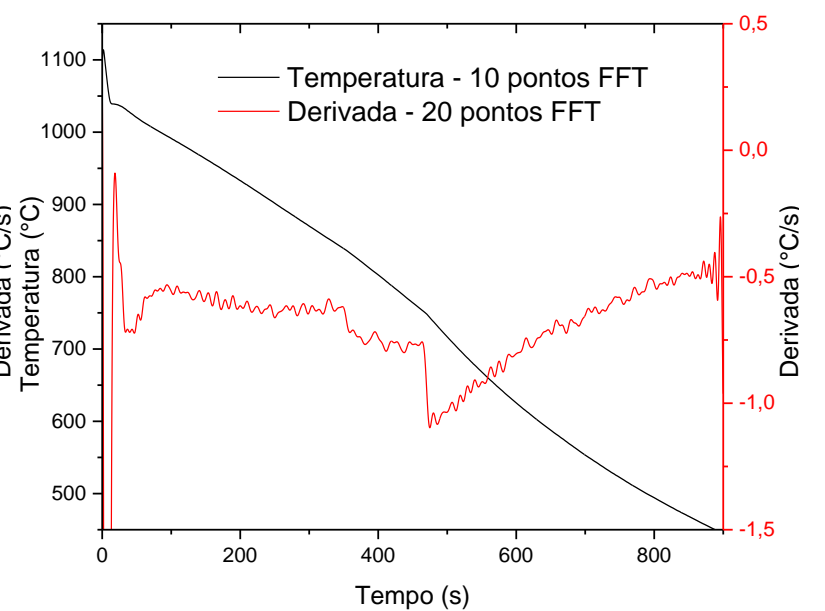

(b)

Figura 30 - Curva de resfriamento e primeira derivada do experimento Cu8Sn0,08Zr. (a) curvas originais sem suavizar, (b) curvas filtradas segundo o filtro de transformada rápida de Fourier (FFT).

\subsubsection{Estimativa da taxa de resfriamento}

A taxa de resfriamento $(R)$ foi estimada de duas formas para todos os experimentos. Na primeira, utilizando-se a curva de resfriamento foram obtidos os instantes de tempo em que as temperaturas estavam na temperatura líquidus $\left(T_{L}=\right.$ $\left.1030{ }^{\circ} \mathrm{C}\right)$ do peritético $\left(T_{p}=798{ }^{\circ} \mathrm{C}\right)$, indicados como $t_{L}$ e $t_{p}$, respectivamente, calculando-se a taxa de resfriamento média como $R_{m}=\left(T_{p}-T_{L}\right) /\left(t_{L}-t_{p}\right)$. Na segunda forma simplesmente calculou-se a derivada numérica de primeira ordem da curva de resfriamento no instante em que se atigiu a temperatura liquidus, ou seja, $R_{L}=\partial T / \partial t$. 


\subsection{Caracterização química e macro-microestrutural}

Neste item serão apresentados os procedimentos utilizados para a preparação das amostras para análise macro e microestrutural, análises químicas, e os procedimentos para medidas de tamanhos de grão e preparação de amostra para a microscopia de transmissão.

\subsubsection{Corte das amostras do lingote.}

Os lingotes cilíndricos (diâmetro $=30 \mathrm{~mm}$, comprimento $=53 \mathrm{~mm}$ ) obtidos no sistema de solidificação foram seccionados longitudinal e transversalmente em diversas posições ao longo de seu comprimento. A Figura 31 (a) mostra uma fotografia do lingote obtido e a Figura 31 (b) apresenta o esquema das posições dos cortes para observações da macro e da microestrutura. No corte longitudinal da Figura 31 (b), na região central do lingote está indicada a cavidade do termopar, como também a região onde foi realizada a medição do tamanho médio de grão. Duas amostras foram obtidas para a realização dos seguintes procedimentos: (1) análise macroestrutural; (2) medidas do tamanho de grão médio e (3) análise microestrutural.

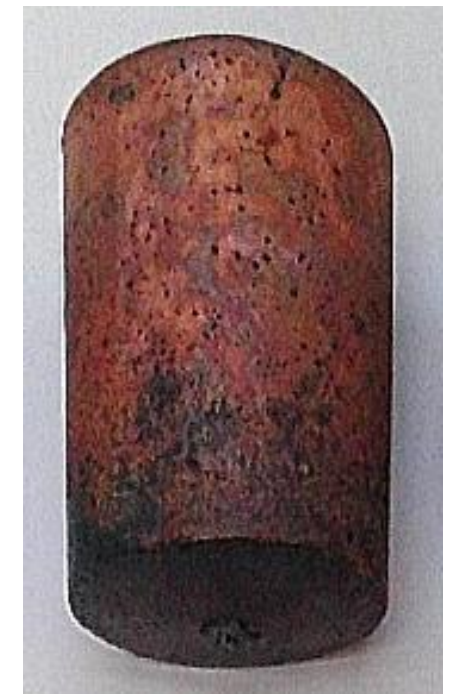

(a)

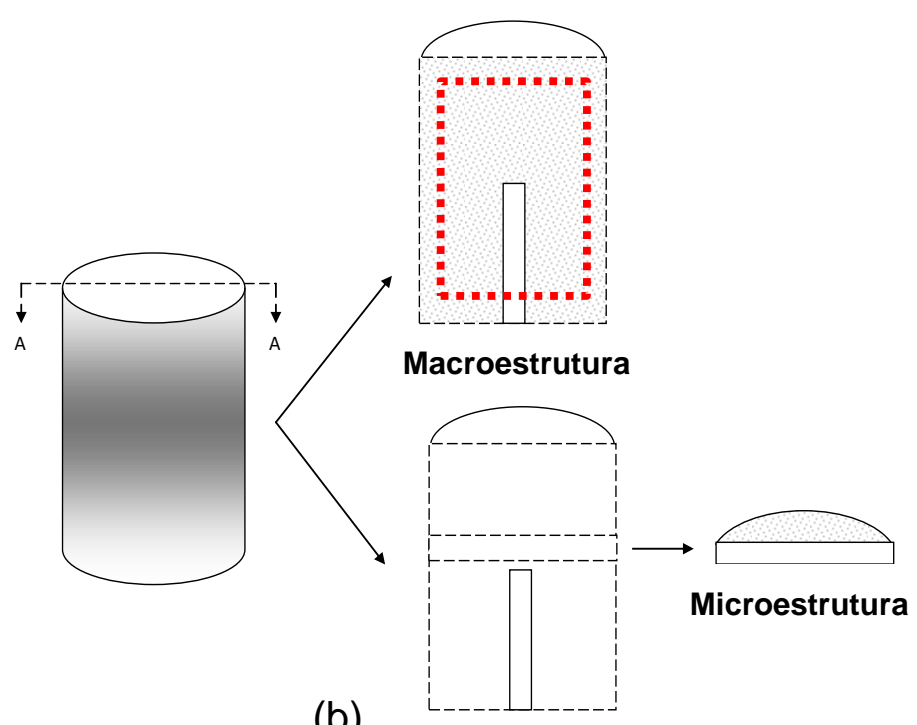

(b)

Figura 31 - (a) Lingote da liga Cu8\%Sn obtido experimentalmente; (b) diagrama dos cortes utilizados para obtenção das amostras para análise macro e microestrutural. A linha tracejada em vermelho indica a área utilizada para a medição do tamanho médio de grão. 


\subsubsection{Análises químicas}

Além dos lingotes obtidos no sistema de solidificação, uma amostra do metal líquido foi retirada para análise da composição química em cada experimento a partir do vazamento do banho em uma pequena coquilha metálica, protegida com tinta refrataria (Foseco - Firit 5) para evitar a contaminação. A Figura 32 apresenta o corte realizado nas amostras para análise química, além do desenho esquemático da coquilha metálica onde o metal foi vazado.

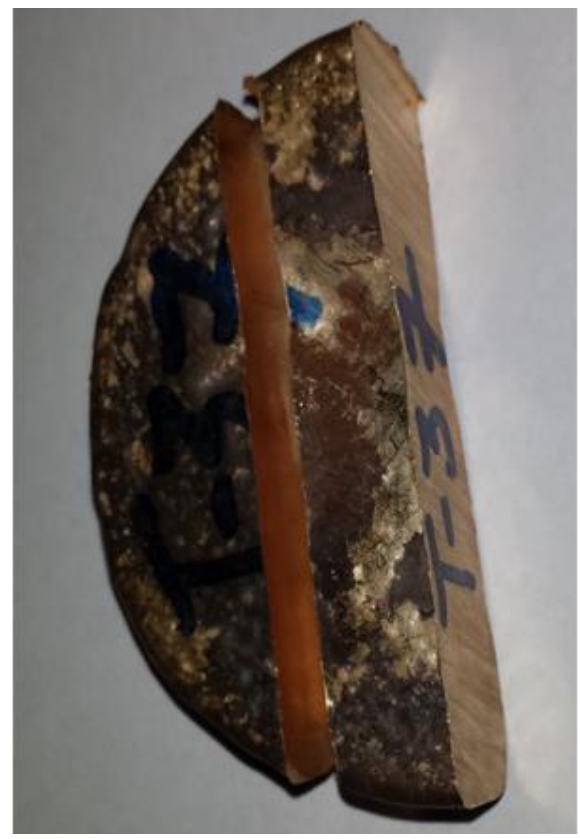

(a)
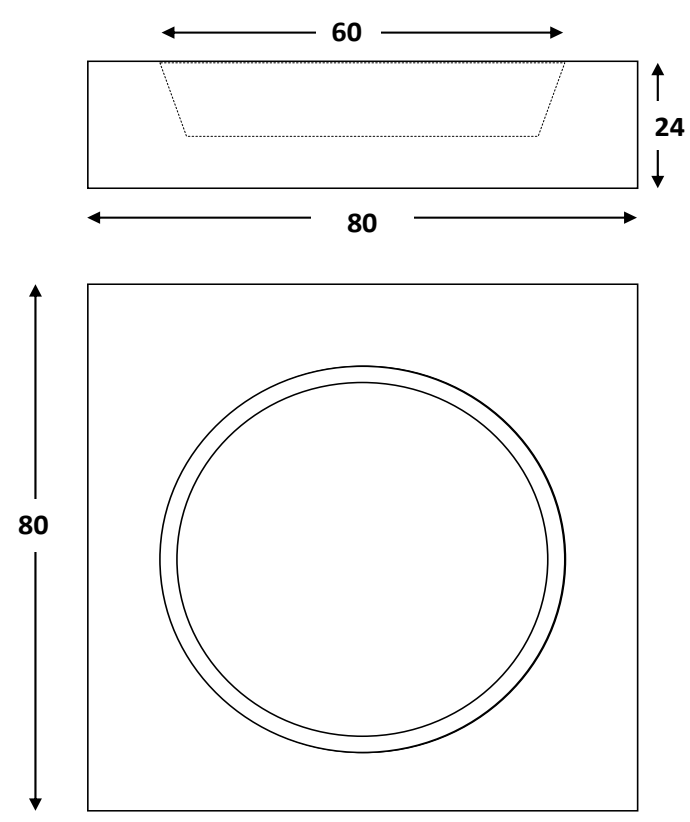

(b)

Figura 32 - a) Corte dos lingotes solidificados no molde metálico. b) desenho esquemático do molde para obter amostras de composição química. Medidas em milímetros.

As análises químicas foram realizadas em vários laboratórios com a finalidade de confirmar os teores obtidos. Estes laboratórios estão descritos abaixo e as técnicas analíticas utilizadas apresentadas na Tabela 9:

- (A) Falcão Bauer;

- (B) Instituto de Pesquisas Tecnológicas IPT;

- (C) Instituto de Pesquisas Energéticas e Nucleares IPEN-CQMA;

- (D) Universidade de Antioquia;

- (E) Paranapanema S. A 
Tabela 9 - Técnicas utilizadas para a análise de composição química das amostras e os laboratórios fornecedores dos resultados.

\begin{tabular}{ll}
\hline Tipo de Análise & Laboratório \\
\hline Espectrometria de Emissão Óptica & D. \\
Espectrometria de Emissão Óptica com Plasma de Argônio Induzido (ICP-OES) & A, C. \\
Fusão sob gás inerte, Infravermelho & A, B, E. \\
\hline
\end{tabular}

\subsubsection{Medida do Tamanho Médio de Grão}

As amostras usadas para a medida do tamanho de grão médio (TG) foram preparadas usando técnicas metalográficas tradicionais para revelar a macroestruturas de grãos. Esta metodologia envolve três procedimentos: (a) preparação da superfície das amostras; (b) obtenção das imagens com contraste entre os grãos e (c) medida do tamanho de grão.

A superfície das amostras foi preparada através do polimento e ataque químico descrito na Tabela 10 (VANDER VOORT, 1984). A imagem dos grãos foi obtida utilizando um digitalizador ("scanner") marca HP Scanjet G4050 com resolução de 2400 dpi. A medida do tamanho médio de grão foi conduzida através do método do intercepto circular segundo a norma ASTM E112-73. A medida foi feita em campos aleatórios da amostra mediante a contagem do número de grãos que interceptam uma circunferência de diâmetro conhecido.

Tabela 10- Procedimentos metalográficos para analise estrutural.

\begin{tabular}{|c|c|c|c|}
\hline Tipo de Análise & Polimento & Ataque químico & Procedimento \\
\hline Macroestrutural & $\begin{array}{l}\text { Lixas: } \\
\text { 100; 200; } \\
400 ; 600 ; \\
1000 ; 2000 \\
\text { Pasta diamante: } \\
9 \mu \mathrm{m}\end{array}$ & $\begin{array}{l}\text { (1) Etanol } 500 \mathrm{ml} \\
\mathrm{FeCl} 325 \mathrm{~g} \\
\mathrm{HCl} 15 \mathrm{ml}\end{array}$ & $\begin{array}{l}\text { Imersão da amostra por } 15 \\
\text { s ou até obter um contraste } \\
\text { desejado, lavagem com } \\
\text { água corrente durante } 5 \\
\text { min. }\end{array}$ \\
\hline \multirow[t]{2}{*}{ Microestrutural } & $\begin{array}{l}\text { Lixas: } \\
\text { 100; 200; } \\
\text { 400; 600; } \\
\text { 1000; 2000; } \\
\text { Pasta diamante: } \\
\text { 9; 3; } 1 \mu \mathrm{m} \\
\text { Sílica coloidal: } \\
0,05 \mu \mathrm{m}\end{array}$ & $\begin{array}{c}\text { (2) } \mathrm{NH}_{4} \mathrm{OH} 20 \mathrm{ml} \\
\mathrm{H}_{2} \mathrm{O}_{2} 10 \mathrm{ml} \\
+ \\
\text { (1) } \mathrm{Etanol}^{2} 00 \mathrm{ml} \\
\mathrm{FeCl}_{3} 25 \mathrm{~g} \\
\mathrm{HCl} 15 \mathrm{ml}\end{array}$ & $\begin{array}{l}\text { Ataque inicial com regente } \\
\text { (2) durante } 5 \mathrm{~s} \text {. } \\
\text { Ataque final com reagente } \\
\text { (1) por } 3 \mathrm{~s} \text {. } \\
\text { Após cada ataque, lavagem } \\
\text { com água corrente durante } \\
1 \mathrm{~min} \text {. }\end{array}$ \\
\hline & $\begin{array}{l}\text { Lixas: } \\
100 ; 200 ; \\
400 ; 600 ; \\
1000 ; 2000\end{array}$ & $\begin{array}{l}\text { (3) Klemm's I } \\
\text { modificado } \\
\mathrm{Na}_{2} \mathrm{~S}_{2} \mathrm{O}_{3} 50 \mathrm{ml}\end{array}$ & $\begin{array}{l}\text { Imersão da amostra por } 2 \\
\text { min ou até obter um } \\
\text { contraste desejado, }\end{array}$ \\
\hline
\end{tabular}




\begin{tabular}{|c|c|c|c|}
\hline Tipo de Análise & Polimento & Ataque químico & Procedimento \\
\hline & $\begin{array}{l}\text { Pasta diamante: } \\
9 ; 3 ; 1 \mu \mathrm{m} \\
\text { Sílica coloidal: } \\
0,05 \mu \mathrm{m}\end{array}$ & $\mathrm{K}_{2} \mathrm{~S}_{2} \mathrm{O}_{5} 1 \mathrm{~g}$ & $\begin{array}{l}\text { lavagem com água corrente } \\
\text { durante } 5 \mathrm{~min} .\end{array}$ \\
\hline & $\begin{array}{l}\text { Lixas: } \\
100 ; 200 ; \\
400 ; 600 ; \\
1000 ; 2000 ; \\
\text { Pasta diamante: } \\
\text { 9; } 3 ; 1 \mu \mathrm{m} \\
\text { Sílica coloidal: } \\
0,05 \mu \mathrm{m}\end{array}$ & $\begin{array}{l}\text { (3) Klemm's I I } \\
\text { modificado } \\
\mathrm{Na}_{2} \mathrm{~S}_{2} \mathrm{O}_{3} 50 \mathrm{ml} \\
\mathrm{K}_{2} \mathrm{~S}_{2} \mathrm{O}_{5} 5 \mathrm{~g}\end{array}$ & $\begin{array}{l}\text { Imersão da amostra por } 1 \\
\text { min ou até obter um } \\
\text { contraste desejado, } \\
\text { lavagem com água corrente } \\
\text { durante } 3 \text { min. }\end{array}$ \\
\hline
\end{tabular}

\subsubsection{Extração de precipitados}

Neste trabalho foram utilizadas as técnicas de dissolução eletrolítica e de extração por réplica para tentar separar e concentrar os precipitados que surgiram na matriz da estrutura bruta de solidificação. Apesar da técnica ter permitido concentrar os precipitados contendo $\mathrm{Zr}$, o que auxiliou na sua caracterização microestrutural, não foi suficiente para a caracterização a partir da difração de raios-X.

A literatura existente relacionada com a extração eletrolítica de precipitados em ligas Cu-Sn é escassa e, portanto, houve inicialmente uma fase exploratória por meio de experimentos potenciodinâmicos. Estes experimentos tiveram o objetivo de se obter os melhores parâmetros para realizar a dissolução da matriz em uma célula eletrolítica. Corpos de prova da liga contendo os precipitados foram embutidos em baquelita, deixando uma área exposta de aproximadamente $1 \mathrm{~cm}^{2}$. Posteriormente esta superfície foi lixada com lixas de 100 até 1000 mesh. Para os experimentos foi utilizada uma célula convencional, usando um eletrodo de referência de prata-cloreto de prata $(\mathrm{Ag} / \mathrm{AgCl})$ e um contra-eletrodo de fio de platina, mantendo-se a temperatura do eletrólito controlada em $22 \pm 2^{\circ} \mathrm{C}$. Durante estes experimentos foram testados dois eletrólitos descritos na literatura (LOU; GRANT, 1984; OZGOWICZ; NAWRAT, 2007), mas o eletrólito adotado foi o ácido fosfórico diluído em $65 \%$, utilizado para extrair precipitados de Cu-Zr e Cu-Cr em ligas de Cu-Zr e Cu-Zr-Cr (LOU; GRANT, 1984). Observou-se que a matriz das amostras foi diluída com a aplicação de um potencial de $0,25 \mathrm{~V}$ e uma densidade de corrente de no máximo $35 \mathrm{~mA} / \mathrm{cm}^{2}$ no eletrólito. 
A Figura 33 (a) mostra que nestas condições houve um ataque seletivo da matriz (Cu- $\alpha$ ), preservando as fases dispersas presentes. A Figura 33 (b) mostra um grupo de partículas aglomeradas que aparentemente não foram atacadas. A Figura 33 (c) e (d) mostram um grau de diluição avançado tanto na matriz como nas partículas dispersas.
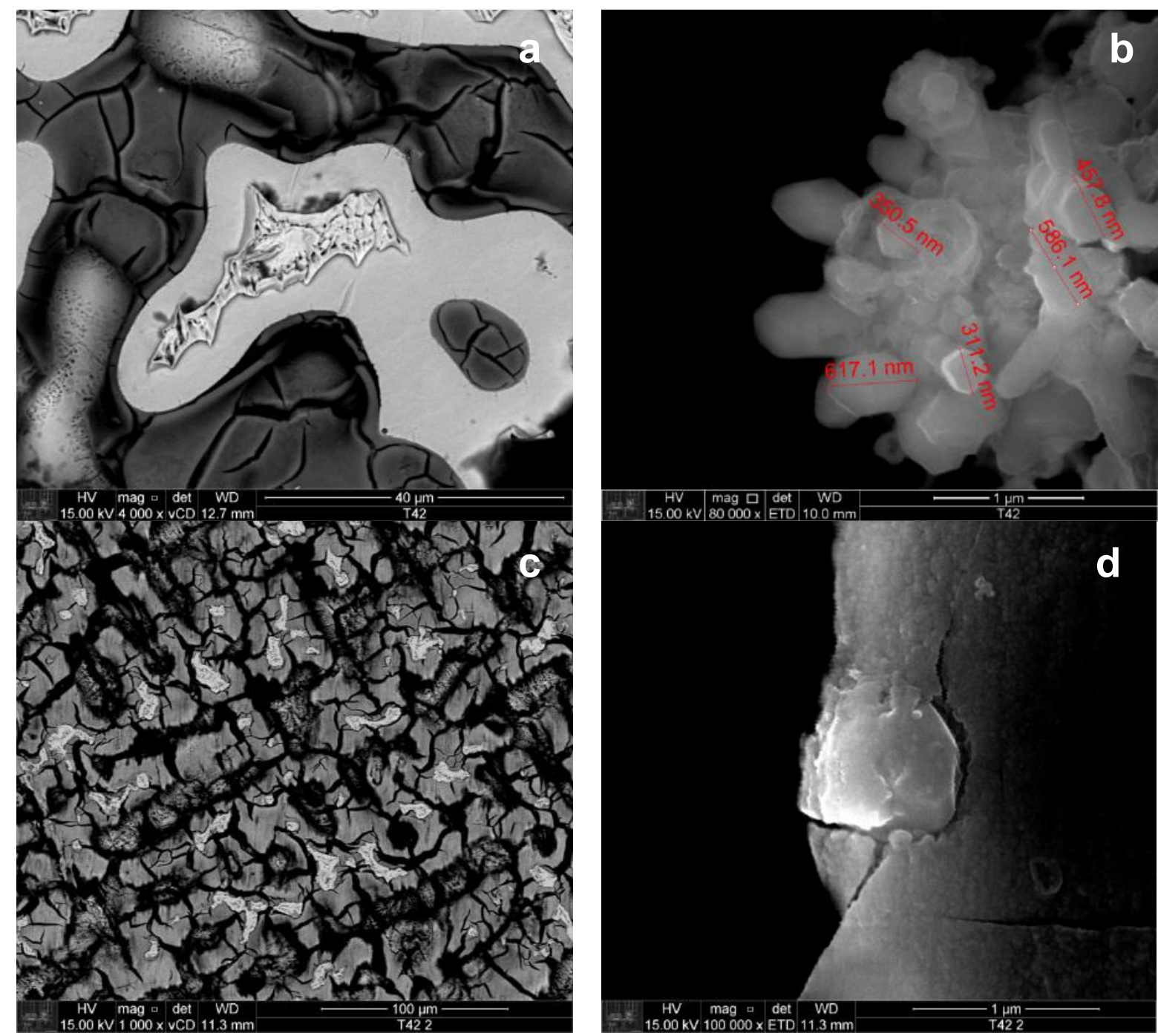

Figura 33 - Fotomicrografia obtida em microscópio eletrônico de varredura FEG do experimento $\mathrm{EN}_{2}$-Inoc após o experimento potenciodinâmico: a) e b) diluída com Ácido fosfórico $65 \%$. c) e d) diluída com Acetato de amônio 4M + amônia 2,5M.

\subsubsection{Extração de precipitados por réplica com filme de carbono}

As condições de ataque eletrolítico definidas no item anterior permitiram um ataque seletivo da fase de $\mathrm{Cu}-\alpha$, preservando e expondo os precipitados. Estas condições foram empregadas para a extração de precipitados via réplica com filme de 
carbono (WILLIAMS; CARTER, 2009). A superfície das amostras foi atacada de forma eletroquímica com uma solução de ácido fosfórico $65 \%$ durante 50 s com um potencial de 5 V. Posteriormente, foram lavadas no ultra-som com acetona e secadas com ar, e finalmente um filme de carbono foi depositado sobre as amostras utilizando-se um evaporador de carbono por arco, localizado no Laboratório de Microscopia Eletrônica do Instituto de Física da USP (IFUSP) (Figura 34 (a) e (b)).

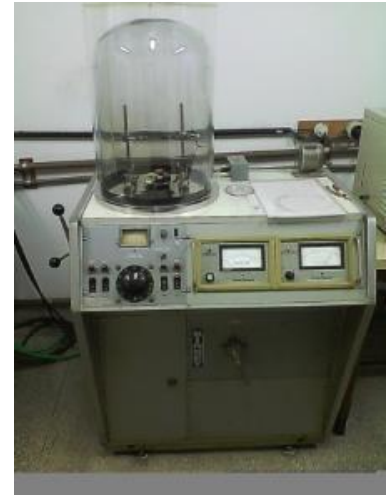

(a)

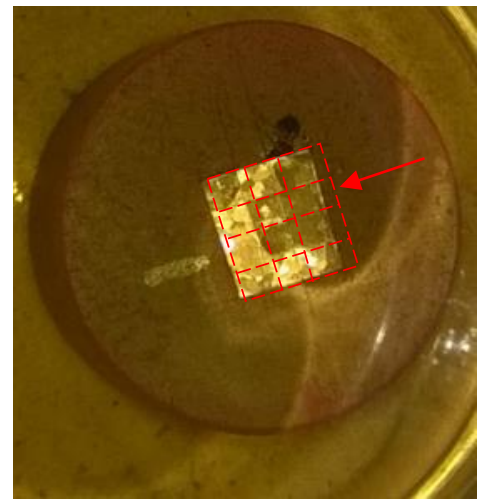

(c)

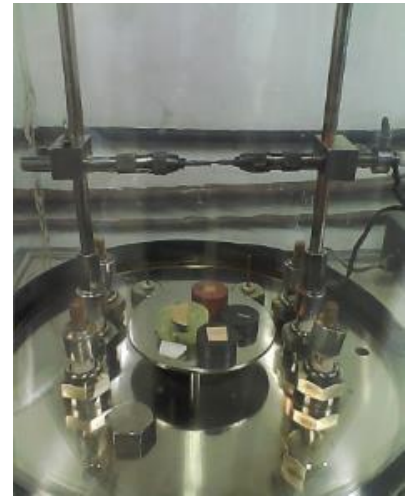

(b)

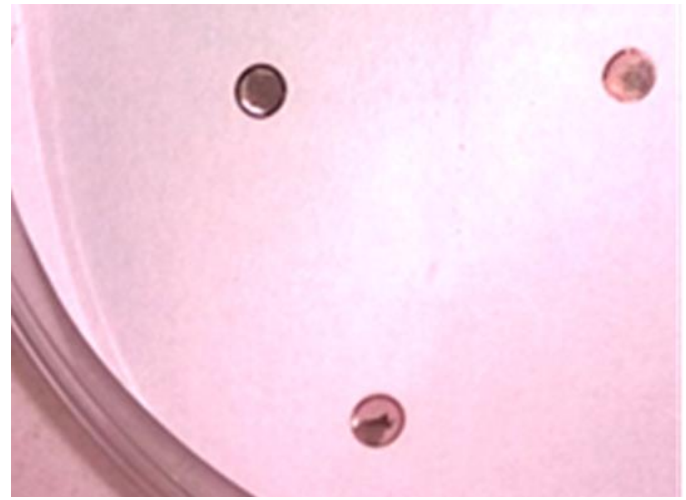

(d)

Figura 34 - Fotografias dos estágios de deposição do filme de carbono no evaporador por arco: a) e b) evaporador de carbono e posicionamento das amostras dentro do equipamento; c) amostra imersa no reagente para a extração do filme de carbono indicando em vermelho os cortes feitos com bisturi; d) filmes no sistema de filtragem com bomba de vácuo.

Para retirar o filme de carbono com os precipitados, foram feitos cortes com bisturi em forma de uma grade de aproximadamente $3 \mathrm{~mm} \times 3 \mathrm{~mm}$ sobre o filme depositado na superfície da amostra (Figura 34 (c)). Posteriormente, a mostra foi imersa em um recipiente contendo a solução de ataque metalográfico (1) da Tabela 10. Após 20 minutos, os quadrados previamente cortados do filme começaram a se desprender da superfície. Com ajuda de uma pinça e uma grade de cobre (mesh 400, 
$3 \mathrm{~mm}$ de diâmetro), foram coletados os filmes soltos na solução e imersos nas soluções de limpeza.

O filme coletado na grade foi imerso em uma solução de etanol anidro para se desprender da grade de cobre. Este procedimento foi conduzido duas vezes, inicialmente utilizando outra solução de etanol anidro e depois água deionizada. Finalmente os filmes coletados da solução foram depositados sobre um papel de filtro para secar, como apresentado na Figura 34(d). Para cada filme obtido, foi empregada uma nova grade de níquel, repetindo-se o procedimento descrito anteriormente.

\subsubsection{Preparação de lâmina fina por FIB}

Neste item se apresenta a metodologia utilizada na fabricação das seções finas do experimento Cu8Sn0,16Zr, para serem analisadas com microscopia eletrônica de transmissão. Para este fim, foi utilizado um Microscópio Eletrônico de Varredura FEG com Dual Feixe de Íons (FIB) e Elétrons e Sistema de Nanofabricação de amostras, Quanta FEG 3D FEI, no Centro de Microscopia da Universidade Federal de Minas Gerais, Belo Horizonte, MG, Brasil.

Inicialmente foi escolhida a região para obtenção da amostra, escolhendo-se um precipitado localizado no interior do grão, que poderia representar um possível centro de nucleação heterogênea. Para encontrar o precipitado, foi feita uma busca no microscópio eletrônico de varredura (MEV) no modo de elétron retroespalhados, com a intenção de diferenciar zonas microssegregadas e diferentes fases. A seguir, foi feita uma análise de composição com auxílio da microssonda EDS, obtendo-se um mapa elementar. Depois de encontrar um precipitado no interior da fase primaria (Cua), foram extraídas duas seções finas incluindo o precipitado e a matriz. Estas amostras devem fornecer informações relacionadas à natureza química e cristalográfica dos precipitados posicionados nas regiões especificas das amostras.

Foram cortadas lâminas de $\mathrm{um} \mathrm{cm}^{2}$ na posição dos cortes para análise microestrutural, como apresentado no Item 4.2.1. A superfície da amostra foi preparada com os procedimentos de polimento microestrutural da Tabela 10, sem ataque químico. As Figura 35 (a) até (h) apresentam a sequência de estágios durante 
a preparação da amostra no interior do microscópio: (a) região escolhida para fazer o corte; b) seleção da região retangular para fazer a deposição de Pt $\approx 2 \times 10 \mu \mathrm{m}$; c) deposição de Pt de $\approx 3 \mu \mathrm{m}$ na região marcada anteriormente; d) Cortes laterais; e) corte em U da lâmina; f) manipulação da amostra com a agulha de Pt Omniprobe e posicionamento no porta amostras de cobre para soldagem; g) amostra soldada; h) amostra desbastada com feixe de gálio, até obter a espessura adequada para transmissão $\approx 100-150 \mathrm{~nm}$.

As lâminas finas foram posicionadas no microscópio eletrônico de transmissão onde se realizou as difrações de elétrons da área selecionada, tanto na matriz, como no precipitado. Foi utilizado o método das razões para indexar os padrões de difração. Inicialmente escolheu-se um ponto para ser a origem na figura de difração, posteriormente foram medidas tanto as distâncias interplanares, como os ângulos de dois pontos não colineares diretamente nos difratogramas. Estas medidas foram comparadas com os padrões de referência a partir de espécimes com distâncias e ângulos interplanares conhecidas do sistema cúbico CFC (THOMPSON-RUSSELL; EDINGTON, 1977). Todas as medições foram feitas com auxílio do software DigitalMicrograph ${ }^{\mathrm{TM}}$, produzido pela Gatam Corporation.

Em seguida foi preparada uma tabela com as razões dos espaçamentos dos planos de difração conhecidos, que para o presente trabalho é CFC, considerando que o fator de estrutura para este sistema cristalino é $h, k$, I todos pares ou todos ímpares (FARINA, 2010). Logo, a razão dos espaçamentos medidos foi comparada com as razões conhecidas até encontrar valores próximos dos planos nesta tabela. Finalmente calculou-se o ângulo entre os planos. Os valores aproximados destes ângulos foram comparados com os valores experimentais e os que apresentaram valores similares foram aceitos na indexação. Já os valores não similares foram descartados e um outro par de planos possíveis foi escolhido. A indexação final foi realizada pela soma de vetores na imagem de difração. 


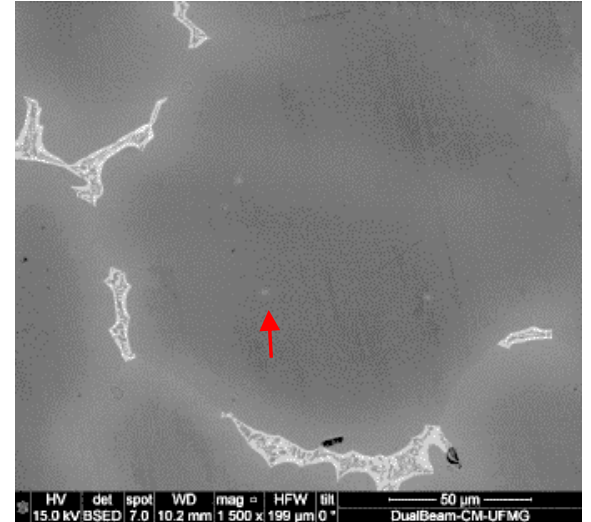

(a)

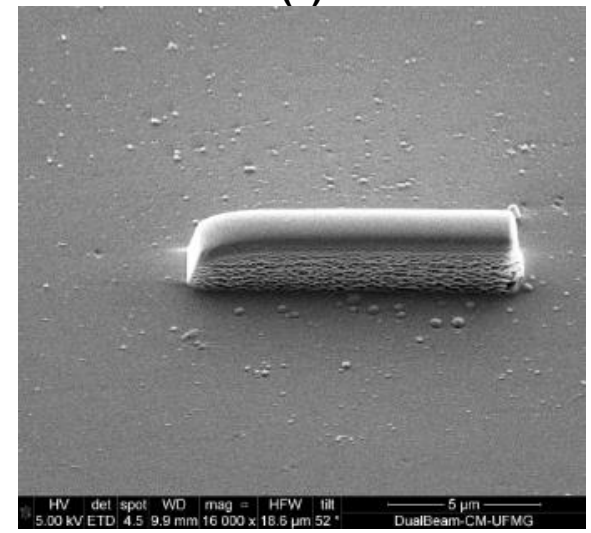

(c)

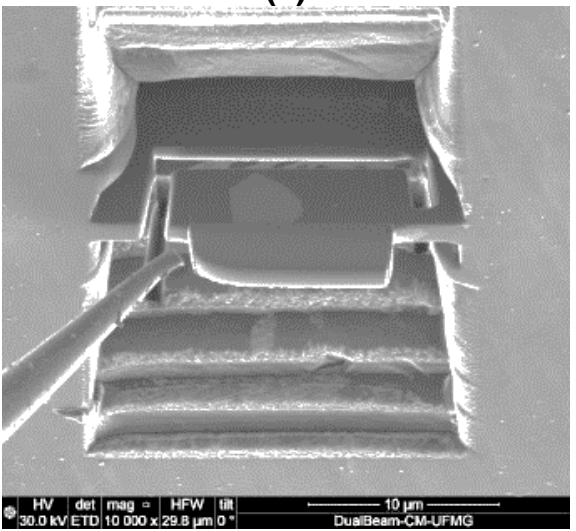

(e)

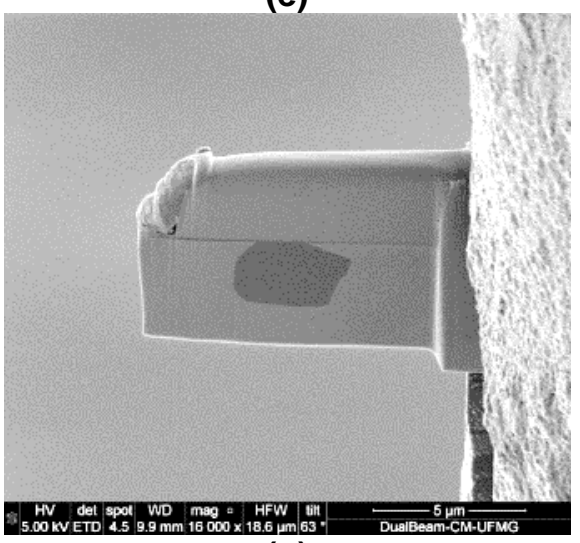

(g)

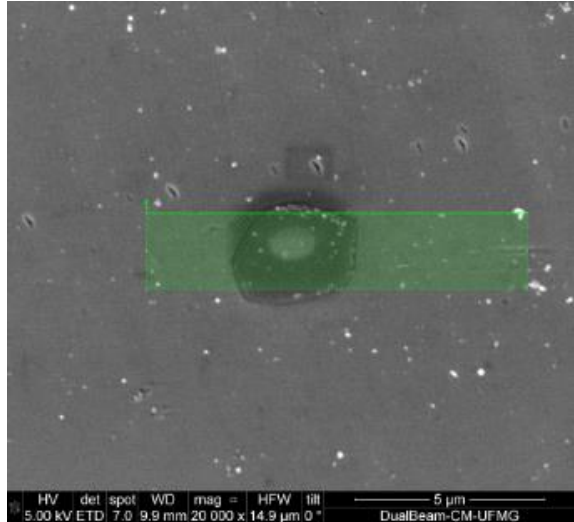

(b)

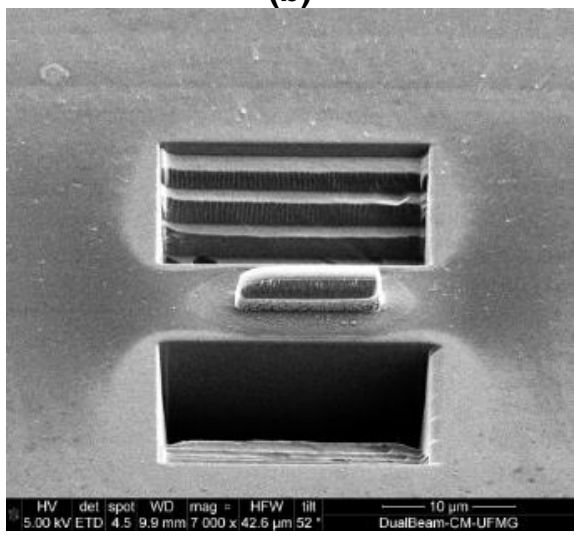

(d)

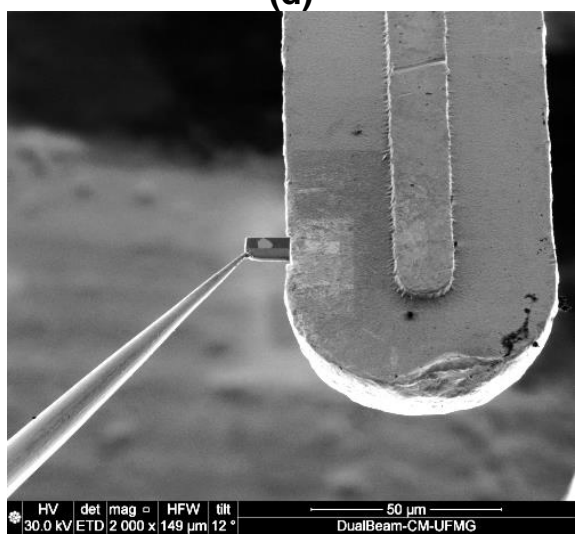

(f)

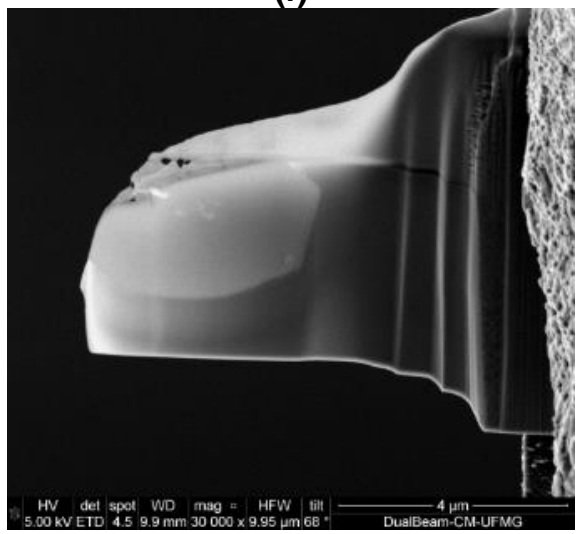

(h)

Figura 35- Fotomicrografias obtida em microscópio eletrônico de varredura FEG do experimento Cu8Sn0,16Zr, apresentando a sequência de corte e preparação da amostra para microscopia de transmissão: a) região selecionada para corte; a seta vermelha mostra o precipitado escolhido; b) região retangular para deposição de $\mathrm{Pt}$; c) deposição de $\mathrm{Pt}$; d) cortes laterais; e) corte em U na lâmina; f) manipulação da amostra com agulha de Pt; g) amostra soldada no porta amostras; h) amostra desbastada. 


\section{RESULTADOS E DISCUSSÃO}

Os resultados obtidos no presente trabalho estão apresentados e discutidos em cinco itens relacionados com: (a) análise química (item 5.1); (b) efeitos das adições ao banho na macroestrutura de grãos (item 5.2); (c) análise térmica (item 5.3); (d) análise microestrutural: identificação das fases e precipitados (item 5.4) e (e) identificação dos mecanismos de inoculação (item 5.5). Na análise térmica serão mostradas evidências relacionadas à transferência de calor que ajudam a confirmar o efeito na macroestrutura de grãos causado pelas adições, além de ajudar na identificação de parâmetros térmicos e eventos ocorridos durantes a solidificação. $\mathrm{Na}$ análise microestrutural, procurou-se identificar a natureza cristalográfica e química dos precipitados e fases presentes na estrutura utilizando diferentes técnicas de caracterização. Finalmente, no último item, procurou-se descrever os mecanismos de inoculação que operam após as adições realizadas. Esta sequência mostra inicialmente resultados obtidos na escala macroscópica (análise química, macrografias e curvas de resfriamento) e posteriormente resultados de escalas de tamanho cada vez menores (micrografias e microanálises) até finalizar com imagens de microscopia de transmissão de alta resolução, atingindo-se uma escala próxima da atômica.

\subsection{Análise química}

A Tabela 11 apresenta os resultados das análises químicas dos lingotes obtidos em cada experimento realizadas pelos laboratórios (a), (b), (c), (d) e (e). Importante lembrar que as amostras dos experimentos com e sem adição de Cu-50\%Zr foram obtidas de partes de um mesmo banho líquido. As análises de Sn dos laboratórios (a) e (d) indicam perdas diferentes em relação ao teor nominal. Essa diferença nos resultados pode indicar a magnitude dos erros associados aos processos de análise química. O Sn em condições padrões apresenta uma maior tendência à oxidação quando comparado ao $\mathrm{Cu}$, indicando que uma perda deste elemento seria esperada. 
Os teores de $\mathrm{Zr}$ indicados pela análise dos laboratórios (a) e (c) da série de composição nominal Cu8\%Sn têm a mesma ordem de grandeza para cada experimento. Estes resultados indicam uma incorporação de $\mathrm{Zr}$ que variou entre 6\% até $40 \%$. A perda deste elemento pode ter ocorrida através de sua oxidação pela atmosfera do forno e pelo oxigênio dissolvido no banho líquido. Esta oxidação resultaria na formação de óxidos, que seriam transportados para a escória sobre a superfície do banho diminuindo o teor Zr total no metal líquido. A adição de P teve o objetivo de minimizar este tipo de oxidação.

O teor de $\mathrm{P}$ nominal da série de composição nominal Cu8\%Sn é de 0,025\% (Tabela 7). O laboratório (a) mostrou novamente teores mais elevados, acima do nominal que os laboratórios (d), podendo indicar erros mais elevados em seus procedimentos de análise. Em termos físicos não seria possível explicar um aumento no teor de $\mathrm{P}$ muito acima do nominal, pois este elemento tem grande tendência à oxidação e poderia formar produtos a serem transportados para a escória, reduzindo o seu teor total no interior do metal líquido. 
Tabela 11 - Resultados das análises químicas dos lingotes obtidos nos experimentos. A incorporação de Zr ao banho também está indicada (Ef).

\begin{tabular}{|c|c|c|c|c|c|c|c|c|c|}
\hline Série & Sigla & $\%$ Sn & $\% \mathbf{Z r}$ & $\% \mathbf{P}$ & $\% \mathbf{C}$ & $\% 0$ & $\% S$ & $\% \mathrm{~Pb}$ & Observações \\
\hline \multirow{21}{*}{$\begin{array}{l}\text { Efeito } \\
\text { geral }\end{array}$} & \multirow[t]{2}{*}{ Cu0Sn0ZrOP } & - & - & $0,0075^{\mathrm{b}}$ & $0,010^{\mathrm{b}}$ & - & $0,003^{b}$ & - & \multirow[t]{2}{*}{$\mathrm{N}_{2}(2 \mathrm{NI} / \mathrm{min})$} \\
\hline & & - & - & - & - & - & - & - & \\
\hline & \multirow{3}{*}{ Cu0Sn0,08Zr0P } & - & $0.005^{b}$ & - & - & $0.032^{b}$ & - & - & \multirow{6}{*}{$\mathrm{N}_{2}(2 \mathrm{NI} / \mathrm{min})$} \\
\hline & & - & - & - & - & - & - & - & \\
\hline & & - & - & - & - & - & - & - & \\
\hline & \multirow{3}{*}{ Cu2Sn0ZrOP } & - & - & - & - & - & - & - & \\
\hline & & - & - & - & - & - & - & - & \\
\hline & & - & - & - & - & - & - & - & \\
\hline & \multirow{2}{*}{ Cu2Sn0,08ZrOP } & - & - & - & - & - & - & - & \multirow{5}{*}{$\begin{array}{c}\text { Cadinho Argila- } \\
\text { Grafita }\end{array}$} \\
\hline & & - & - & - & - & - & - & - & \\
\hline & \multirow{3}{*}{ Cu8Sn0Zr0C } & - & - & - & - & - & - & - & \\
\hline & & - & - & - & - & - & - & - & \\
\hline & & - & - & - & - & - & - & - & \\
\hline & \multirow{3}{*}{ Cu8Sn0,08Zr0C } & - & - & - & - & - & - & - & \multirow{3}{*}{$\begin{array}{l}\text { Cadinho Argila- } \\
\text { Grafita }\end{array}$} \\
\hline & & - & - & - & - & - & - & - & \\
\hline & & - & - & - & - & - & - & - & \\
\hline & Cu8Sn0Zr0P & - & - & - & - & - & - & - & $\operatorname{Ar}(2 \mathrm{NI} / \mathrm{min})$ \\
\hline & & - & - & - & - & - & - & - & \\
\hline & Cu8Sn0 087rnP & - & - & - & - & - & - & - & $\operatorname{Ar}(2 \mathrm{~N} I / \min )$ \\
\hline & & - & - & - & - & - & - & - & \\
\hline & & - & - & - & - & - & - & - & \\
\hline & Cu8Sn0Zr & $7,08^{\mathrm{a}}$ & $<0,0010^{\mathrm{a}}$ & $0,0154^{a}$ & $0,0042^{\mathrm{a}}$ & $0,0101^{\mathrm{e}}$ & $0,0009^{a}$ & $<0,0072^{\mathrm{a}}$ & \\
\hline & & $\frac{-}{7.96^{d}}$ & $\begin{array}{l}<0,0001^{\mathrm{c}} \\
<0,001^{\mathrm{d}}\end{array}$ & $0.0350^{d}$ & $0,004^{b}$ & $\frac{-}{-}$ & $\frac{-}{00021^{d}}$ & $\frac{-}{0.010^{d}}$ & - \\
\hline & Cu8Sn0,04Zr & - & $0,0044^{\mathrm{a}}$ & - & $0,0030^{\mathrm{a}}$ & - & - & - & $\mathrm{Ef}^{\mathrm{a}}{ }^{\mathrm{Z}} \mathrm{Zr}(10 \%)$ \\
\hline & & - & $0,0045^{c}$ & - & $<0,004^{b}$ & - & - & - & \\
\hline & & $8,02^{\mathrm{d}}$ & - & $0,0340^{d}$ & - & 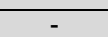 & $0,0029^{d}$ & $0,012^{\mathrm{d}}$ & \\
\hline & Cu8Sn0,08Zr & $7,29^{\mathrm{a}}$ & $0,0148^{\mathrm{a}}$ & $0,0152^{\mathrm{a}}$ & $0,0054^{a}$ & $0,0341^{\mathrm{e}}$ & $0,0011^{a}$ & $<0,0072^{\mathrm{a}}$ & Ef. ${ }^{a} \operatorname{Zr}(12 \%)$ \\
\hline & & $-\bar{c}$ & $0,0108^{\mathrm{c}}$ & - & $0,004^{b}$ & - & - & $\frac{-}{0-11 d}$ & \\
\hline & Cu8Sn0 127r & 1,30 & $0.0139^{\mathrm{a}}$ & $\frac{0,0360^{\circ}}{-}$ & $\frac{-}{0.0058^{\mathrm{a}}}$ & - & $0,0025^{\circ}$ & $\frac{0,011^{\mathrm{a}}}{-}$ & $\mathrm{Ef}^{\mathrm{a}} \mathrm{Zr}(8 \%)$ \\
\hline Etelto do & CUOJIIU, ILCL & - & $0,0159^{c}$ & - & $0,004^{b}$ & - & - & - & ㄷ. $21(0 \%)$ \\
\hline & & $7,94^{\mathrm{d}}$ & - & $0,029^{d}$ & - & - & $0,0029^{d}$ & $0,029^{d}$ & \\
\hline & Cu8Sn0.167r & $6,71^{a}$ & $0,0425^{\mathrm{a}}$ & $0,0157^{a}$ & $0,0042^{\mathrm{a}}$ & $0,0042^{\mathrm{e}}$ & $0,0012^{\mathrm{a}}$ & $0,0075^{\mathrm{a}}$ & Ef. ${ }^{a} \operatorname{Zr}(25 \%)$ \\
\hline & & - & $0,0011^{\mathrm{c}}$ & & $<0,004^{b}$ & - & - & - & \\
\hline & & $7,82^{\mathrm{d}}$ & - & $0,031^{\mathrm{d}}$ & - & - & $0,0028^{d}$ & $0,011^{\mathrm{d}}$ & \\
\hline & Cu8Sn0,24Zr & - & $0,0732^{\mathrm{a}}$ & - & $0,0058^{\mathrm{a}}$ & - & - & - & Ef. $^{a} \mathrm{Zr}(29 \%)$ \\
\hline & & - & $0,0149^{c}$ & - & $0,004^{b}$ & - & - & - & \\
\hline & & $8,07^{d}$ & - & $0,030^{\mathrm{d}}$ & - & - & $0,0032^{\mathrm{d}}$ & $0,012^{\mathrm{d}}$ & \\
\hline & Cu8Sn0,32Zr & - & $0,0219^{\mathrm{a}}$ & - & $0,0040^{\mathrm{a}}$ & - & - & - & Ef. $^{2} \operatorname{Zr}(6 \%)$ \\
\hline & & - & $0,0522^{\mathrm{c}}$ & - & $<0,004^{b}$ & - & - & - & \\
\hline & $000=017$ & $8,07^{\mathrm{d}}$ & - & $0,035^{\mathrm{d}}$ & - & - & $0,0028^{\mathrm{d}}$ & $0,013^{\mathrm{d}}$ & \\
\hline & Cu8Sn0,40Zr & - & $0,1800^{\mathrm{a}}$ & - & $0,0048^{\mathrm{a}}$ & - & - & - & Ef. ${ }^{a} \operatorname{Zr}(40 \%)$ \\
\hline & & $7 \overline{-} 84^{\mathrm{d}}$ & $\frac{0,1254^{c}}{-}$ & $-\overline{-}$ & $0,005^{b}$ & - & $-\overline{-}$ & $-\overline{-}$ & \\
\hline & Cu0Sn0Zr & - & $<0,0010^{a}$ & $0,0173^{\mathrm{a}}$ & $0,0134^{\mathrm{a}}$ & $0,0032^{\mathrm{e}}$ & $0,0011^{\mathrm{a}}$ & $<0,0072^{\mathrm{a}}$ & \\
\hline & & $<0,0001^{d}$ & $<0,001^{d}$ & $0,020^{d}$ & $<0,004^{b}$ & - & $0,0020^{d}$ & $0,0033^{d}$ & - \\
\hline & & - & - & - & - & - & - & - & \\
\hline & Cu0Sn0.08Zr & $<0,0102^{a}$ & $0,0020^{\mathrm{a}}$ & - & $0,0203^{a}$ & - & - & - & \\
\hline & & - & $0,0049^{c}$ & - & $0,004^{b}$ & - & - & - & - \\
\hline & & $<0,0001^{d}$ & - & $0,021^{d}$ & - & - & $0,0021^{d}$ & $0,0034^{d}$ & \\
\hline & Cu2Sn0Zr & $2,09^{a}$ & - & - & - & - & - & - & - \\
\hline & Cu2Sn0.08Zr & $1,81^{\mathrm{a}}$ & $0,0068^{\mathrm{a}}$ & - & $0,0027^{a}$ & - & - & - & \\
\hline & & - & - & - & $<0,004^{b}$ & - & - & - & - \\
\hline & Cu4Sn0Zr & $3,74^{a}$ & - & - & - & - & - & - & \\
\hline ETelto do & & $3,51^{d}$ & $<0,001^{d}$ & $0,032^{d}$ & - & - & $0,0027^{d}$ & $0,0033^{d}$ & - \\
\hline & & - & - & - & - & - & - & - & \\
\hline & Cu4Sn0.08Zr & $3,32^{\mathrm{a}}$ & $0,0078^{\mathrm{a}}$ & - & $0,0051^{a}$ & - & - & - & \\
\hline & & - & $0,0048^{c}$ & - & $0,004^{b}$ & - & - & - & - \\
\hline & & $3,54^{d}$ & - & $0,031^{d}$ & - & - & $0,0029^{d}$ & $0,0031^{d}$ & \\
\hline & Cu8Sn0Zr & $7,08^{\mathrm{a}}$ & $<0,0010^{a}$ & $0,0154^{a}$ & $0,0042^{\mathrm{a}}$ & $0,0101^{\mathrm{e}}$ & $0,0009^{a}$ & $<0,0072^{a}$ & \\
\hline & & $7,97^{d}$ & $<0,001^{d}$ & $0,035^{d}$ & $0,004^{b}$ & - & $0,0021^{d}$ & $0,010^{\mathrm{d}}$ & - \\
\hline & Cu8Sn0,08Zr & $7,29^{a}$ & $0,0148^{\mathrm{a}}$ & $0,0152^{a}$ & $0,0054^{a}$ & $0,0341^{\mathrm{e}}$ & $0,0011^{a}$ & $<0,0072^{\mathrm{a}}$ & \\
\hline & & - & $0,0108^{c}$ & - & $0,004^{b}$ & - & - & - & - \\
\hline & & $7,93^{\mathrm{d}}$ & - & $0,036^{d}$ & - & - & $0,0025^{d}$ & $0,011^{d}$ & \\
\hline & Cu12Sn0Zr & $10,880^{a}$ & - & - & - & - & - & - & \\
\hline & & $12,08^{\mathrm{d}}$ & $<0,001^{d}$ & $0,026^{d}$ & - & - & $0,0030^{d}$ & $0,029^{d}$ & - \\
\hline & Cu12Sn0.08Zr & $11,10^{\mathrm{a}}$ & $0,0064^{a}$ & - & $0,0048^{a}$ & - & - & - & \\
\hline & CUI ISSHU, 0OLI & $11,65^{d}$ & - & $0,028^{d}$ & $0,005^{b}$ & - & $0,0033^{d}$ & $0,032^{d}$ & - \\
\hline
\end{tabular}




\subsection{Efeito das adições ao banho na macroestrutura de grãos}

Neste item serão apresentadas as macroestruturas brutas de solidificação das seções longitudinais dos lingotes cilíndricos preparados com os procedimentos descritos na Tabela 10. Inicialmente, serão analisados os efeitos das adições de $\mathrm{P}, \mathrm{Zr}$ e C para teores de $0 \%$ Sn, $2 \%$ Sn e $8 \%$ Sn. A seguir serão apresentadas as análises detalhadas dos efeitos das adições de Zr para uma liga com teor fixo de $8 \% \mathrm{Sn}$ (Cu8\%Sn). Finalmente, uma análise detalhada dos efeitos combinados das adições de Sn e Zr será apresentada.

\subsubsection{Efeito geral das adições de P, C e Zr na macroestrutura de grãos}

A Figura 36 apresenta o efeito da adição de $0,08 \% Z r$ na macroestrutura do cobre eletrolítico com (Figura 36a,b) ou sem (Figura 36c,d) a presença do P para a desoxidação e ambos casos com fonte de grafite na cobertura do banho. Na Tabela 12 estão apresentadas as medidas de tamanho de grão com os respectivos desviospadrão. Os experimentos com adição de $P$ apresentaram uma estrutura de grãos heterogênea contendo grãos colunares próximos à parede e grãos equiaxiais no centro dos lingotes. $O$ exame visual não evidencia uma diminuição significativa do tamanho de grão com a adição de Zr. Entretanto, uma análise estatística (teste de hipótese da igualdade de médias) indica que a amostra contendo $\mathrm{Zr}$ (Figura 36b) apresenta em sua região central (região de medida) um tamanho de grão menor do que aquela sem $\operatorname{Zr}$ (Figura 36a) com $1 \%$ de significância. Isto significa que a probabilidade de os tamanhos de grão nas duas amostras serem iguais está na faixa de $1 \%$ e, portanto, esta hipótese é rejeitada. As amostras sem a adição de $\mathrm{P}$ apresentaram uma estrutura de grãos completamente colunar (Figura 36c,d), diferente do caso com adição de $P$. Novamente, um exame visual indica que a adição de Zr não causou uma alteração significativa do tamanho de grão, porém o teste de hipóteses estatístico com $1 \%$ de significância indica que o tamanho de grão é menor na amostra com adição de $\mathrm{Zr}$. 
Comparando-se a Figura 36a com a Figura 36c, e a Figura 36b com a Figura $36 d$ nota-se que a adição de $P$ resultou na eliminação dos grão colunares e causou o aparecimento de grãos equiaxiais no centro do lingote com ou sem a presença de $\mathrm{Zr}$. O teste de hipótese com $1 \%$ de significância também indicou que o tamanho de grão nas amostras com $\mathrm{P}$ (medido no centro do lingote) é menor do que as amostras correspondentes sem $P$.

A Figura 37 apresenta o efeito da adição de 0,08\%Zr na macroestrutura da liga Cu-2\%Sn com (Figura 37a,b) ou sem (Figura 37c,d) a presença do P para a desoxidação. Na Tabela 13 estão apresentadas as medidas de tamanho médio de grão e os desvios-padrão correspondentes. A estrutura de grãos das amostras com $P$ (Figura 37a,b) parece um pouco mais uniforme do que a das amostras apresentadas na Figura 36a,b (sem Sn). Entretanto, sem a adição de Zr (Figura 37a) ainda existem grãos maiores na parede e menores no centro do lingote. A adição de Zr (Figura 37b) parece eliminar estes grãos maiores, obtendo-se uma estrutura de grãos completamente equiaxiais. Nota-se que o efeito do $\mathrm{Zr}$ no tamanho médio de grão não foi pronunciado, mas um teste de hipóteses indica, com $1 \%$ de significância, que o tamanho de grão da amostra com Zr é menor do que o da amostra sem Zr. O mesmo tipo de conclusão pode ser aplicado aos casos sem adição de P (Figura 37c,d), para o tamanho de grão na região central do lingote. Uma comparação visual entre a Figura 37a com a Figura 37c e da Figura 37b com a Figura 37d indica que o $P$ não alterou significativamente a estrutura de grãos como observado no cobre eletrolítico (Figura 36). Porém, novamente, o teste de hipótese mostrou, com 1\% de significância, que o tamanho de grão nas amostras com P é menor.

Finalmente o teor de Sn foi incrementado para 8\%. As macroestruturas resultantes estão apresentadas na Figura 38 e as medidas de tamanho de grão médio, na Tabela 14. O exame visual das macrografias mostra uma redução significativa do tamanho de grão quando o Zr é adicionado, seja na presença (Figura 38a,b) ou não (Figura 38c,d) de P. O efeito da adição de P pode ser examinado comparando-se a Figura 38a com a Figura 38c e a Figura 38b com a Figura 38d. O mesmo teste de hipótese realizado nos dois casos anteriores indicou tanto para $1 \%$ como para $5 \%$ de significância que os tamanhos de grão médios das amostras com ou sem P são iguais, ou seja, no caso do Cu-8\%Sn a adição do fósforo não altera o tamanho de grão. 
As macroestruturas apresentadas neste item mostram que a adição de $\mathrm{Zr}$ diminui o tamanho de grão médio na presença de $P$ ou não. Esta diminuição é relativamente pequena nos casos sem $\mathrm{Sn}$ (cobre eletrolítico) ou com $2 \% \mathrm{Sn}$, porém é significativa com $8 \% \mathrm{Sn}$, indicando que o Sn potencializa o efeito do $\mathrm{Zr}$ em diminuir o tamanho médio de grão. Este efeito de potencialização pode ser explicado pela restrição ao crescimento causado pelo $\mathrm{Sn}$ em solução de acordo com a teoria descrita no item 3.3.2 e será examinado em mais detalhes no item 5.2.4. Por outro lado, a adição de $\mathrm{P}$ parece causar uma diminuição do tamanho de grão, mas somente para os menores teores de $\mathrm{Sn}$ (0 e $2 \%$ ). Nas amostras com $8 \% \mathrm{Sn}$, o P não altera significativamente a estrutura de grãos e o tamanho de grão médio. $O$ efeito esperado do $\mathrm{P}$ é a diminuição do teor de oxigênio dissolvido no banho, evitando a oxidação do Zr e aumentando a quantidade deste elemento disponível para a inoculação. No entanto, os resultados mostraram que para 0 e $2 \%$ de Sn, o P parece causar uma diminuição do tamanho de grão mesmo sem a adição de Zr. Não há relatos na literatura a respeito do efeito do $P$ sobre o tamanho de grão em ligas de cobre e este efeito não será examinado em mais detalhes no presente trabalho. 


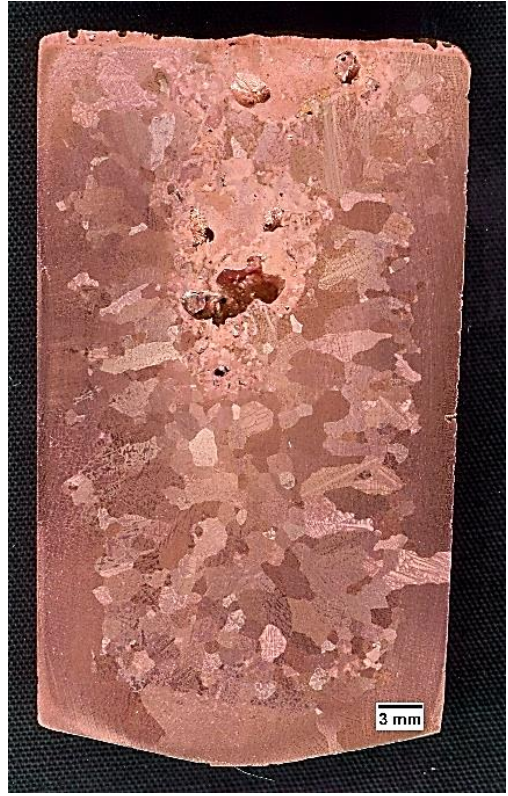

(a) CuOSnOZr

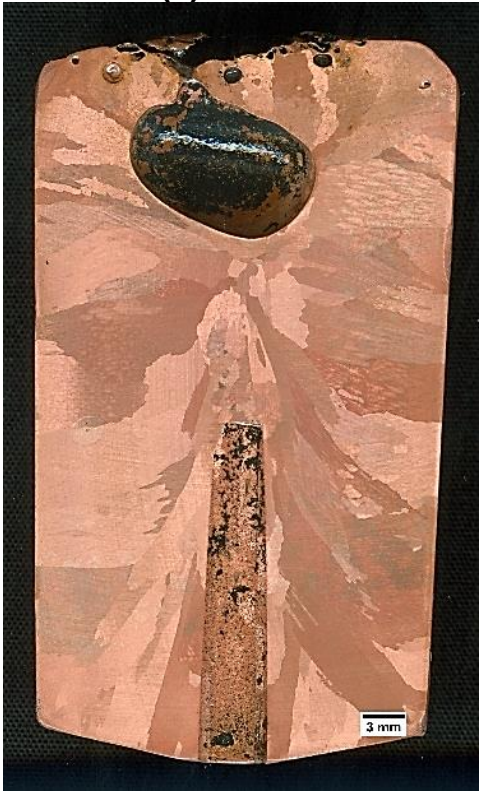

(c) Cu0Sn0ZroP

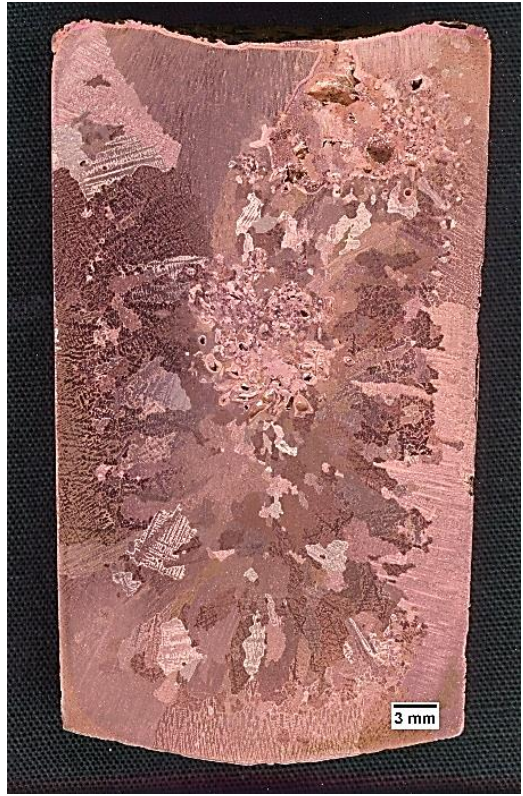

(b) Cu0Sn0,08Zr

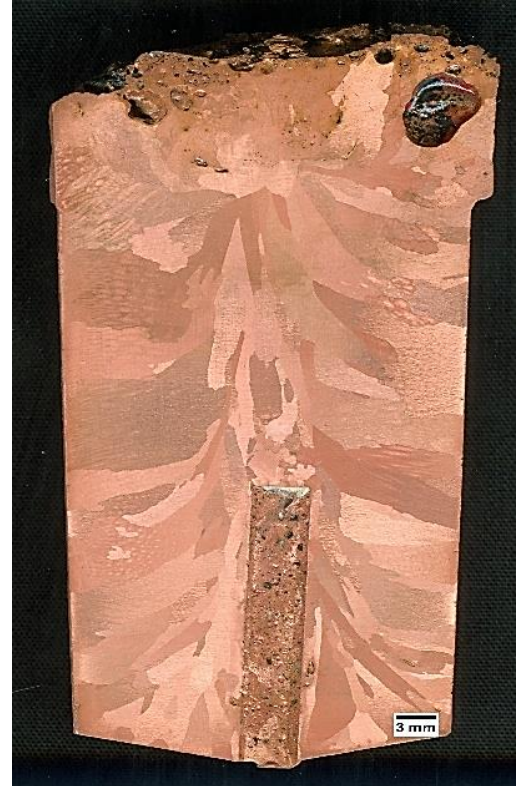

(d) Cu0Sn0,08ZrOP

Figura 36- Macroestruturas da seção longitudinal dos lingotes dos experimentos da liga Cu0\%Sn com fonte de carbono: a) e b) com adição de $\mathrm{P}$; b) e c) sem adição de $\mathrm{P}$, degaseificado com $\mathrm{N}_{2}$ (2 NI/min); ambos, sem e com adição de 0,08\%Zr. Reagente: Etanol 500ml, $\mathrm{FeCl} 325 \mathrm{~g}, \mathrm{HCl} 15 \mathrm{ml}$.

Tabela 12- Tamanho de grão medido (TG) e desvio padrão de medida para os lingotes de Cu. O número de campos (N) medidos também está indicado.

\begin{tabular}{lccc}
\hline Experimento & (\% Zr) & TG $(\boldsymbol{m m})$ & N \\
\hline Cu0Sn0Zr & - & $1,34 \pm 0,09$ & 20 \\
\hline Cu0Sn0,08Zr & 0,08 & $1,24 \pm 0,13$ & 20 \\
\hline Cu0Sn0Zr-P & - & $5,04 \pm 0,93$ & 15 \\
\hline Cu0Sn0,08Zr-P & 0,08 & $3,93 \pm 0,68$ & 15 \\
\hline
\end{tabular}




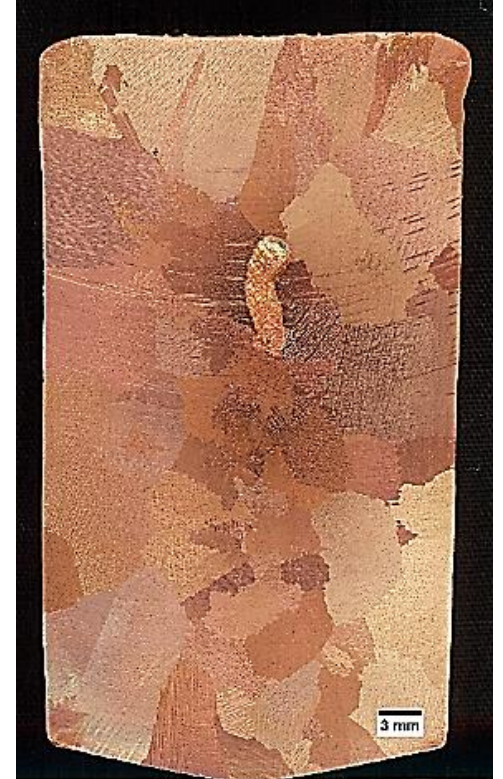

(a) Cu2Sn0Zr

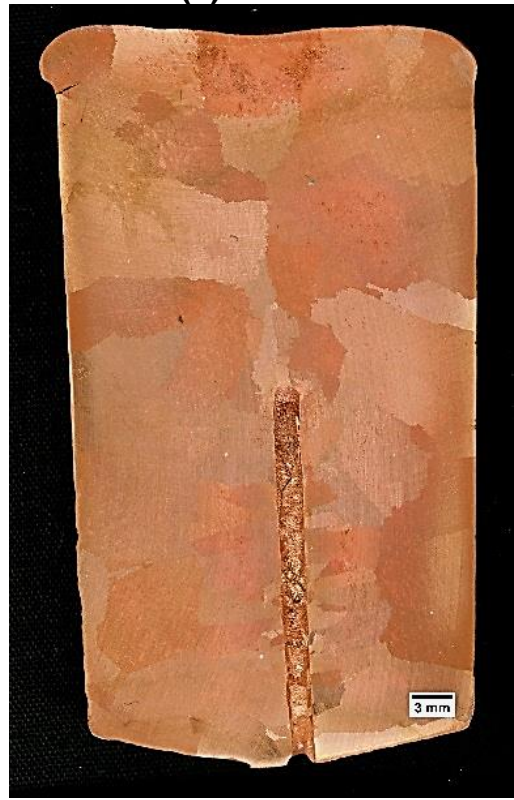

(c) Cu2Sn0ZrOP

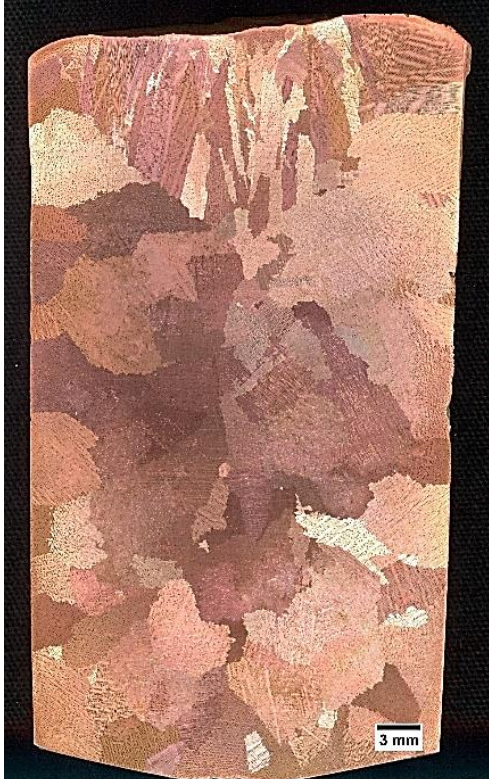

(b) Cu2Sn0,08Zr

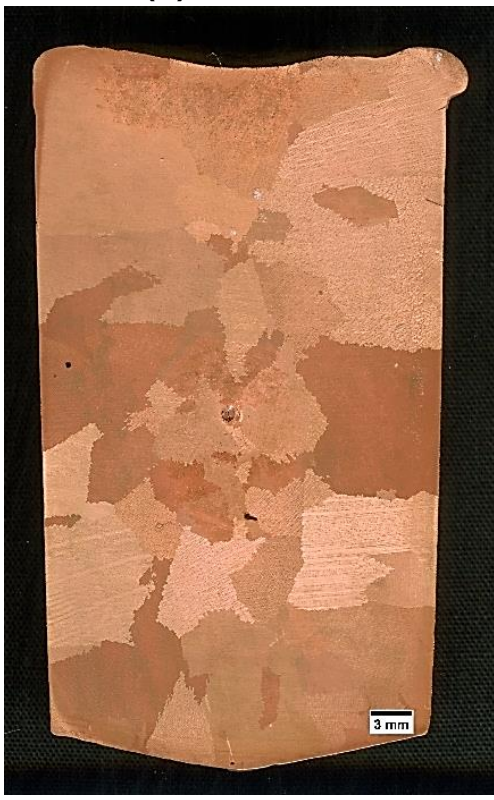

(d) Cu2Sn0,08ZroP

Figura 37- Macroestruturas da seção longitudinal dos lingotes dos experimentos da liga Cu2\%Sn com fonte de carbono: a) e b) com adição de P; b) e c) sem adição de P; ambos, sem e com adição de $0,08 \% Z$ r. Reagente: Etanol 500ml, $\mathrm{FeCl} 325 \mathrm{~g}, \mathrm{HCl} 15 \mathrm{ml}$.

Tabela 13- Tamanho de grão medido (TG) e desvio padrão de medida para os lingotes da liga Cu2\%Sn. 0 número de campos $(\mathrm{N})$ medidos também está indicado.

\begin{tabular}{lccc}
\hline Experimento & $(\% \mathbf{Z r})$ & TG $(\boldsymbol{m m})$ & $\mathbf{N}$ \\
\hline Cu2Sn0Zr & - & $3,84 \pm 0,61$ & 18 \\
\hline Cu2Sn0,08Zr & 0,08 & $2,66 \pm 0,54$ & 18 \\
\hline Cu2Sn0Zr-P & - & $4,97 \pm 0,75$ & 15 \\
\hline Cu2Sn0,08Zr-P & 0,08 & $4,70 \pm 1,33$ & 15 \\
\hline
\end{tabular}




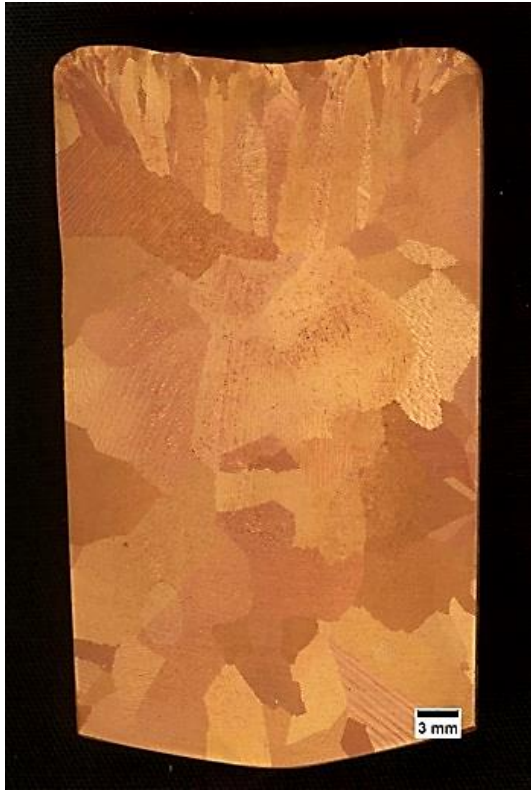

(a) Cu8Sn0Zr

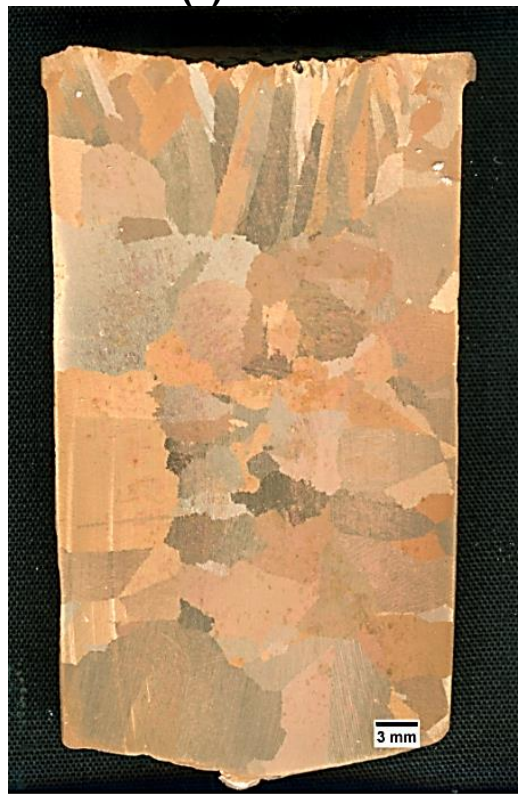

(c) Cu8Sn0ZroP

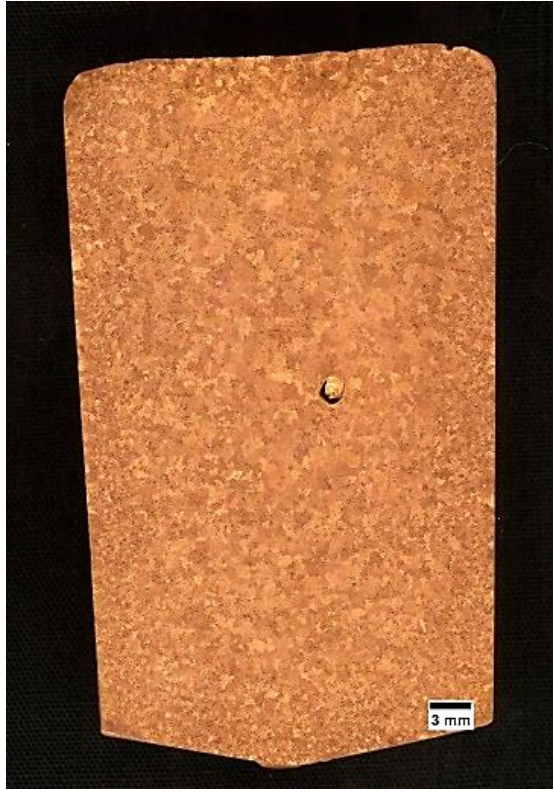

(b) Cu8Sn0,08Zr

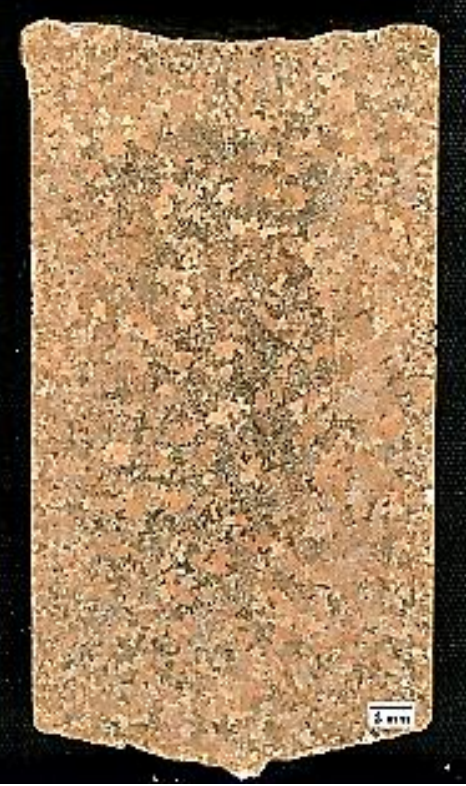

(d) Cu8Sn0,08Zr0P

Figura 38- Macroestruturas da seção longitudinal dos lingotes dos experimentos da liga Cu8\%Sn com fonte de carbono: a) e b) com adição de P; (b) e c) sem adição de P, degaseificado com Argônio (2 N1/min); Reagente: Etanol $500 \mathrm{ml}, \mathrm{FeCl} 325 \mathrm{~g}, \mathrm{HCl} 15 \mathrm{ml}$.

Tabela 14- Tamanho de grão medido (TG) e desvio padrão de medida para os lingotes da liga Cu8\%Sn. 0 número de campos $(\mathrm{N})$ medidos também está indicado.

\begin{tabular}{lccc}
\hline Experimento & $(\% \mathbf{Z r})$ & TG $(\boldsymbol{m m})$ & $\mathbf{N}$ \\
\hline Cu8Sn0Zr & - & $4,30 \pm 0,52$ & 20 \\
\hline Cu8Sn0,08Zr & 0,08 & $0,58 \pm 0,06$ & 20 \\
\hline Cu8Sn0Zr-P & - & $4,53 \pm 0,92$ & 20 \\
\hline Cu8Sn0,08Zr-P & 0,08 & $0,59 \pm 0,08$ & 20 \\
\hline
\end{tabular}




\subsubsection{Efeito geral das adições de $\mathrm{Zr}$ e $\mathrm{C}$ na macroestrutura de grãos}

Os efeitos combinados ou não das adições de $\mathrm{Zr} \mathrm{e} \mathrm{C} \mathrm{(cobertura} \mathrm{de} \mathrm{grafite} \mathrm{sobre}$ o banho líquido) são essenciais para o entendimento dos mecanismos de inoculação examinados no presente trabalho. De forma geral estes efeitos podem ser entendidos a partir das macroestruturas apresentadas na Figura 39. Na Figura 39a e Figura 39b o efeito do $\mathrm{Zr}$ pode ser observado sem a presença de fontes de carbono evidentes. Nestes dois ensaios (Cu8Sn0Zr0C e Cu8Sn0,08Zr0C), não existiu a cobertura de póde-grafita sobre o banho, o bastão para agitação foi de sílica e o cadinho de argilagrafita, em lugar do cadinho de grafita utilizado em todos os outros experimentos. Visualmente o efeito da adição de $\mathrm{Zr}$ no tamanho de grão médio não é claro, porém, um teste de hipótese com $1 \%$ de significância utilizando as medidas de tamanho de grão médio (Tabela 15) indica que a hipótese da igualdade dos tamanhos de grão deve ser recusada, ou seja, que ocorreu uma diminuição.

Quando as fontes de C estão presentes, principalmente com a adição da cobertura de grafita ao banho, observa-se uma redução significativa (90\%) no tamanho de grão médio após a adição de $\mathrm{Zr}$ (Figura 39c,d). O tamanho de grão foi reduzido de $4,3 \mathrm{~mm}$ para $0,58 \mathrm{~mm}$. Por outro lado, o efeito da adição de $C$ pode ser examinado comparando-se a Figura 39a com a Figura 39c e a Figura 39b com a Figura 39d. Na presença de $Z r$, houve um efeito notável de diminuição de tamanho de grão com a adição de C (Figura 39b,d), porém, sem Zr (Figura 39a,c) a adição de C indica visualmente um leve aumento de tamanho de grão, confirmado com o teste de hipótese para $1 \%$ de significância. Este aparente aumento de tamanho de grão com a adição de $C$ pode ser algum tipo de erro experimental. A partir destes resultados podese inferir que as ligas Cu8\%Sn com adições de $\mathrm{Zr}$ com fontes de carbono apresentam um alto refinamento ao passo que o zircônio aparentemente isolado não tem efeito de refinamento. Os mecanismos causadores destes efeitos serão examinados em maiores detalhes a seguir. 


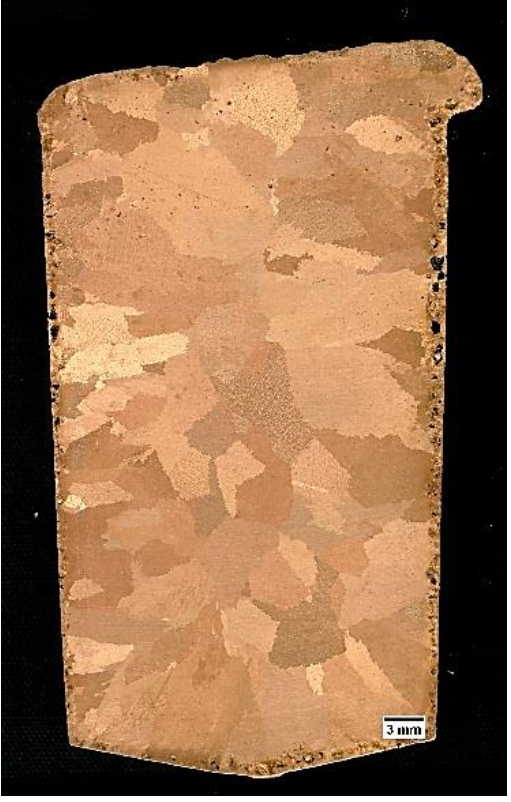

(a) Cu8Sn0ZroC

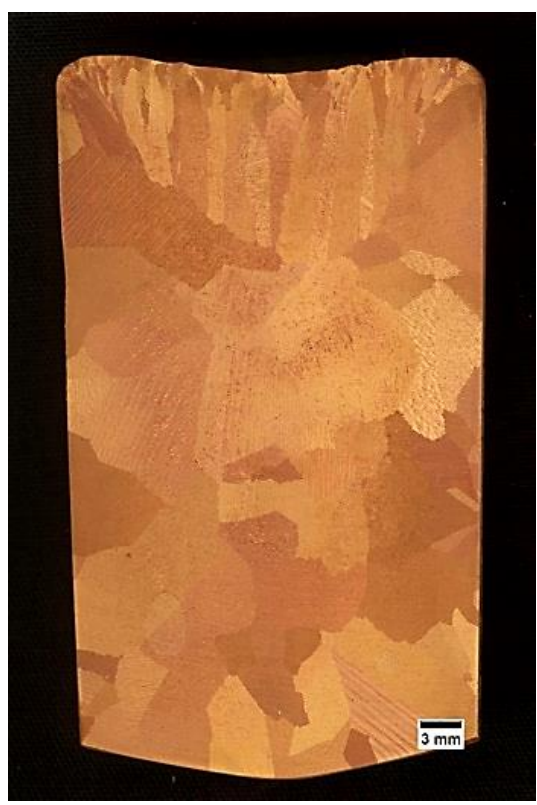

(c) Cu8Sn0Zr

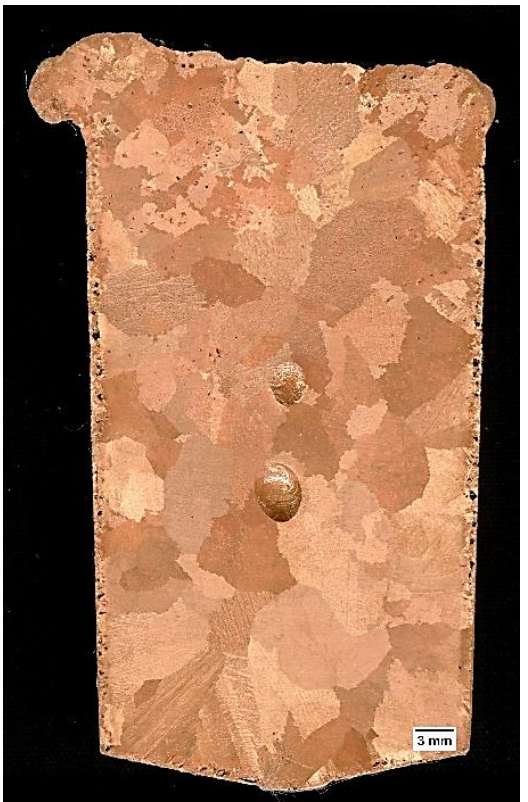

(b) Cu8Sn0,08ZroC

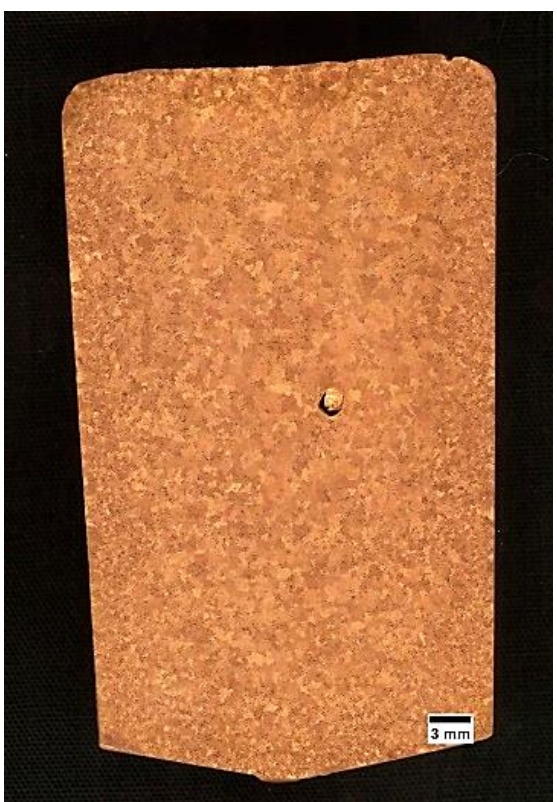

(d) Cu8Sn0,08Zr

Figura 39- Macroestruturas da seção longitudinal dos lingotes dos experimentos da liga Cu8\%Sn: (a) e (b) sem fontes de carbono; (c) e (d) com fonte de carbono. Reagente: Etanol 500ml, FeCl3 25g, $\mathrm{HCl} 15 \mathrm{ml}$.

Tabela 15- Tamanho de grão medido (TG) e desvio padrão de medida para os lingotes da liga Cu8\%Sn. 0 número de campos $(\mathrm{N})$ medidos também está indicado.

\begin{tabular}{lccc}
\hline Experimento & $(\% \mathbf{Z r})$ & TG $(\mathbf{m m})$ & $\mathbf{N}$ \\
\hline Cu8Sn0Zr0C & - & $3,20 \pm 0,53$ & 18 \\
\hline Cu8Sn0,08Zr0C & 0,08 & $2,7 \pm 0,40$ & 18 \\
\hline Cu8Sn0Zr & - & $4,30 \pm 0,52$ & 20 \\
\hline Cu8Sn0,08Zr & 0,08 & $0,58 \pm 0,06$ & 20 \\
\hline
\end{tabular}


As microestruturas dos lingotes apresentados na Figura 39 foram analisadas no microscópio eletrônico de varredura. Nos experimentos sem fonte de $\mathrm{C}$, com ou sem a adição de $\mathrm{Zr}$ (Cu8Sn0Zr0C e Cu8Sn0,08Zr0C), os únicos precipitados encontrados têm formato facetado e são ricos em estanho e oxigênio (Figura 40), como observado no espectro de EDS, indicando a presença de óxidos de Sn. A isenção da cobertura de $C$ possivelmente causou um aumento do oxigênio dissolvido no banho a um teor suficientemente elevado para oxidar parte do Sn presente.

A adição da cobertura de $C$ à liga sem adição de $Z$ r (Cu8Sn0Zr0C) eliminou estes óxidos e foram observados precipitados esporádicos com $\mathrm{Si}$ em regiões isoladas da amostra. Quando o Zr foi adicionado (Cu8Sn0,08Zr), no entanto, observaram-se precipitados facetados ricos em zircônio, cobre e carbono (Figura 41), como indicado pelo espectro de EDS. Estas evidências sugerem que as adições combinadas de $\mathrm{Zr}$ e C causaram a formação de algum tipo de precipitado que funcionou como centro para nucleação heterogênea. Como adição de $C$ foi necessária à formação destes precipitados, já que eles não surgiram apenas com a adição de $Z r$, uma possibilidade é que eles sejam constituídos de $\mathrm{ZrC}$. A presença de Cu no espectro de EDS pode ser simplesmente um efeito a matriz, já que estes precipitados têm tamanhos na ordem de $2 \mu \mathrm{m}$. Estas hipóteses serão analisadas em maior detalhe no item 5.4.

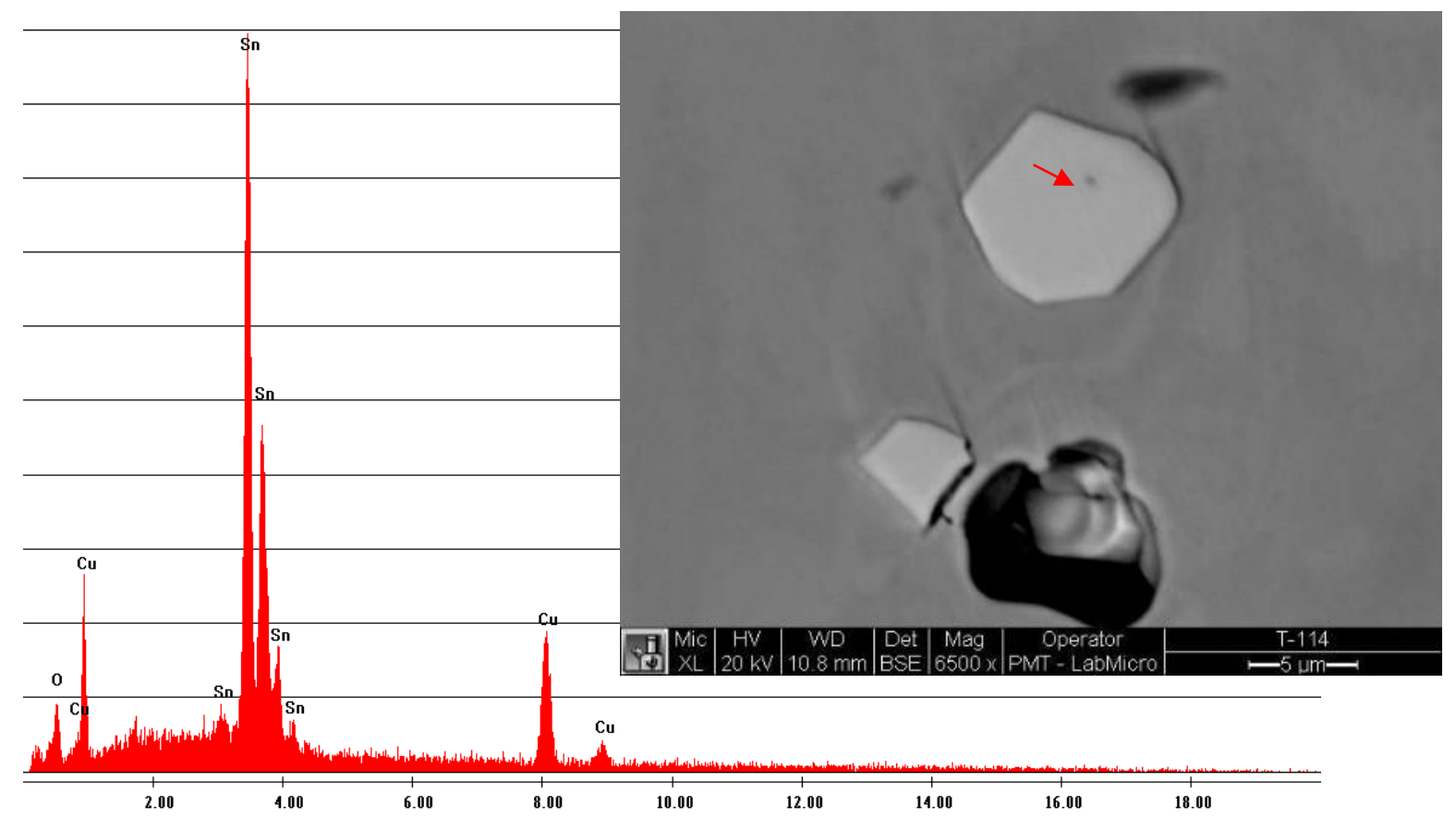

Figura 40- Fotomicrografia obtida por MEV com elétrons retroespalhados e espectros de energia dispersiva de raios-X (EDS) na posição assinalada com seta dos precipitados encontrados na microestrutura dos lingotes dos experimentos Cu8Sn0Zr0C e Cu8Sn0,08ZroC. Polimento até 0,05 $\mu \mathrm{m}$ com sílica, sem ataque químico. 


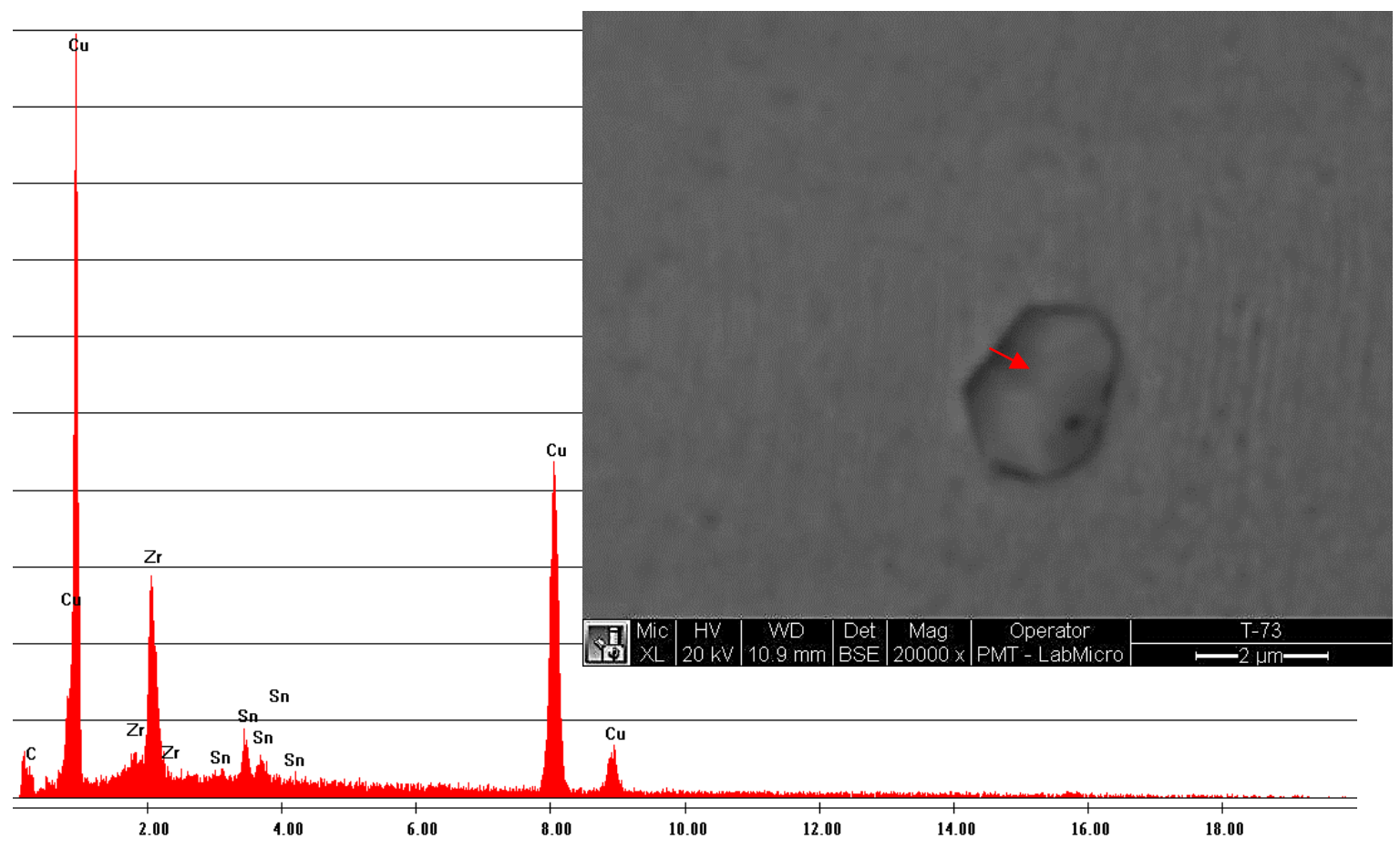

Figura 41- Fotomicrografia obtida por MEV com elétrons retroespalhados e espectros de energia dispersiva de raios-X (EDS) na posição assinalada com seta, dos precipitados encontrados na microestrutura dos lingotes do experimento Cu8Sn0,08Zr. Polimento até $0,05 \mu \mathrm{m}$ com sílica, sem ataque químico.

Em uma análise termodinâmica simples da formação de precipitados envolvendo $\mathrm{Zr}$, foram calculados os valores de energia livre em estado padrão de formação dos compostos $\mathrm{ZrC}, \mathrm{ZrN}$ e $\mathrm{ZrO}_{2}$ num intervalo de temperatura entre 25 e 1850 ํ․ Na Tabela 16 estão apresentados os dados termodinâmicos e as reações de formação consideradas. Na Figura 42 pode-se observar que os três compostos apresentam retas ascendentes, ou seja, que a energia livre de formação se torna mais positiva com o aumento da temperatura, diminuindo a estabilidade destes compostos. $\mathrm{Na}$ temperatura de preparação das ligas $\left(1250^{\circ} \mathrm{C}\right)$ o $\mathrm{ZrO}_{2}$ é mais estável que o $\mathrm{ZrN}$ e que o $\mathrm{ZrC}$, indicando que, na ausência de um elemento desoxidante como o $\mathrm{P}$, parte do $\mathrm{Zr}$ seria consumido na formação de $\mathrm{ZrO}_{2}$, reduzindo a quantidade de $\mathrm{ZrC}$ e provavelmente aumentando o tamanho de grão final. Esta análise, entretanto, considera que a atividade de Zr, C, N e O são unitárias. Quando estes elementos se dissolvem no banho, suas atividades decrescem, podendo alterar a estabilidade relativa de cada composto. 
Tabela 16- Valores das variações de entalpia padrão e de entropia padrão no intervalo de temperatura para as reações (EVANS, 1982).

\begin{tabular}{|c|c|c|c|}
\hline Reação & $\Delta \mathbf{H}^{\circ}\left(\mathrm{kcal} \mathrm{mol}^{-1}\right)$ & $\Delta \mathbf{S}^{\circ}\left(\mathrm{kcal}_{\mathrm{mol}} \mathrm{mol}^{-1}\right)$ & Intervalo de temperatura $\left({ }^{\circ} \mathrm{C}\right)$ \\
\hline $\mathrm{Zr}(\mathrm{s})+\mathrm{C}(\mathrm{s}) \rightarrow \mathrm{ZrC}(\mathrm{s})$ & -47 & $-0,0022$ & $25-1850$ \\
\hline $\mathrm{Zr}(\mathrm{s})+\frac{1}{2} \mathrm{~N}_{2}(\mathrm{~g}) \rightarrow \mathrm{ZrN}(\mathrm{s})$ & $-86,9$ & $-0,022$ & $25-1850$ \\
\hline $\mathrm{Zr}(\mathrm{s})+\mathrm{O}_{2}(\mathrm{~g}) \rightarrow \mathrm{ZrO}_{2}(\mathrm{~s})$ & -261 & $-0,0439$ & $25-1850$ \\
\hline
\end{tabular}

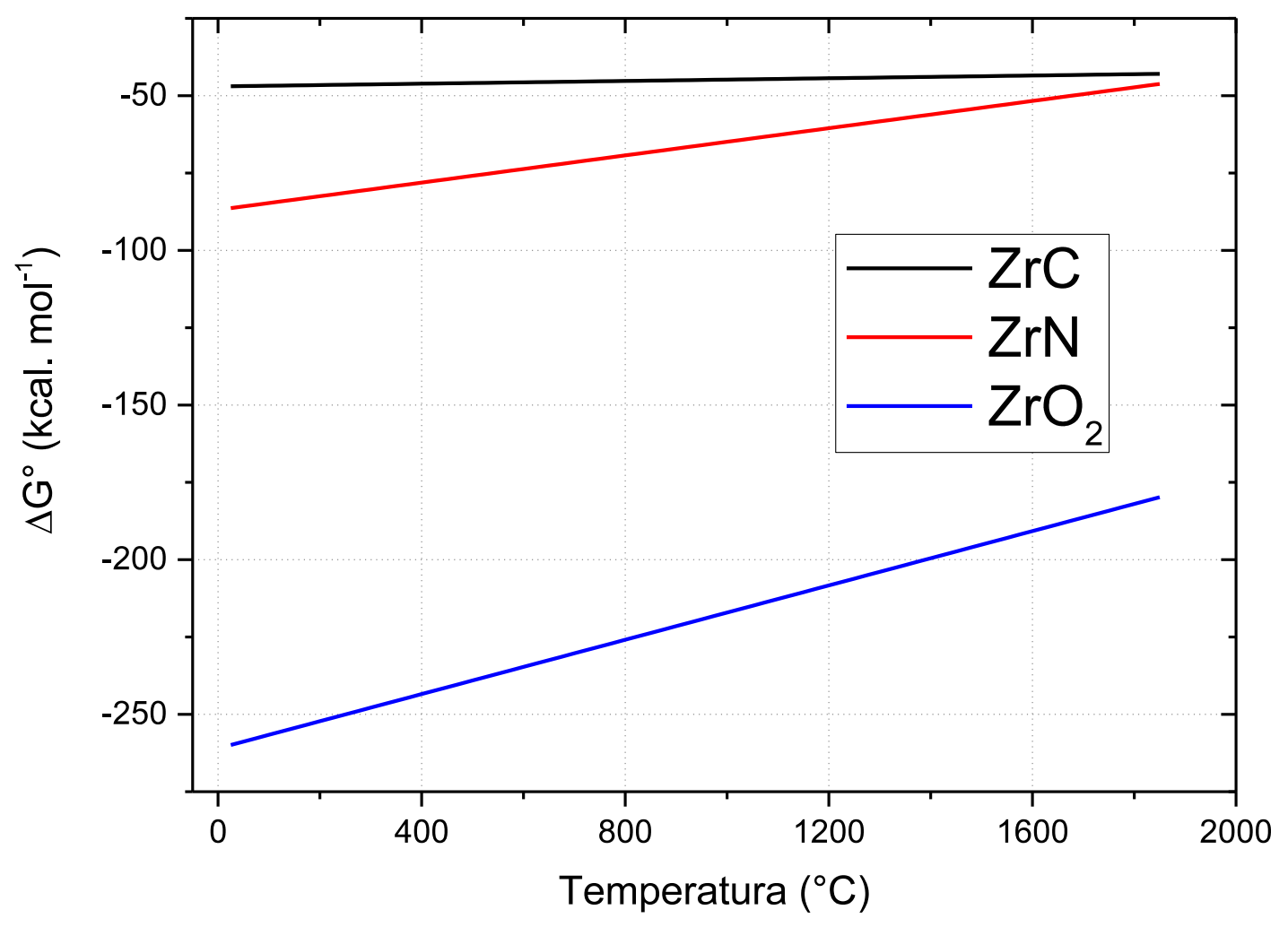

Figura 42- Variação da energia livre padrão $\left(\Delta G^{\circ}=\Delta \overline{\boldsymbol{H}}^{\circ}+T \Delta \overline{\boldsymbol{S}}^{\circ}\right)$ em função da temperatura, calculada para a formação dos compostos $\mathrm{ZrC}, \mathrm{ZrN}$ e $\mathrm{ZrO}_{2}$.

Apesar de não terem sido observados precipitados após a adição de $\mathrm{Zr}$ sem fontes evidentes de $\mathrm{C}$, concluiu-se anteriormente que houve uma leve redução no tamanho de grão (Figura 39a,b). Este efeito poderia ser explicado pela restrição ao crescimento oferecido pelo $\mathrm{Zr}$ dissolvido no banho líquido. Os fatores $\mathrm{P}$ e $\mathrm{Q}$ que indicam o nível de restrição valem 62,1 e 1,04 respectivamente, para um teor de $0,08 \% Z r$. Estes valores são suficientemente elevados para causar um efeito de restrição (JOHNSSON; BACKERUD, 1996). 


\subsubsection{Efeito das adições de Zr na macroestrutura de grãos do Cu-8\%Sn}

Devido ao grande potencial de inoculação observado nas adições de Zr quando na presença de uma fonte de carbono e de teores mais elevados de Sn, o efeito crescente destas adições à liga Cu-8\%Sn foi examinado neste item. A Figura 43 apresenta as macroestruturas brutas de solidificação das seções longitudinais dos lingotes obtidos com adições crescentes de $\mathrm{Zr}$ até o valor nominal de 0,4\%. Nota-se uma evidente variação de estrutural dos grãos, iniciando com uma estrutura de grãos grosseiros (Figura 43a) quando não há Zr, apresentando um tamanho de grão superior a $4 \mathrm{~mm}$ (Cu8Sn0Zr). As adições crescentes de $\mathrm{Zr}$ tornam a estrutura de grãos equiaxial e cada vez mais fina, atingindo um tamanho médio de grão mínimo de 180 $\mu \mathrm{m}$ para um teor nominal de $0,24 \% \mathrm{Zr}$, como mostram as medidas de tamanho de grão apresentadas na Tabela 17 e Figura 44. Esse valor mínimo é seguido por um leve aumento do tamanho de grão para maiores teores de $\mathrm{Zr}$, o que pode estar associado a algum mecanismo de perda do efeito inoculante, comumente chamado "fading" (1976) (JONES; PEARSON, 1976). Este mecanismo pode incluir o coalescimento e a decantação/flotação das partículas que funcionam como centros de nucleação no banho líquido, o que atenua o efeito inoculante propiciando numa estrutura não refinada.

É importante ressaltar que na amostra com adições de $0,4 \% Z r$, ocorreu a precipitação de uma fase intermetálica de composição 10,4\%(at.)Zr e 89,6\%(at.)Cu, identificada por microanálise EDS, como pode ser visto na Figura 45. Esta fase, que aparece associada à fase Cua em uma morfologia de eutético, pode ser o intermetálico $\mathrm{Cu}_{9} \mathrm{Zr}_{2}$ indicada pelo diagrama de fases apresentado na Figura 69. Essa evidência parece indicar que para teores superiores a 0,4\%Zr, o C disponível no sistema não é suficiente para reduzir os teores de $\mathrm{Zr}$ dissolvido no banho a ponto de evitar a reação eutética indicada no diagrama de fases. Desta forma, o teor nominal de $0,4 \% Z r$, que resultou em um teor medido de $\sim 0,2 \% Z r$ parece ser um limite máximo para se refinar as ligas de $\mathrm{Cu}$ com adições de Zr. Em termos tecnológicos, a Figura 45 indica que um ponto ótimo para o teor de $\mathrm{Zr}$ seria o valor nominal de 0,16\% $\mathrm{Zr}$, representando um teor medido de 0,04\%Zr. Maiores adições de Zr não resultam em um decréscimo significativo do tamanho médio de grão. 
Tabela 17 - Tamanho de grão medido (TG) e desvio padrão de medida para os lingotes obtidos na série com adição de $\mathrm{Zr}$, $\mathrm{P}$ e carbono. $\mathrm{O}$ número de campos (N) medidos também está indicado.

\begin{tabular}{lccc}
\hline Experimento & $(\% \mathbf{Z r})$ & TG $(\boldsymbol{m m})$ & $\mathbf{N}$ \\
\hline Cu8Sn0Zr & 0 & $4,30 \pm 0,52$ & 20 \\
\hline Cu8Sn0,04Zr & 0,04 & $2,10 \pm 0,17$ & 20 \\
\hline Cu8Sn0,08Zr & 0,08 & $0,58 \pm 0,06$ & 20 \\
\hline Cu8Sn0,12Zr & 0,12 & $0,48 \pm 0,04$ & 20 \\
\hline Cu8Sn0,16Zr & 0,16 & $0,21 \pm 0,03$ & 15 \\
\hline Cu8Sn0,24Zr & 0,24 & $0,18 \pm 0,01$ & 16 \\
\hline Cu8Sn0,32Zr & 0,32 & $0,36 \pm 0,02$ & 20 \\
\hline Cu8Sn0,40Zr & 0,40 & $0,42 \pm 0,02$ & 20 \\
\hline
\end{tabular}




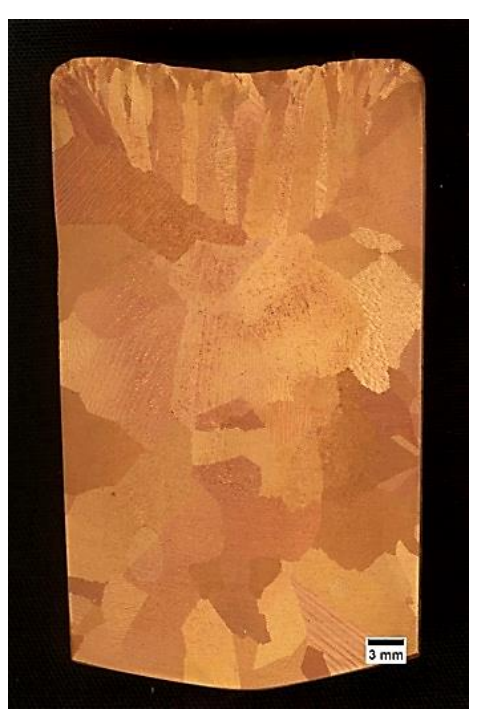

(a)

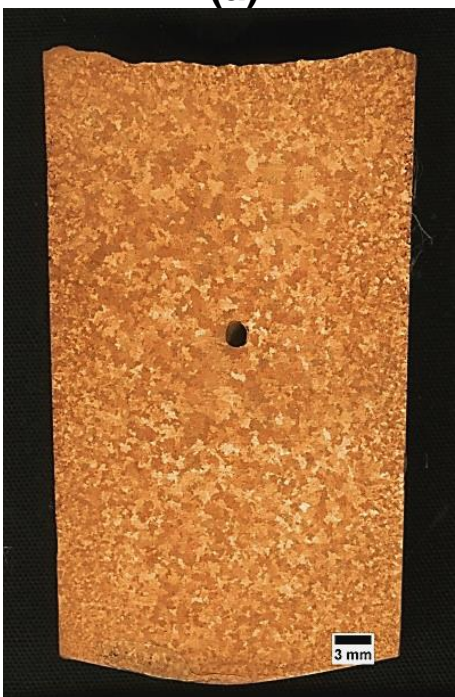

(e)

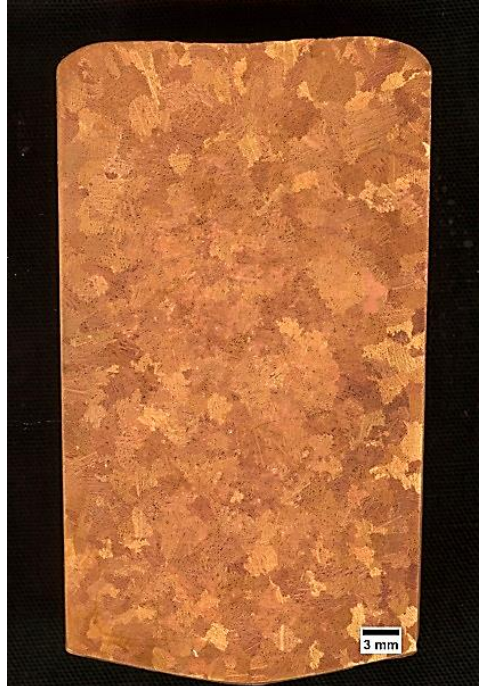

(b)

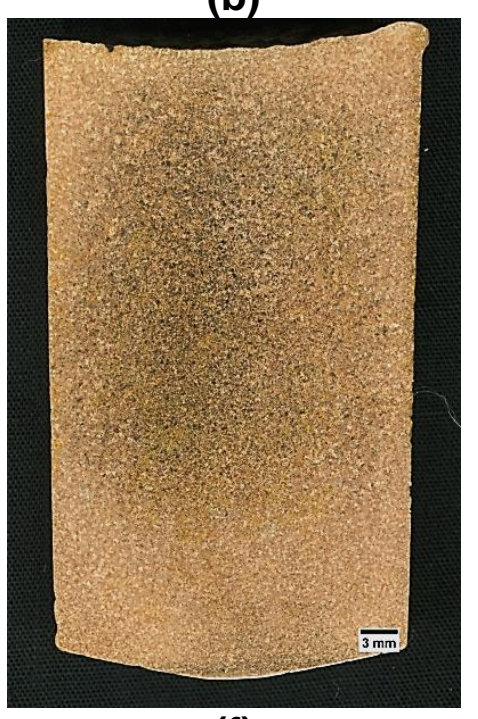

(f)

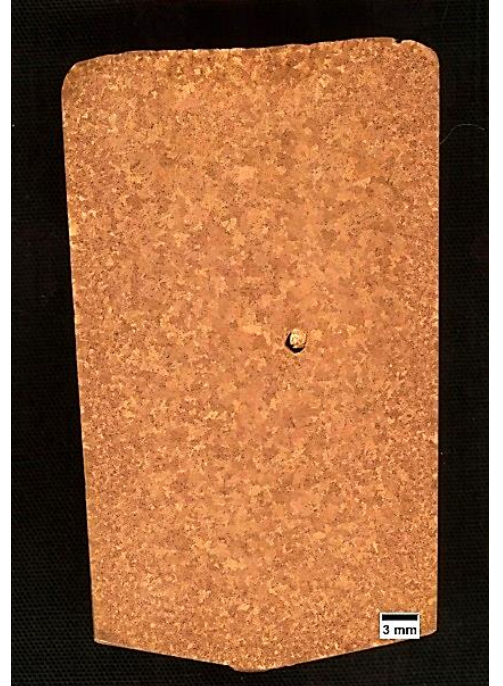

(c)

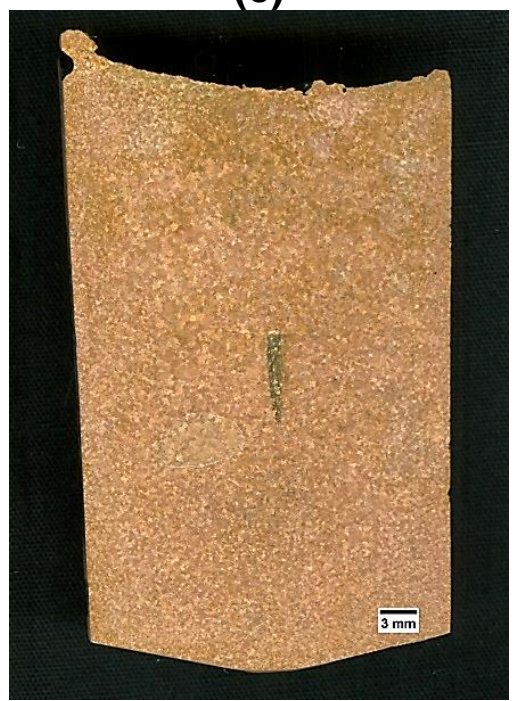

(g)

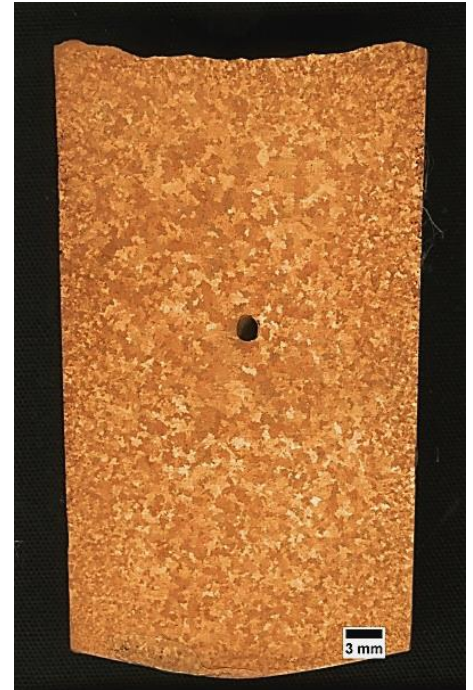

(d)

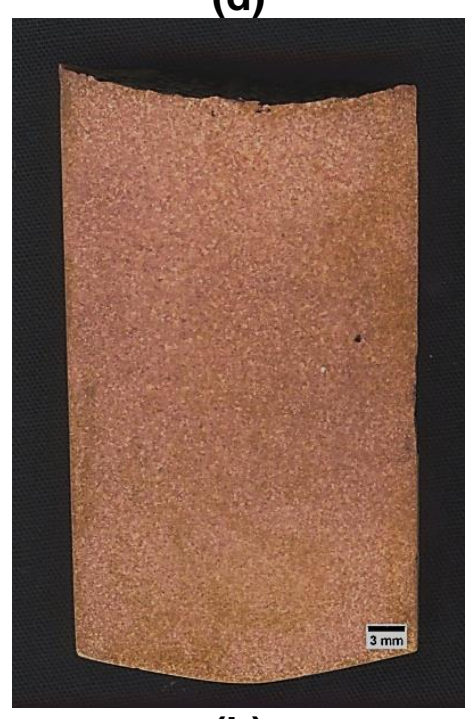

(h)

Figura 43- Macroestruturas da seção longitudinal da série dos experimentos com adição de fósforo, zircônio e carbono: a) Cu8Sn0Zr, (b) Cu8Sn0,04Zr, (c) Cu8Sn0,08Zr, (d) Cu8Sn0,12Zr, (e) Cu8Sn0,16Zr, (f) Cu8Sn0,24Zr, (g) Cu8Sn0,32Zr e (h) Cu8Sn0,4Zr. Reagente: Etanol 500ml, FeCl3 25g, HCl 15ml. 


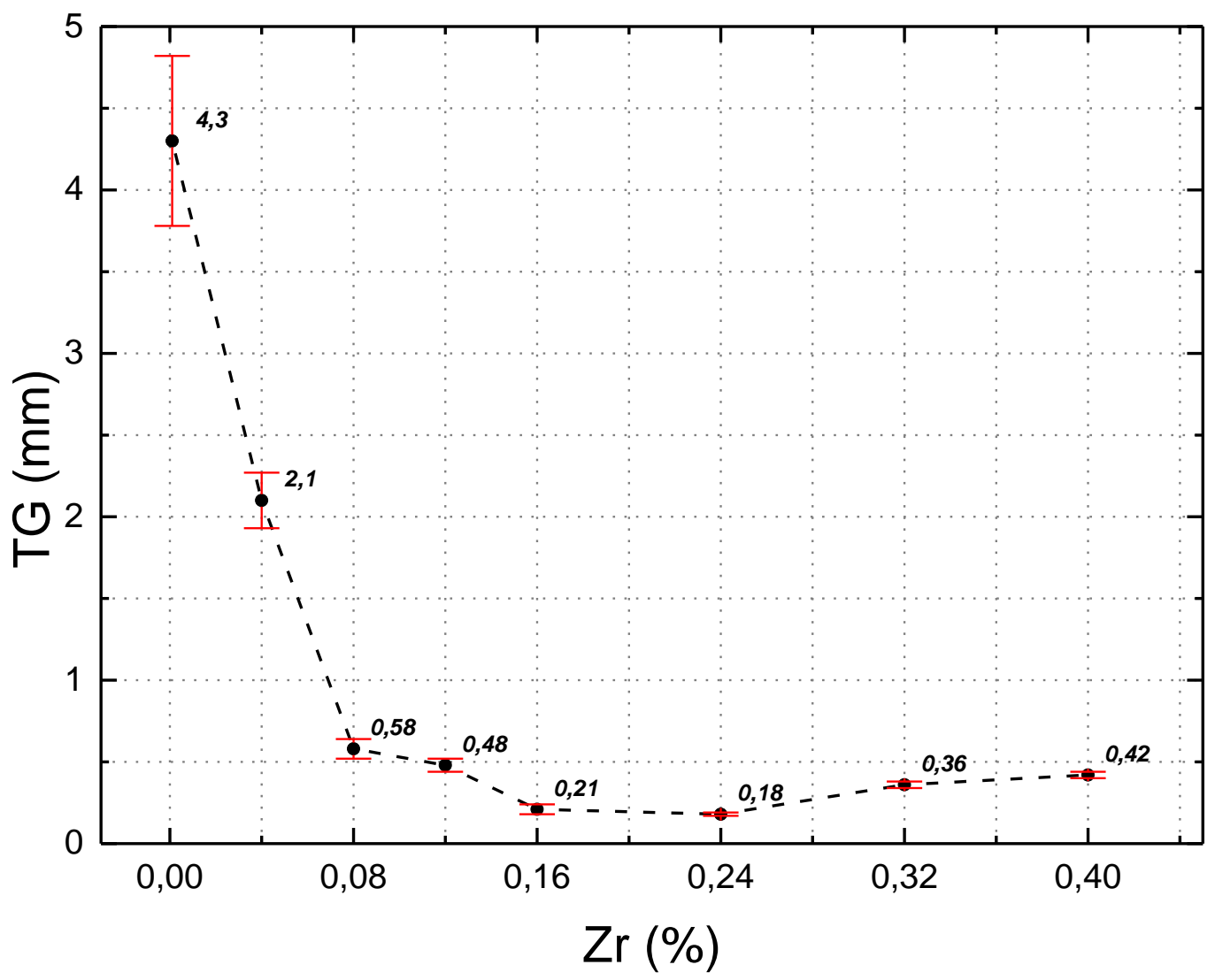

Figura 44- Curva de tamanho de grão médio com diferentes adições nominais de Zr para a série da liga Cu-8\%Sn-0,025\%P, com fonte de carbono.
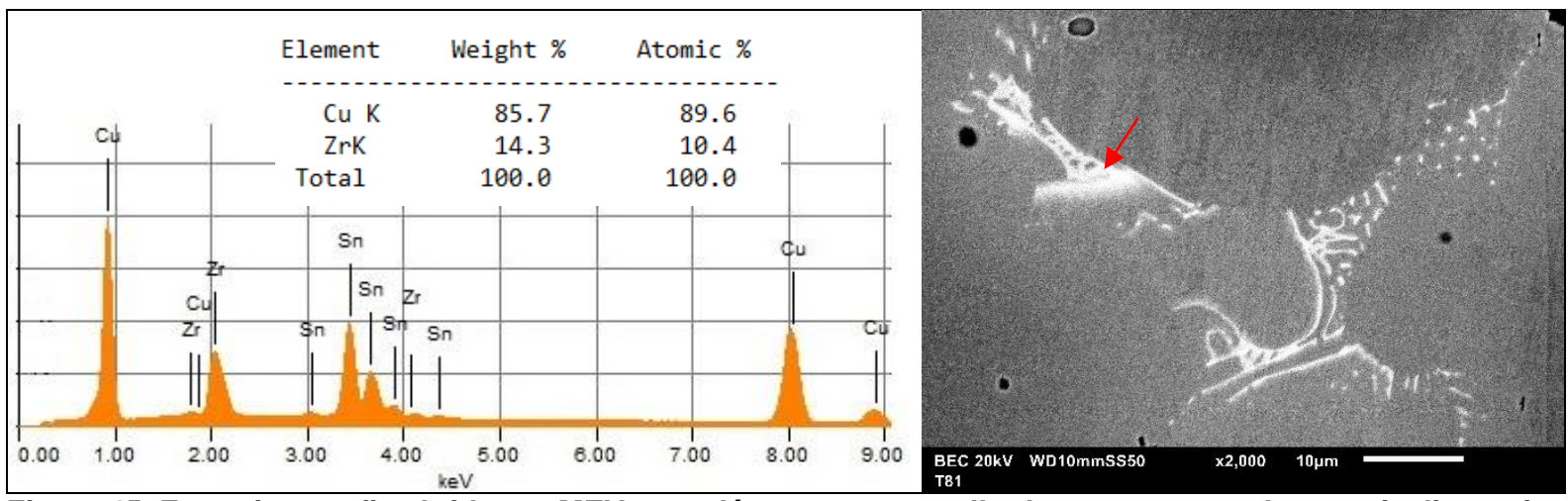

Figura 45- Fotomicrografia obtida por MEV com elétrons retroespalhados e espectros de energia dispersiva de raios-X (EDS) na posição assinalada com seta, do experimento Cu8Sn0,4Zr. Polimento até 0,05 $\mu \mathrm{m}$ com sílica, sem ataque químico.

\subsubsection{Efeito das adições de Sn e Zr macroestrutura de grãos}

No item 5.2.1 foi mostrado que o Sn tem um papel importante no refino de grão a partir de adições de Zr. Notou-se que o efeito do Zr era relativamente pequeno sem a presença de Sn ou om $2 \%$ Sn, mas era significativo para $8 \%$ Sn. Neste item, o efeito 
de teores crescentes de Sn, mantendo-se o teor nominal de Zr fixo em 0,08\%, será examinado em mais detalhes.

A Figura 46 apresenta as macroestruturas brutas de solidificação para ensaios realizados com adições crescentes de Sn até o valor nominal de 12\%Sn. Duas séries de experimentos foram realizadas, uma sem (coluna superior da Figura 46) e outra com (coluna inferior da Figura 46) a adição de 0,08\%Zr. Um exame visual mostra claramente que para teores de $\mathrm{Sn} \geq 4 \%$ as adições de $\mathrm{Zr}$ causaram um decréscimo significativo no tamanho médio de grão. Em menores teores de Sn, a estrutura apresenta-se heterogênea a não se observa uma alteração significativa após a adição de Zr. Estas observações podem ser confirmadas quantitativamente a partir da Figura 47a. Como não foram observados precipitados ricos em Sn na estrutura, o efeito de potencialização da inoculação pelo Zr causado pelo Sn para teores $\geq 4 \%$ pode ser explicado pela restrição ao crescimento de grão resultante da presença deste elemento em solução. No teor de 4\%, os fatores P e Q são 40 e 21, respectivamente, o que indica um efeito de restrição significativo. Pode-se dizer que a adição de Zr tanto ao $\mathrm{Cu}$ eletrolítico como ao $\mathrm{Cu}-2 \% \mathrm{Sn}$ não diminuiu o tamanho de grão significativamente pela ausência de restrição de crescimento, impossibilitando a nucleação sobre as partículas intermetálicas contendo Zr, provavelmente ZrC (item 5.4), antes destas serem consumidas pelos grãos em crescimento.

Tabela 18- Tamanho de grão medido (TG) e desvio padrão de medida para os lingotes obtidos na série variando o teor de Sn e Zr. O número de campos (N) medidos também está indicado.

\begin{tabular}{lcccc}
\hline Experimento & (\% Sn) & (\% Zr) & TG $(\mathbf{m m})$ & $\mathbf{N}$ \\
\hline Cu0Sn0Zr & - & - & $1,34 \pm 0,09$ & 20 \\
\hline Cu0Sn0,08Zr & - & 0,08 & $1,24 \pm 0,13$ & 20 \\
\hline Cu2Sn0Zr & 2 & - & $3,84 \pm 0,61$ & 18 \\
\hline Cu2Sn0,08Zr & 2 & 0,08 & $2,66 \pm 0,54$ & 18 \\
\hline Cu4Sn0Zr & 4 & - & $5,40 \pm 0,57$ & 15 \\
\hline Cu4Sn0,08Zr & 4 & 0,08 & $2,80 \pm 0,30$ & 15 \\
\hline Cu8Sn0Zr & 8 & - & $4,30 \pm 0,52$ & 20 \\
\hline Cu8Sn0,08Zr & 8 & 0,08 & $0,58 \pm 0,06$ & 20 \\
\hline Cu12Sn0Zr & 12 & - & $3,04 \pm 0,27$ & 20 \\
\hline Cu12Sn0,08Zr & 12 & 0,08 & $0,25 \pm 0,01$ & 20 \\
\hline
\end{tabular}


A potencialização do efeito inoculante das adições de Zr causada pelo Sn pode ser visto mais claramente quando se examina a diminuição de tamanho de grão médio ( $\Delta T G$ ) causada pela a adição de $0,08 \% Z r$ em teores crescentes de Sn (Figura 48a). Nota-se que esta variação se torna significativa quando \%Sn $\geq 4$. Na Figura 48b, está mostrado o aumento da densidade de número de grãos na estrutura $(\Delta n)$, também causado pela adição de $0,08 \% Z r$, indicando que este aumento se torna significativo para teores de $\mathrm{Sn}>4 \%$. Pode-se finalmente concluir que a adição nominal de $0,08 \% \mathrm{Zr}$ na presença de fontes de $\mathrm{C}$ e na taxa de resfriamento do sistema de solidificação utilizado somente causa um refino de grão significativo quando o teor de Sn está acima de $4 \%$.

Nos parágrafos anteriores concluiu-se que um aumento do teor de Sn acima de $4 \%$ causa uma potencialização do efeito inoculante das adições de Zr. Esta conclusão explica o decréscimo de tamanho de grão médio observado na Figura 47a, para Sn $\geq 4 \%$. Este mesmo tipo de decréscimo pode ser observado na curva referente aos experimentos sem adição de Zr, também apresentada na Figura 47a. Uma explicação análoga pode ser aplicada, ou seja, o Sn causa restrição ao crescimento para teores maiores de $4 \%$ e possibilita a nucleação heterogênea sobre partículas de impurezas nativas do banho. 


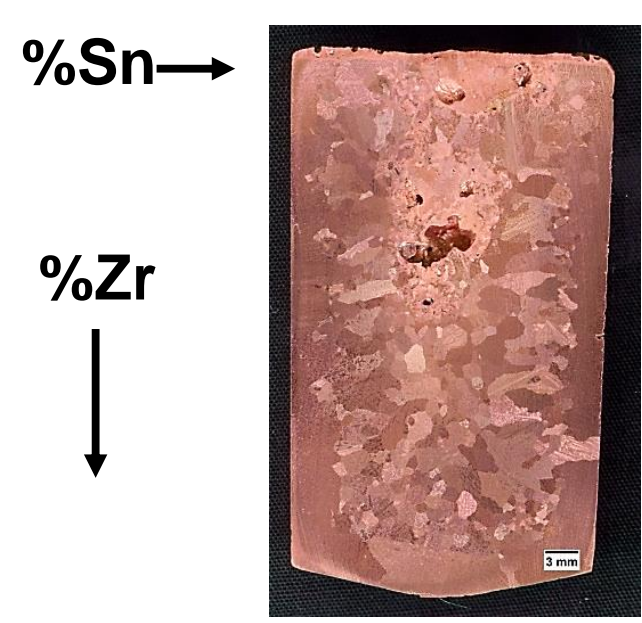

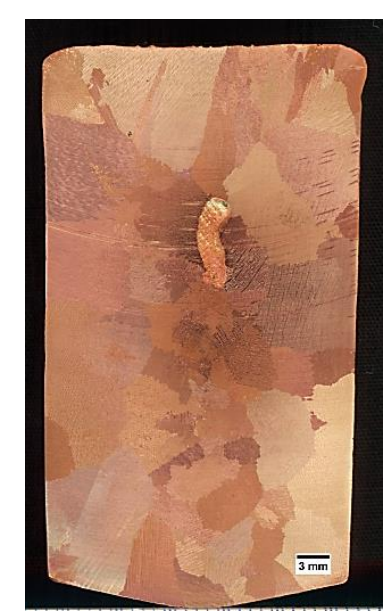

(c)

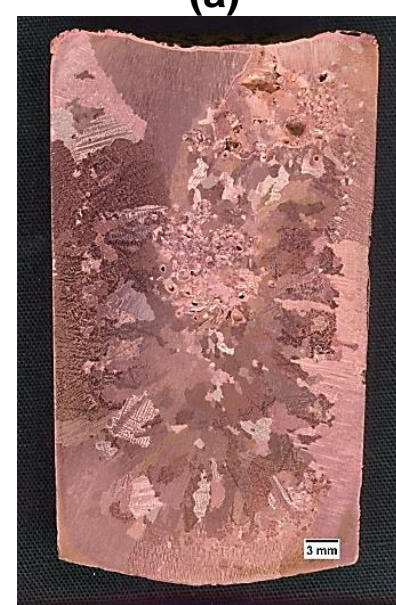

(b)

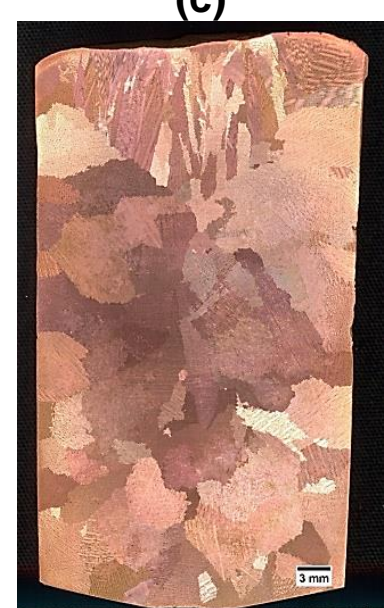

(d)

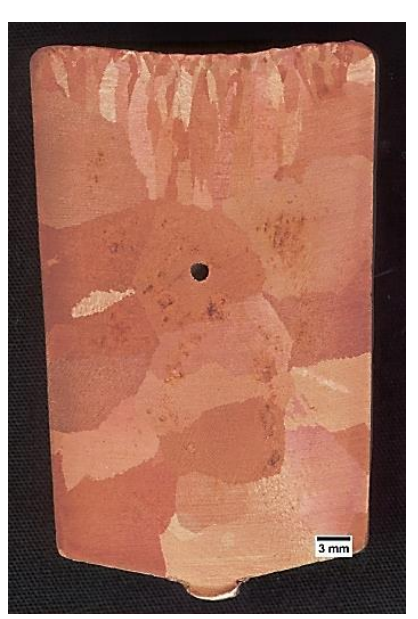

(e)

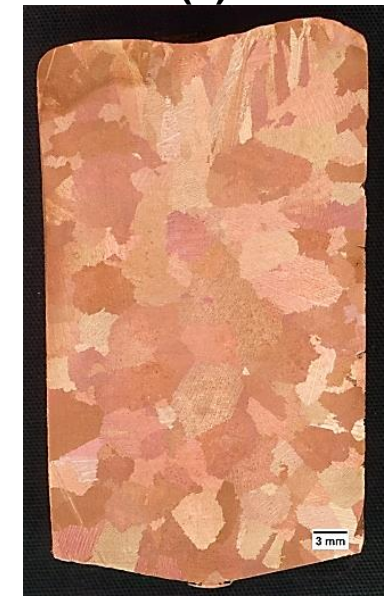

(f)

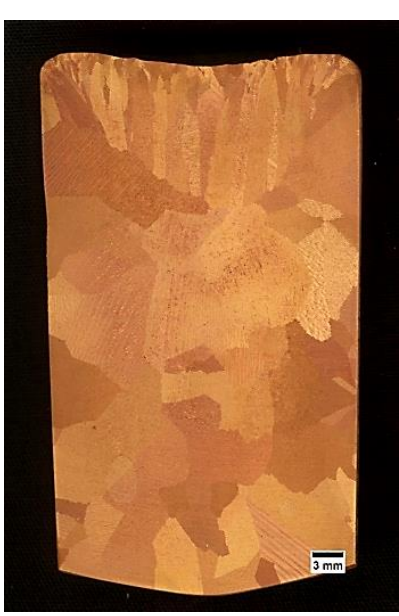

(g)

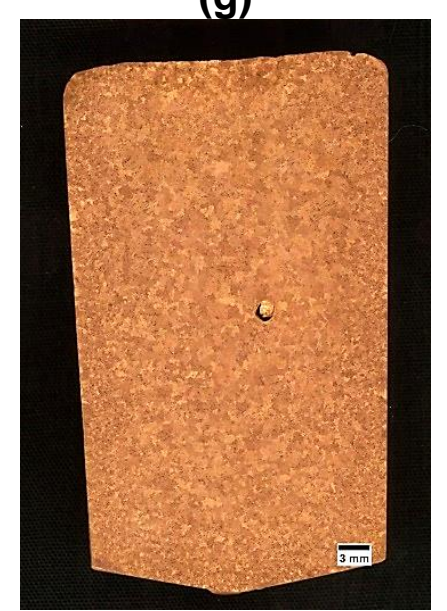

(h)

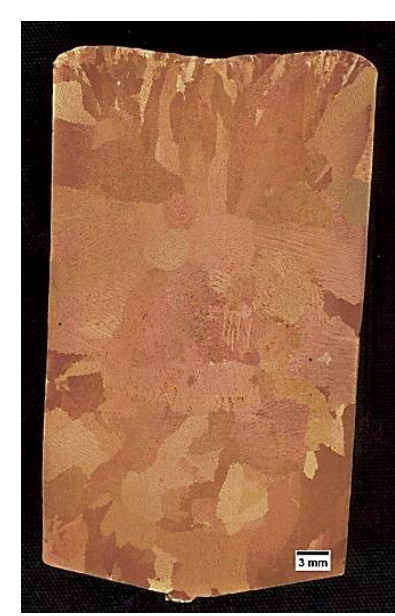

(i)

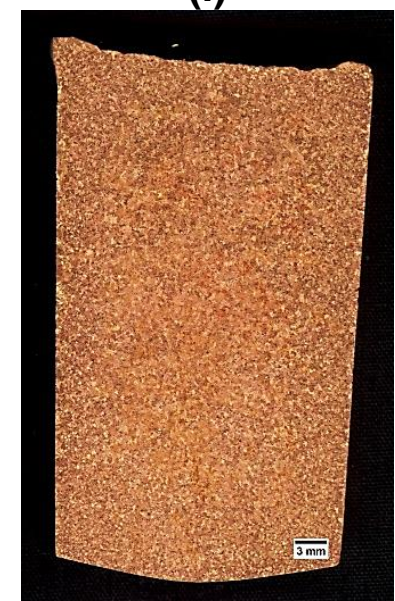

(j)

Figura 46- Macroestruturas da seção longitudinal das amostras dos experimentos da série variando o teor de Sn e Zr: a) Cu0Sn0Zr, (b) Cu0Sn0,08Zr, (c) Cu2Sn0Zr, (d) Cu2Sn0,08Zr, (e) Cu4Sn0Zr, (f) Cu4Sn0,08Zr, (g) Cu8Sn0Zr, (h) Cu8Sn0,08Zr, (i) Cu12Sn0Zr e (j) Cu12Sn0,08Zr. Reagente: Etanol 500ml, FeCl $25 \mathrm{~g}, \mathrm{HCl}$ $15 \mathrm{ml}$ 

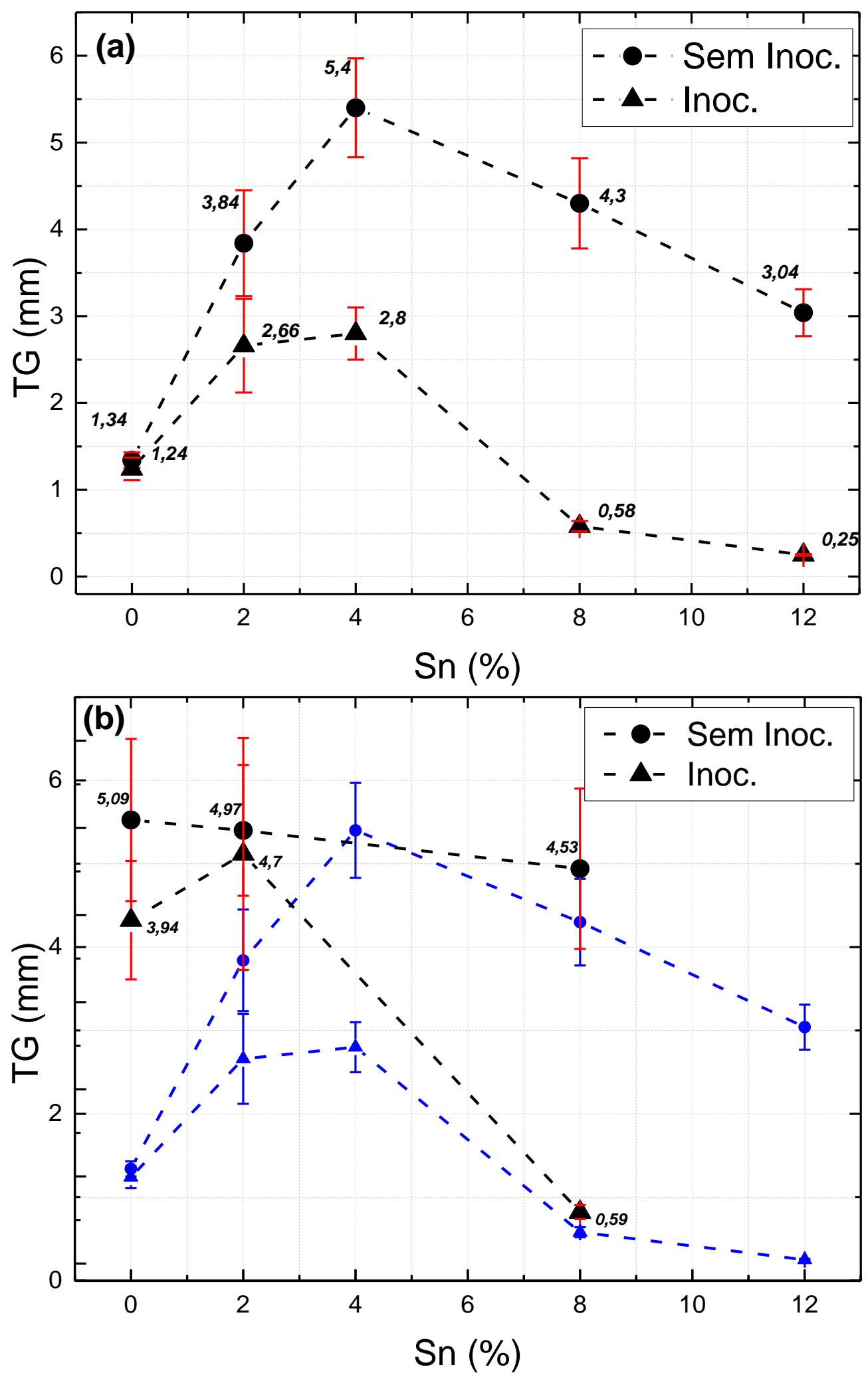

Figura 47 - Efeito do tamanho de grão médio com diferentes adições de Sn com e sem adição de Zr: (a) com adição de $\mathbf{P}$ e (b) Superposição da curva (a) com $\mathbf{P}$ (azul) e a curva sem adição de $\mathbf{P}$ (preta). 

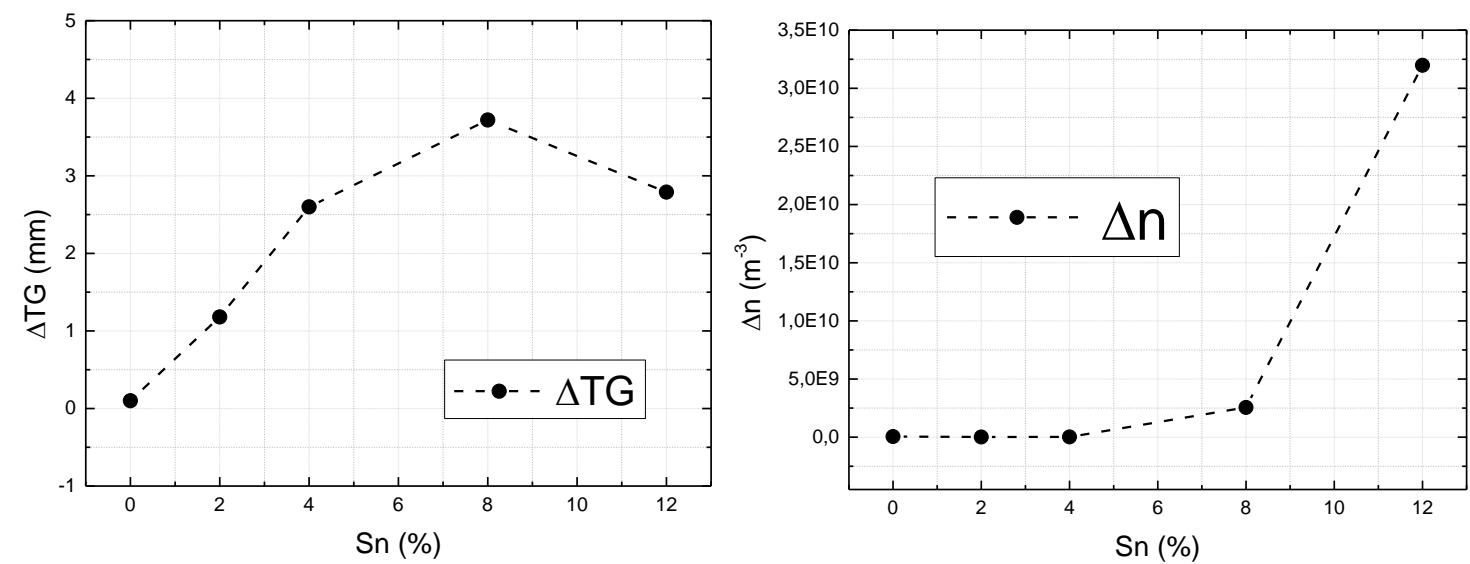

Figura 48 - Efeito de adições crescentes de Sn: (a) variação de tamanho de grão médio e (b) aumento da densidade de número de grãos causados pela adição de $0,08 \% \mathrm{Zr}$.

As curvas sem e com adição de Zr mostram uma diminuição de tamanho de grão com o decréscimo do teor de Sn abaixo de 4\%, indicando a preponderância de algum outro tipo de efeito diferente da restrição ao crescimento. Existem evidências experimentais para ligas de Ni (TARSHIS et al., 1971) e para ligas de Al (JOHNSSON; BACKERUD, 1996) mostram um efeito de diminuição crescente devido à restrição ao crescimento a partir do experimento sem qualquer adição. No caso das ligas Al-Si, nota-se um ponto de mínimo nas curvas, mas nunca foi observado um ponto de máximo, como mostrado na Figura 47a. Os dados apresentados no item 5.2.1 mostram que o $\mathrm{P}$ pode diminuir o tamanho de grão quando na presença de teores reduzidos de Sn, seja com ou sem a adição de Zr. Desta forma, os resultados dos ensaios sem a adição de $\mathrm{P}$, para teores crescentes de Sn na presença ou ausência de $\mathrm{Zr}$ foram sobrepostos às curvas da Figura 47a e estão apresentados na Figura 47b. Estas novas curvas mostram agora praticamente um aumento de tamanho de grão com a diminuição do teor de Sn, com ou sem a adição de Zr. Desta forma, foram formuladas duas hipóteses para este comportamento: (a) o P em solução no líquido causa uma restrição ao crescimento de grão que somente é significativa quando o teor de Sn é reduzido; (b) o P forma partículas intermetálicas no banho líquido cuja superfície é "envenenada" na presença de Sn, perdendo o seu efeito inoculante. Nenhuma destas hipóteses foi examinada em detalhes no presente trabalho. 


\subsection{Análise térmica}

Neste item serão apresentadas as curvas de resfriamento obtidas segundo a metodologia descrita no item 4.1.3 e as curvas de derivada em relação ao tempo. Observa-se que quando a recalescência aparece nas curvas de resfriamento, tem-se uma indicação de uma estrutura de grãos equiaxiais (KURZ; FISHER, 1989; MARTORANO; CAPOCCHI, 2000). Também foi amplamente verificado para ligas de Al que um menor tamanho desta recalescência pode indicar uma maior inoculação e, portanto, um menor tamanho de grão (APELIAN et al., 1984). Contudo, a ausência de recalescência nas curvas de resfriamento pode indicar uma estrutura de grãos colunares ou uma estrutura extremamente refinada de grãos equiaxiais.

No presente trabalho, parâmetros de temperatura e tempo foram extraídos da recalescência existente nas curvas de resfriamento para confirmar os efeitos observados na macroestrutura e para indicar a possibilidade do controle do tamanho de grão médio a partir da análise térmica. Deve-se ressaltar que apenas as curvas do termopar posicionado longitudinal na região central do molde cilíndrico (item 4.1.2) foram analisadas, as curvas do termopar transversal não foram analisadas por te tratar de um termopar de suporte em caso de falha.

\subsubsection{Efeito das adições de Zr}

As curvas de resfriamento para todos os experimentos conduzidos com adições crescentes de $\mathrm{Zr}$ à liga $\mathrm{Cu}-8 \% \mathrm{Sn}$ estão apresentadas na Figura 49, juntamente com a indicação das seguintes temperaturas de transformação: liquidus ( $\mathrm{T} L$ ), peritético ( $\mathrm{TP}$ : $\alpha+L=\beta$ ) e eutetóides ( $\mathrm{T}_{\mathrm{E} 1:} \beta=\alpha+\gamma$ ) e (TE2: $\gamma=\alpha+\delta$ ). As curvas mostram uma queda da temperatura inicial que dura poucos segundos, seguida de um pequeno patamar que indica o início da solidificação da fase primária $(\alpha)$. Percebe-se a existência posterior de diversos desvios muito suaves de inclinação que não parecem indicar claramente algum outro tipo de evento. A derivada primeira destas curvas, no entanto, realça estes eventos térmicos e pode indicar outras possíveis transformações de fase. As curvas de primeira derivada em relação ao tempo (dT/dt) de todas as 
curvas de resfriamento apresentadas na Figura 49 foram calculadas. Um exemplo destas curvas está mostrado na Figura 50 , sobreposto à curva de resfriamento. A partir das curvas derivada foram obtidas as taxas de resfriamento $\left(R_{m}, R_{L}\right)$ e as temperaturas de início $\left(T_{N}\right)$ e final de solidificação $\left(T_{f}\right)$, como descrito no item 4.1.5. Estes parâmetros estão apresentados na Tabela 19.

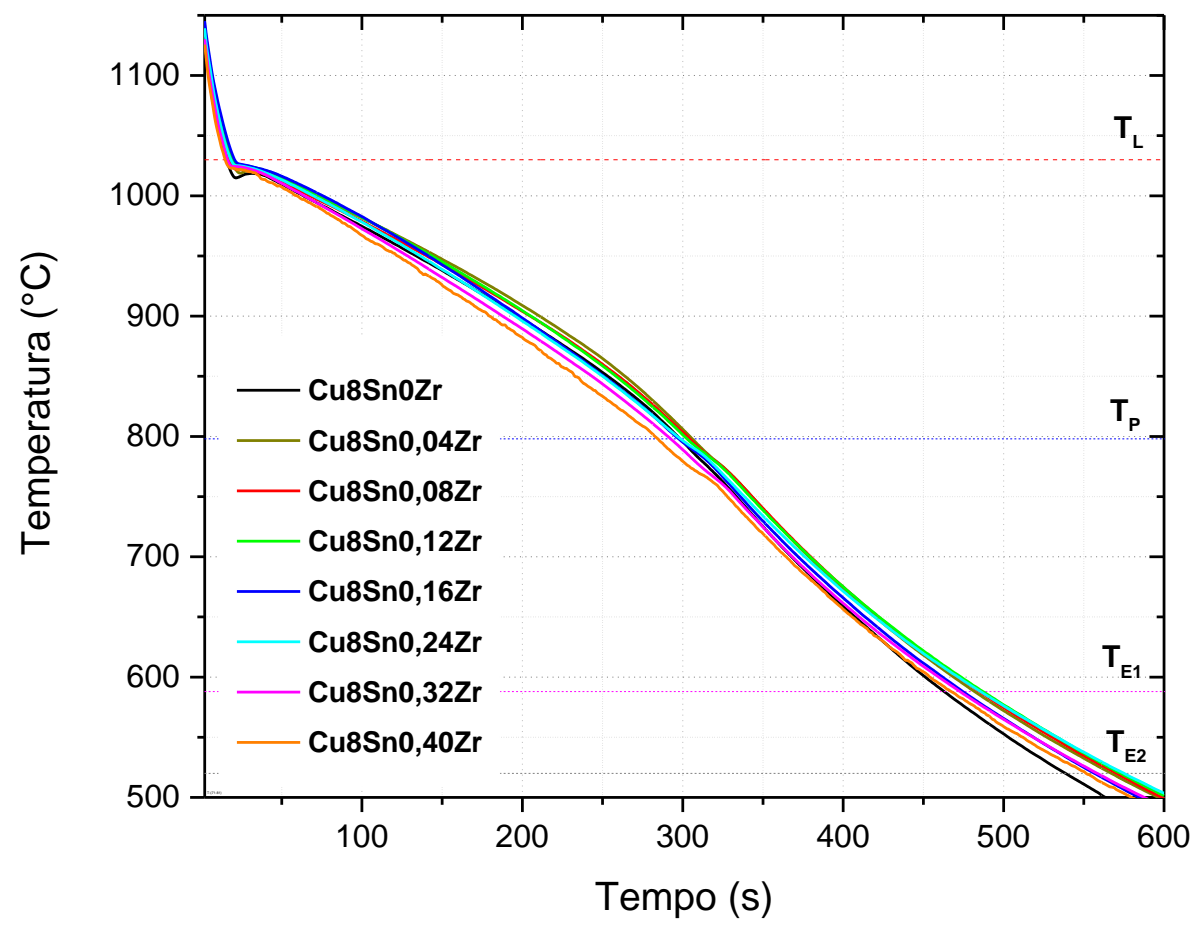

Figura 49 - Curvas de resfriamento (filtradas em relação ao ruído) da série experimental onde adições crescentes de $\mathrm{Zr}$ foram realizadas à liga $\mathrm{Cu}-8 \% \mathrm{Sn}$.

Tabela 19 - Parâmetros extraídos da ampliação das curvas de resfriamento e de sua derivada obtidas nos experimentos de adições crescentes de Zr à liga $\mathrm{Cu}-8 \% \mathrm{Sn}$.

\begin{tabular}{lcccccccc}
\hline Parâmetro & Cu8Sn0Zr & $\begin{array}{l}\text { Cu8Sn } \\
\mathbf{0 , 0 4 Z r}\end{array}$ & $\begin{array}{c}\text { Cu8Sn } \\
\mathbf{0 , 0 8 Z r}\end{array}$ & $\begin{array}{c}\text { Cu8Sn } \\
\mathbf{0 , 1 2 Z r}\end{array}$ & $\begin{array}{c}\text { Cu8Sn } \\
\mathbf{0 , 1 6 Z r}\end{array}$ & $\begin{array}{c}\text { Cu8Sn } \\
\mathbf{0 , 2 4 Z r}\end{array}$ & $\begin{array}{c}\text { Cu8Sn } \\
\mathbf{0 , 3 2 Z r}\end{array}$ & $\begin{array}{c}\text { Cu8Sn } \\
\mathbf{0 , 4 0 Z r}\end{array}$ \\
\hline $\mathbf{R}_{\mathbf{m}}\left({ }^{\circ} \mathbf{C} / \mathbf{s}\right)$ & $-0,82$ & $-0,81$ & $-0,81$ & $-0,82$ & $-0,84$ & $-0,83$ & $-0,84$ & $-0,86$ \\
\hline $\mathbf{R} \mathbf{L}\left({ }^{\circ} \mathbf{C} / \mathbf{s}\right)$ & $-4,14$ & $-3,34$ & $-3,24$ & $-2,98$ & $-2,35$ & $-2,76$ & $-3,41$ & $-3,32$ \\
\hline $\mathbf{T}_{\mathbf{u}}\left({ }^{\circ} \mathbf{C}\right)$ & 1014,9 & 1018,9 & 1021,9 & 1023,5 & 1026,5 & 1025,1 & 1024,3 & 1022,9 \\
\hline $\mathbf{T}_{\mathbf{R}}\left({ }^{\circ} \mathbf{C}\right)$ & 1018,6 & 1021,0 & 1022,5 & 1023,94 & 0 & 0 & 1024,4 & 1023,1 \\
\hline $\mathbf{T}_{\mathbf{N}}\left({ }^{\circ} \mathbf{C}\right)$ & 1094,3 & 1105,6 & 1107,7 & 1111,6 & 1115,0 & 1107,6 & 1097,8 & 1091,5 \\
\hline $\mathbf{T}_{\mathbf{f}}\left({ }^{\circ} \mathbf{C}\right)$ & 747,2 & 754,3 & 755,8 & 756,4 & 759,4 & 769 & 751,6 & 754,3 \\
\hline $\mathbf{T}_{\mathbf{p}}\left({ }^{\circ} \mathbf{C}\right)$ & 791 & 796,7 & 795,2 & 801,7 & 807 & 809,2 & 784,6 & 793,3 \\
\hline $\boldsymbol{\Delta} \mathbf{T}_{\mathbf{R}-\mathbf{U}}\left({ }^{\circ} \mathbf{C}\right)$ & 3,8 & 2,2 & 0,5 & 0,4 & 0 & 0 & 0,1 & 0,3 \\
\hline $\mathbf{\Delta} \mathbf{T}_{\mathbf{N}-\mathbf{U}}\left({ }^{\circ} \mathbf{C}\right)$ & 75,7 & 84,6 & 85,3 & 87,7 & 0 & 0 & 73,4 & 68,4 \\
\hline $\boldsymbol{\Delta} \mathbf{T}_{\mathbf{R}-\mathbf{N}}\left({ }^{\circ} \mathbf{C}\right)$ & 79,5 & 86,7 & 85,8 & 88,1 & 88,5 & 82,5 & 73,5 & 68,7 \\
\hline $\mathbf{t}_{1}\left({ }^{\circ} \mathbf{C}\right)$ & 10,1 & 6,2 & 2,8 & 2,6 & 0 & 0 & 1 & 1 \\
\hline $\mathbf{t}_{\mathbf{2}}\left({ }^{\circ} \mathbf{C}\right)$ & 16,3 & 19,7 & 17,9 & 18,7 & 18,3 & 16,7 & 14,6 & 13,6 \\
\hline $\mathbf{t}_{3}\left({ }^{\circ} \mathbf{C}\right)$ & 26,4 & 25,9 & 20,7 & 21,3 & 0 & 0 & 15,6 & 14,6 \\
\hline $\mathbf{P L}\left({ }^{\circ} \mathbf{C} . \mathbf{s}\right)$ & 3,8 & 2,2 & 0,6 & 0,5 & 0 & 0 & 0,05 & 0,01 \\
\hline
\end{tabular}


Em todos os experimentos analisados a taxa de resfriamento média durante a solidificação, $R_{m}$, foi aproximadamente $0,8{ }^{\circ} \mathrm{C} / \mathrm{s}$, indicando condições experimentais reprodutíveis. Os tempos de início de solidificação podem ser determinados no momento em que a curva de dT/dt apresenta um aumento abrupto (BARLOW; STEFANESCU, 1997), como mostra a Figura 50 (esquerda). A taxa de resfriamento decresceu (em módulo) devido ao surgimento de uma nova fase que libera calor latente diminuindo o decréscimo de temperatura. Este critério de determinação da temperatura de início de solidificação aplicado ao experimento Cu8Sn0,08Zr indica $T_{N}$ $=1115^{\circ} \mathrm{C}$ (Tabela 19), que está acima da temperatura liquidus obtida a partir da composição química $\left(1030^{\circ} \mathrm{C}\right)$. O mesmo tipo de comportamento foi observado para todos os experimentos. Logo, o critério proposto por Barlow e Stefanescu (BARLOW; STEFANESCU, 1997) parece indicar um momento anterior ao início da solidificação, onde as temperaturas ainda eram maiores do que a liquidus fornecida pelo diagrama de fases.

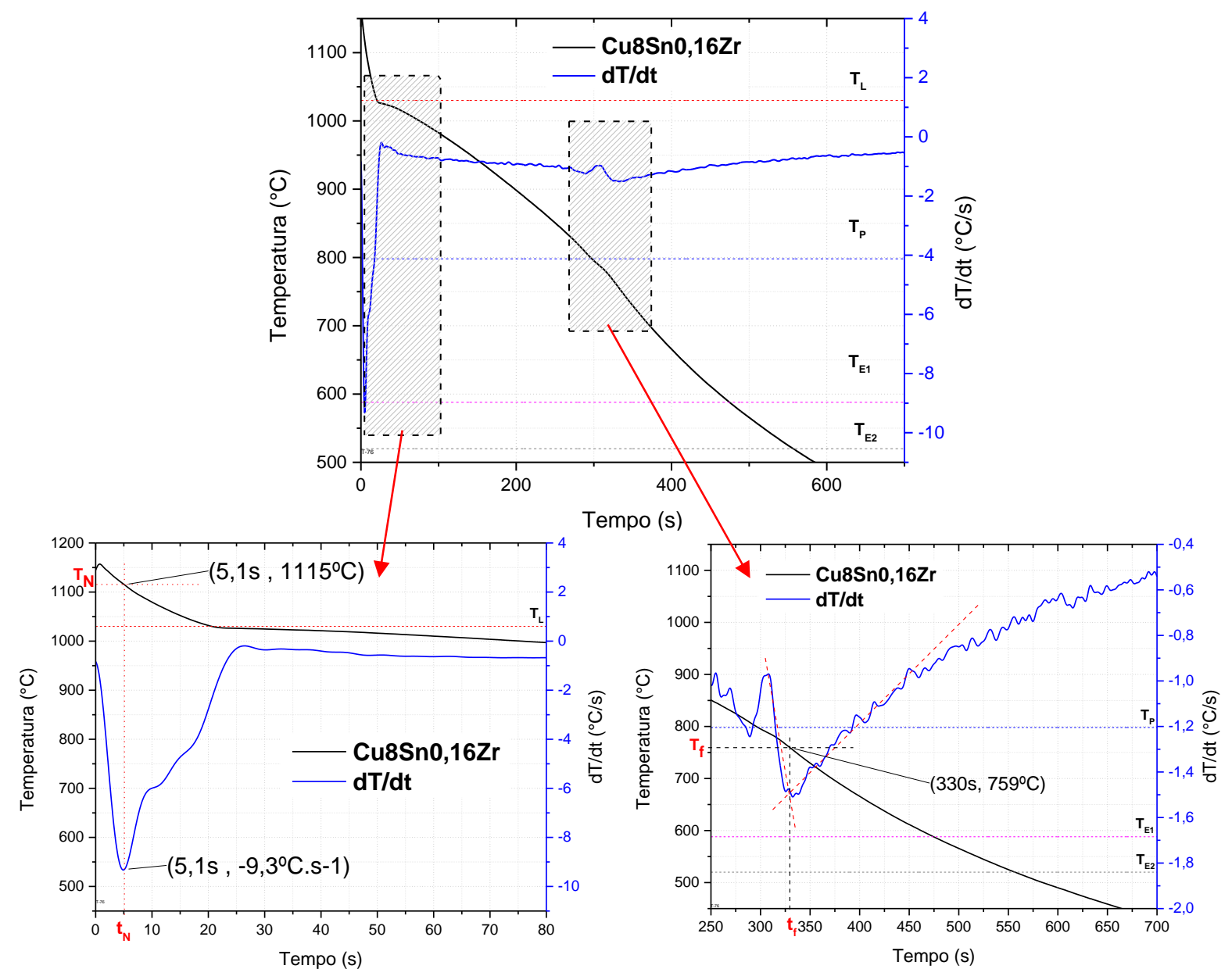

Figura 50- (Superior) Curvas de resfriamento (T) e de taxa de resfriamento (dT/dt) do experimento Cu8Sn0,16Zr. (Inf. esquerda) Aumento do trecho inicial das curvas mostrando a determinação da temperatura de início da solidificação $\left(\mathrm{T}_{\mathrm{N}=1115} \mathrm{O}\right)$ ). (Inf. direita) Aumento do trecho final das curvas mostrando a possível temperatura de final da solidificação $\left(\mathrm{Tf}=759^{\circ} \mathrm{C}\right)$. 
Foi sugerido por Barlow e Stefanescu (BARLOW; STEFANESCU, 1997) que o final da solidificação pode ser identificado através de um vale final na curva de dT/dt, como mostra a Figura 50 (direita). Estas temperaturas $\left(T_{f}\right)$ estão apresentadas na Tabela 19 e indicam valores $\sim 50^{\circ} \mathrm{C}$ abaixo da temperatura da reação peritética mostrada pelo diagrama de fases $\left(T_{p}=798^{\circ} \mathrm{C}\right)$. Esta diferença poderia indicar a existência de um super-resfriamento para o crescimento da estrutura peritética ou ainda que a reação peritética parou devido à formação do novo sólido ao redor da fase primária e o líquido remanescente solidificou isoladamente em menores temperaturas.

Em uma tentativa de identificar os estágios de solidificação apresentados por Barlow e Stefanescu (BARLOW; STEFANESCU, 1997) para ligas AI-Si (item 3.4.1), foram utilizadas as curvas de dT/dt do presente trabalho, exemplificada na Figura 51 para o experimento Cu8Sn0Zr. O exame visual da curva indicou:

a) Estágio 1 - nucleação e crescimento inicial rápido das dendritas primárias;

b) Estágio 2 - crescimento dendrítico da parede do molde em direção ao centro;

c) Estágio 3 - espessamento dos braços dendríticos;

d) Estágio 6 - nucleação e crescimento de uma nova fase, possivelmente a reação peritética $(\alpha+L=\beta)$ que ocorre a uma temperatura próxima de $\mathrm{T}_{\mathrm{p}}=798{ }^{\circ} \mathrm{C} \mathrm{e}$ e) Estágio 7 - término da solidificação.

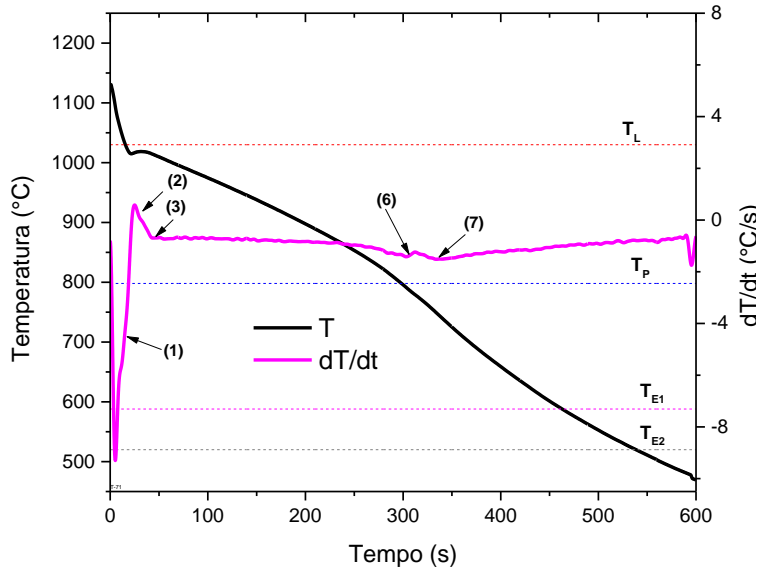

(a)

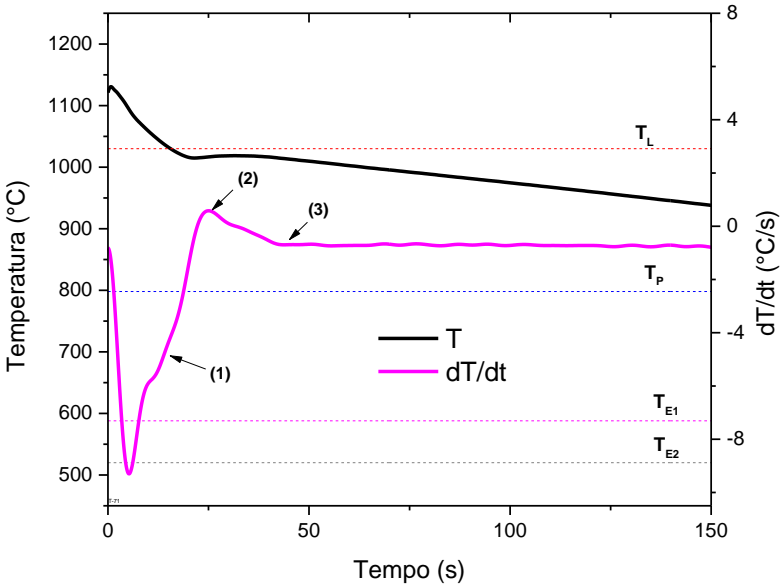

(b)

Figura 51 - Curvas de resfriamento $(\mathrm{T})$ sobreposta à curva de taxa de resfriamento (dT/dt) do experimento r: a) estágios de solidificação apresentados por Barlow e Stefanescu (BARLOW; STEFANESCU, 1997), b) aumento do trecho inicial das curvas mostrando em detalhe os estágios de solidificação. 
Como mencionado anteriormente, o formato e tamanho da recalescência estão intimamente relacionados com a nucleação de sólido ocorrida no banho líquido. As recalescências, tanto nas curvas de resfriamento como nas curvas derivadas, serão ampliadas e examinadas em detalhes utilizando-se parâmetros quantitativos extraídos destas curvas.

A Figura 52 apresenta uma ampliação da região da recalescência das curvas apresentadas na Figura 49. Nota-se que a adição de $\mathrm{Zr}$ ao banho causou alterações no formato e no tamanho das recalescências. Na Figura 53 está mostrada uma ampliação da recalescência observada na curva de resfriamento do experimento Cu8Sn0Zr, indicando-se como foram extraídos os parâmetros mencionados no item 3.4.1: parâmetros de tempo $\left(t_{1}, t_{2}, t_{3}\right) ; \Delta T_{N-U}$ e $\Delta T_{N-R}$, que estão relacionados com a temperatura de nucleação $\left(T_{N}\right)$ e o super-resfriamento da recalescência $\Delta T_{R-U}$, este último definido como a diferença entre a temperatura máxima ( $\left.T_{R}\right)$ e mínima da recalescência (Tu). Uma ampliação da curva derivada está também apresentada na Figura 54 junto com a área hachurada utilizada para o cálculo do parâmetro PL, como descrito no item 3.4.1. Os valores de todos estes parâmetros para as curvas apresentadas na Figura 52 estão apresentados na Tabela 19.

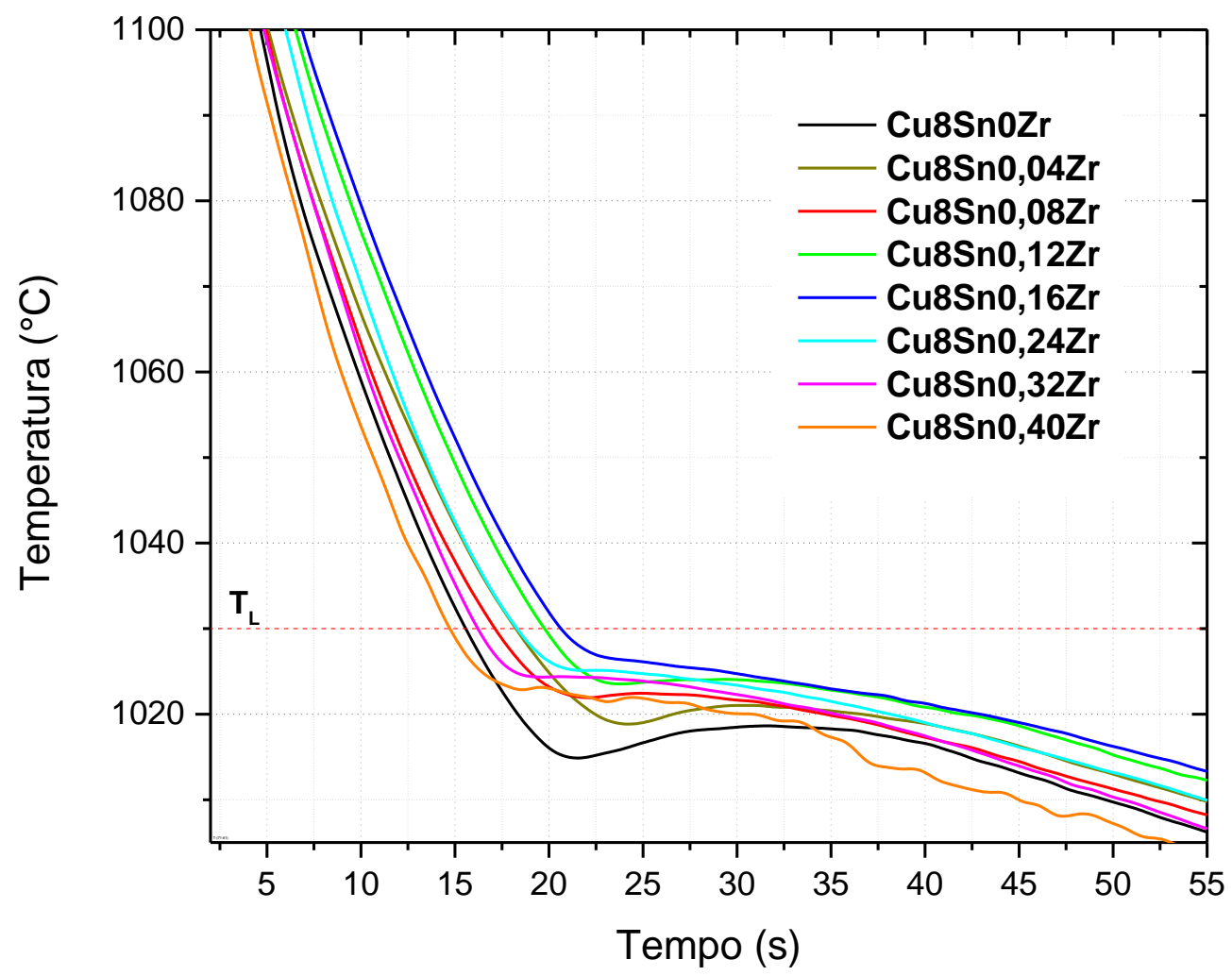

Figura 52 - Curvas de resfriamento (filtradas em relação ao ruído) na região da recalescência da série Efeitos do Zr e C, com adição de fósforo incremento o teor de inoculante. 


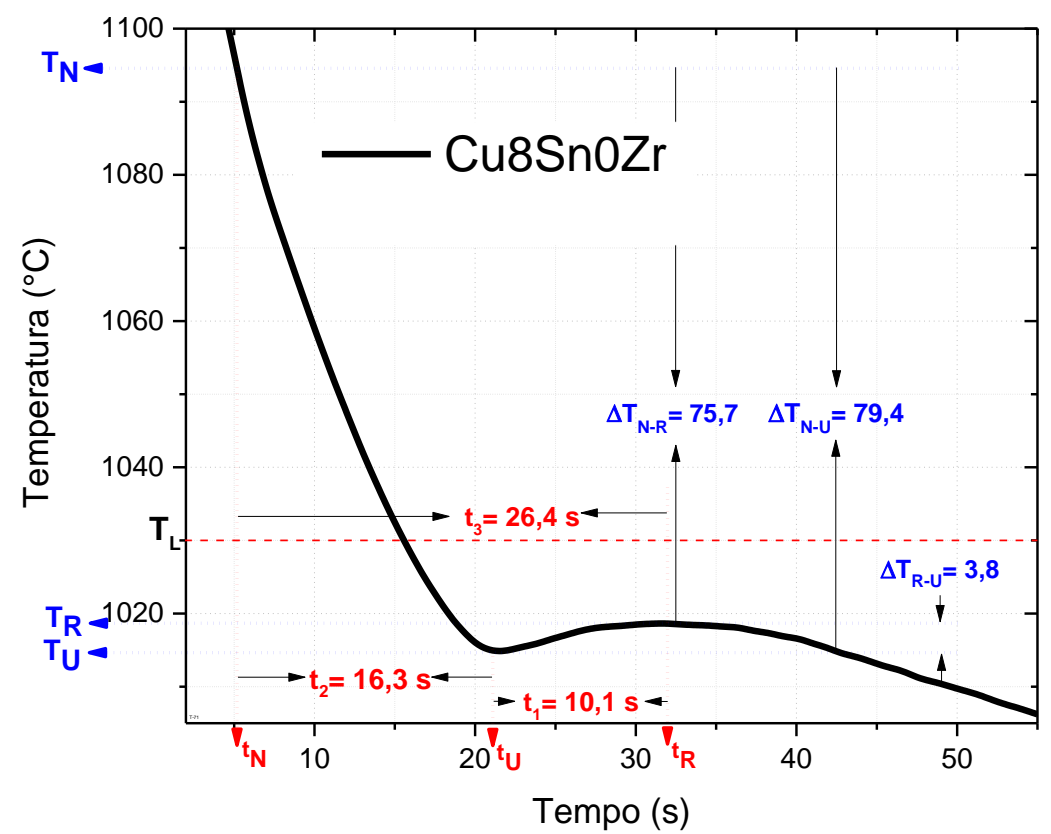

Figura 53- Ampliação da curva de resfriamento (filtrada em relação ao ruído) na região da recalescência do experimento desoxidados com fósforo sem adição de inoculante (Cu8Sn0Zr), mostrando o superresfriamento da recalescência $\left(\Delta T_{R-U}\right)$, as diferenças de temperatura $\Delta T_{N-U}$ e $\Delta T_{N-R}$, o período da recalescência $\left(t_{1}\right)$, o período do estágio da nucleação $\left(t_{2}\right)$, o período entre a nucleação e o final da recalescência $\left(t_{3}\right)$ e a temperatura de líquido $T_{L}$.

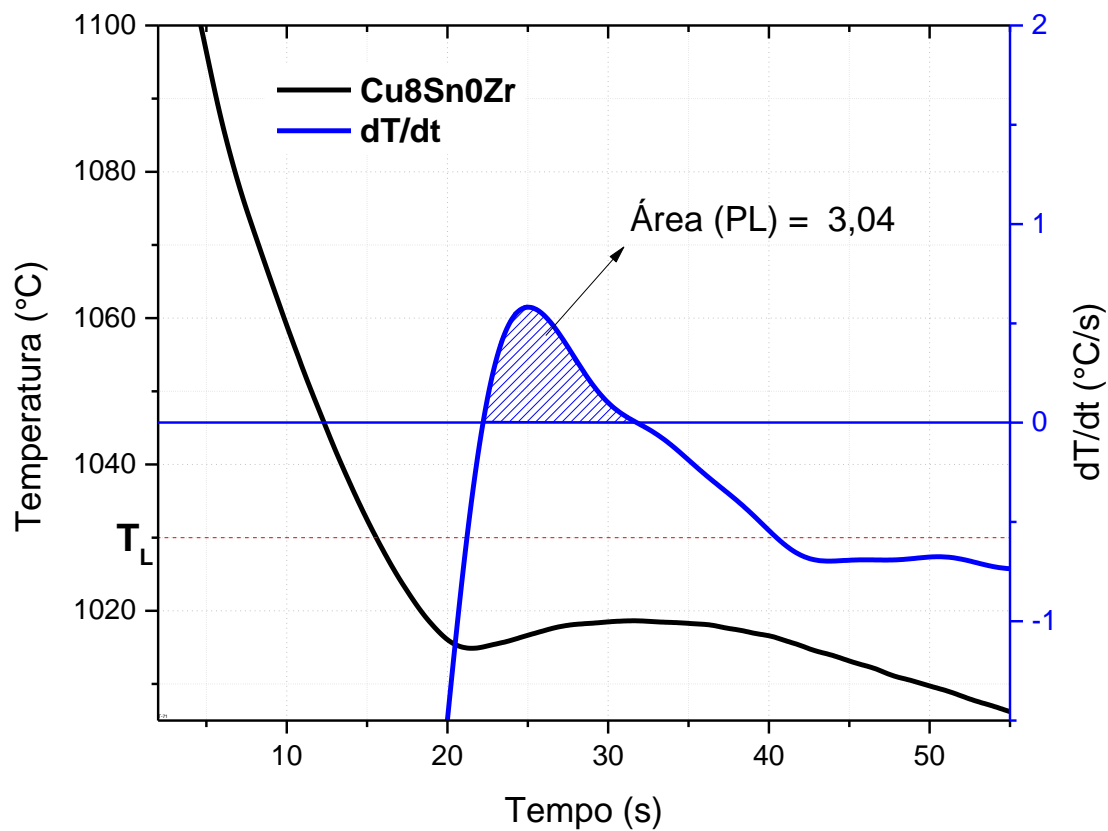

Figura 54- Curva de resfriamento (filtradas em relação ao ruído) e de taxa de resfriamento (dT/dt) do experimento Cu8Sn0Zr mostrando a medição do parâmetro PL.

Alguns destes parâmetros foram plotados em função do teor nominal de $\mathrm{Zr}$ na Figura 55, observando-se correlações evidentes. O aumento da quantidade de $\mathrm{Zr}$ elevou a temperatura mínima Tu, onde a recalescência tem início. Este efeito ocorre porque o número de grãos em crescimento aumentou com o aumento do teor de $\mathrm{Zr}$ (Figura 43, Figura 44), ocasionando uma maior taxa de liberação de calor latente com 
o tempo e elevando a temperatura de mínimo, que é onde ocorre o equilíbrio entre calor latente liberado e o calor extraído. Resultados semelhantes para ligas de Al foram obtidos por Charbonnier (CHARBONNIER, 1984). Observa-se também que o aumento do teor de $\mathrm{Zr}$ reduziu o tamanho da recalescência $\left(\Delta \mathrm{T}_{\mathrm{R}-U}\right)$ até quase o seu completo desaparecimento nos teores de 0,16\%Zr e 0,24\%Zr. Este comportamento também foi observado por Sadayappan et al. (SADAYAPPAN et al., 2004) após adições de B para diminuir o tamanho de grão em ligas Cu-36\%Zn-0,3\%Sn-1,5\%Pb.

Os parâmetros $\Delta \mathrm{T}_{\mathrm{R}-\mathrm{U}}, \mathrm{t}_{1}$ e $\mathrm{PL}$ decrescem com o aumento do teor de $\mathrm{Zr}$ até 0,24\% e posteriormente sofrem um pequeno aumento, indicando uma mudança de comportamento consistente com a presença de um pequeno mínimo na curva de tamanho de grão médio em função do teor de Zr (Figura 44). Por outro lado, a mínima temperatura da recalescência (Tu), apresentou um comportamento semelhante, porém no sentido inverso, ou seja, aumentou com a diminuição do tamanho de grão até o tamanho mínimo e depois diminuiu quando o tamanho de grão passou a aumentar. Desta forma, o efeito do teor de $\mathrm{Zr}$ nos parâmetros extraídos da recalescência da curva de resfriamento está consistente com o efeito do teor de Zr no tamanho de grão médio e portanto, uma correlação direta entre eles será examinada na Figura 56.

Os mesmos parâmetros apresentados na Figura 55 foram também correlacionados com o tamanho de grão médio (Figura 56), visando uma possível aplicação prática para a previsão do tamanho médio de grão utilizando as curvas de resfriamento. $\mathrm{Na}$ taxa de resfriamento média obtida nos presentes experimentos $\left(\mathrm{R}_{\mathrm{m}}\right.$ 0,8 K/s) os parâmetros $\Delta \mathrm{T}_{\mathrm{R}-\mathrm{U}}, \mathrm{t}_{1}$, Tu e $\mathrm{PL}$ apresentaram uma excelente correlação com o tamanho de grão $\left(R^{2}>0,99\right)$ quando se utiliza uma função quadrática. Por outro lado, a correlação entre o tamanho de grão e os parâmetros t2 e t3 da Tabela 19 foi pobre e, portanto, não foi apresentada. Nota-se que o tamanho de grão médio aumentou com a elevação dos parâmetros $\Delta T_{R-U}$, $t_{1}$ e $P L$ e diminuiu com o aumento de Tu. Desta forma, concluiu-se que a diminuição do tamanho de grão causa uma redução do tamanho da recalescência tanto no eixo da temperatura como no eixo do tempo. Este comportamento para $\Delta \mathrm{T}_{\mathrm{R}-\mathrm{U}}$ e $\mathrm{t}_{1}$ foi também observado nas curvas de resfriamento coletadas em ligas de Al da série 356 (IBARRA, 1999). Porém, a correlação no caso das ligas de Al apresentou menor $\mathrm{R}^{2}$. 

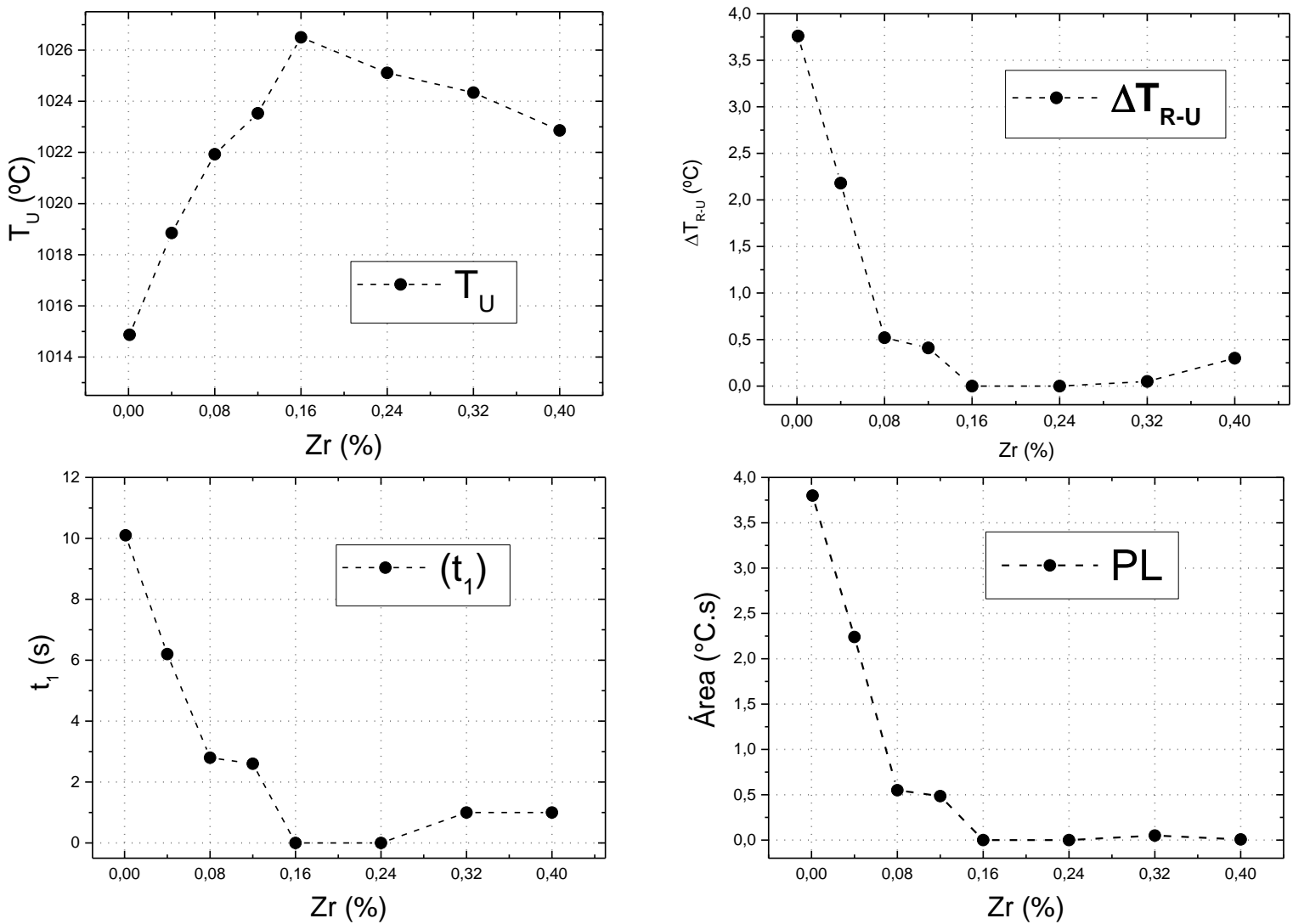

Figura 55- Parâmetros de temperatura e de tempo extraídos das curvas de resfriamento em função do teor de Zr nominal.
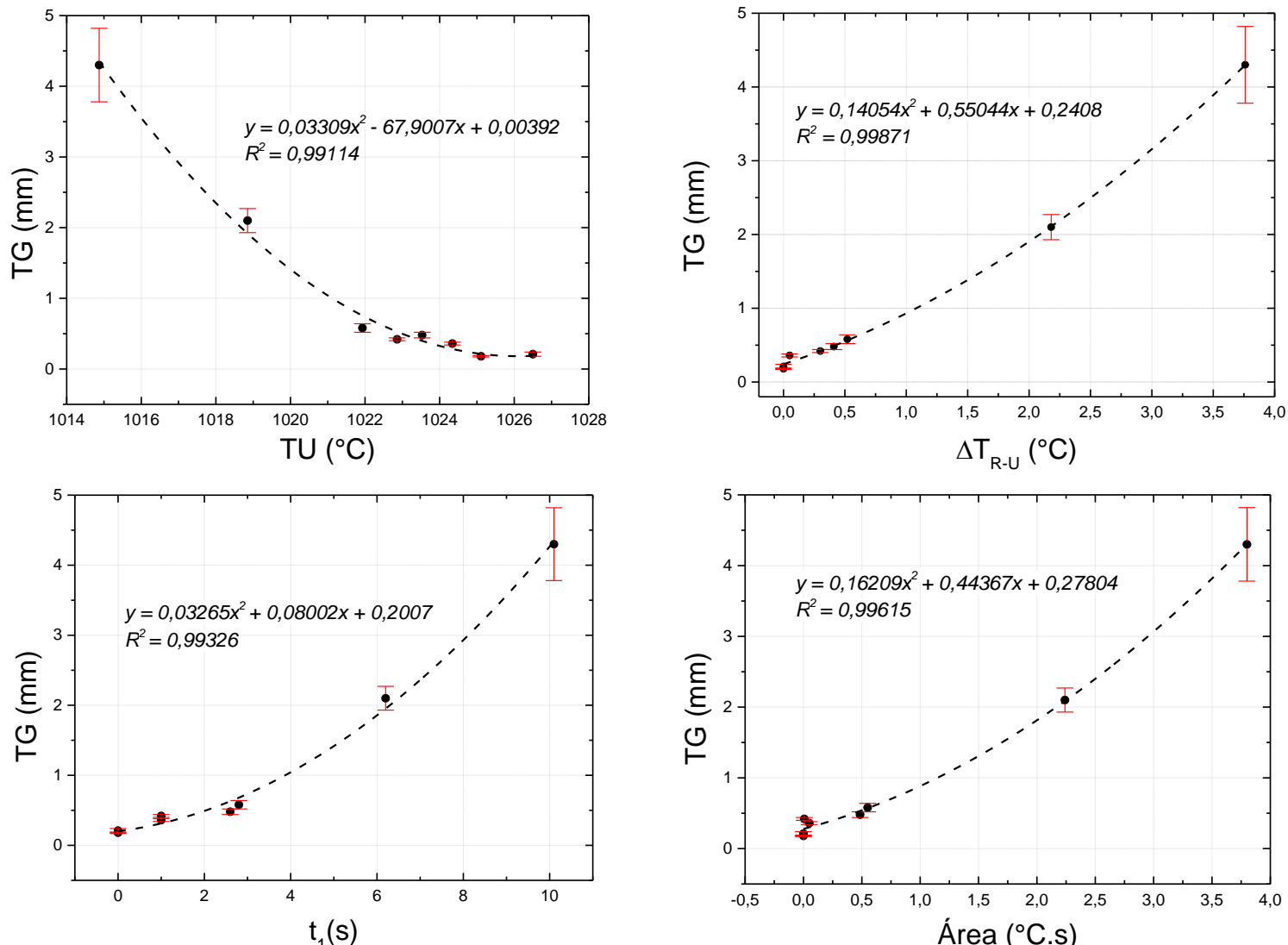

Figura 56- Tamanho médio de grão em função dos parâmetros de temperatura e tempo extraídos da região da recalescência das curvas de resfriamento. 


\subsubsection{Efeito das adições de Sn e Zr}

As curvas de resfriamento obtidas na série experimental para crescentes teores de Sn foram analisadas de forma análoga ao item anterior. As curvas sem e com a adição de 0,08\%Zr estão apresentadas na Figura 57 e na Figura 58. Observa-se uma queda inicial que dura poucos segundos, seguida de um pequeno patamar que indica o início da solidificação da fase primária $(\alpha)$. Percebe-se também a existência posterior de diversos desvios muito suaves de inclinação. A partir destas curvas foram calculados os mesmos parâmetros apresentados no item anterior e estão reportados na Tabela 20. Estes parâmetros também foram plotados em função do teor de Sn em cada experimento (Figura 61) e em função do tamanho de grão médio (Figura 62).

A diminuição da temperatura do mínimo da recalescência, Tu, com o aumento do teor de Sn (Figura 61) deve ocorrer principalmente pela diminuição da temperatura liquidus que ocorre para maiores concentrações de Sn. Uma diminuição da temperatura liquidus desloca praticamente toda a curva de resfriamento, incluindo a região da recalescência, para menores temperaturas. No entanto, nota-se um aumento dos valores de Tu com a adição de 0,08\%Zr para o mesmo teor de Sn. Esta diminuição deve ser causada pelo maior nível de inoculação, como mostrado em detalhes no item anterior. Além disso, nota-se que este aumento é maior quando o teor de $S n$ se eleva e é significativo para \%Sn $\geq 4$, o que pode estar relacionado com o maior efeito de refino de grão nos maiores teores de Sn.

As curvas para os parâmetros $\Delta T_{R-U}, t_{1}$ e $P_{L}$ indicam de forma consistente uma tendência a um ponto de máximo na região de aproximadamente 4\%Sn. Na Figura 47 observa-se que houve um ponto de máximo no tamanho de grão médio em função do \%Sn também em 4\%Sn, indicando uma possível correlação. Desta forma, a Figura 62 mostra diretamente esta correlação, onde se pode observar que um aumento de $\Delta T_{R}$ $\mathrm{u}, \mathrm{t}_{1}$ e $\mathrm{PL}_{\mathrm{L}}$ indicam um aumento de tamanho de grão médio também quando esta variação de tamanho é causada pela variação do teor de Sn. Entretanto, esta correlação não foi tão clara como aquela apresentada na Figura 56, quando o tamanho de grão é alterado devido a variações no teor de Zr. Desta forma, pode-se concluir que o tamanho de grão médio em ligas com teor de $\mathrm{Sn}$ e $\mathrm{Zr}$ variáveis na faixa examinada apresentam uma boa correlação com os parâmetros $\Delta T_{R-U}, t_{1}$ e $P_{L}$, 
extraídos da região da recalescência das curvas de resfriamento. Estes parâmetros poderiam, então, ser utilizados para o controle do tamanho de grão.

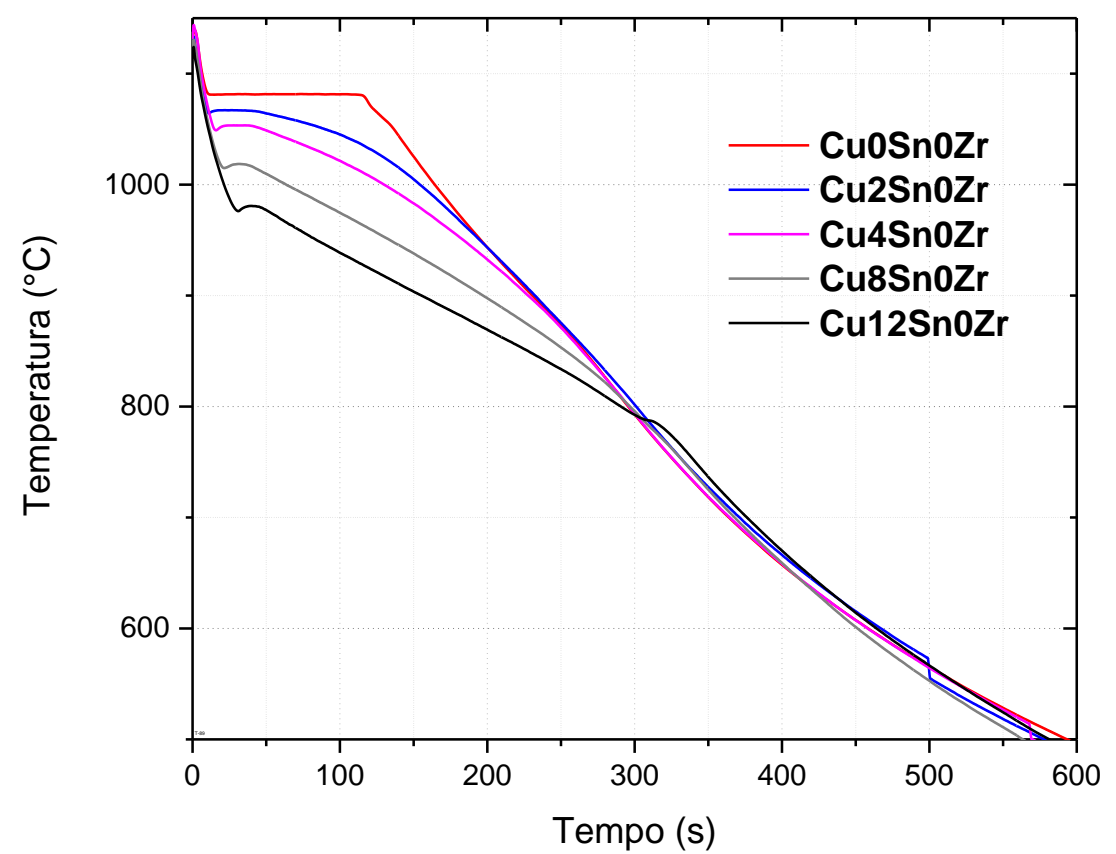

Figura 57- Curvas de resfriamento dos experimentos com adições crescentes de Sn sem adição de Zr.

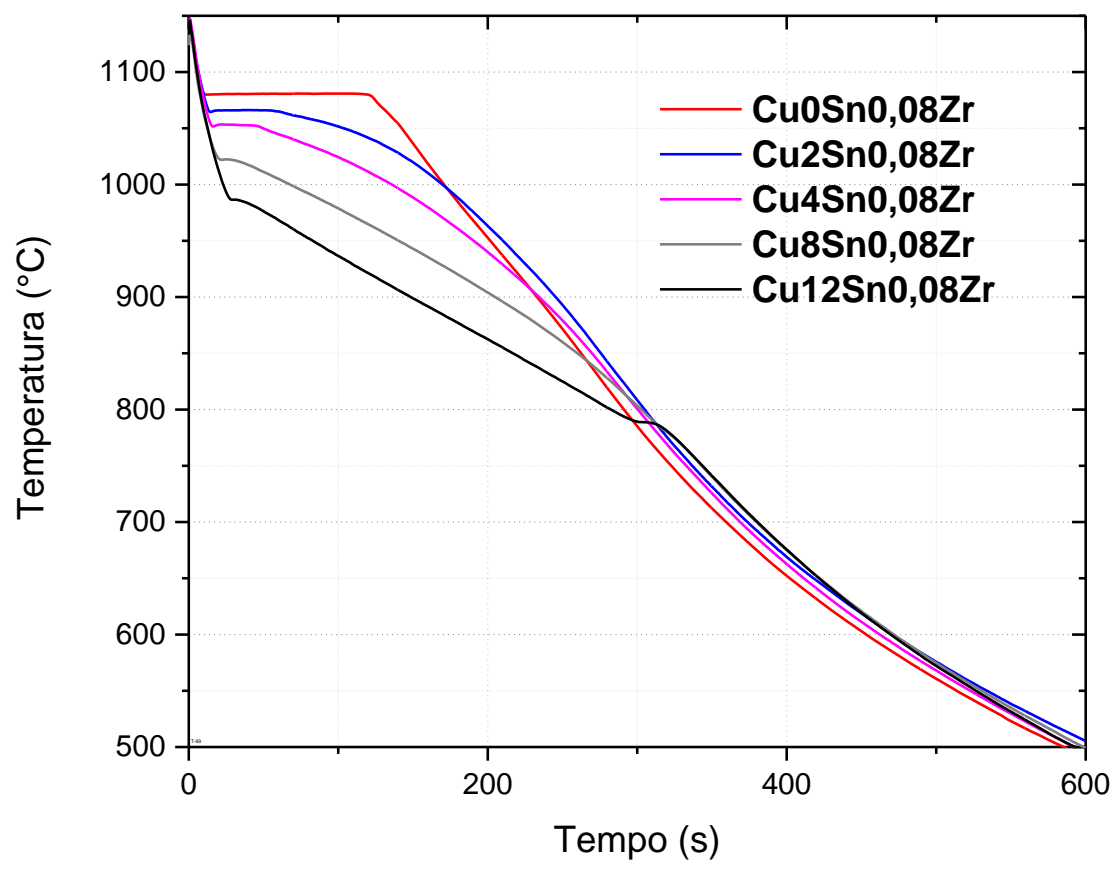

Figura 58 - Curvas de resfriamento dos experimentos com adições crescentes de Sn com adição de $0,08 \% Z r$. 


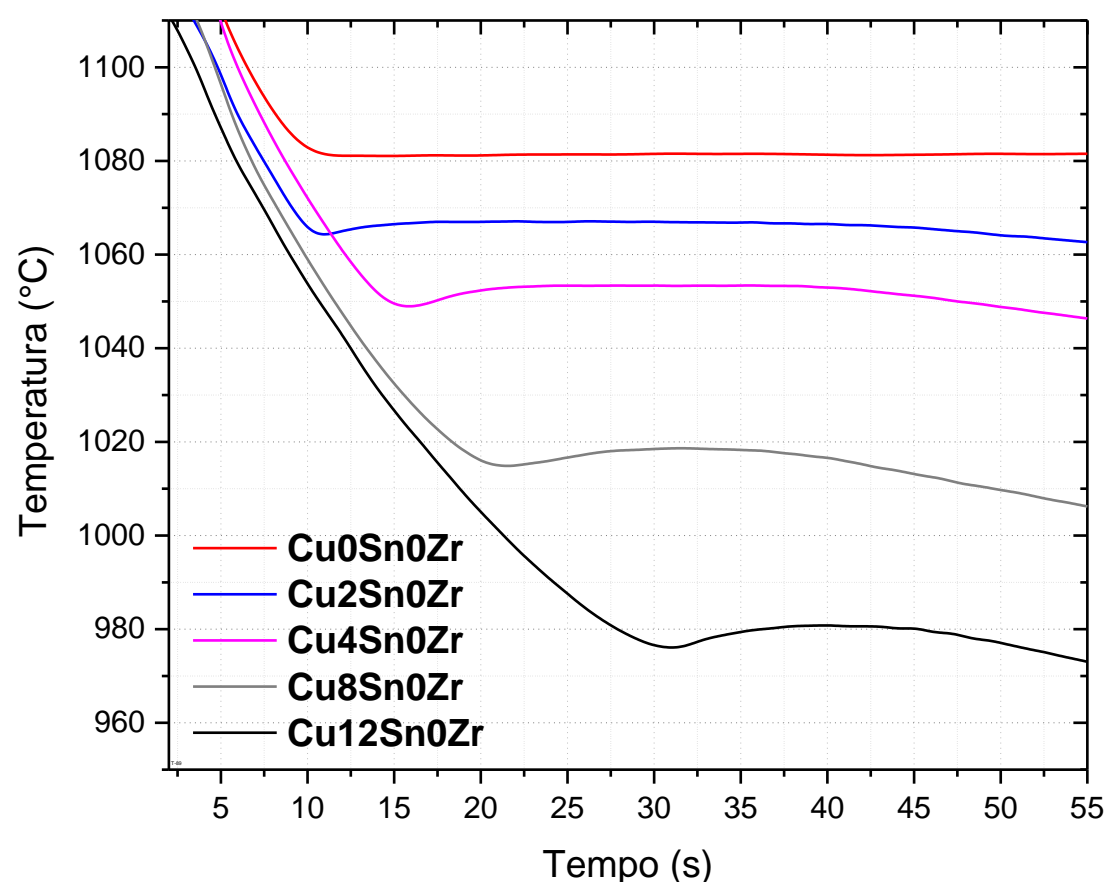

Figura 59- Ampliação das curvas de resfriamento na região da recalescência dos experimentos com adições crescentes de Sn sem adição de $\mathrm{Zr}$.

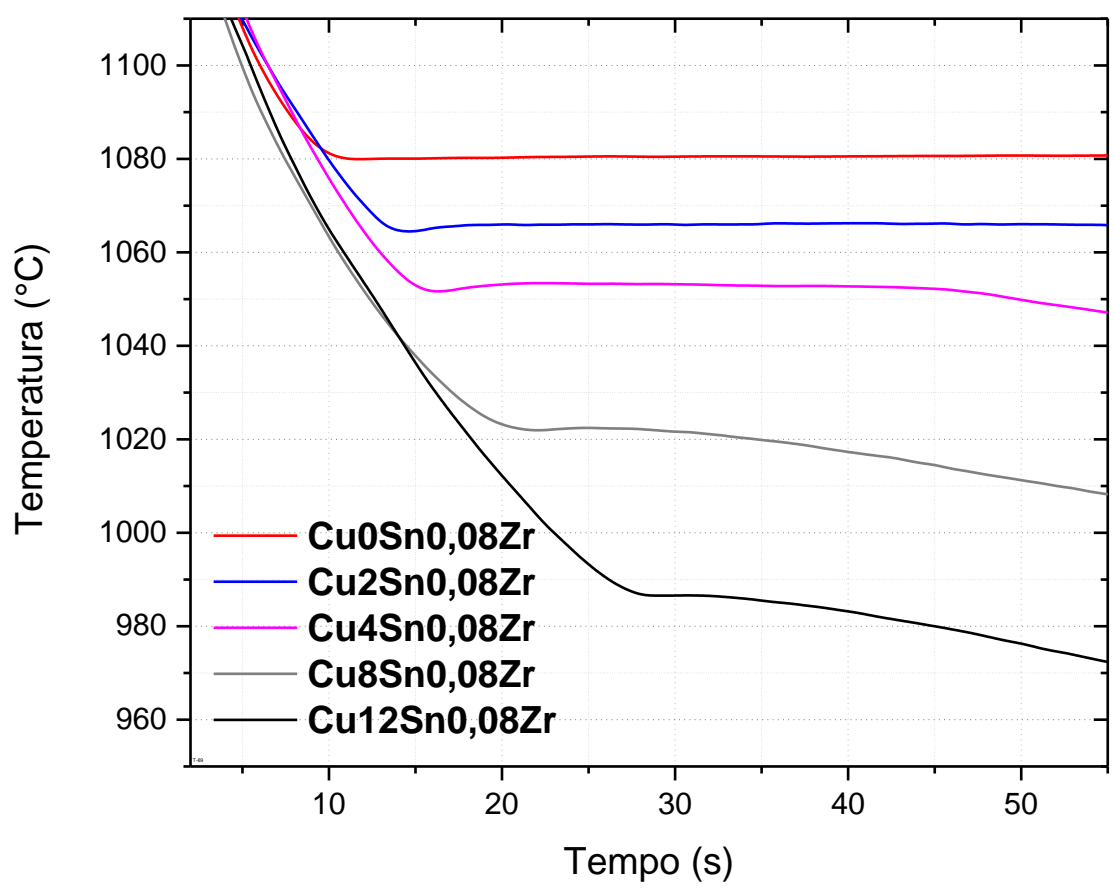

Figura 60 - Ampliação das curvas de resfriamento na região da recalescência dos experimentos com adições crescentes de Sn e com adição de $0,08 \%$ Zr. 
Tabela 20 - Parâmetros extraídos das curvas de resfriamento e de sua derivada obtidas nos experimentos com adições crescentes de Sn sem e com a presença do teor nominal de $0,08 \% Z$ r.

\begin{tabular}{|c|c|c|c|c|c|c|c|c|c|c|}
\hline Parâmetro & $\begin{array}{c}\text { CuOSn } \\
\text { OZr }\end{array}$ & $\begin{array}{l}\text { Cu0Sn } \\
0,08 Z r\end{array}$ & $\begin{array}{c}\text { Cu2Sn } \\
\text { OZr }\end{array}$ & $\begin{array}{l}\text { Cu2Sn } \\
0,08 \mathrm{Zr}\end{array}$ & $\begin{array}{c}\text { Cu4Sn } \\
\text { OZr }\end{array}$ & $\begin{array}{l}\text { Cu4Sn } \\
0,08 \mathrm{Zr}\end{array}$ & $\begin{array}{c}\text { Cu8Sn } \\
\text { 0Zr }\end{array}$ & $\begin{array}{l}\text { Cu8Sn } \\
0,08 Z r\end{array}$ & $\begin{array}{c}\text { Cu12Sn } \\
0 \mathrm{Zr}\end{array}$ & $\begin{array}{c}\text { Cu12Sn } \\
0,08 \mathrm{Zr}\end{array}$ \\
\hline$R_{m}\left({ }^{\circ} \mathrm{C} / \mathrm{s}\right)$ & -1 & -1 & $-0,9$ & $-0,9$ & $-0,9$ & $-0,9$ & $-0,8$ & $-0,8$ & $-0,7$ & $-0,7$ \\
\hline $\mathrm{R}_{\mathrm{L}}\left({ }^{\circ} \mathrm{C} / \mathrm{s}\right)$ & $-3,5$ & $-3,5$ & $-4,6$ & $-4,1$ & $-4,5$ & $-4,1$ & 4,1 & $-3,3$ & $-3,3$ & $-2,8$ \\
\hline $\mathrm{T}_{\mathrm{U}}\left({ }^{\circ} \mathrm{C}\right)$ & 1080,7 & 1079,9 & 1064,3 & 1064,5 & 1049,0 & 1051,6 & 1014,9 & 1021,9 & 976,1 & 984,6 \\
\hline $\mathrm{T}_{\mathrm{R}}\left({ }^{\circ} \mathrm{C}\right)$ & 0 & 0 & 1067,0 & 1066,0 & 1053,3 & 1053,4 & 1018,6 & 1022,4 & 981,0 & 986,6 \\
\hline $\mathrm{T}_{\mathrm{N}}\left({ }^{\circ} \mathrm{C}\right)$ & 1106,1 & 1105,5 & 1094,7 & 1108,4 & 1103,4 & 1107,7 & 1094,3 & 1107,7 & 1084,6 & 1101,6 \\
\hline$\Delta \mathrm{T}_{\mathrm{R}-\mathrm{U}}\left({ }^{\circ} \mathrm{C}\right)$ & 0 & 0 & 2,7 & 1,5 & 4,3 & 1,8 & 3,7 & 0,5 & 4,9 & 0,04 \\
\hline$\Delta \mathrm{T}_{\mathrm{N}-\mathrm{U}}\left({ }^{\circ} \mathrm{C}\right)$ & 0 & 0 & 27,7 & 42,4 & 50,1 & 54,3 & 75,7 & 85,3 & 103,6 & 115,0 \\
\hline$\Delta T_{\mathrm{R}-\mathrm{N}}\left({ }^{\circ} \mathrm{C}\right)$ & 25,4 & 25,6 & 30,4 & 43,9 & 54,4 & 56,1 & 79,5 & 85,8 & 108,5 & 115,0 \\
\hline$t_{1}\left({ }^{\circ} \mathrm{C}\right)$ & 0 & 0 & 6,8 & 4,3 & 8,5 & 5,8 & 10,1 & 2,8 & 9 & 1,8 \\
\hline$t_{2}\left({ }^{\circ} \mathrm{C}\right)$ & 5,6 & 6,5 & 5,6 & 9,4 & 10,2 & 10,8 & 16,3 & 17,9 & 25,7 & 23,6 \\
\hline$t_{3}\left({ }^{\circ} \mathrm{C}\right)$ & 0 & 0 & 12,4 & 13,7 & 18,7 & 16,6 & 26,4 & 20,7 & 34,7 & 25,4 \\
\hline $\mathrm{PL}\left({ }^{\circ} \mathrm{C} . s\right)$ & 0 & 0 & 2,6 & 1,4 & 4,2 & 1,8 & 3,8 & 0,5 & 4,0 & 0,04 \\
\hline
\end{tabular}
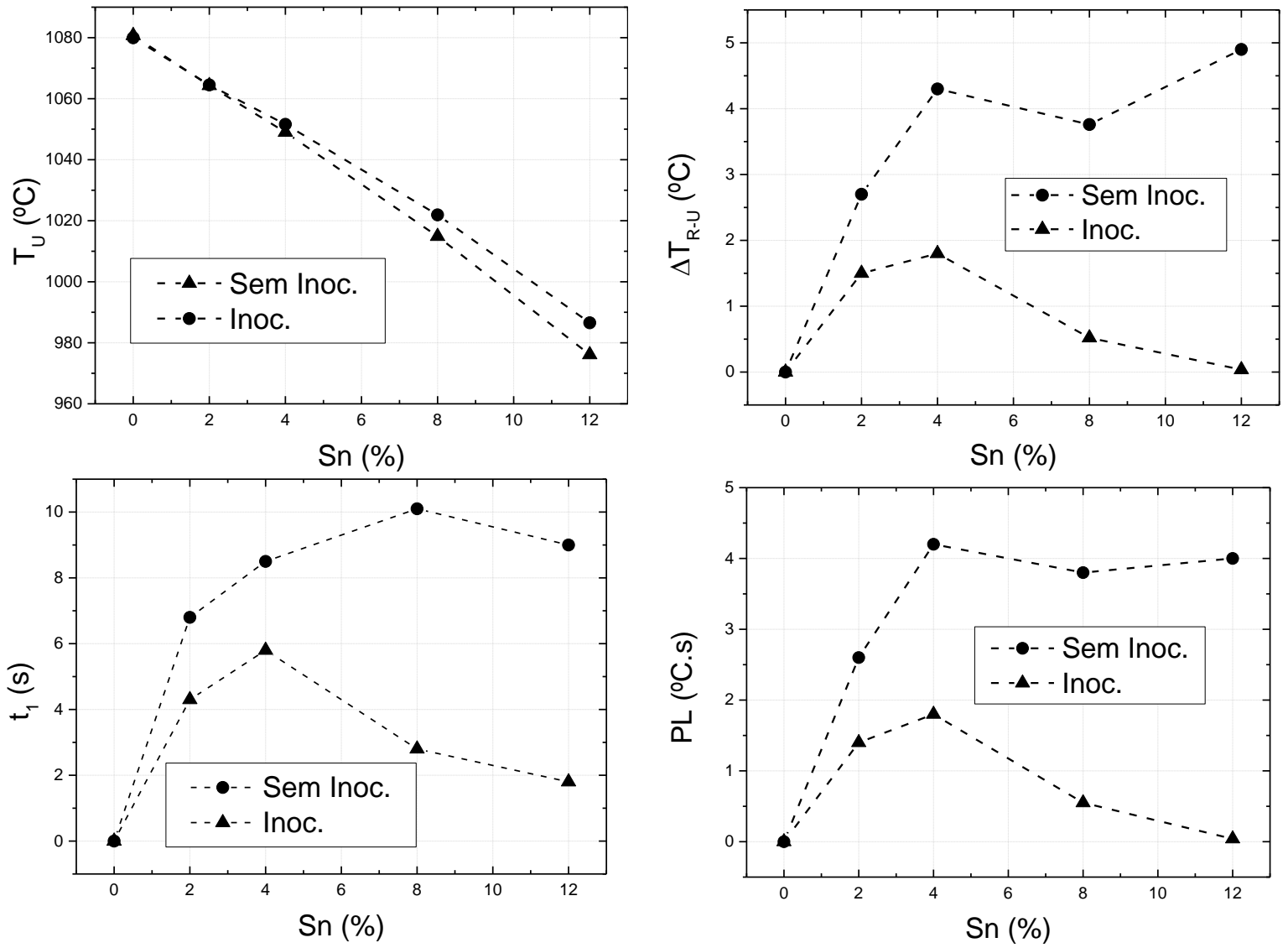

Figura 61 - Parâmetros de temperatura e de tempo extraídos das curvas de resfriamento em função do teor de Sn, sem ou com a adição de $0,08 \% Z r$ (Inoc). 

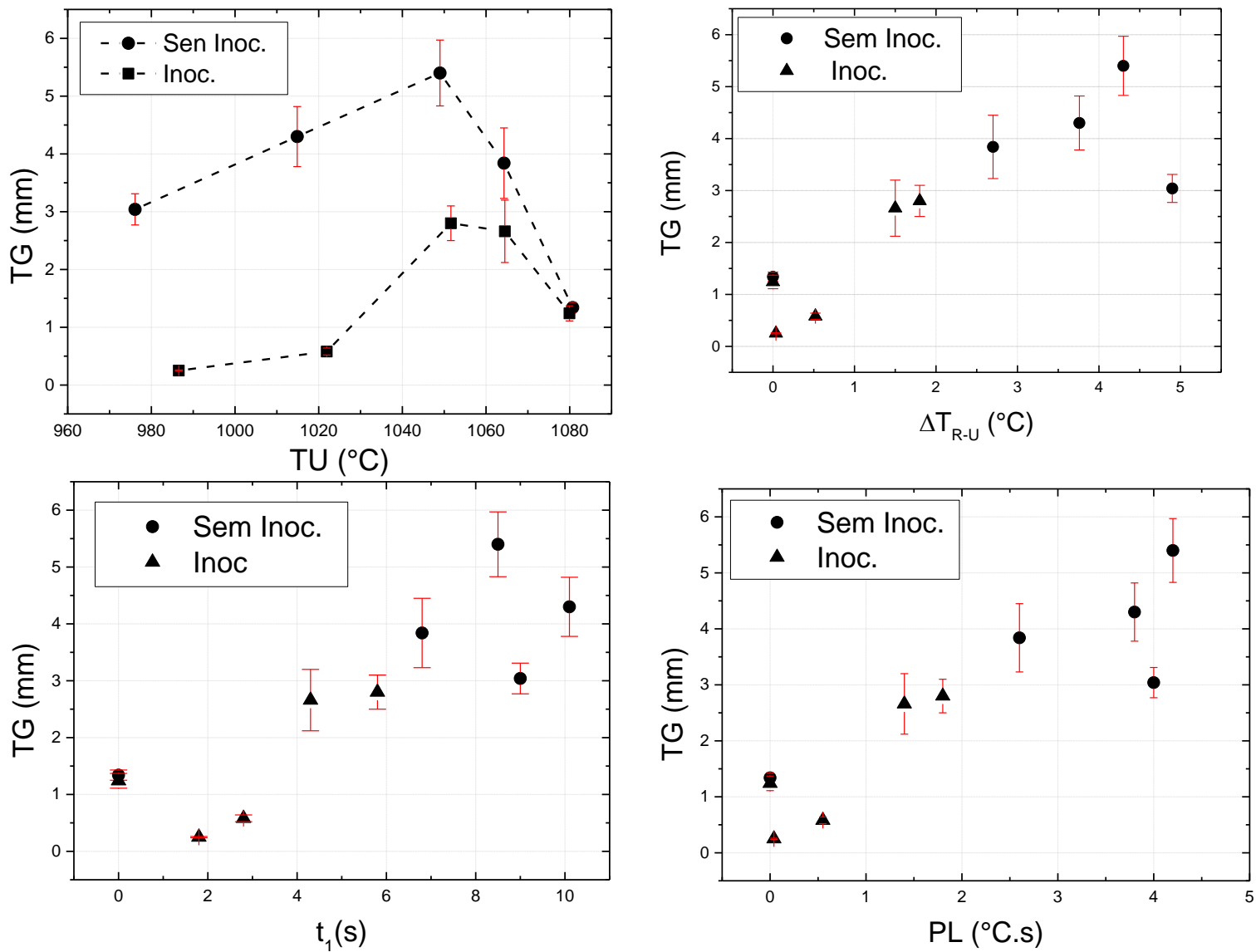

Figura 62 - Tamanho médio de grão em função dos parâmetros de temperatura e tempo extraídos da região da recalescência das curvas de resfriamento nos experimentos com adições crescente de $\mathrm{Sn}$, sem e com a adição de $0,08 \%$ Zr (Inoc).

\subsection{Análise microestrutural - Identificação das fases e precipitados}

A seguir serão apresentadas e discutidas as microestruturas observadas a partir de microscopia óptica e microscopia eletrônica de varredura e de transmissão. Um dos principais objetivos desta análise microestrutural é de auxiliar o entendimento do efeito das adições sobre a estrutura final de grãos. Particularmente, as micrografias serão utilizadas para tentar identificar e caracterizar possíveis partículas que funcionaram como substratos efetivos para a nucleação heterogênea da fase primária $\mathrm{Cu}-\alpha$. 


\subsubsection{Análise microestrutural da liga Cu8\%Sn}

A Figura 63 mostra as micrografias obtidas por microscopia óptica dos lingotes dos ensaios Cu8Sn0Zr e Cu8Sn0,08Zr. As Figura 63 (a) e (c) mostram evidências do crescimento dendrítico da fase primária e da microssegregação de Sn. Segundo o diagrama de fases (Figura 23), as regiões que solidificam posteriormente apresentam maior teor de Sn e estão na posição interdendrítica (coloração amarelada) e as regiões de menores teores de Sn estão no centro dos braços dendríticos (coloração alaranjada). Nas Figura 63 (b) e (d), pode-se também notar a presença de uma fase com contraste de coloração azulada na região interdendrítica. Esta fase foi identificada como $\delta$ (veja diagrama de fases - Figura 23) em trabalhos da literatura através de microanálise EDS (MARTORANO; CAPOCCHI, 2000) e através da metalografia com contraste de cor azulada (ACHARYA; MUKUNDA, 1988).
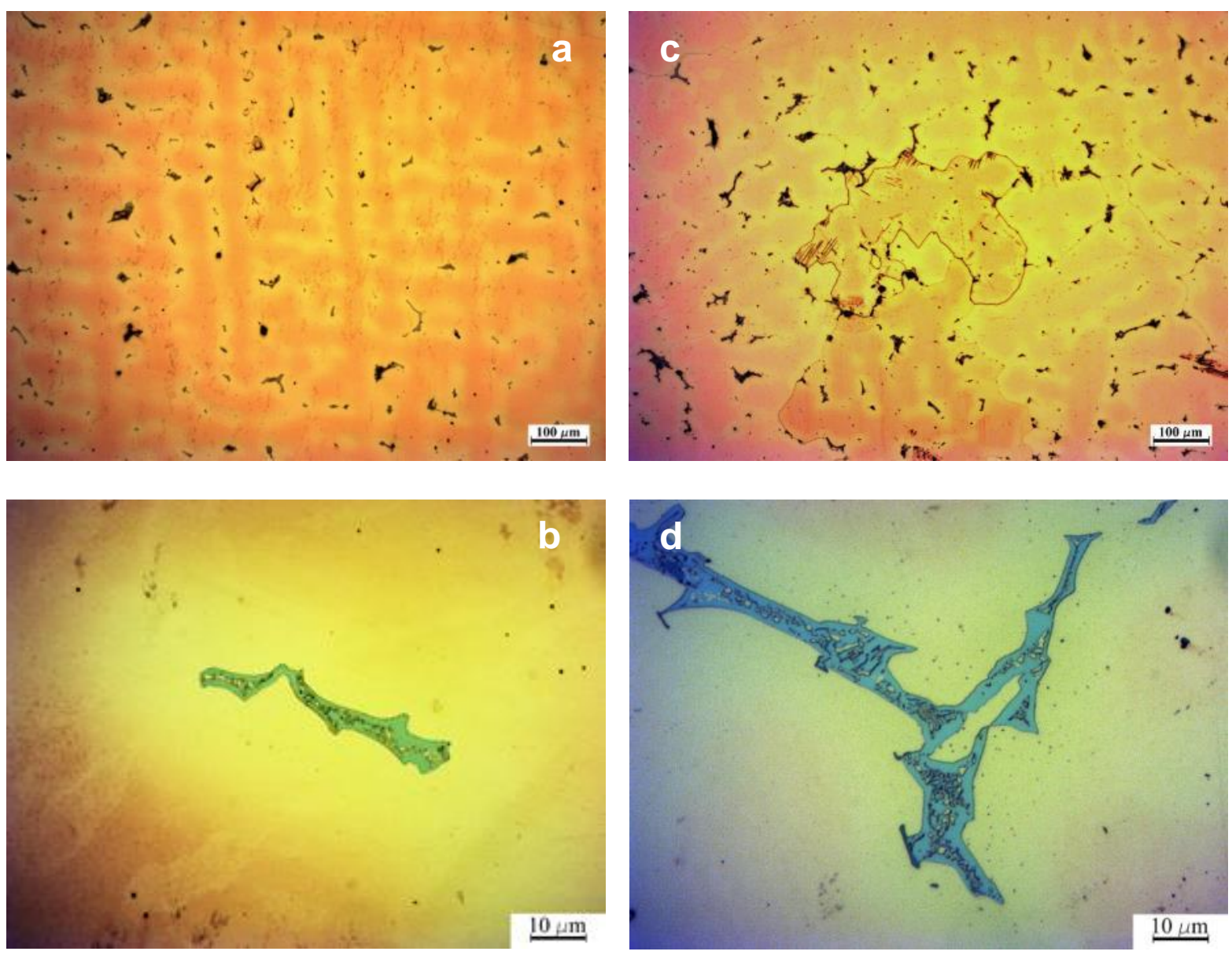

Figura 63 - Microestruturas das seções transversais dos lingotes dos experimentos: a); b) Cu8Sn0Zr; c) e d) Cu8Sn0,08Zr. Reagentes: $\mathrm{NH} 4 \mathrm{OH} 20 \mathrm{ml}, \mathrm{H} 2 \mathrm{O} 210 \mathrm{ml}$ e Etanol 500ml, FeCl3 25g, HCl $15 \mathrm{ml} .2$ 
Estas afirmações podem ser corroboradas com as micrografias obtidas em contraste de elétrons retroespalhados no microscópio eletrônico de varredura, apresentadas na Figura 64. As regiões mais claras são ricas no elemento de maior número atômico, ou seja, o Sn. A Figura 65 (a) e (b) mostra a microestrutura da fase rica em $S n$ e o resultado de duas microanálises por energia dispersiva de raios- $X$ (EDS). O resultado mostra um espectro de EDS e a concentração de Sn na fase dispersa $(\delta)$. A concentração de Sn na análise 1 é de 28,22\%(massa), indicando a fase que resulta do eutetóides $\gamma=\alpha+\delta(27 \%$ Sn com 15,8\% $\alpha$ e $32,55 \% \delta)$ no sistema Cu-Sn (Figura 23).

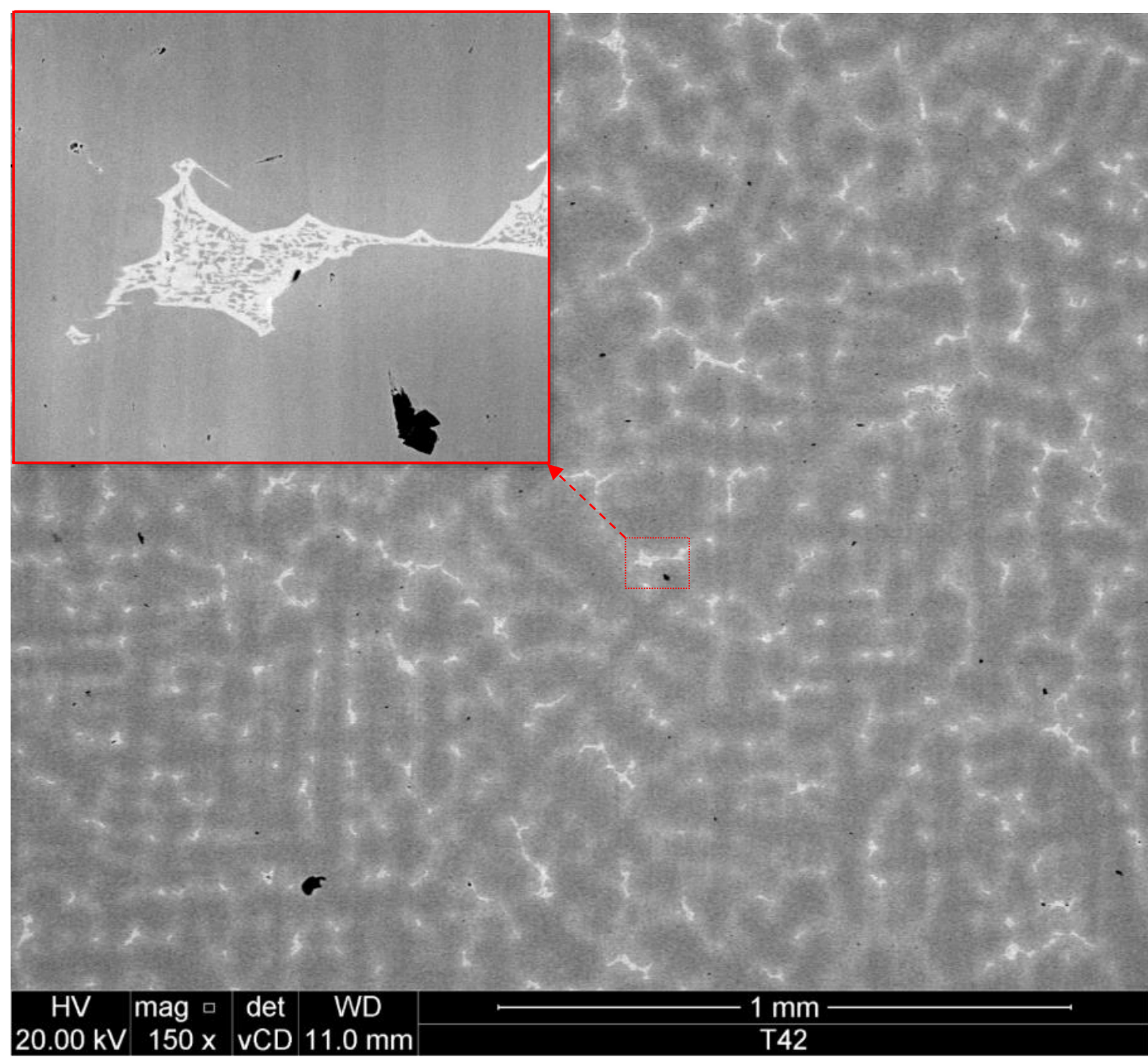

Figura 64 - Microestrutura obtida em microscópio eletrônico de varredura FEG das seções transversais dos lingotes do experimento Cu8Sn0,08Zr. Polimento até 0,05 $\mu \mathrm{m}$ com sílica, sem ataque químico. 
A Figura 65 (c) apresenta o resultado da microanálise por energia dispersiva de raios-X (EDS) da matriz e o cálculo da concentração de Sn na matriz. A concentração é de 10,24\%(peso)Sn, menor que o limite de solubilidade da fase $\alpha$ na tempertura do peritético que é de 15.8\%(peso)Sn (SAUNDERS; MIODOWNIK, 1990). Desta forma a matriz corresponde basicamente a uma solução sólida de Cu-Sn (Cu $\alpha$ ).

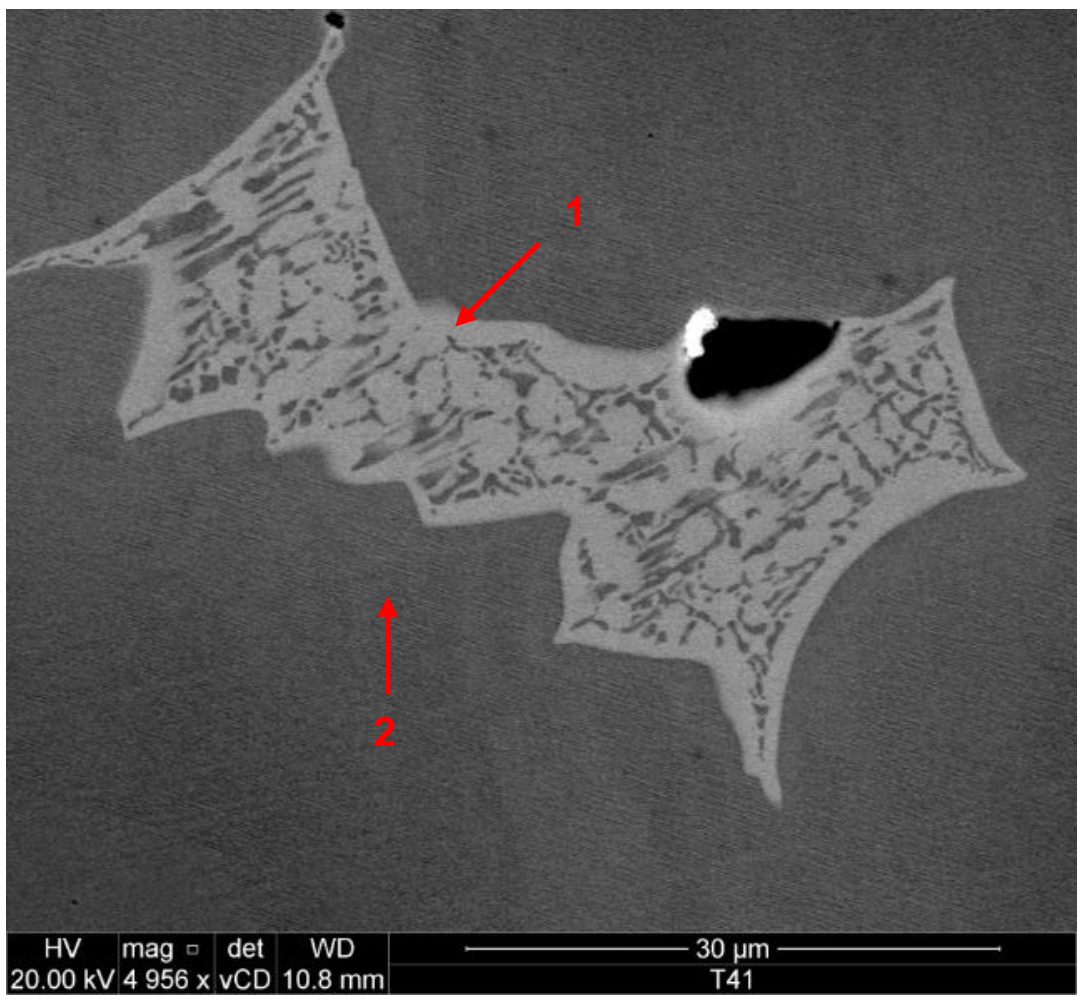

(a)

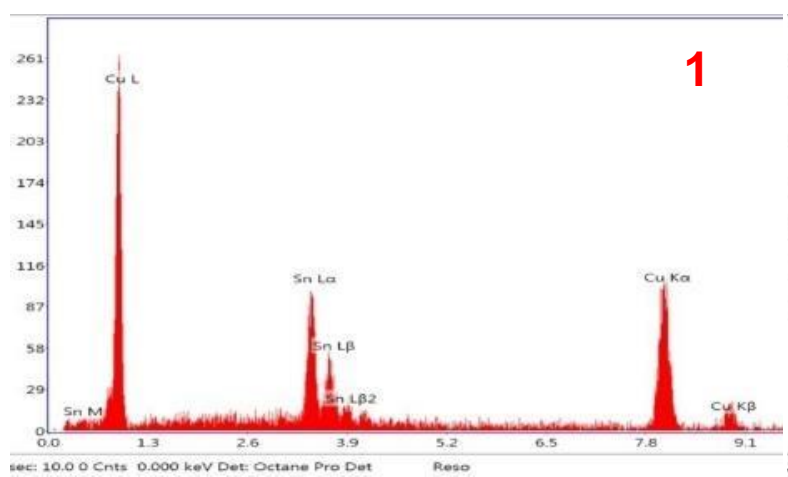

Element Weight \% Atomic \% Net Int. Net Int. Error

\begin{tabular}{lllll} 
SnL & 28.22 & 17.39 & 104.88 & 0.1 \\
\hline CuK & 71.78 & 82.61 & 163.28 & 0.04 \\
\hline
\end{tabular}

(b)

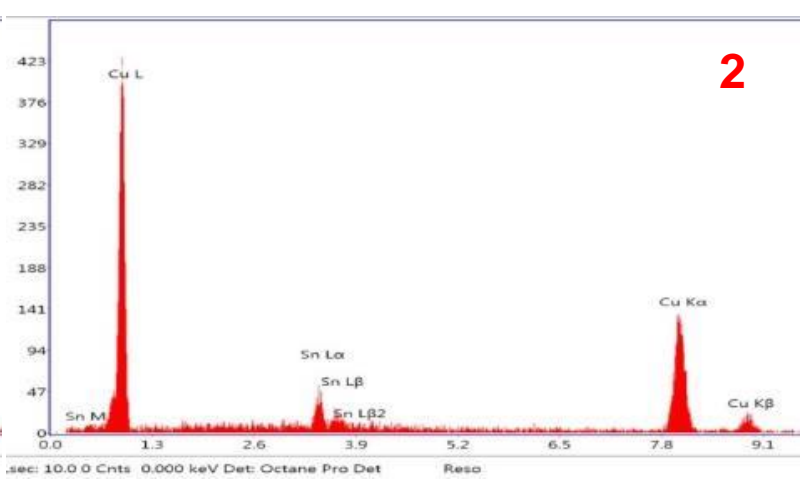

Element Weight \% Atomic \% Net Int. Net Int. Error

\begin{tabular}{lllll} 
SnL & 10.24 & 5.75 & 38.73 & 0.22 \\
\hline CuK & 89.76 & 94.25 & 206.16 & 0.03
\end{tabular}

(c)

Figura 65 - a) Fotomicrografia obtida por MEV FEG da microestrutura dos lingotes do experimento Cu8Sn, b) e c) espectros de energia dispersiva de raios-X (EDS) na posição assinalada com setas. Polimento até $0,05 \mu \mathrm{m}$ com sílica, sem ataque químico. 


\subsubsection{Análise microestrutural da liga Cu50\%Zr}

Foi realizada uma análise microestrutural da liga Cu-50\%Zr utilizada como ligamãe para se adicionar Zr ao banho liquido. O objetivo desta análise é a identificação de partículas que seriam sólidas e estáveis na temperatura do banho líquido e que poderiam funcionar como centros de nucleação heterogênea. A Figura 66 apresenta as micrografias obtidas em contraste de elétrons retroespalhados (MEV) e resultados da microanálise por EDS das fases da liga-mãe Cu-50\%Zr. As regiões mais claras indicam regiões ricas no elemento de maior número atômico, ou seja, o Zr. Ao comparar as concentrações obtidas por microanálise EDS com as do diagrama de fase da Figura 69, podemos inferir que a análise 1 ( $\mathrm{Zr}=32,5 \%$ (massa)) pode indicar a presença da fase Cu8Zr3 com composição 35\%Zr-65\%Cu (\%massa). Na análise 2 o teor de Zr é de 65,26\%(massa) sugerindo a presença da fase CuZr com composição $60 \% \mathrm{Zr}$ (massa). Finalmente a análise 3 com concentração de 48,5\% Zr (massa) indica que a matriz é o intermetálico $\mathrm{Cu}_{10} \mathrm{Zr}_{7}$, de composição $50 \% \mathrm{Zr}$ e $50 \% \mathrm{Cu}$ (massa). Todas estas fases seriam fundidas na temperatura utilizada para manter o banho líquido $\left(1250^{\circ} \mathrm{C}\right)$ nos experimentos do presente trabalho, como pode ser concluído a partir do diagrama de fases do sistema Cu-Zr (Figura 69). 


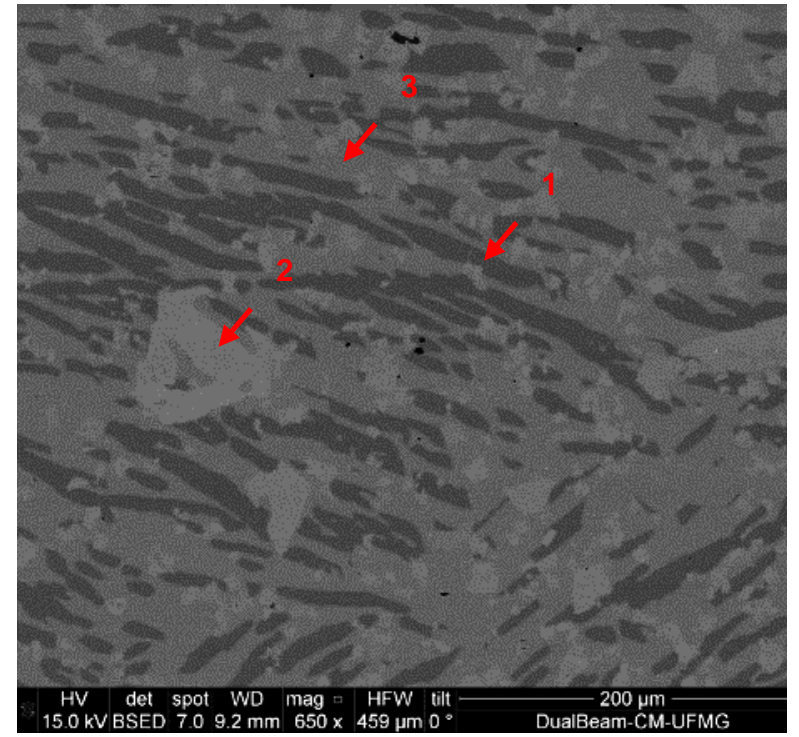

(a)

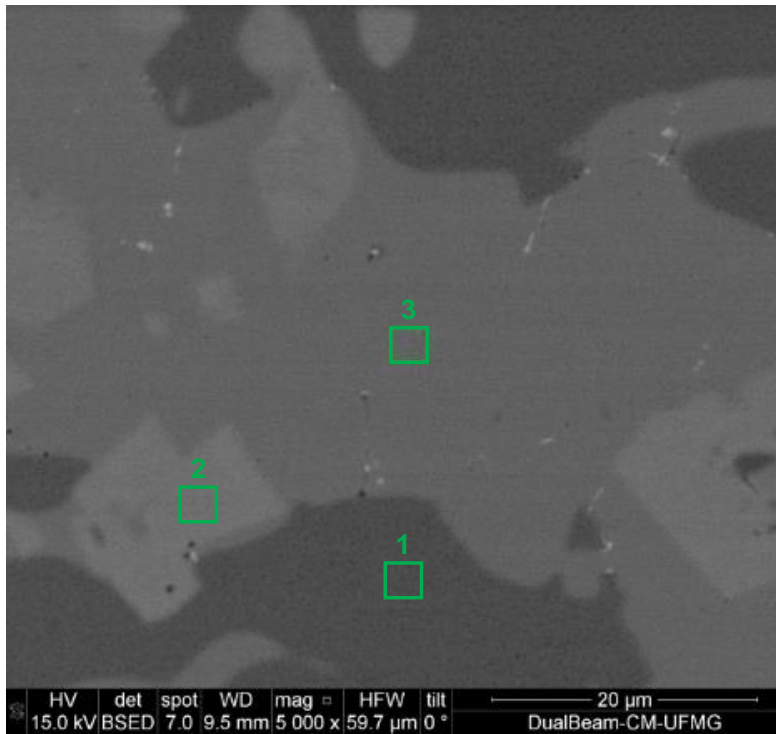

(b)

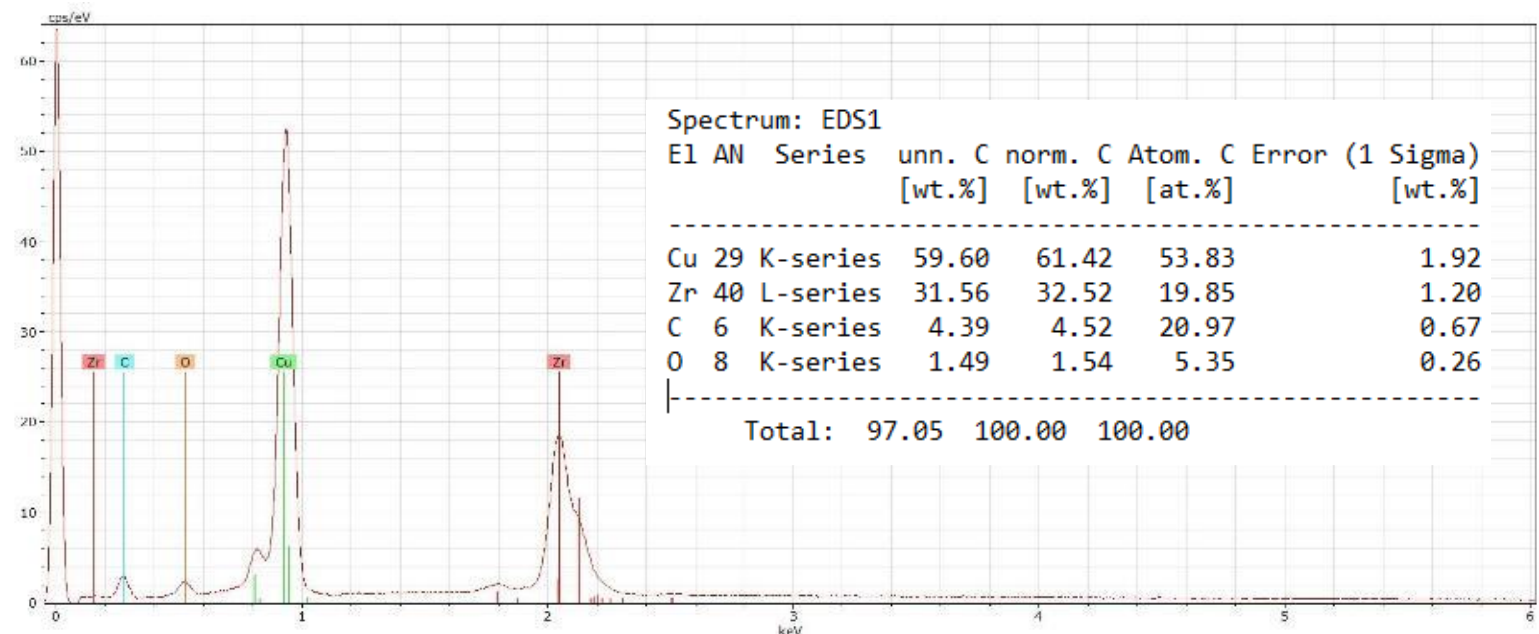

(1)

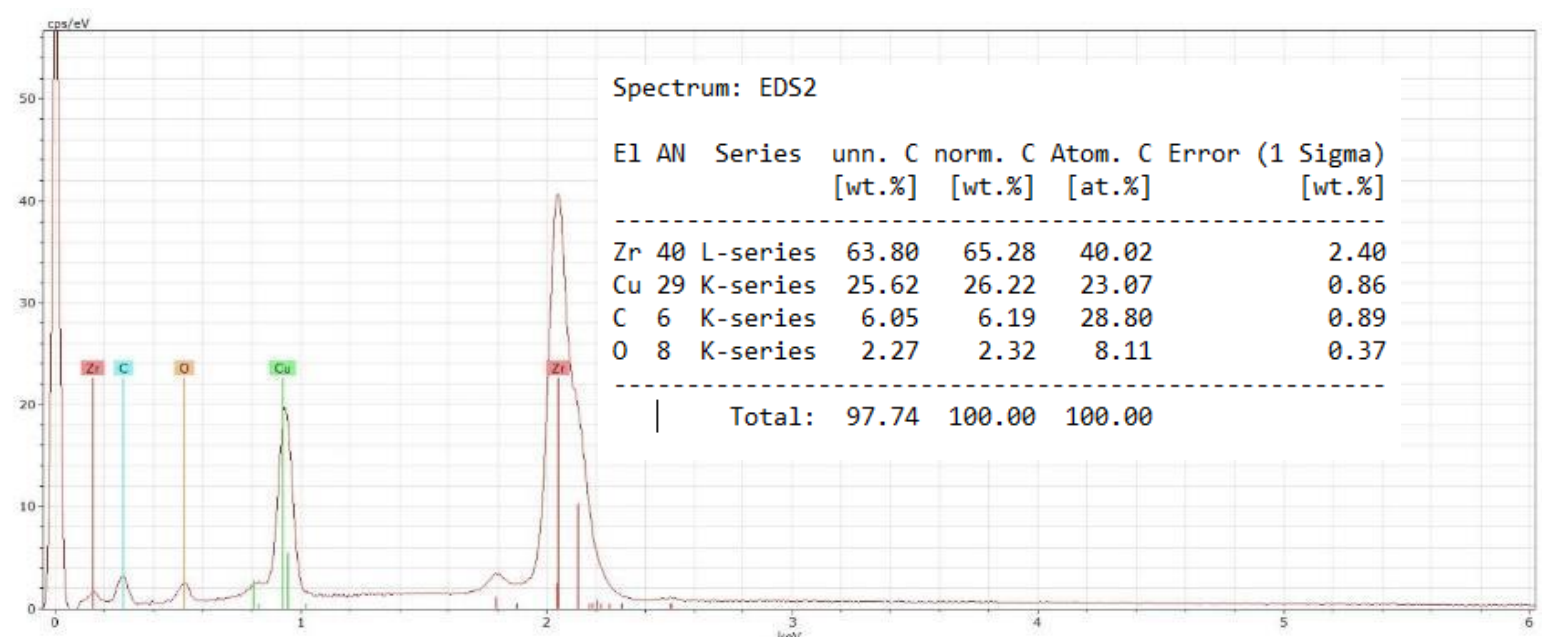

(2) 


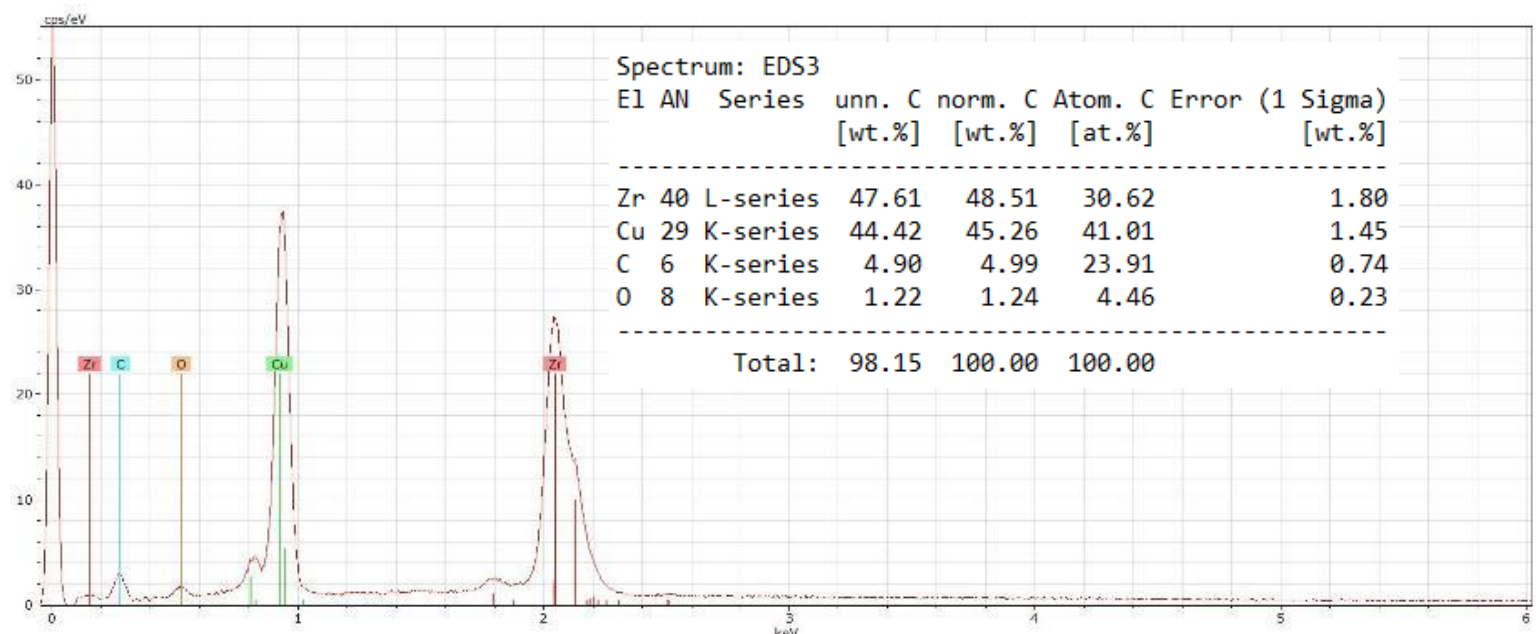

(3)

Figura 66 - Fotomicrografias obtidas por MEV FEG da microestrutura da liga Cu50\%Zr utilizada como inoculante: (a) e (b) imagem de elétrons retroespalhados; (1), (2) e (3) espectros de energia dispersiva de raios-X (EDS) na posição assinalada com setas. Polimento até $0,05 \mu \mathrm{m}$ com sílica, sem ataque químico.

\subsubsection{Análise microestrutural dos precipitados}

Os precipitados observados nas amostras obtidas a partir de adições crescentes de Zr a uma liga Cu-8\%Sn foram caracterizados em detalhe. Os resultados serão apresentados neste item. Inicialmente examinou-se a amostra sem adição de $\mathrm{Zr}$ (Cu8Sn0Zr), onde foram observadas poucas partículas ricas em enxofre e chumbo, no interior das regiões enriquecidas com estanho (última região a solidificar), como pode-se observar nas micrografias e espectros de EDS apresentados na Figura 67. Nesta amostra não apareceram partículas com formatos facetados, hexagonais ou bastonetes.

Quando o $\mathrm{Zr}$ foi adicionado na presença de uma fonte de carbono, precipitados facetados, na sua maioria com formato de disco hexagonal, apareceram na microestrutura. A Figura 68 apresenta um formato típico de precipitado e seu espectro de EDS correspondente para cada teor de $\mathrm{Zr}$, que aumentou na faixa de $0,04 \%$ a $0,4 \%$. O aumento do teor de $\mathrm{Zr}$ não parece causar uma diferença significativa na forma ou no tamanho destes precipitados. Em todos os espectros de EDS apresentados, o $\mathrm{Zr}$ é o elemento preponderante, as aparecem também em pelo menos um destes espectros os picos das energias características do $\mathrm{Cu}$ e/ou $\mathrm{C}$. Deve-se ressaltar que a energia dos fótons do elemento $\mathrm{C}$ é detectada com maior dificuldade pelo equipamento utilizado. Devido ao tamanho reduzido destes precipitados, o 
aparecimento dos picos das energias relativas ao Cu pode ser um efeito da matriz. No entanto, o diagrama de fases Cu-Zr (Figura 69) mostra a possibilidade da existência de intermetálicos do tipo $\mathrm{Cu}_{x} Z r_{y}$. Esta hipótese será examinada a partir de uma análise mais detalhada da composição e cristalográfica destes precipitados.
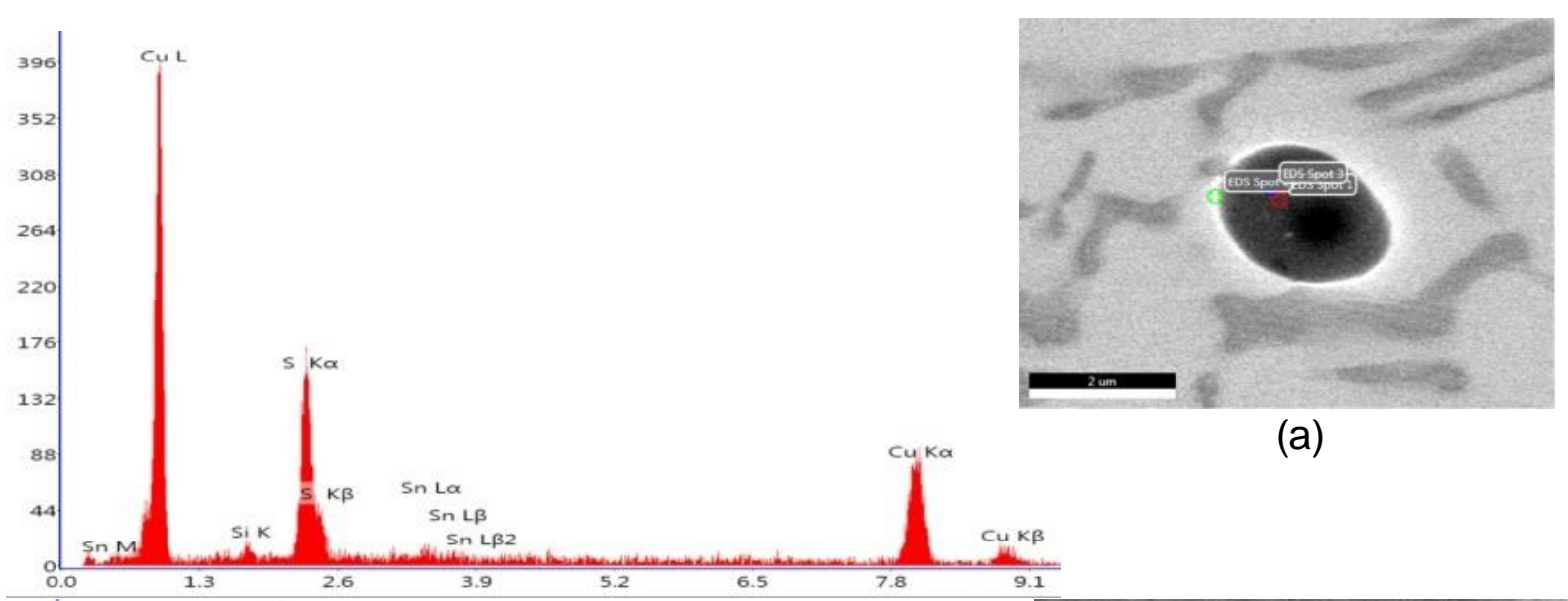

(a)

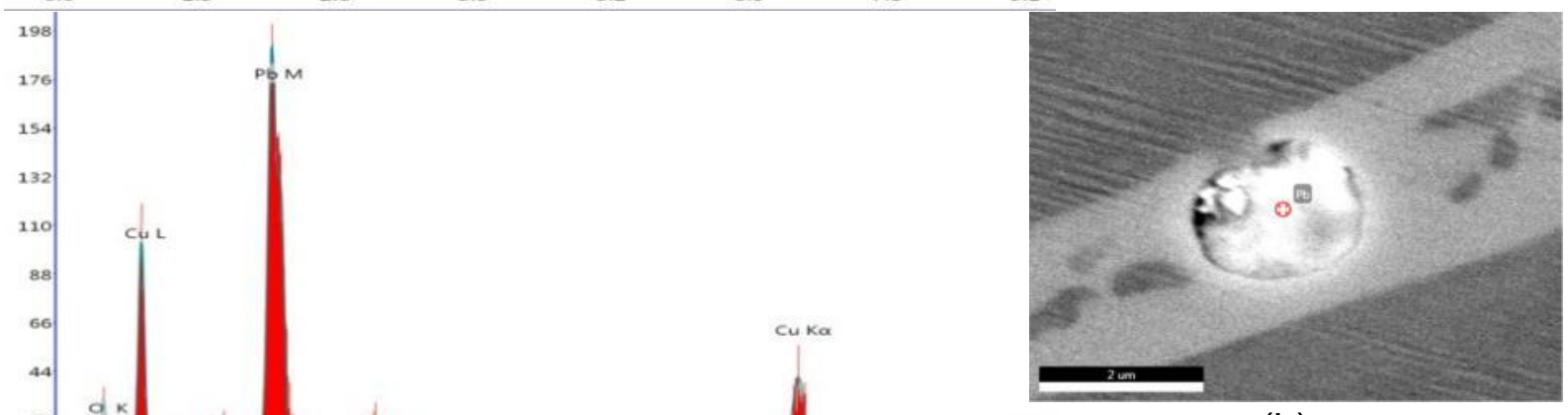

(b)
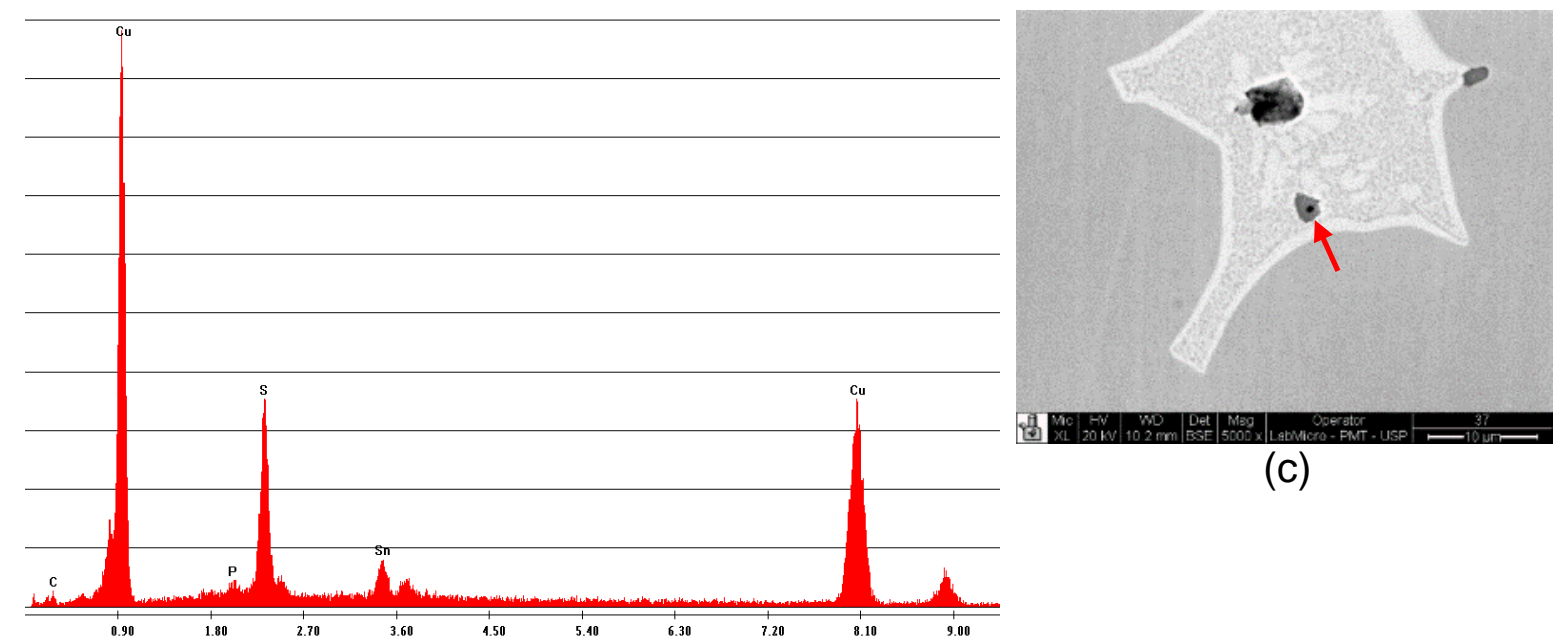

(c)

Figura 67 - Fotomicrografia obtida por MEV FEG da microestrutura dos lingotes do experimento Cu8Sn0Zr: (a) e (c) precipitados ricos em $\mathrm{S}$; b) precipitado rico em $\mathrm{Pb}$. Espectros de energia dispersiva de raios- $\mathrm{X}$ (EDS) na posição assinalada com seta vermelha. Polimento até $0,05 \mu \mathrm{m}$ com sílica, sem ataque químico. 

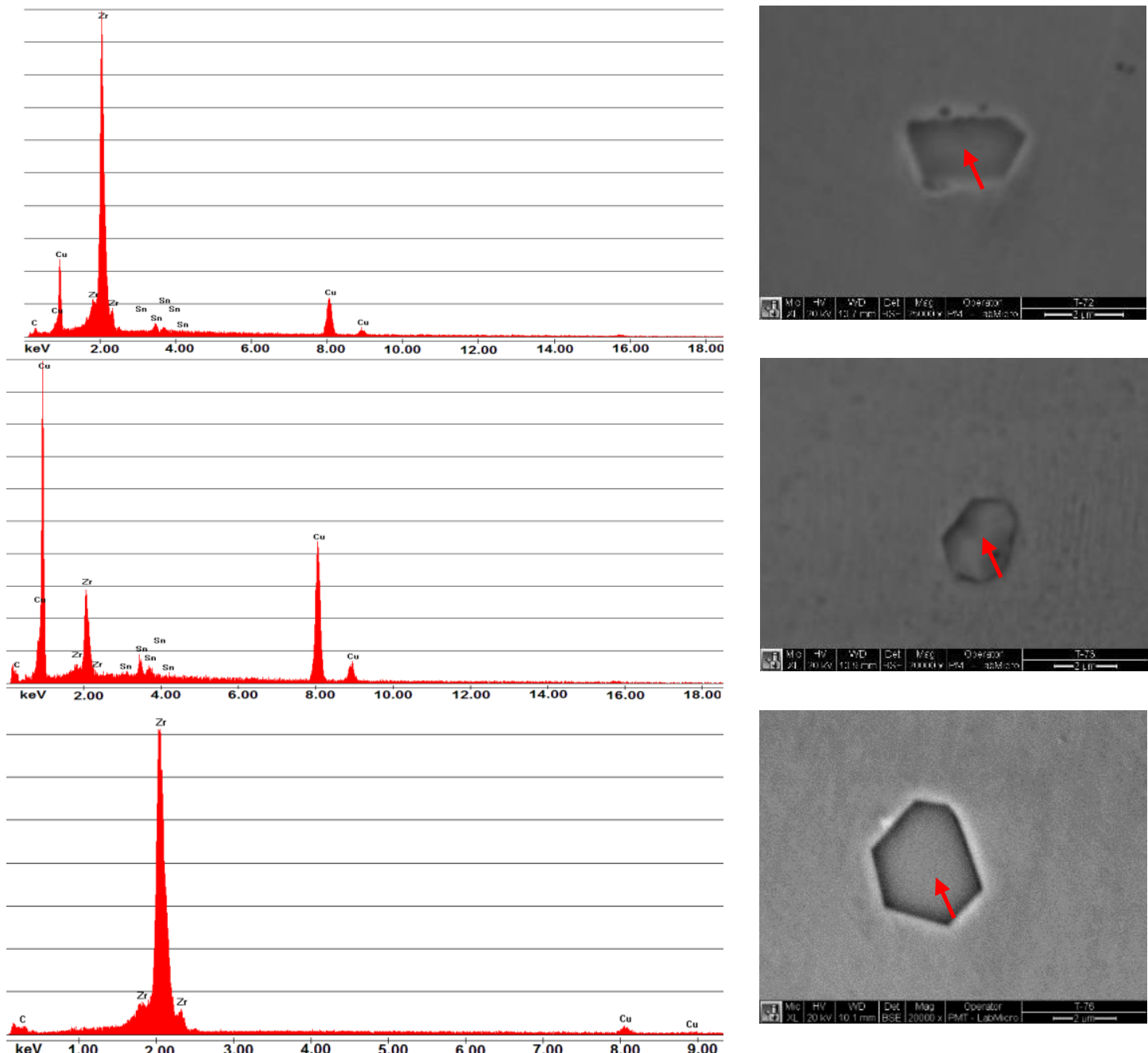

(a)

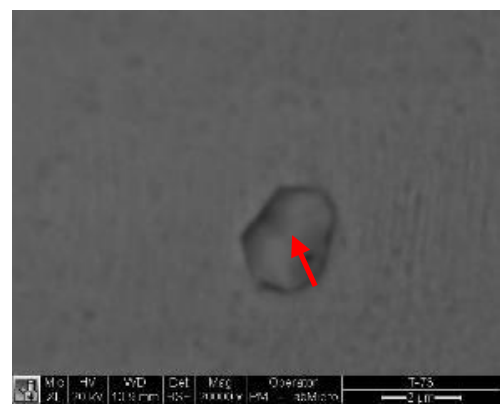

(b)

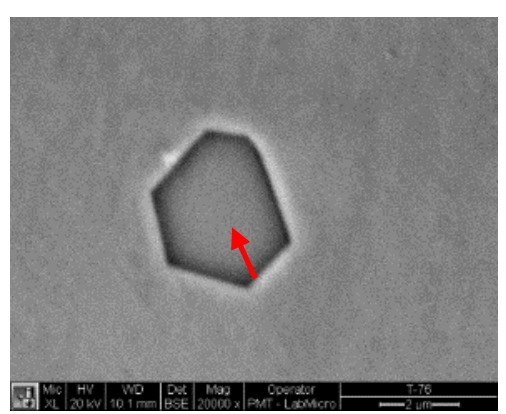

(c)
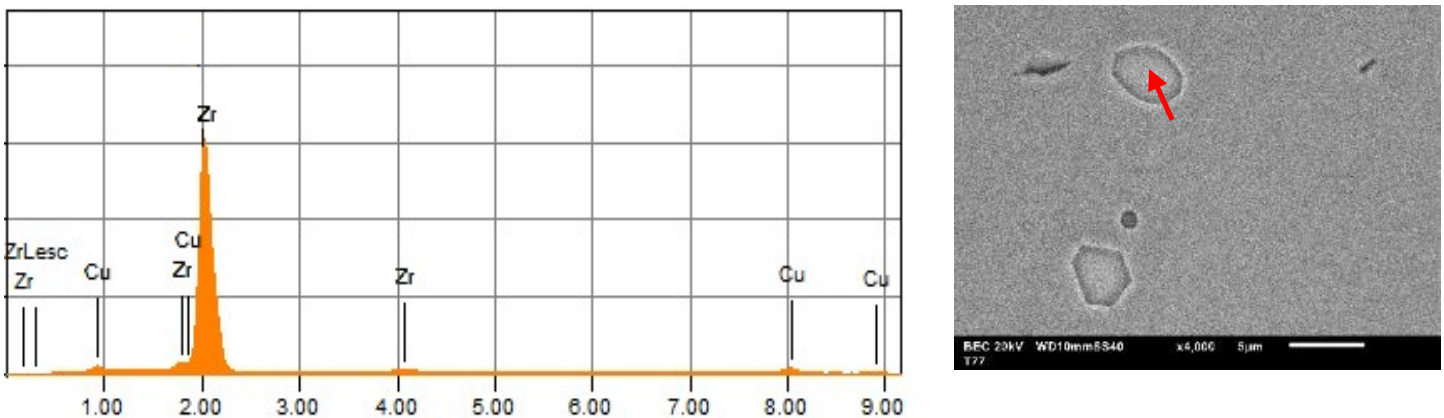

(d)

keV
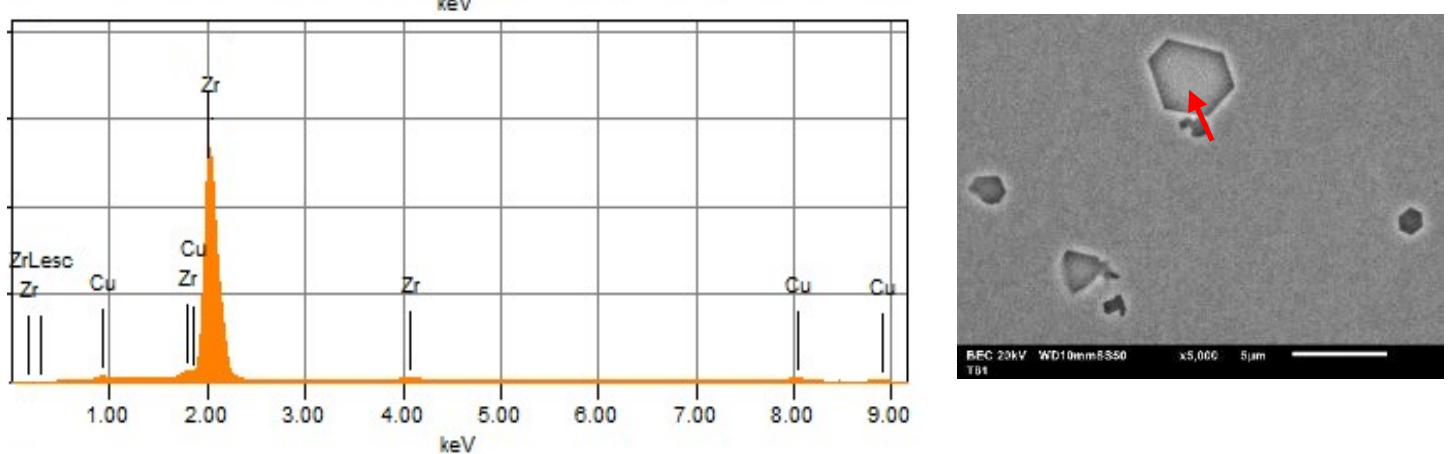

(e)

Figura 68 - Fotomicrografias eletrônicas no modo de elétrons retroespalhados e espectros de energia dispersiva de raios-X (EDS) na posição assinalada com setas, da série do experimento com adição de fósforo, zircônio e carbono: (a) Cu8Sn0,04Zr, (b) Cu8Sn0,08Zr, (c) Cu8Sn0,16Zr, (d) Cu8Sn0,24Zr, (e) Cu8Sn0,4Zr. Polimento até $0,05 \mu \mathrm{m}$ com sílica, sem ataque químico. 


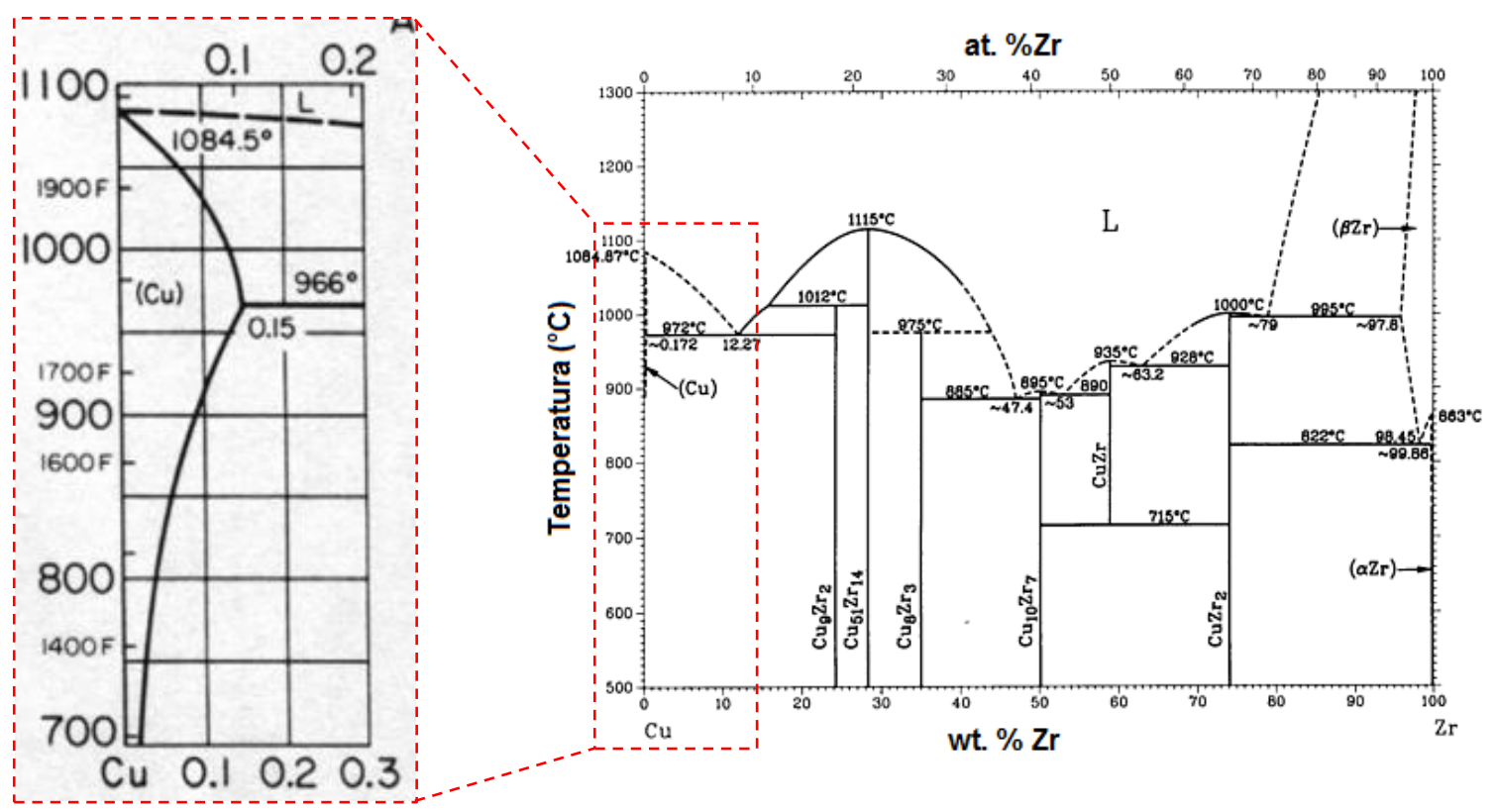

Figura 69 - Diagrama de fases Cu-Zr. Adaptado: (ARIAS; ABRIATA, 1990)

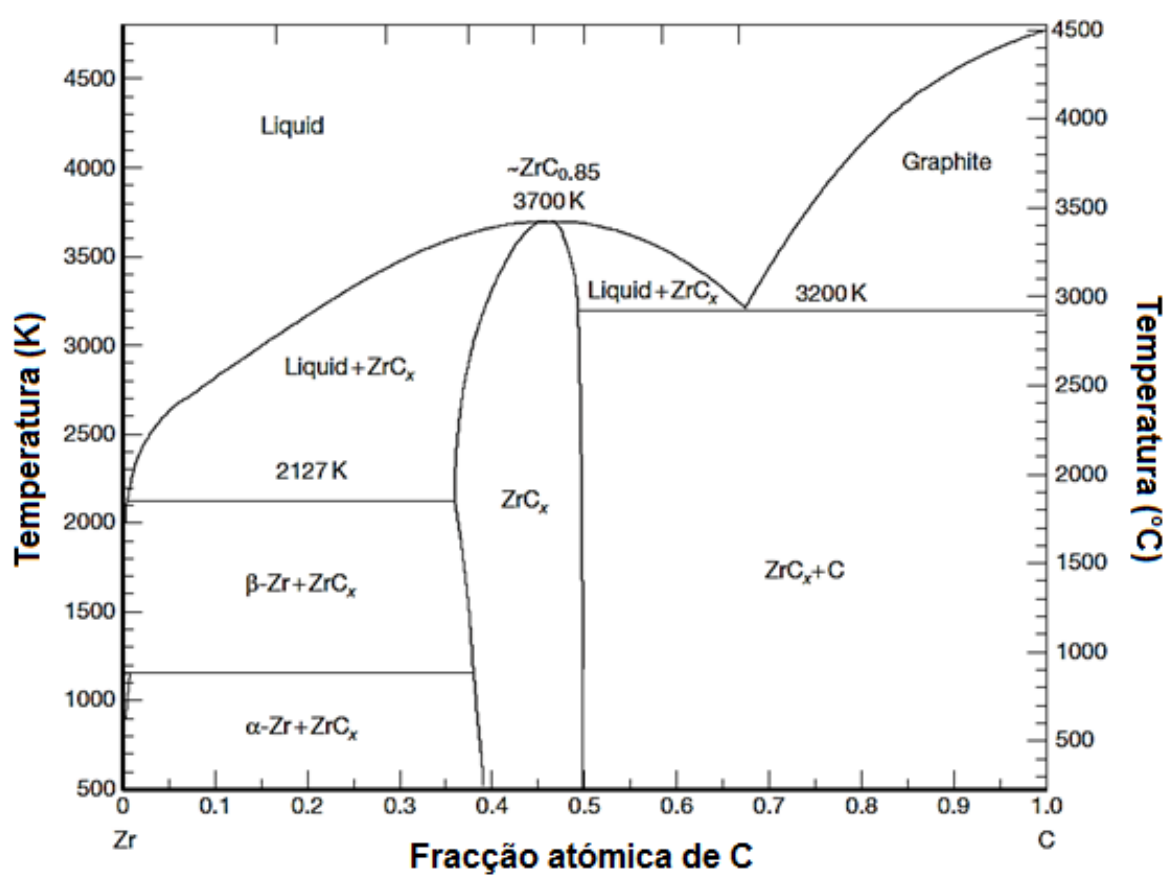

Figura 70 - Diagrama de fases Zr-C. (JACKSON; LEE, 2012)

Os precipitados facetados existentes na amostra do experimento Cu8Sn0,08Zr foram examinados em maiores detalhes na Figura 71 e Figura 72 . A Figura 71 mostra um precipitado na forma de bastão, que não foi a mais comum observada nas amostras deste trabalho. O espectro de EDS mostra a presença de $\mathrm{Zr}$ e $\mathrm{Cu}$ na 
proporção atômica $1 \mathrm{Cu}: 3 \mathrm{Zr}$, que não pode representar uma possível fase do diagrama Cu-Zr (Figura 69). Logo, a presença do Cu e em menor intensidade do Sn pode ser um efeito da matriz. Este efeito praticamente desaparece no espectro de EDS da partícula hexagonal analisada na Figura 72, representando mais uma evidência de que os picos de energia do Cu representam um efeito da matriz. A possibilidade destes precipitados serem formados por ZrC não é possível ser confirmada pelos espectros, já que, apesar do elemento $\mathrm{C}$ ser detectado como um pequeno pico na Figura 72 , este elemento está no limite da capacidade do detector.
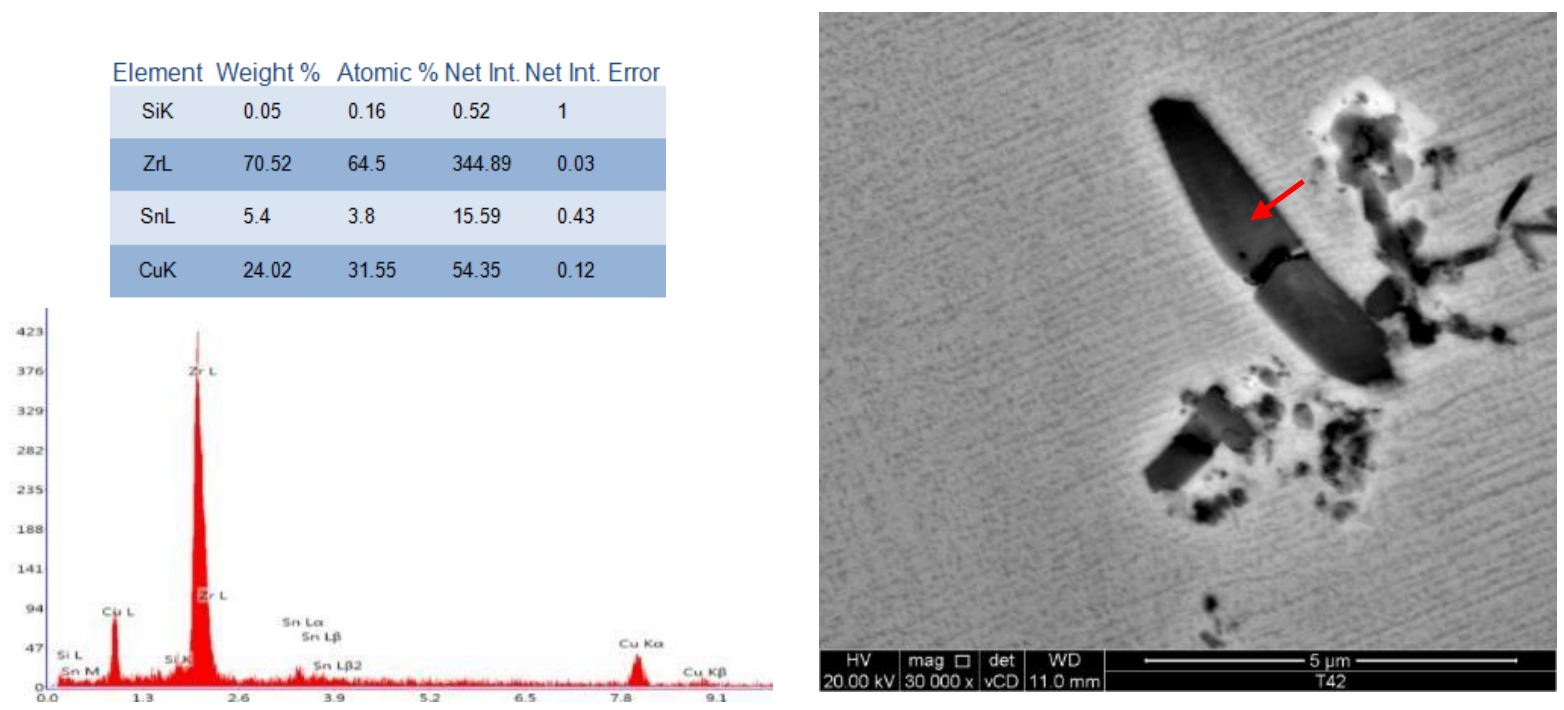

Figura 71 - Fotomicrografia obtida por MEV FEG dos precipitados na liga Cu8Sn0,08Zr. Polimento até $0,05 \mu \mathrm{m}$ com sílica, sem ataque químico (esquerda). Espectros de energia dispersiva de raios-X (EDS) na posição assinalada com a seta.
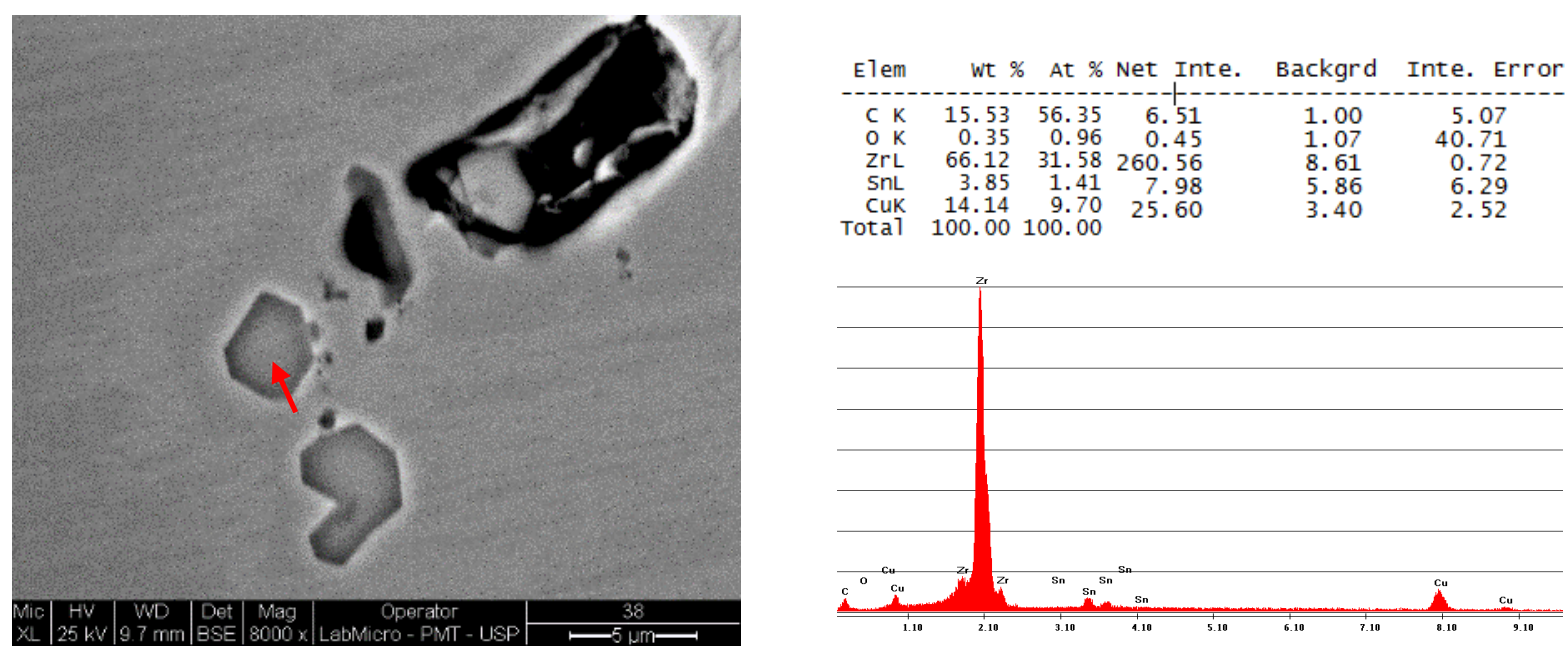

Figura 72 - Fotomicrografia obtida por MEV FEG do precipitado do experimento Cu8Sn0,08Zr. Polimento até $0,05 \mu \mathrm{m}$ com sílica, sem ataque químico (esquerda). Espectros de energia dispersiva de raios-X (EDS) na posição assinalada com a seta. 
Micrografias de um outro tipo de resíduo coletado pelo filtro estão apresentadas na Figura 73. A imagem da Figura 73(a), com um menor aumento, mostra um esqueleto, provavelmente resultante de uma dissolução parcial da estrutura dendrítica da fase primária. A Figura 73(b) e Figura 73(c) mostram maiores aumentos de um detalhe deste esqueleto (quadrado vermelho pontilhado). No maior aumento observado (Figura 73(d)) foi possível identificar um aglomerado de partículas de tamanhos da ordem de 0,1 $\mu \mathrm{m}$. O espectro de EDS sobre estas partículas mostra a marcante presença de $\mathrm{Zr}$, um pouco de $\mathrm{Cu}$ e $\mathrm{O}$ e um pico reduzido de $\mathrm{C}$. Estas partículas podem ser do mesmo tipo daquelas observadas na Figura 71 e Figura 72 , porém submetidas a um processo de dissolução que reduziu o seu tamanho e alterou o seu formato. Diversos resíduos retidos pelo filtro foram examinados e nenhum deles continha as partículas hexagonais de tamanho $\sim 3 \mu \mathrm{m}$, como observado na Figura 72 .
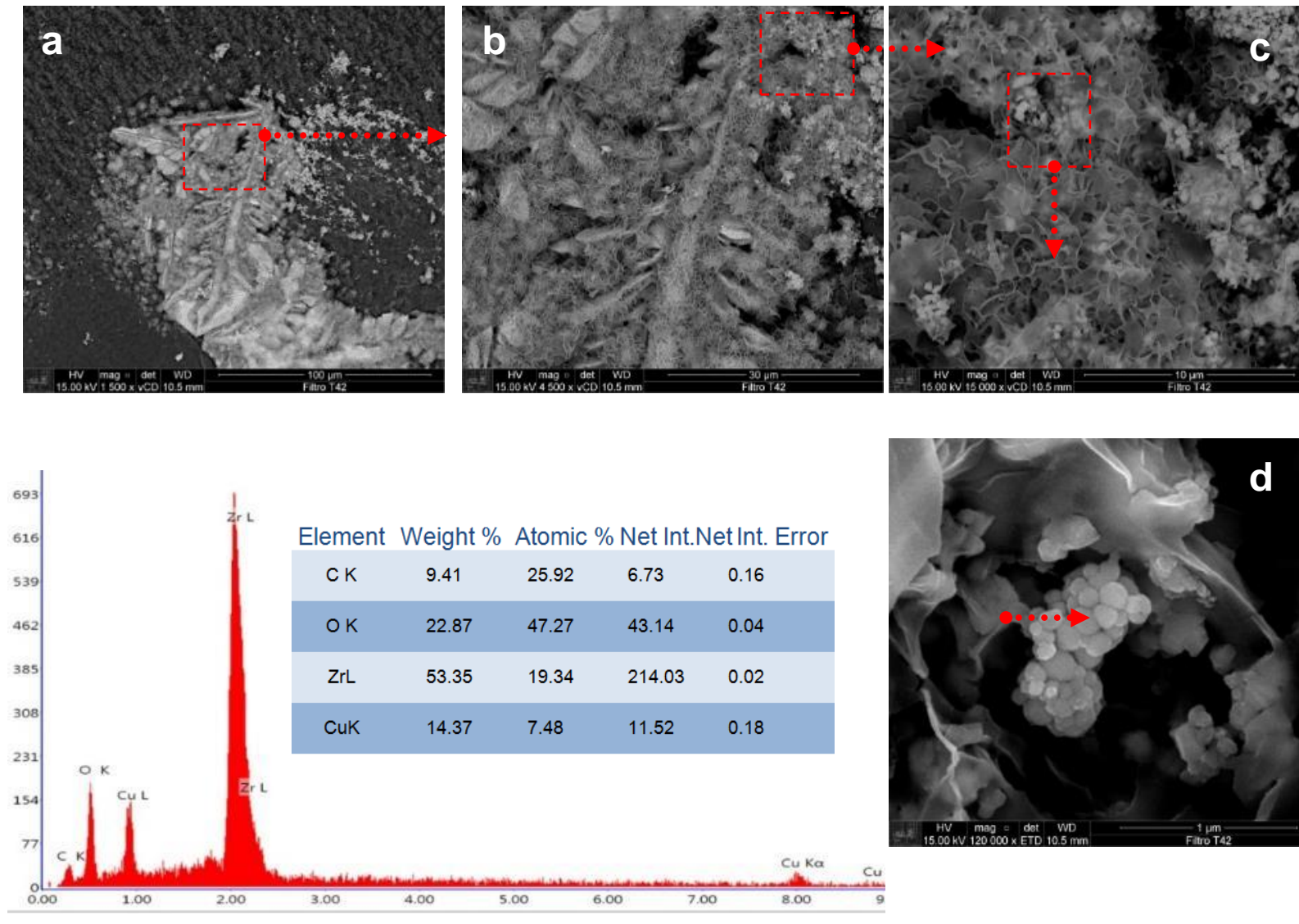

Figura 73 - Sequencia de aumentos na superfície do filtro: a) resíduo depositado no filtro, Imagens obtida por MEV FEG energia dispersiva de raios-X (EDS) na posição assinalada com a seta. Experimento Cu8Sn0,08Zr. 
Uma amostra do experimento analisado nos parágrafos anteriores (Cu8Sn0,8Zr) foi submetida ao processo de extração por réplica em filme de carbono em uma tentativa de eliminar o efeito do $\mathrm{Cu}$ possivelmente originário da matriz. $\mathrm{A}$ Figura 74 mostra as partículas depositadas no filme de carbono, que apresentam formatos de discos hexagonais e bastonetes e tamanhos da ordem de $3 \mu \mathrm{m}$, como aquelas apresentadas na Figura 68, Figura 71 e Figura 72, indicando que 0 procedimento de extração de precipitados conservou as partículas inicialmente presentes. O espectro de EDS apresentado na Figura 75 indica partículas ricas em $\mathrm{Zr}$, mas agora completamente sem a presença de $\mathrm{Cu}$, fornecendo uma forte evidência de que o Cu presente nos espectros de EDS anteriores era realmente um efeito da matriz e de que os precipitados hexagonais são formados por ZrC. Ainda nada pode ser concluído em relação à presença de $\mathrm{C}$, pois o pico relativo à energia deste elemento que aparece na Figura 75 pode ser originário do filme de carbono utilizado para a extração e não necessariamente do precipitado.

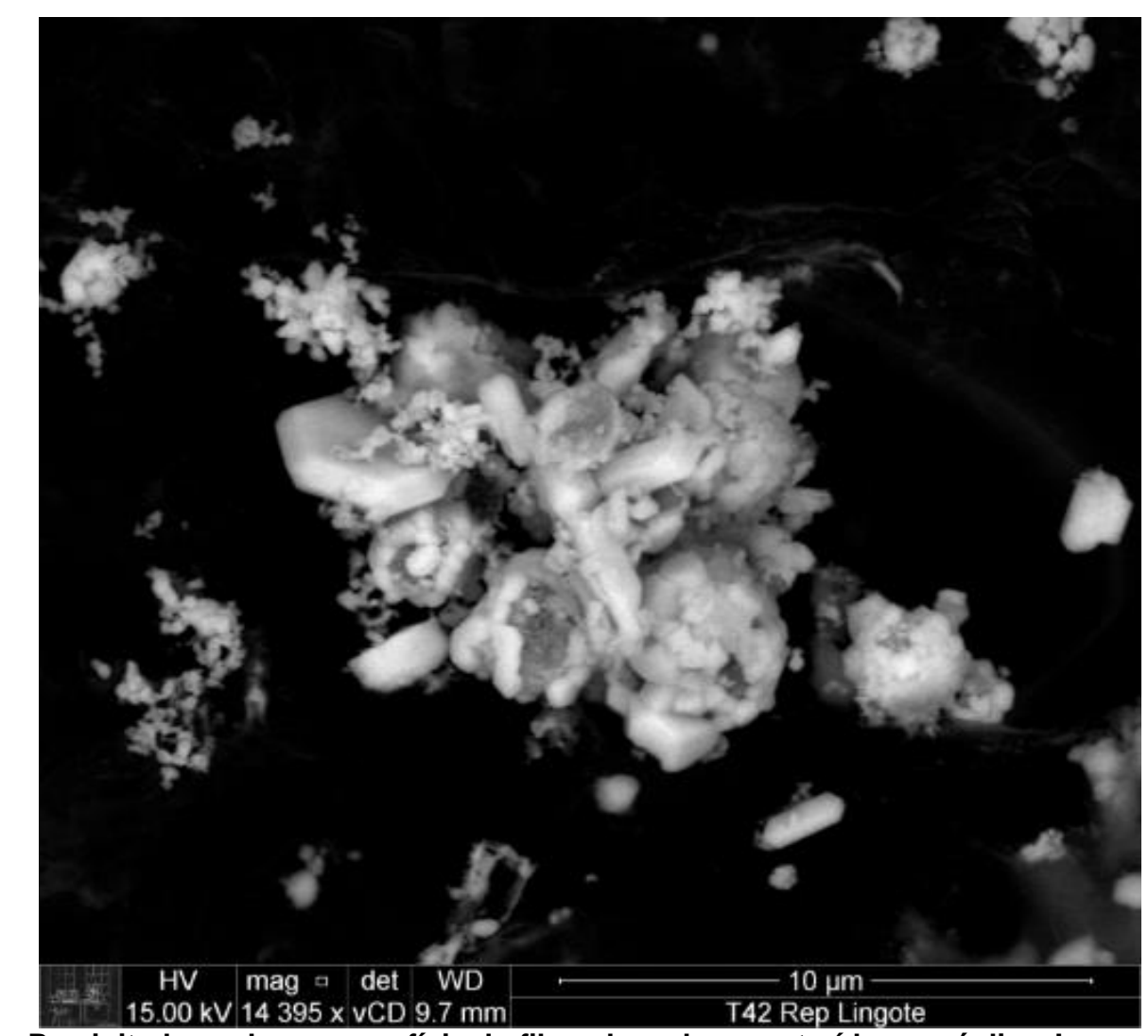

Figura 74 - Precipitados sobre a superfície do filme de carbono extraído por réplica. Imagem obtida por MEV-FEG. Experimento Cu8Sn0,08Zr. 


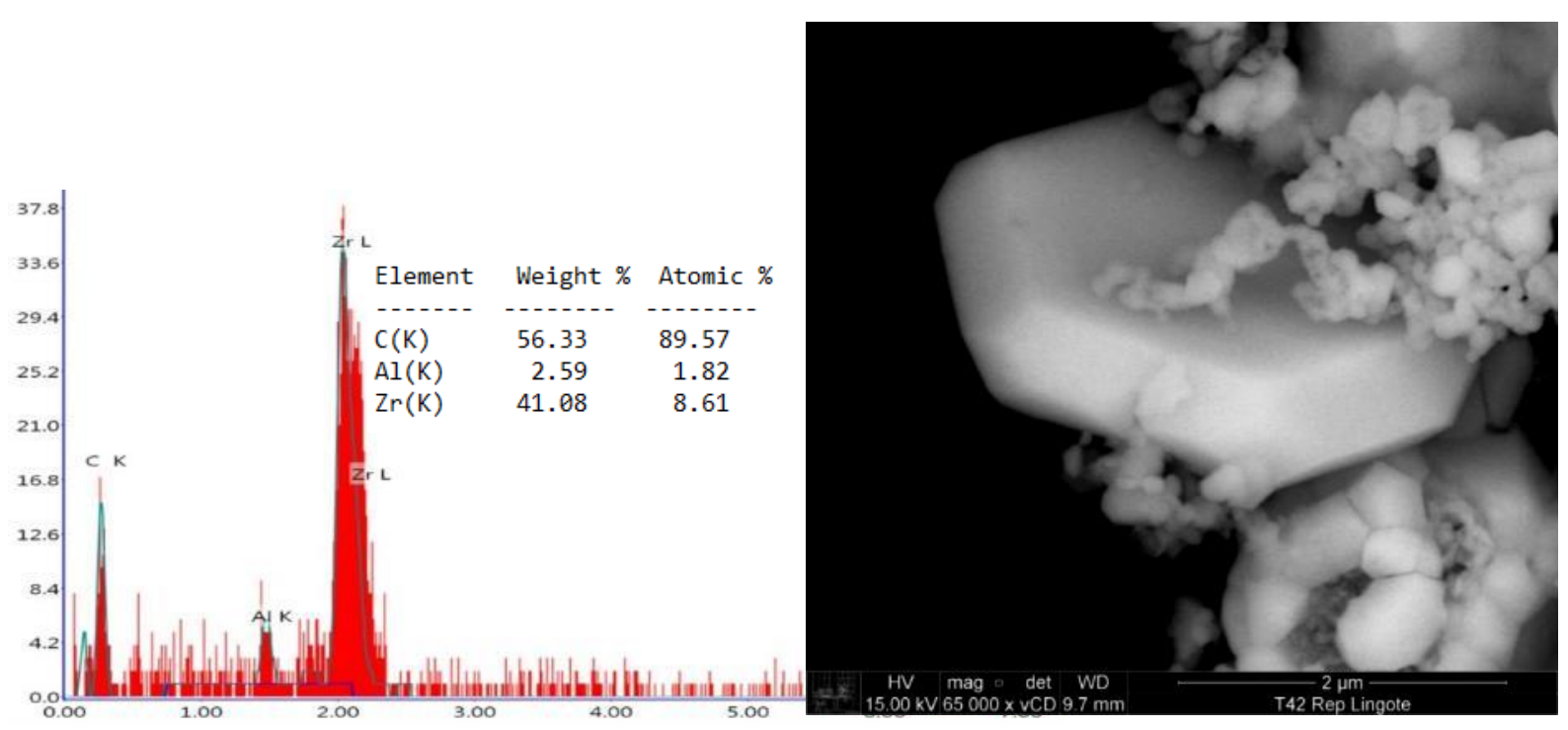

Figura 75 - Precipitados na superfície do filme de carbono. Imagem eletrônica e espectro de energia dispersiva de raios-X (EDS). Experimento Cu8Sn0,08Zr.

A técnica de extração por réplica em filme de carbono foi aplicada a uma amostra do experimento Cu8Sn0,16Zr, portanto contendo o dobro da adição nominal de $\mathrm{Zr}$ em comparação com a amostra analisada nos parágrafos anteriores (Cu8Sn0,08Zr). O filme de carbono com os precipitados foi examinado em um microscópio eletrônico de Transmissão Tecnai G2-20 - SuperTwin FEI - 200 kV, disponível no Centro de Microscopia da Universidade Federal de Minas Gerais, Belo Horizonte, MG, Brasil. Na Figura 76 está apresentada uma micrografia de um precipitado obtida por MET com o um espectro de EDS coletado sobre este precipitado. $\mathrm{O}$ espectro mostra mais acentuada a presença de $\mathrm{Zr}$, incluindo os picos $\mathrm{Ka}$ com 15,7keV e Kß com 17,6 keV, devido à maior tensão de aceleração do microscópio de 200kV. Pode-se observar novamente que não há a presença do $\mathrm{Cu}$, confirmando que o pico referente a este elemento era um efeito da matriz. O pico de energia do Ni é referente a grade que suporta o filme de carbono. Também ainda não se pode concluir sobre a existência de $C$ no precipitado, pois o pico da energia de $C$ observado pode ser um efeito do filme. 


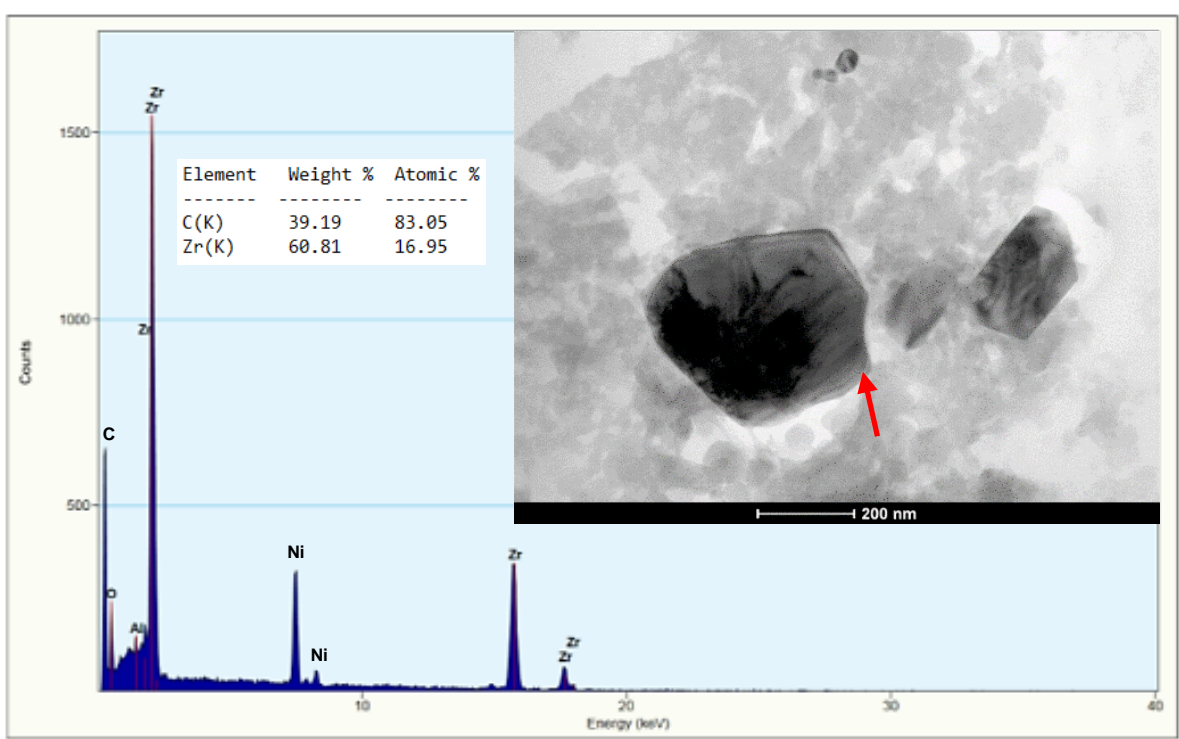

Figura 76 - Precipitados extraídos por réplica do experimento Cu8Sn0,16Zr. Imagem em campo claro e espectro de energia dispersiva de raios-X (EDS), na posição assinalada com a seta, obtida no MET Tecnai G2-20 - SuperTwin FEI - 200 kV.

Duas lâminas de uma amostra do experimento Cu8Sn0,16Zr contendo os precipitados hexagonais ricos em Zr foram extraídas com MEV-FEG-FIB (4.2.4.2) e analisadas em microscópio eletrônico de varredura (MEV) e microscópio eletrônico de transmissão (MET). As duas lâminas finas foram nomeadas de $(A)$ e $(B)$ e estão apresentadas na Figura 77 e na Figura 78, respectivamente. Nas imagens de elétrons secundários obtidas no MEV, pode-se observar parte dos precipitados facetados no interior da matriz e a interface entre as duas fases (interface precipitado-matriz), esta última ressaltada com a linha tracejada vermelha. A amostra apresenta tons de cinzas onde as partes mais claras representam as regiões de menor densidade das lâminas finas, condição necessária para se ter a transmissibilidade necessária à observação no microscópio eletrônico de transmissão. A seção do precipitado apresenta novamente um formato facetado e aproximadamente hexagonal.

Foram obtidos espectros de EDS nestes precipitados e na matriz ao redor utilizando-se o MET. Agora, como as amostras não foram obtidas pela técnica de extração de precipitados, não deverá existir a interferência do filme de $\mathrm{C}$ e nem da matriz $(\mathrm{Cu})$, visto que a região afetada pelo feixe de elétrons do MET é muito menor do que o tamanho do precipitado. Os espectros (Figura 77c e Figura 78c) mostram que a matriz junto ao precipitado contém aproximadamente 3\%(massa) Sn. Está bem estabelecido que a solução sólida da fase $\mathrm{Cu}$ - $\alpha$, tem uma composição de Sn na faixa 
de 0 até 13.5\%(massa) segundo (SAUNDERS; MIODOWNIK, 1990), o que corrobora a existência desta fase. Por outro lado, segundo o diagrama de fases $\mathrm{Zr}$-C (Figura 70), o $\mathrm{ZrC}$ contém uma faixa de composição de C que varia entre 37,5 e 49,5\%(atômica) C. Os espectros de EDS sobre as partículas hexagonais (Figura 77b e Figura 78b) mostram que o teor de carbono está dentro desta faixa. Estas evidências indicam fortemente que os precipitados facetados são formados de $\mathrm{ZrC}$, confirmando a hipótese inicial. 

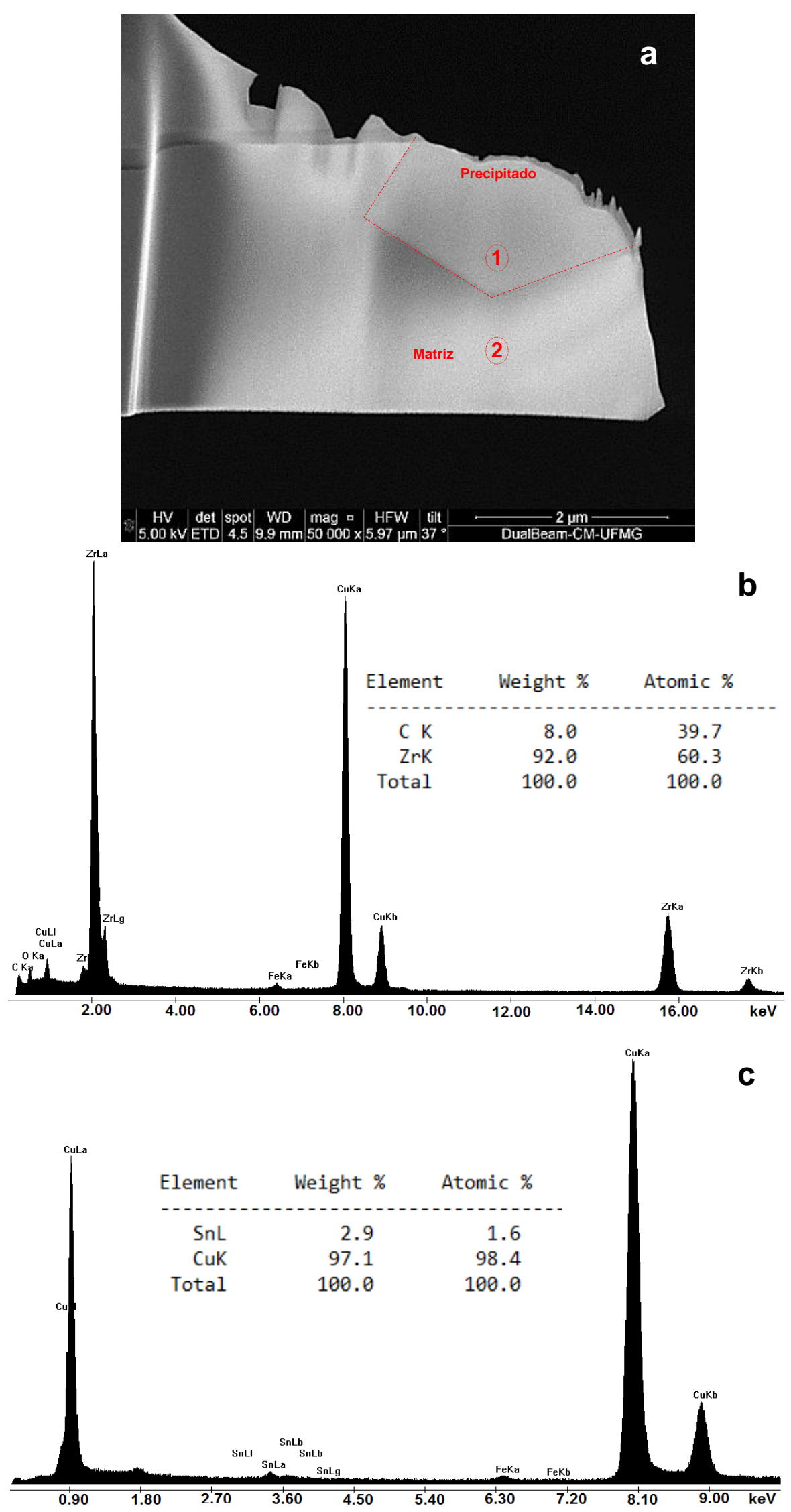

Figura 77- (a) Fotomicrografia em elétrons secundários obtida em microscópio eletrônico de varredura FEG da amostra (A) do experimento Cu8Sn0,16Zr contendo o precipitado e a matriz, (b) espectro de EDS na região 1 (precipitado), (c) espectro de EDS na região 2 (matriz). Espectros de EDS obtidos no MET Tecnai G2-20 - SuperTwin FEl - 200 kV. 


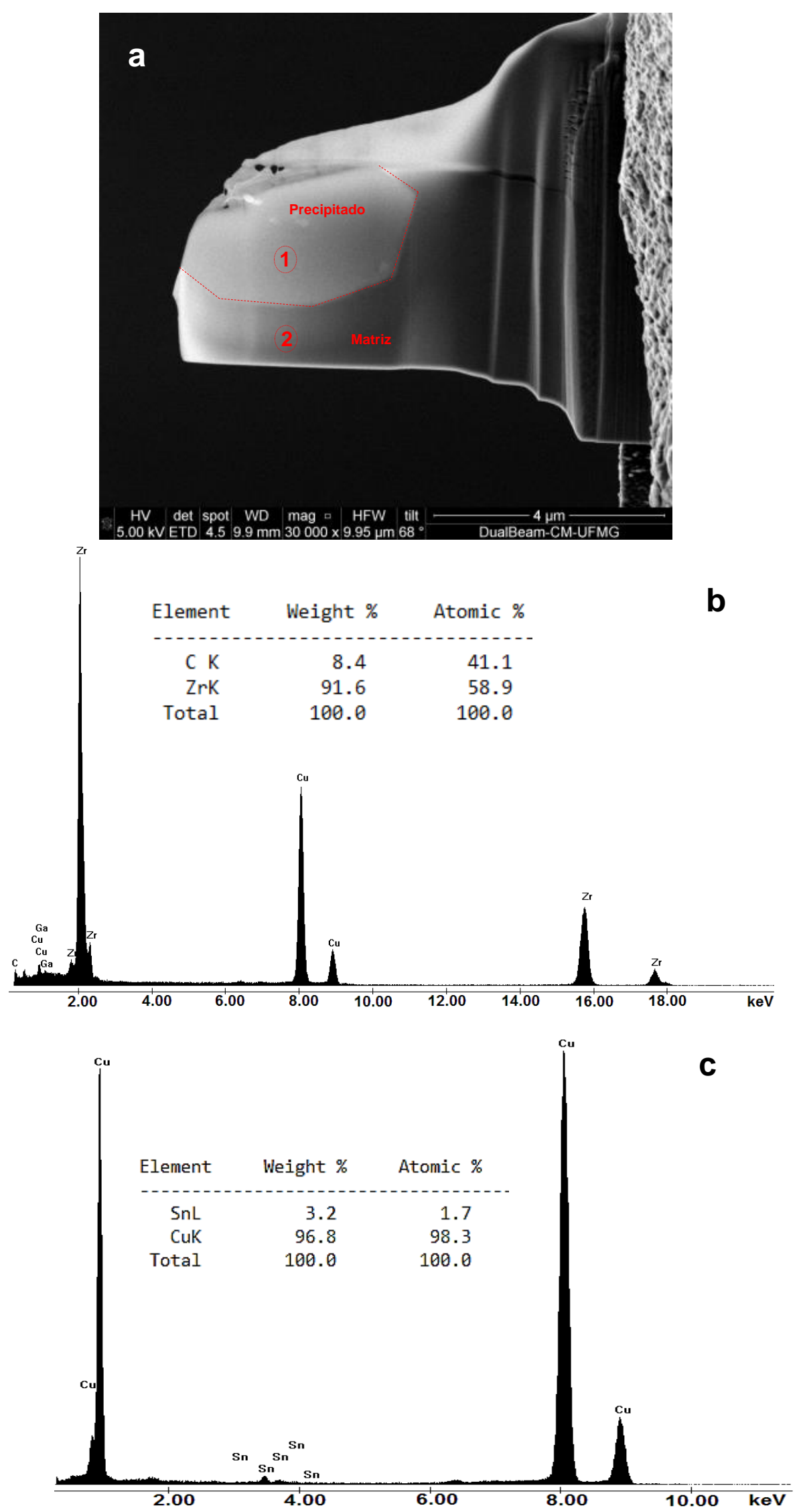

Figura 78- (a) Fotomicrografia em elétrons secundários obtida no microscópio eletrônico de varredura FEG da amostra (B) extraída com MEV-FEG-FIB do experimento Cu8Sn0,16Zr contendo o precipitado e a matriz, (b) espectro de EDS na região 1 (precipitado), (c) espectro de EDS na região 2 (matriz). Espectros de EDS obtidos no MET Tecnai G2-20 - SuperTwin FEI - 200 kV. 


\subsubsection{Análise Cristalográfica dos precipitados}

No item anterior, foi confirmada que o efeito acentuado de refino de grão que ocorre quando o $\mathrm{Zr}$ é adicionado a banhos da liga Cu-Sn na presença de uma fonte de $\mathrm{C}$ coincide com o aparecimento de partículas de $\mathrm{ZrC}$. Neste item, uma análise aprofundada da cristalografia destes carbonetos foi realizada a partir da técnica de difração de elétrons aplicada às laminas finas descritas no item anterior. Na sequência da Figura 79 até a Figura 82 estão apresentados os conjuntos de padrões de difração de elétrons obtidos nas regiões marcadas com o círculo vermelho da imagem de campo claro apresentada em cada figura. A sequência da Tabela 21 até a Tabela 24 mostra os planos indexados nos padrões de difração e suas respectivas distâncias interplanares $\left(\mathbf{d}_{\mathbf{h k}}\right)$.

Como inicialmente a estrutura do precipitado é supostamente desconhecida, as imagens de difração foram obtidas utilizando o porta-objeto de dupla inclinação dentro do microscópio com a finalidade de se obter condições de difração ótimas para registrar no mínimo 3 eixos de zona para o precipitado e a matriz. As imagens de difração foram indexadas utilizando como ponto de partida a possível estrutura do ZrC, que cristaliza numa estrutura cúbica de faces centradas do tipo $\mathrm{NaCl} \mathrm{Fm-3m}$, do grupo espacial 225 (TOTH, 2014). Este sistema cristalino é igual ao da fase-matriz, Cu-a (MORIKAWA et al., 1967). Os resultados da indexação dos padrões de difração feitos pelo método das razões como descrito no Item 4.2.4.2, confirmam que a matriz corresponde a fase $\mathrm{Cu}-\alpha$ e que o precipitado facetado investigado é o $\mathrm{ZrC}$. 


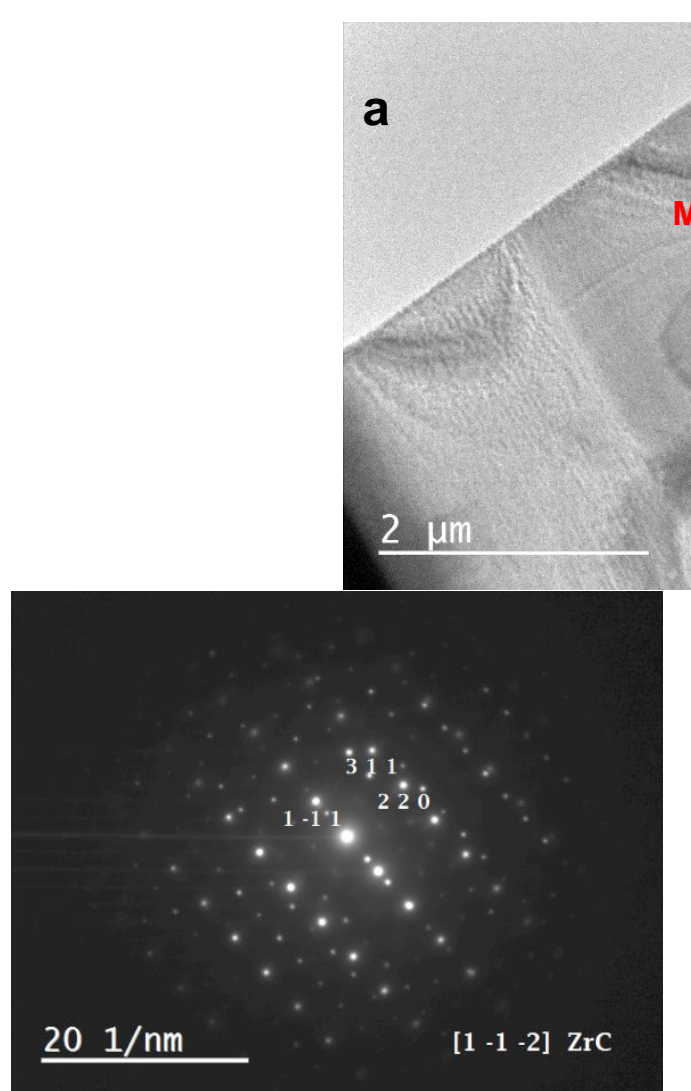

(b)

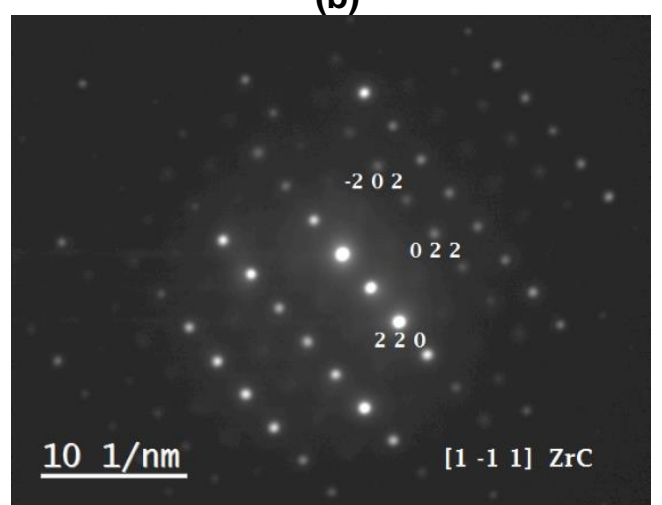

(d)

\section{Matriz}

Precipitado

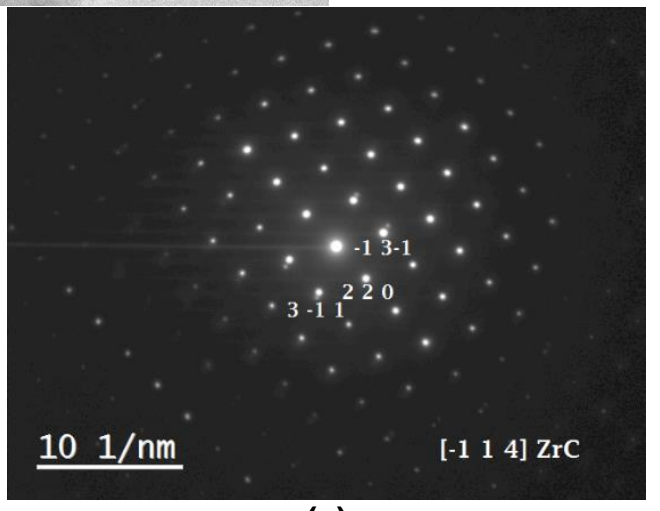

(c)

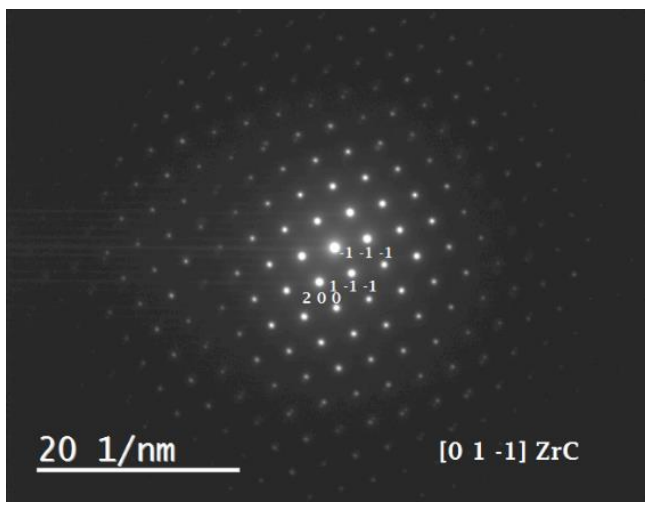

(e)

Figura 79- Padrões de difração indexados do precipitado da lâmina (A): a) imagem em campo claro, o círculo vermelho marca a área de coleta das difrações; b) eixo de zona [1 -1 -2]; c) eixo de zona [-1 14$]$, d) eixo de zona [ 1 -1 1] e e) eixo de zona [0 1 -1]. Imagens obtidas no MET Tecnai G2-20 - SuperTwin FEI - 200 kV.

Tabela 21- Distancias interplanares medidas dos padrões de difração da Figura 79, comparadas com o cartão padrão do ZrC (ICSD: Inorganic Crystal Structure Database, código: 159874) *.

\begin{tabular}{|c|c|c|c|c|c|}
\hline \multirow{2}{*}{\multicolumn{2}{|c|}{$\operatorname{ZrC~} d_{h k l}{ }^{*}$}} & \multicolumn{4}{|c|}{ Eixo de zona } \\
\hline & & {$\left[\begin{array}{lll}1 & -1 & -2\end{array}\right]$} & {$\left[\begin{array}{llll}-1 & 1 & 4\end{array}\right]$} & {$\left[\begin{array}{lll}1 & -1 & 1\end{array}\right]$} & {$\left[\begin{array}{lll}0 & 1 & -1\end{array}\right]$} \\
\hline Plano & d (nm) & $d(n m)$ & d (nm) & d (nm) & d (nm) \\
\hline (1 111 ) & 0,27122 & $0,221+0,050$ & & & $0,300-0,028$ \\
\hline$\left(\begin{array}{lll}2 & 0 & 0\end{array}\right)$ & 0,23488 & & & & $0,267-0,032$ \\
\hline$\left(\begin{array}{lll}2 & 2 & 0\end{array}\right)$ & 0,16609 & $0,136+0,030$ & 0,332 & $0,168-0,002$ & \\
\hline (3 111$)$ & 0,14164 & & 0,296 & & \\
\hline
\end{tabular}




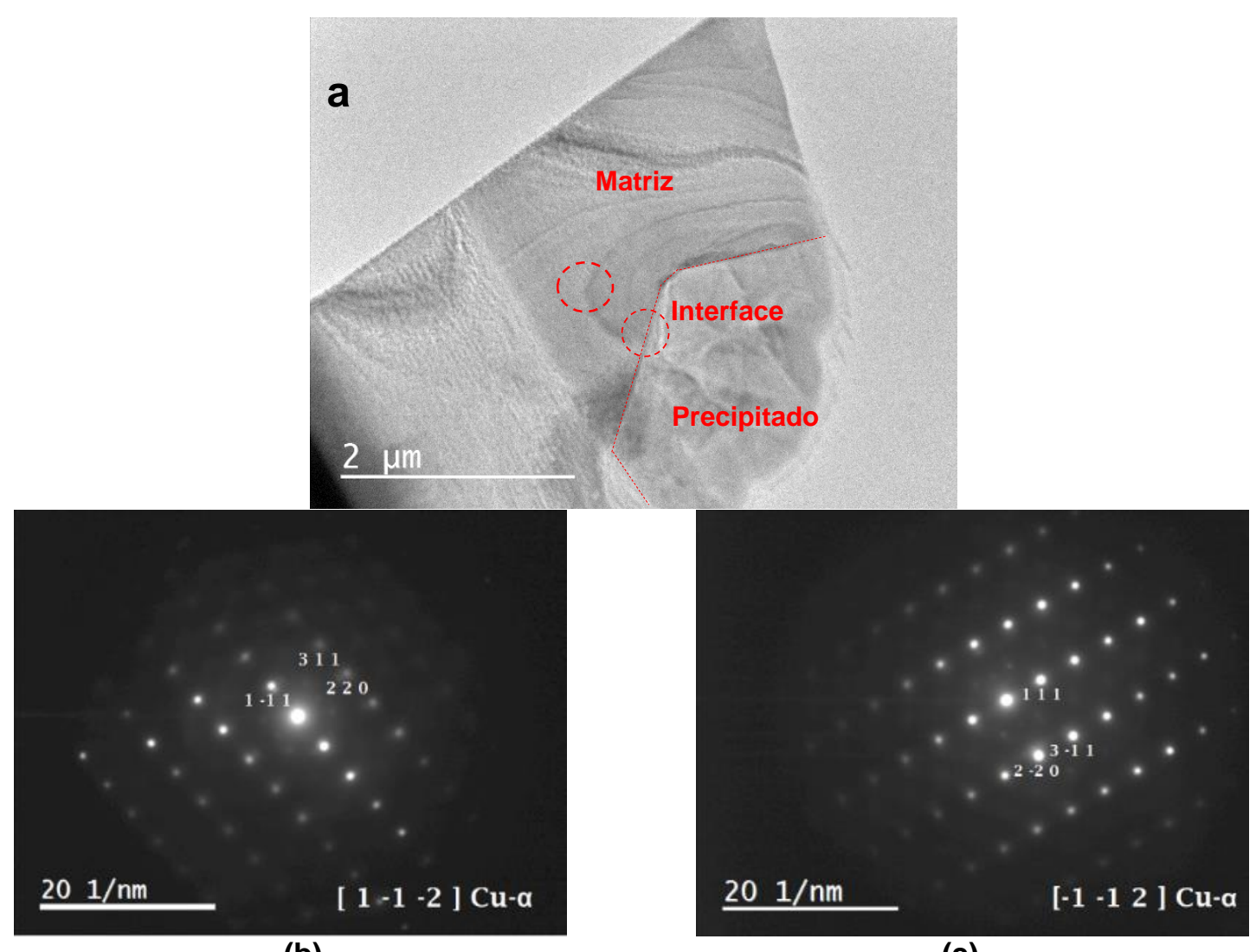

(b)

(c)
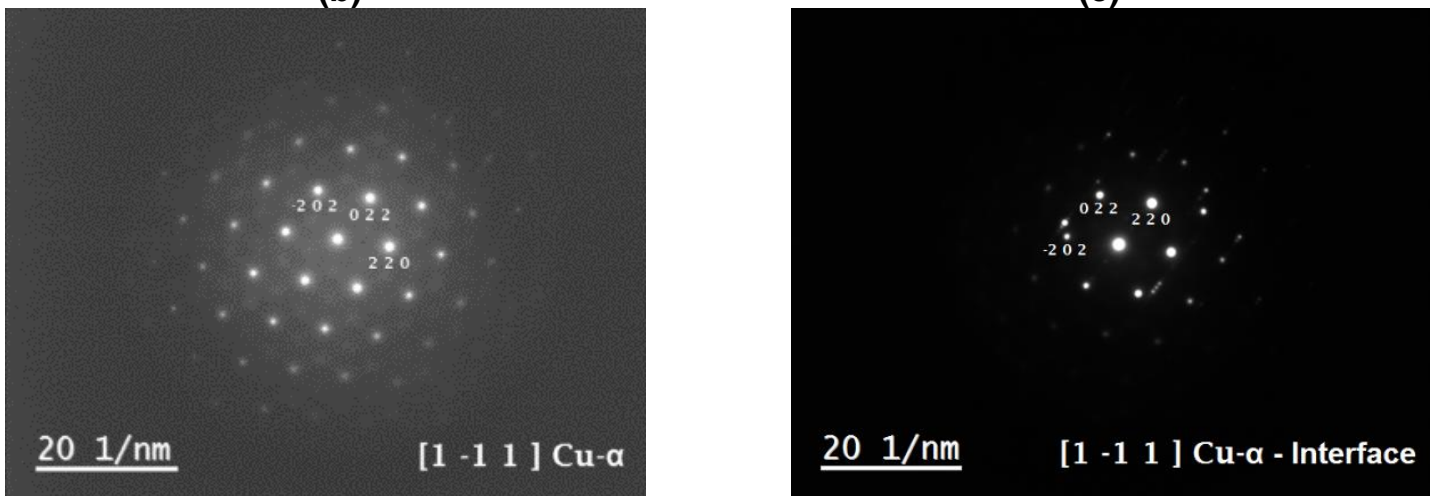

(d)

(e)

Figura 80- Padrões de difração indexados da matriz da lâmina (A): a) imagem em campo claro, o círculo vermelho marca a área de coleta das difrações; b) eixo de zona [1 -1 -2]; c) eixo de zona [-1 -1 2], d) eixo de zona [1 -1 1] e e) interface com eixo de zona [1 -1 1], na posição da interface. Imagens obtidas no MET Tecnai G2-20 - SuperTwin FEI - 200 kV.

Tabela 22- Distancias interplanares medidas nos padrões de difração Figura 80, comparadas com o cartão padrão do Cu-a (ICSD: Inorganic Crystal Structure Database, código: 03-065-682) *.

\begin{tabular}{|c|c|c|c|c|c|}
\hline \multicolumn{2}{|c|}{ Cu- $\alpha d_{h k l}$ * } & \multicolumn{4}{|c|}{ Eixo de zona } \\
\hline & & {$\left[\begin{array}{lll}1 & -1 & -2\end{array}\right]$} & {$\left[\begin{array}{lll}-1 & -1 & 2\end{array}\right]$} & {$\left[\begin{array}{lll}1 & -1 & 1\end{array}\right]$} & {$\left[\begin{array}{lll}1 & -1 & 1\end{array}\right]$} \\
\hline Plano & $d(n m)$ & $d(n m)$ & $d(n m)$ & $d(n m)$ & $d(n m)$ \\
\hline (1 1111$)$ & 0,212927 & $0,2200-0,008$ & $0,2229-0,010$ & & \\
\hline$\left(\begin{array}{lll}2 & 0 & 0\end{array}\right)$ & 0,184400 & & & & \\
\hline$\left(\begin{array}{lll}2 & 2 & 0\end{array}\right)$ & 0,130391 & $0,1357-0,005$ & $0,1364-0,006$ & $0,1346-0,004$ & $0,1339-0,004$ \\
\hline (3 1 1) & 0,111197 & $0,1149-0,003$ & $0,1162-0,005$ & & \\
\hline
\end{tabular}



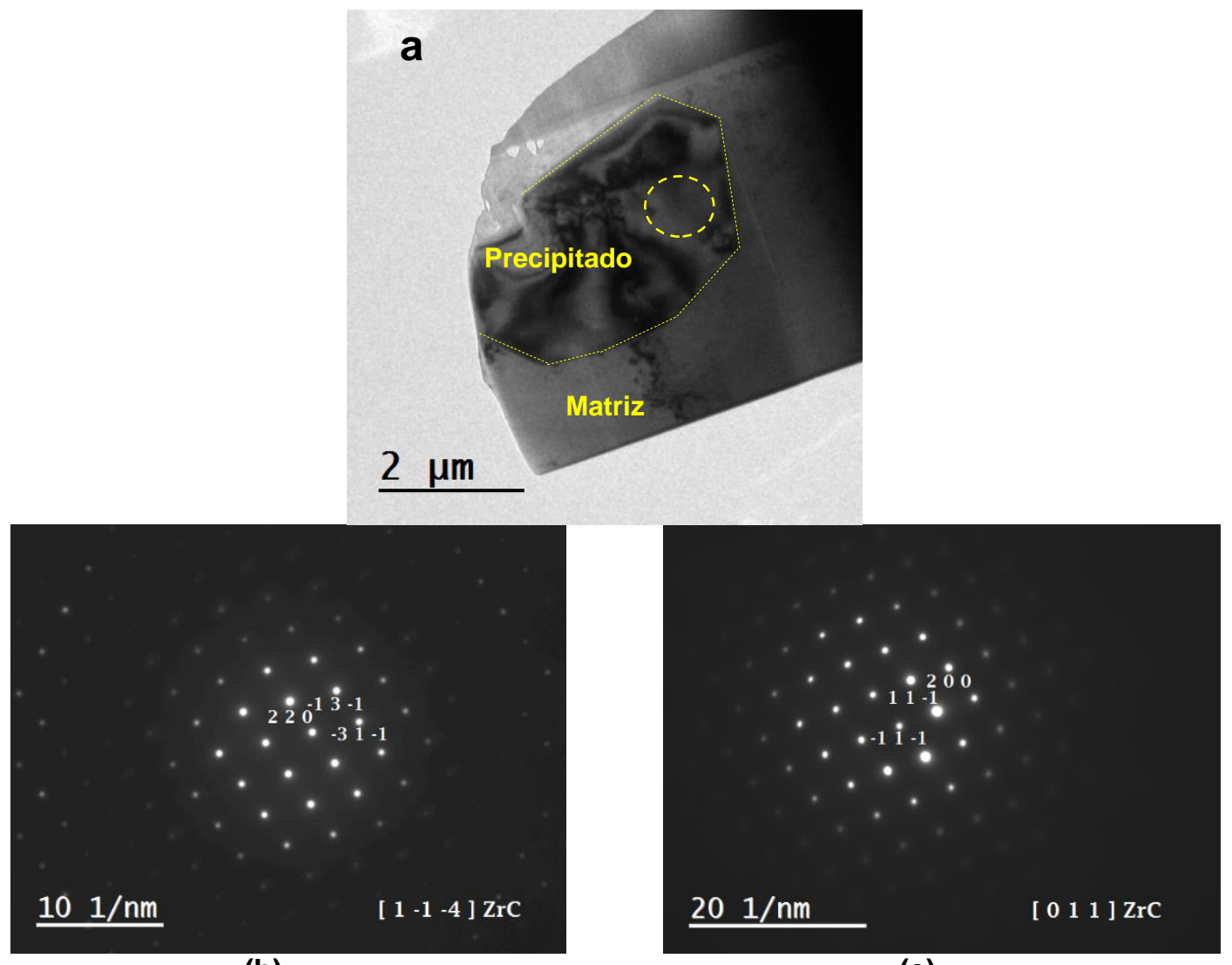

(b)

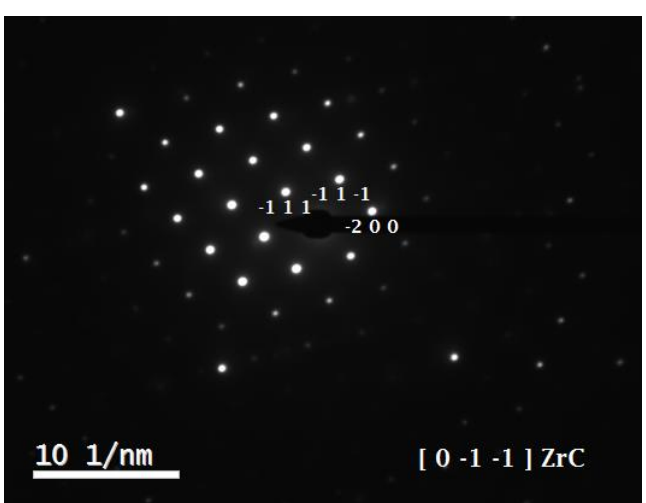

(c)

(d)

Figura 81- Padrões de difração indexados do precipitado da lâmina (B): a) imagem em campo claro, o círculo amarelo marca a área de coleta das difrações; b) eixo de zona [1 -1 -4]; c) eixo de zona [0 1 1] e d) eixo de zona [0 -1 -1]. Imagens obtidas no MET Tecnai G2-20 - SuperTwin FEI - 200 kV.

Tabela 23- Distancias interplanares medidas dos padrões de difração da Figura 81, comparadas com o cartão padrão do ZrC (ICSD: Inorganic Crystal Structure Database, código: 159874)*.

\begin{tabular}{|c|c|c|c|c|}
\hline \multicolumn{2}{|c|}{ ZrC dhkl * } & \multicolumn{3}{|c|}{ Eixo de zona } \\
\hline & & {$\left[\begin{array}{lll}1 & -1 & -4\end{array}\right]$} & {$\left[\begin{array}{lll}0 & 1 & 1\end{array}\right]$} & {$\left[\begin{array}{lll}0 & -1 & -1\end{array}\right]$} \\
\hline Plano & $d(n m)$ & $\mathrm{d}(\mathrm{nm})$ & d (nm) & $d(n m)$ \\
\hline (1 1111$)$ & 0,27122 & & $0,222+0,05$ & $0,293-0,02$ \\
\hline$\left(\begin{array}{lll}2 & 0 & 0\end{array}\right)$ & 0,23488 & & $0,192+0,04$ & $0,260-0,02$ \\
\hline$\left(\begin{array}{lll}2 & 2 & 0\end{array}\right)$ & 0,16609 & 0,331 & $0,136+0,03$ & $0,188-0,02$ \\
\hline (3 111$)$ & 0,14164 & 0,264 & & \\
\hline
\end{tabular}




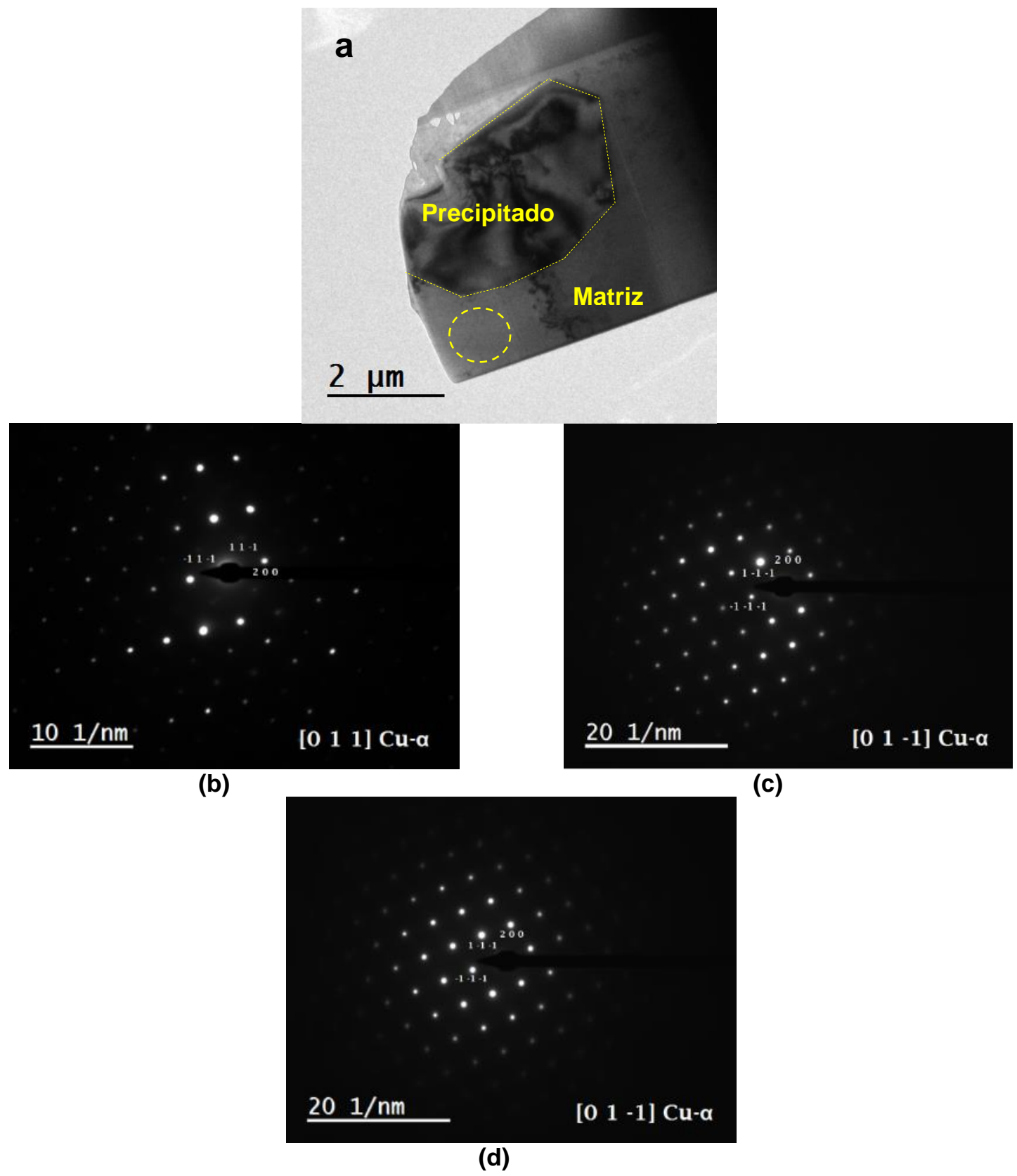

Figura 82- - Padrões de difração indexados da matriz da lâmina (B): a) imagem em campo claro, o círculo amarelo marca a área de coleta das difrações; b) eixo de zona [0 1 1]; c) eixo de zona [0 1 -1] e d) eixo de zona [0 1 1] e d) eixo de zona [0 1 -1]. Imagens obtidas no MET Tecnai G2-20 - SuperTwin FEI - 200 kV.

Tabela 24- Distancias interplanares medidas nos padrões de difração da Figura 82, comparadas com o cartão padrão do Cu-a (ICSD: Inorganic Crystal Structure Database, código: 03-065-682) *.

\begin{tabular}{|c|c|c|c|c|}
\hline \multirow{2}{*}{\multicolumn{2}{|c|}{ Cua d dnk * }} & \multicolumn{3}{|c|}{ Eixos de zona } \\
\hline & & {$\left[\begin{array}{lll}0 & 1 & 1\end{array}\right]$} & {$\left[\begin{array}{lll}0 & 1 & -1\end{array}\right]$} & {$\left[\begin{array}{lll}0 & 1 & -1\end{array}\right]$} \\
\hline Plano & $d(n m)$ & d (nm) & $d(n m)$ & $d(n m)$ \\
\hline$\left(\begin{array}{lll}1 & 11\end{array}\right)$ & 0,212927 & $0,2691-0,05$ & $0,2275-0,015$ & $0,23091-0,017$ \\
\hline$\left(\begin{array}{lll}2 & 0 & 0\end{array}\right)$ & 0,184400 & $0,19315+0,03$ & $0,1978-0,014$ & $0,2007-0,012$ \\
\hline$\left(\begin{array}{lll}2 & 2 & 0\end{array}\right)$ & 0,130391 & & $0,1403-0,01$ & $0,1415-0,011$ \\
\hline
\end{tabular}




\subsection{Evidências da nucleação heterogênea sobre os precipitados}

No presente trabalho foram mostradas evidências experimentais de que o acréscimo de $\mathrm{Sn}$ em teores $\geq 4 \%$ (massa) reduz o tamanho médio de grão. Este efeito foi atribuído à restrição ao crescimento dos grãos dendríticos. Também foram apresentadas evidências experimentais de que nesta faixa de teores de Sn, a adição de $\mathrm{Zr}$ ao banho líquido, na presença de uma fonte de $\mathrm{C}$ causava uma diminuição significativa do tamanho médio de grão. Esta diminuição significativa coincidiu com o aparecimento de precipitados facetados ricos em $\mathrm{Zr}$, com fortes evidências de que são partículas de ZrC. Esta coincidência do aparecimento dos precipitados de ZrC com a redução do tamanho de grão é uma evidência de que ocorre nucleação heterogênea significativa da fase Cua sobre as partículas de $\mathrm{ZrC}$. Nestes itens serão examinadas mais evidências teóricas e experimentais deste mecanismo de nucleação heterogênea.

Partículas que funcionam como centros de nucleação heterogênea devem ser sólidas e estáveis nas temperaturas do banho líquido. O diagrama de fases do sistema $\mathrm{Zr}$-C (Figura 70) indica que o carboneto $\mathrm{ZrC} \mathrm{C}_{\mathrm{x}}$, tem um ponto de fusão de $\sim 3427^{\circ} \mathrm{C} \mathrm{e}$, portanto, deve ser sólido nas temperaturas máximas atingidas pelos banhos líquidos do presente trabalho $\left(1250^{\circ} \mathrm{C}\right)$. A estabilidade do $\mathrm{ZrC}$ pode ser vista na Figura 42 , que mostra que a sua formação em condições padrões é um fenômeno espontâneo $\left(\Delta \mathrm{G}^{\circ}<0\right)$ nas temperaturas do banho líquido. Entretanto, como mencionado anteriormente, uma análise termodinâmica mais detalhada das atividades dos elementos $\mathrm{C}, \mathrm{Zr}, \mathrm{N}$ e O dissolvidos no banho líquido seria necessário para se concluir que estas partículas realmente são estáveis nas condições do presente trabalho. Outras duas evidências de que partículas presentes no banho funcionaram como centros de nucleação heterogênea estão relacionadas ao seu reticulado cristalino e ao seu posicionamento relativo aos grãos, após a solidificação. Estas evidências são examinadas em detalhes nos próximos itens. 


\subsubsection{Análise do Desajuste entre Reticulados}

O material de partículas que funcionam como centros efetivos de nucleação heterogênea deve ter uma energia de interface relativamente baixa com a fase que nucleia $(\mathrm{Cu}-\alpha)$. Esta energia interfacial reduzida é normalmente resultado de um "bom" encaixe entre os reticulados cristalinos da partícula e da fase que nucleia. Uma indicação quantitativa deste encaixe pode ser calculada através do parâmetro de desajuste cristalográfico entre os reticulados, $\delta$. A Tabela 25 mostra o resultado deste cálculo de desajuste através da Eq. (13) entre os reticulados do Cua e do $\mathrm{ZrC}$ ou do $\mathrm{Cu}_{9} \mathrm{Zr}$ 2, que representa um possível intermetálico formado com a adição de $\mathrm{Zr}$ ao $\mathrm{Cu}$ líquido (Figura 69). Nota-se que o desajuste é muito menor para o $\mathrm{ZrC}(27 \%)$, o que significa que a nucleação heterogênea sobre esta partícula seria muito maior do que sobre um possível Cu9Zr2 (85\%). De um modo geral, desajustes menores do que $15 \%$ indicam um bom substrato para a nucleação heterogênea, mas há evidências de que o efeito é muito mais significante quando o desajuste é menor do que 5\% (TURNBULL; VONNEGUT, 1952; BRAMFITT, 1970; MONDOLFO, 1982; CAI et al., 2000; LU et al., 2005; WANG et al., 2006).

Tabela 25 - Parâmetros estruturais da fase $\mathrm{Cu} \alpha$ e das possíveis partículas sólidas presentes no banho líquido e o parâmetro de desajuste entre reticulados $(\delta)$.

\begin{tabular}{lccccc}
\hline Fase & Estrutura & Parâmetro de rede $(\mathbf{n m})$ & $\boldsymbol{\delta}(\%)$ & Referência \\
& & $\mathbf{a}$ & $\mathbf{c}$ & & \\
\hline $\mathbf{C u}-\alpha$ & CFC & 0,37019 & & MORIKAWA et al., (1967) \\
\hline $\mathbf{Z r C}$ & $\mathrm{NaCl}$ & 0,36078 & & WANG; KONNO, (2012) \\
\hline $\mathbf{C u} \mathbf{Z r}_{2}$ & Tetragonal & 0,6856 & 0,6882 & $85-86$ & ARIAS; ABRIATA, (1990) \\
\hline
\end{tabular}

A Eq. (13), utilizada para calcular os parâmetros de desajuste apresentados na Tabela 25, representa a proposta mais simples disponível. Este cálculo quantifica o desajuste para duas células unitárias dos dois reticulados com suas faces e arestas posicionadas paralelamente. BRAMFITT (1970) Apresentou uma proposta mais elaborada, representada pela Eq. (15), onde são considerados o desajuste entre planos e orientações (direções) específicas dos dois reticulados. Foi realizado o 
cálculo de $\delta$ entre o plano (100) do ZrC e os planos (100), (110) e (111) da estrutura do $\mathrm{Cu}-\alpha$. O resultado deste cálculo está apresentado na Tabela 26 e foi realizado a partir dos reticulados indicados na Figura 83, que apresenta a orientação relativa entre os reticulados definindo-se o ângulo entre duas direções cristalográficas. Analogamente, o mesmo tipo de cálculo foi conduzido a partir da Figura 84 e da Figura 85 alterando-se o plano do reticulado do ZrC para (111) e (110), respectivamente. Os resultados também estão mostrados na Tabela 26.

Os valores de $\delta$ calculados e apresentados na Tabela 26 indicam uma faixa de 1,9 a 27,1\%. O valor mínimo, representando o melhor ajuste entre os reticulados ocorre para os planos-direções (110) [001] do $\mathrm{ZrC} \mathrm{e} \mathrm{(111)} \mathrm{[-101]} \mathrm{do} \mathrm{Cu \alpha .} \mathrm{Este} \mathrm{tipo} \mathrm{de}$ desajuste foi amplamente calculado para o caso de ligas de Al (Tabela 2) e concluiuse que um efeito significativo de diminuição de tamanho de grão ocorre para $\delta<15 \%$. Este critério é satisfeito para diversas combinações testadas na Tabela 26 e, portanto, representa mais uma evidência da potencialidade do $\mathrm{ZrC}$ como centro de nucleação heterogênea.

$\mathrm{Na}$ Tabela 26 foram mostradas diversas possibilidades de desajustes entre os reticulados cristalinos do $\mathrm{ZrC}$ e do $\mathrm{Cu} \alpha$, indicando valores de $\delta$ tão pequenos quanto 1,9\%. Entretanto, para que a potencialidade deste desajuste reduzido seja utilizada durante a nucleação heterogênea, é necessário que a face do precipitado coincida com os planos cristalinos que possibilitam este desajuste. A partir dos padrões de difração de elétrons apresentados no item 5.4.4, obtidos nas duas lâminas finas observadas no microscópio eletrônico de transmissão, foi realizada uma tentativa de se identificar o desajuste presente entre os reticulados. A Figura 80(e) apresenta um

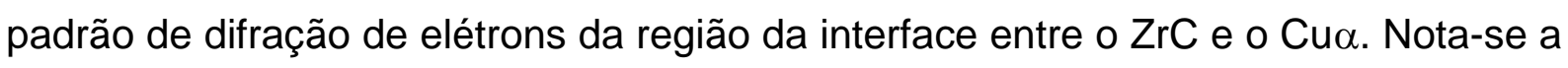

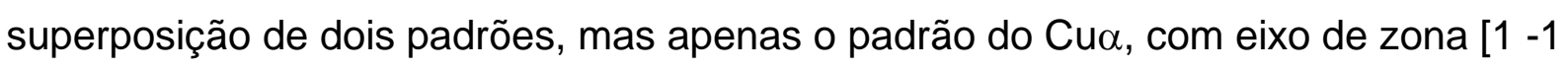
1], foi facilmente indexado, sendo semelhante à indexação presentada na Figura

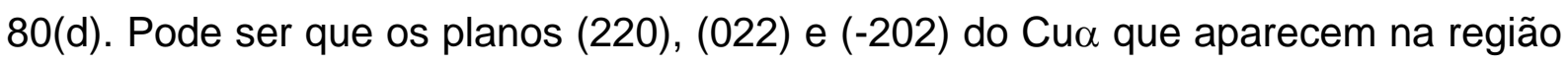
da interface formem um desajuste reduzido com alguns planos do $\mathrm{ZrC}$. 

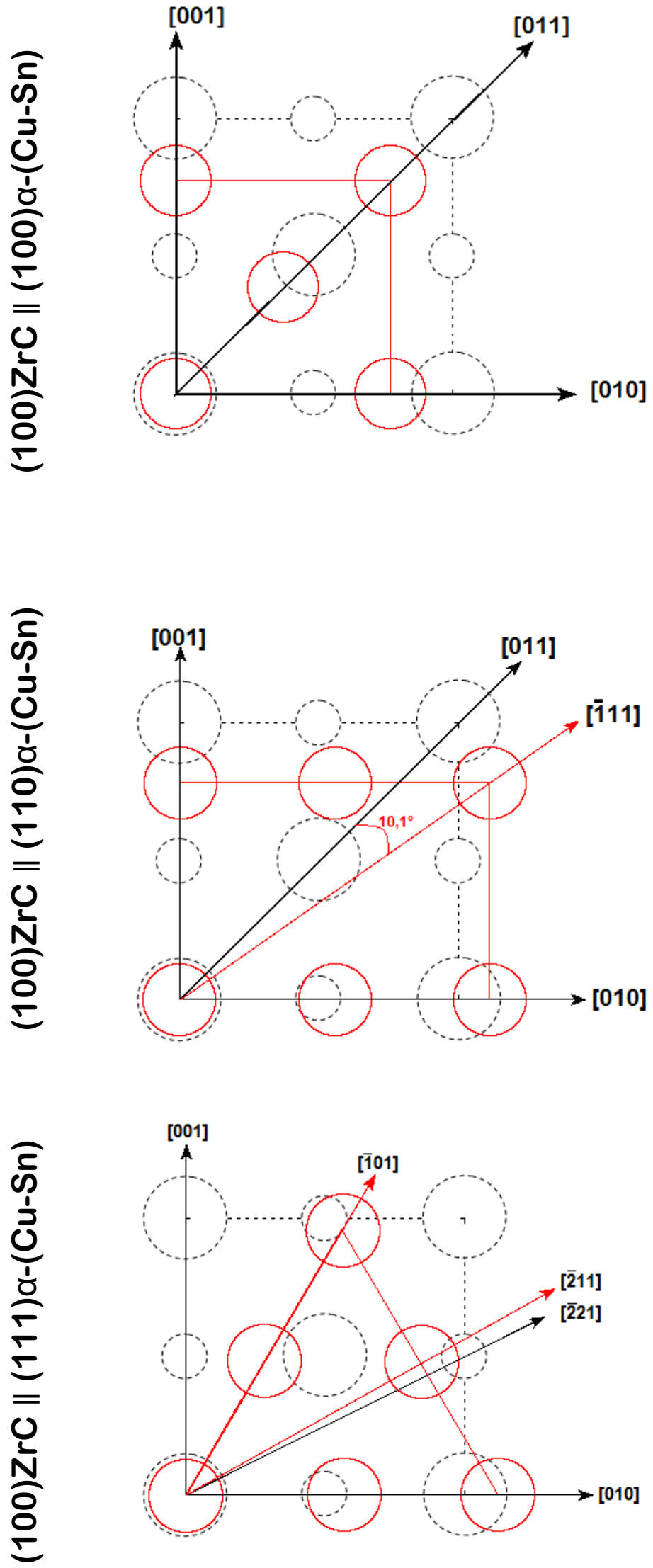

Figura 83 - Representação esquemática das relações cristalográficas das interfases dos planos (100) do ZrC (linhas tracejadas) e os planos (100),(110) e (111) do Cu- $\alpha$ (linhas cheias). 


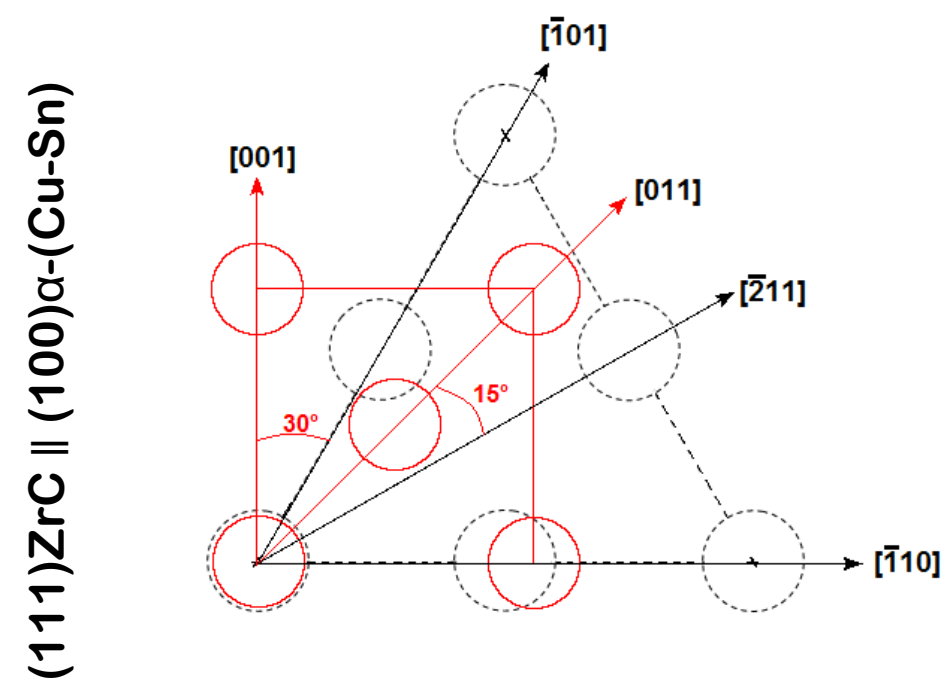

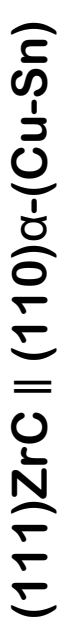

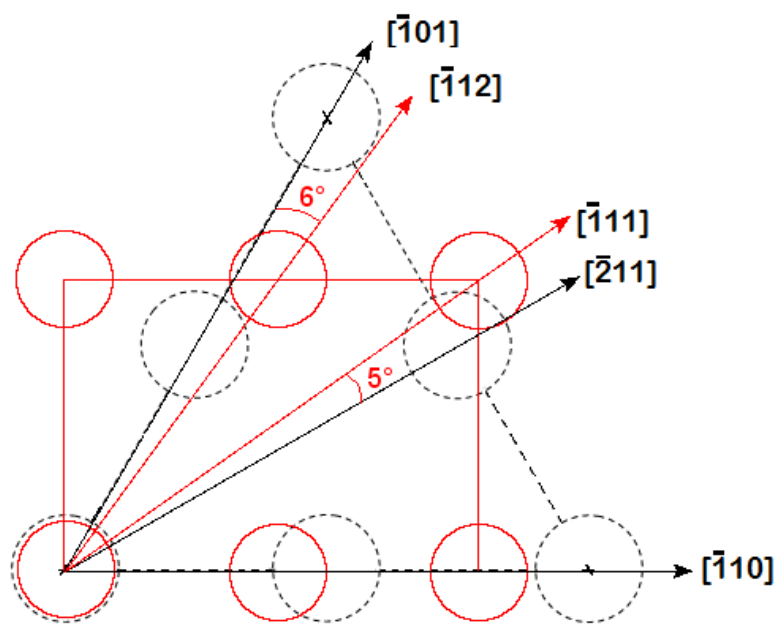

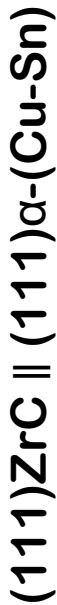

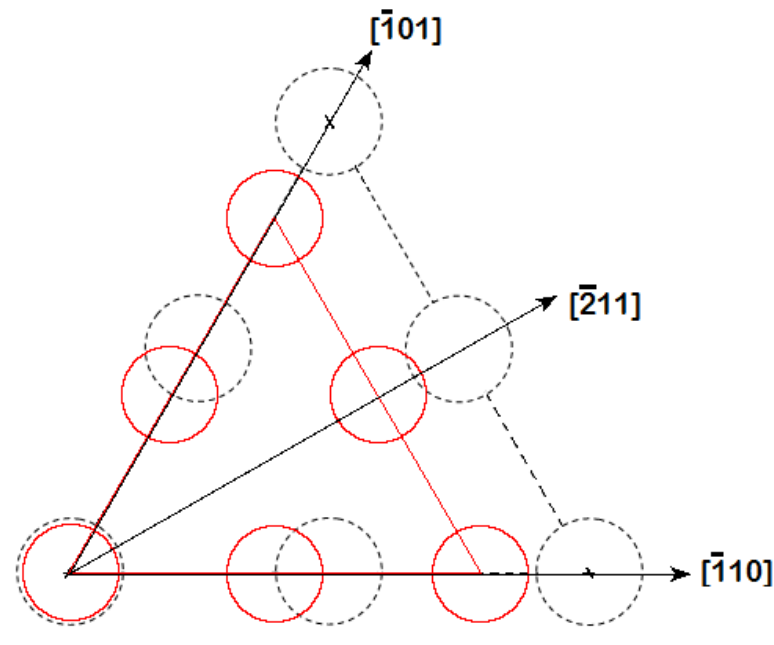

Figura 84 - Representação esquemática das relações cristalográficas das interfases dos planos (111) do ZrC (linhas tracejadas) e os planos (100), (110) e (111) do Cu- $\alpha$ (linhas cheias) 

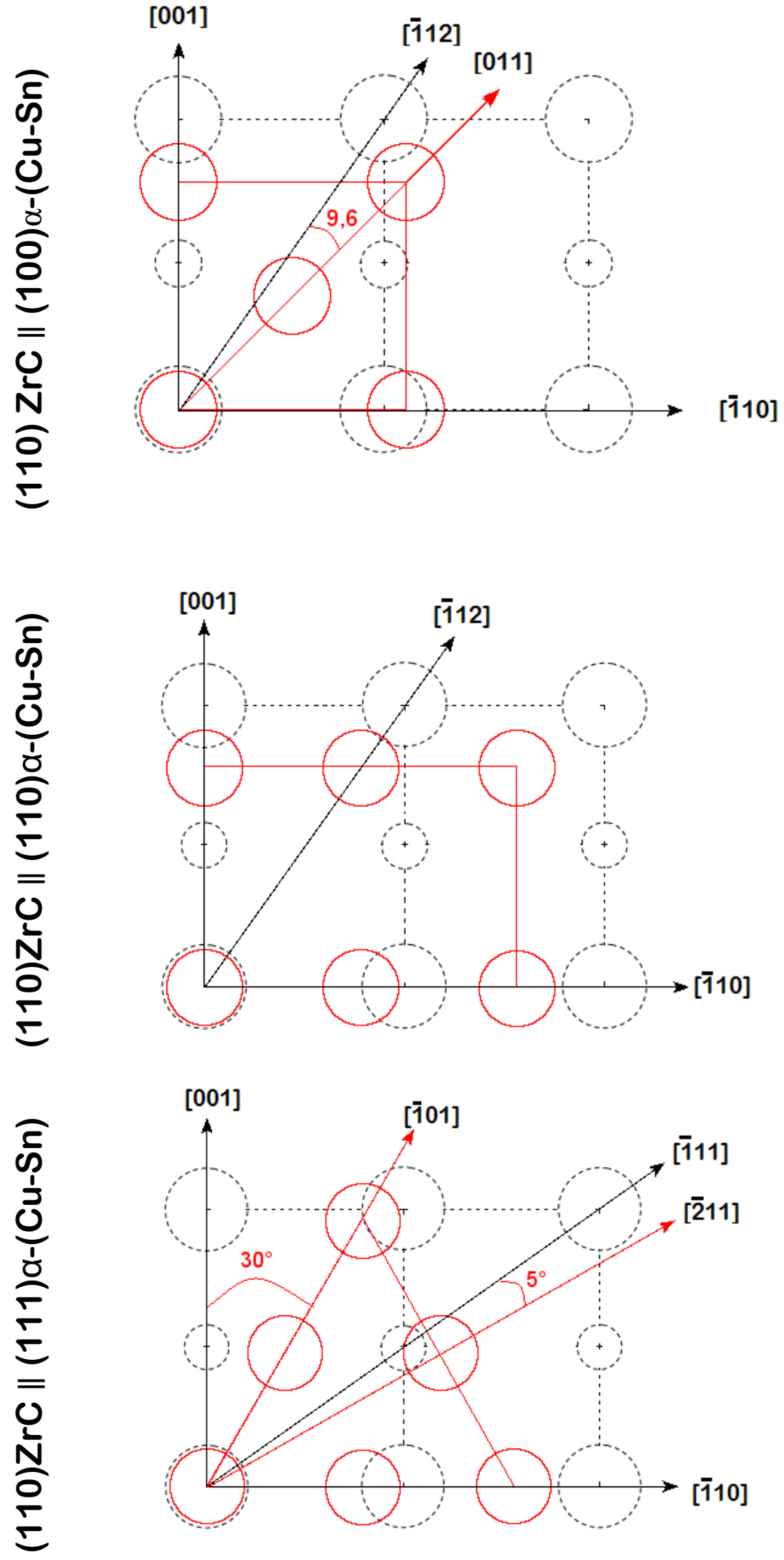

Figura 85 - Representação esquemática das relações cristalográficas das interfases dos planos (110) do ZrC (linhas tracejadas) e os planos (100), (110) e (111) do Cu-a (linhas cheias). 
Tabela 26- Cálculo do desajuste planar $(\delta)$ segundo bramfit para de fase $\mathrm{Cu}-\alpha$ e as possíveis partículas inoculantes de ZrC.

\begin{tabular}{|c|c|c|c|c|c|c|c|}
\hline Planos & [hkl]s & {$[\mathrm{hkl}] \mathrm{n}$} & $d[h k l] s$ & $d[h k l] n$ & $\theta\left({ }^{\circ}\right)$ & $\mathrm{d}[\mathrm{hkl}] \mathrm{s} \cos \theta$ & $\delta(\%)$ \\
\hline \multirow{3}{*}{$(100)_{\mathrm{Zrc}} \|(100)_{\alpha-(\mathrm{Cu}-\mathrm{Sn})}$} & {$[010] \mathrm{s}$} & {$[010] \mathrm{n}$} & 4,691 & 3,688 & 0 & 4,691 & \multirow{3}{*}{27,1} \\
\hline & [011]s & [011]n & 3,310 & 2,610 & 0 & 3,310 & \\
\hline & [001]s & [001]n & 4,691 & 3,688 & 0 & 4,691 & \\
\hline \multirow{3}{*}{$(100)_{z r c} \|(110)_{\alpha-(C u-S n)}$} & [010]s & {$[-110] \mathrm{n}$} & 4,691 & 5,220 & 0 & 4,691 & \multirow{3}{*}{6,4} \\
\hline & [0111]s & {$[-111] n$} & 6,634 & 6,391 & 10,1 & 6,531 & \\
\hline & {$[001] \mathrm{s}$} & [001]n & 4,691 & 3,688 & 0 & 4,691 & \\
\hline \multirow{3}{*}{$(100)_{z r c} \|(111)_{\alpha-(C u-S n)}$} & [010]s & {$[-110] n$} & 4,691 & 5,220 & 0 & 4,691 & \multirow{3}{*}{5,5} \\
\hline & {$[-221] s$} & {$[-211] n$} & 5,240 & 4,500 & 3,6 & 5,230 & \\
\hline & [001]s & {$[-101] n$} & 4,691 & 5,220 & 30,5 & 4,042 & \\
\hline \multirow{3}{*}{$(111)_{z r c} \|(100)_{\alpha-(C u-S n)}$} & {$[-110] \mathrm{s}$} & [010]n & 3,315 & 3,688 & 0 & 3,315 & \multirow{3}{*}{8,7} \\
\hline & {$[-211] \mathrm{s}$} & [011]n & 5,745 & 5,220 & 15 & 5,549 & \\
\hline & {$[-101] \mathrm{s}$} & [001]n & 3,315 & 3,688 & 30 & 2,871 & \\
\hline \multirow{3}{*}{$(111)_{z r c} \|(110)_{\alpha-(C u-S n)}$} & {$[-110] s$} & {$[-110] n$} & 3,315 & 2,610 & 0 & 3,315 & \multirow{3}{*}{3,5} \\
\hline & {$[-211] s$} & {$[-111] n$} & 5,745 & 6,391 & 5 & 5,723 & \\
\hline & {$[-101] \mathrm{s}$} & {$[-112] n$} & 3,315 & 4,520 & 6 & 3,297 & \\
\hline \multirow{3}{*}{$(111)_{z r c} \|(111)_{\alpha-(C u-S n)}$} & {$[-110] \mathrm{s}$} & {$[-110] n$} & 3,315 & 2,610 & 0 & 3,315 & \multirow{3}{*}{27,0} \\
\hline & {$[-211] \mathrm{s}$} & {$[-211] n$} & 5,745 & 4,520 & 0 & 5,745 & \\
\hline & {$[-101] \mathrm{s}$} & {$[-101] n$} & 3,315 & 2,610 & 0 & 3,315 & \\
\hline \multirow{3}{*}{$(110)_{z r c} \|(100)_{\alpha-(C u-S n)}$} & {$[-110] \mathrm{s}$} & {$[-110] n$} & 3,315 & 3,688 & 0 & 3,315 & \multirow{3}{*}{8,5} \\
\hline & {$[-112] s$} & [011]n & 5,744 & 5,220 & 9,6 & 5,664 & \\
\hline & [001]s & [001]n & 4,691 & 3,688 & 0 & 4,691 & \\
\hline \multirow{3}{*}{$(110)_{\mathrm{zrc}} \|(110)_{\alpha-(\mathrm{Cu}-\mathrm{Sn})}$} & {$[-110] s$} & {$[-110] n$} & 3,315 & 2,610 & 0 & 3,315 & \multirow{3}{*}{27,1} \\
\hline & {$[-112] \mathrm{s}$} & {$[-112] n$} & 5,744 & 4,520 & 0 & 5,744 & \\
\hline & [001]s & [001]n & 4,691 & 3,688 & 0 & 4,691 & \\
\hline \multirow{3}{*}{$(110)_{z r c} \|(111)_{\alpha-(C u-S n)}$} & {$[-110] s$} & {$[-110] n$} & 3,315 & 2,610 & 0 & 3,315 & \multirow{3}{*}{1,9} \\
\hline & {$[-111] s$} & {$[-211] n$} & 4,060 & 4,520 & 5 & 4,045 & \\
\hline & {$[001] \mathrm{s}$} & {$[-101] \mathrm{n}$} & 2,346 & 2,610 & 30 & 2,031 & \\
\hline
\end{tabular}


Num esforço de compreender quais planos do precipitado poderiam estar relacionados com planos da matriz, na região da interface, o software CrysTBox

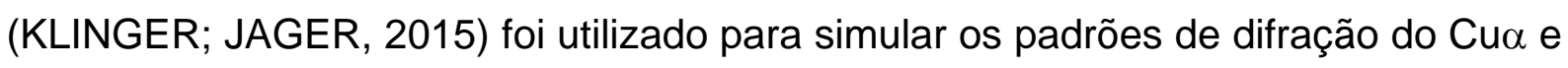
do ZrC. Para o Cua, o mesmo eixo de zona do padrão medido na Figura 79(b) foi adotado. No caso do ZrC, foram testados diversos eixos de zona até se adotar aquele identificado no padrão da Figura 79(b). Observou-se que quando o eixo de zona [1-1 1] para o Cu- $\alpha$ estava paralelo ao eixo de zona [1-1-2] para o $\mathrm{ZrC}$ e quando se

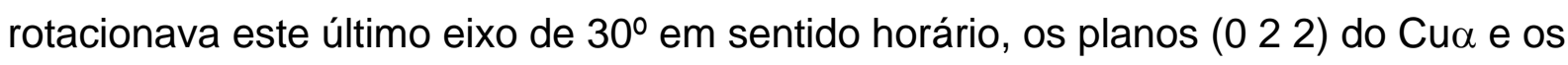
planos (2 -2 2) do ZrC quase coincidiam, como mostra a Figura 86. Posteriormente, o parâmetro de desajuste entre os reticulados do Cua e $\mathrm{ZrC}$ foi calculado segundo a Eq. (15) e apresentado na Tabela 27 para estas orientações utilizadas na simulação. Os reticulados no espaço real estão ilustrados na Figura 87. Para os espaçamentos interplanares $d_{022}=0,1303 \mathrm{~nm}$ e o $d_{2-22}=0,1356 \mathrm{~nm}$, o desajuste foi de $4,5 \%$, que é um valor considerado suficientemente baixo para se ter uma nucleação heterogênea efetiva. Este resultado, apesar de não ter uma evidência experimental, indica a existência de uma possível relação de orientação entre o Cu- $\alpha$ e o $\mathrm{ZrC}$ do tipo (0 22 2) [ 1 -1 1] Cu- $\alpha$ II (2 -2 2) [ 1-1-2 ]ZrC.

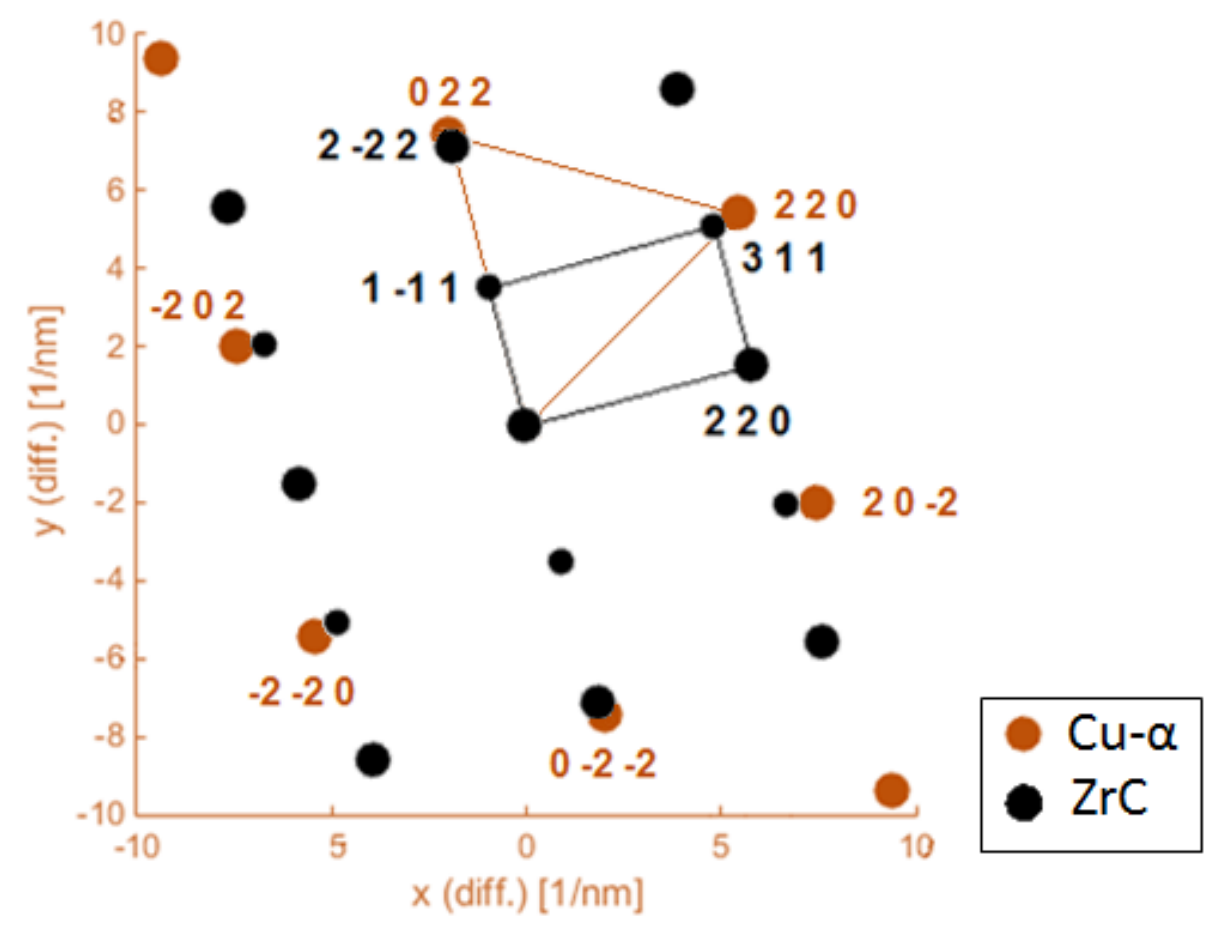

Figura 86- Superposição dos padrões de difração indexados [1-1 1]Cu- $\alpha$ II [1-1-2]ZrC 


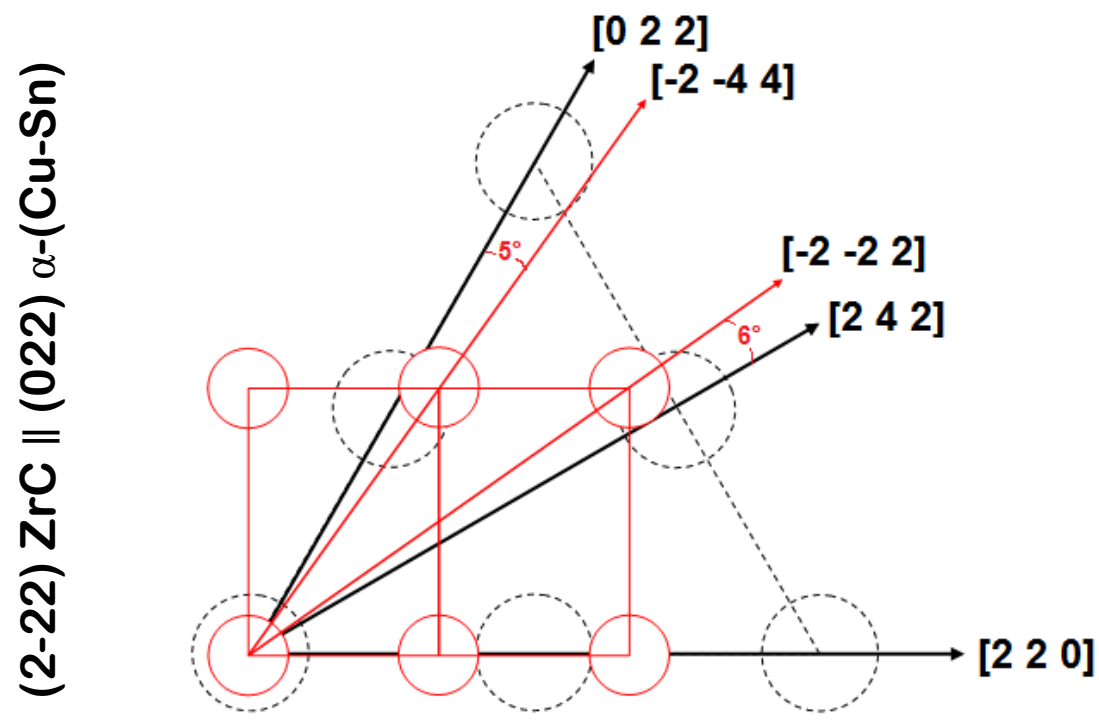

Figura 87- Representação esquemática das relações cristalográficas das interfases do plano (2-22) do ZrC (linhas tracejadas) e o plano (022) do Cu- $\alpha$ (linhas cheias).

Tabela 27- Cálculo do desajuste planar ( $\delta$ ) segundo bramfit para os planos (2-22) do ZrC e (022) do Cu-a paralelos.

\begin{tabular}{|c|c|c|c|c|c|c|c|}
\hline Planos & [hkl]s & [hkl]n & $d[h k l] s$ & d[hkl]n & $\theta\left({ }^{\circ}\right)$ & $d[h k l] s \cos \theta$ & $\delta(\%)$ \\
\hline \multirow{3}{*}{$(2-22)_{z r c} \|(022)_{\alpha-(C u-S n)}$} & [220]s & {$[-100] \mathrm{n}$} & 3,315 & 3,6900 & 0 & 3,3150 & \multirow{3}{*}{4,5} \\
\hline & [242]s & {$[-2-22] n$} & 5,7400 & 4,5190 & 5 & 5,7182 & \\
\hline & [022]s & {$[-2-44] n$} & 3,3150 & 3,3910 & 6 & 3,2968 & \\
\hline
\end{tabular}

Uma evidência experimental da existência de um desajuste reduzido entre os reticulados do Cua e do ZrC foi obtida em imagens de alta resolução no microscópio de transmissão de diversas regiões da interface entre as duas fases, observadas em uma das lâminas finas. A Figura 88 apresenta imagens de alta resolução de diferentes partes da interface. Nota-se na Figura 88a e Figura 88b, a presença de franjas de rede alinhadas entre a matriz e o precipitado, representando uma forte evidência de um desajuste reduzido. Por outro lado, na Figura $88 \mathrm{c}$ e Figura $88 \mathrm{~d}$ nota-se a falta de coerência entre os reticulados em duas outras regiões da interface. 


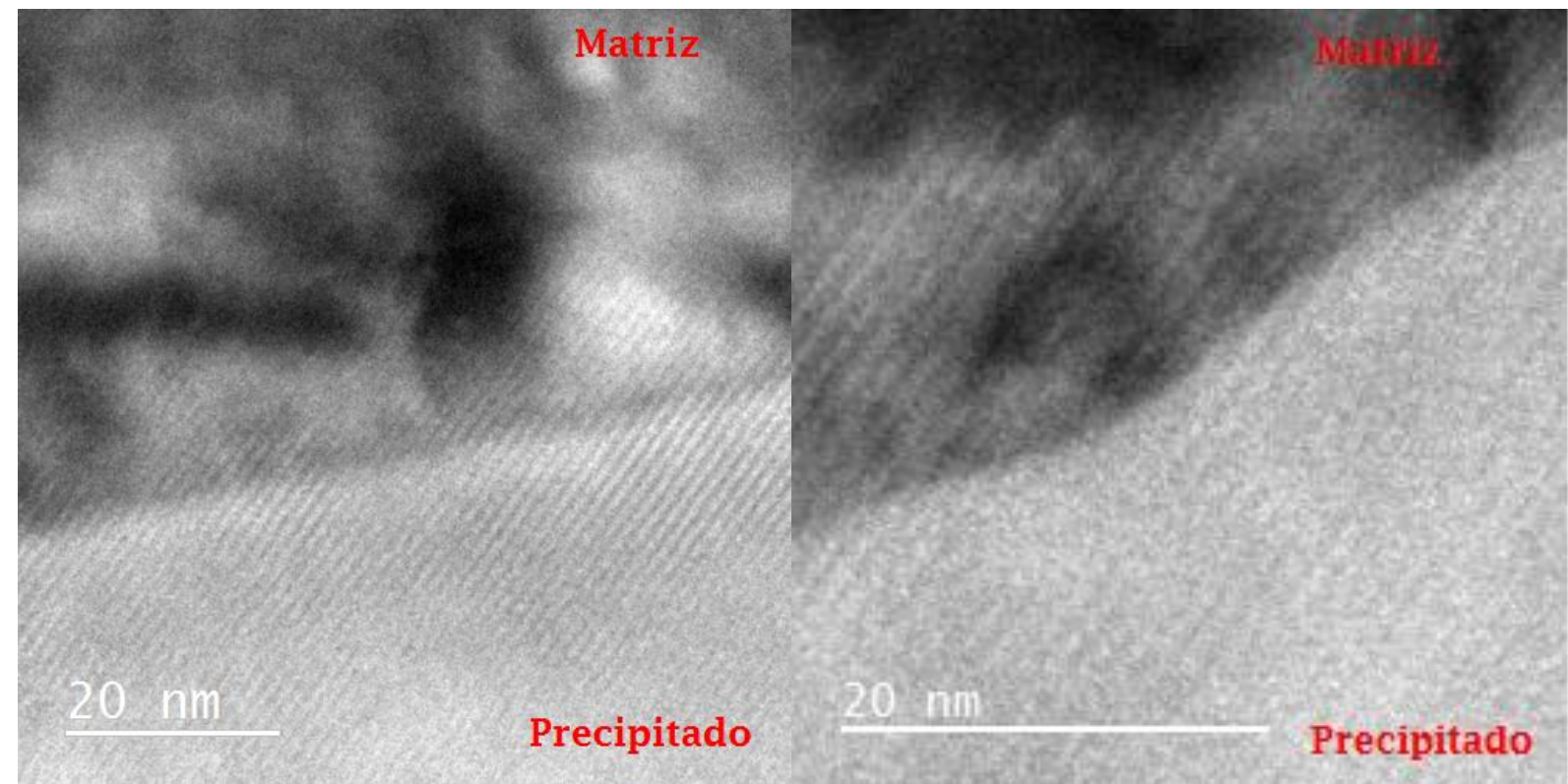

(a)

(b)

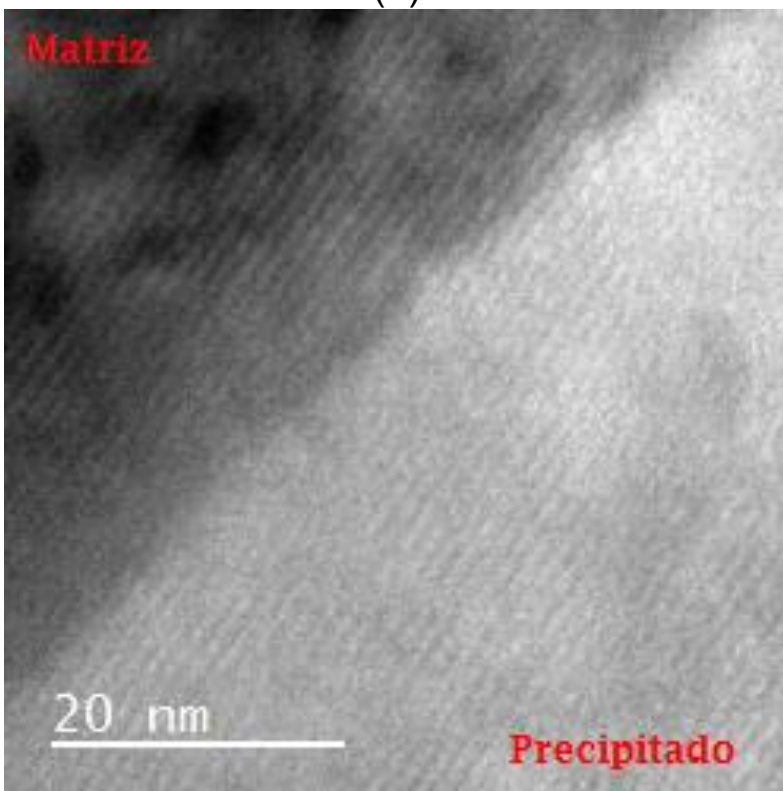

(c)

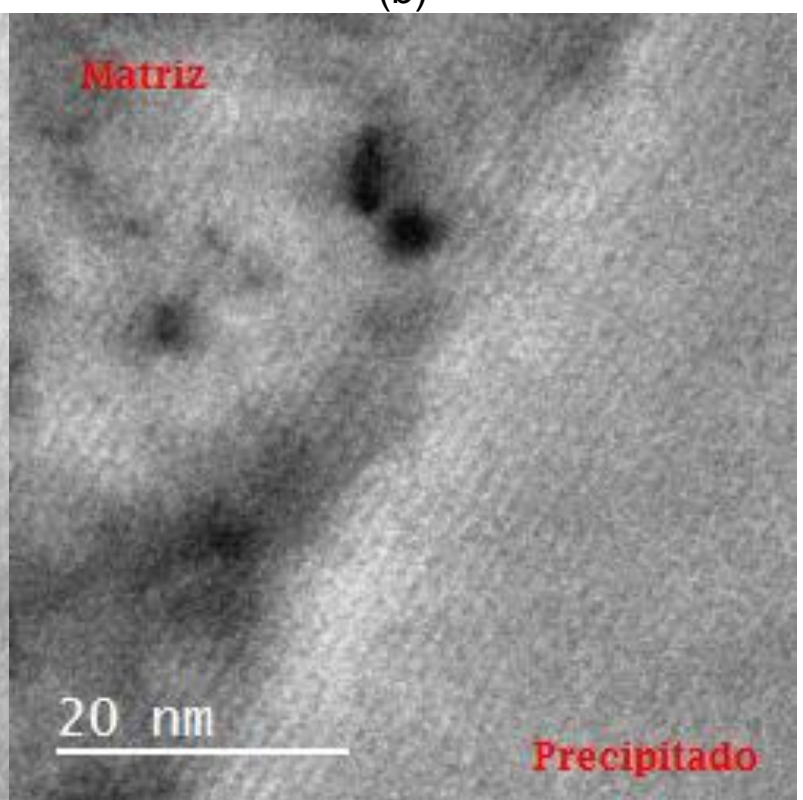

$(d)$

Figura 88- Imagens de alta resolução da interface matriz precipitado da lâmina (A): (a) e (b) regiões da interface apresentando coerência entre os reticulados da matriz e precipitado; (c) e (d) regiões da interface sem coerência aparente entre os reticulados.

\subsubsection{Observações do posicionamento relativo dos precipitados}

Uma outra evidência de que um determinado precipitado existente no líquido representa um centro de nucleação heterogênea é a sua localização no interior do grão após a solidificação. Partículas que aparecem no contorno de grão ou na região interdendrítica têm pouca probabilidade de terem sido centros de nucleação, já que a 
fase sólida nucleada cresce ao redor do precipitado sobre o qual nucleou. Entretanto, quando o precipitado não foi o centro de nucleação, uns grãos em crescimento podem encapsular este precipitado ("engulfment"), posicionando-o no interior do grão, ou pode empurrá-lo para a região interdendrítica ("pushing"). STEFANESCU (2009) Mostra a existência de uma velocidade crítica da interface sólido-líquido abaixo da qual a partícula é empurrada e acima da qual a partícula é encapsulada.

Desta forma, partículas que aparecem em regiões interdendríticas dificilmente funcionaram como um centro de nucleação heterogênea, ao passo que partículas que aparecem no interior do grão podem ou não ser centros de nucleação. Cisse et al. (CISSÉ et al., 1974) reportaram o aparecimento de partículas de TiC na região interna de uma dendrita equiaxial como uma evidência de sua eficácia como substrato para a nucleação heterogênea do Al- $\alpha$. Nas amostras coletadas no presente trabalho, foram observados precipitados facetados, provavelmente ZrC, tanto no interior dos grãos, como em regiões interdendríticas. Desta forma, o aparecimento de partículas no interior dos grãos representa mais uma evidência do seu funcionamento como centro de nucleação heterogênea.

A Figura 89 e a Figura 90 mostram precipitados facetados na forma de discos e bastonetes em regiões interdendríticas. A Figura 92 (a) e (b), por outro lado, mostra a presença de uma partícula com formato de disco na região interna de um grão, distante da região interdendrítica. $\mathrm{Na}$ imagem em contraste de elétrons retroespalhados, nota-se que esta região onde está a partícula contém um teor de Sn menor do que o das regiões interdendríticas, também indicando que a partícula está posicionada nas primeiras regiões do grão a solidificar, ou seja, próximo ao núcleo sólido. Na Figura 93 (a) e (b), por outro lado, observa-se uma partícula no interior e outra na região interdendrítica. 

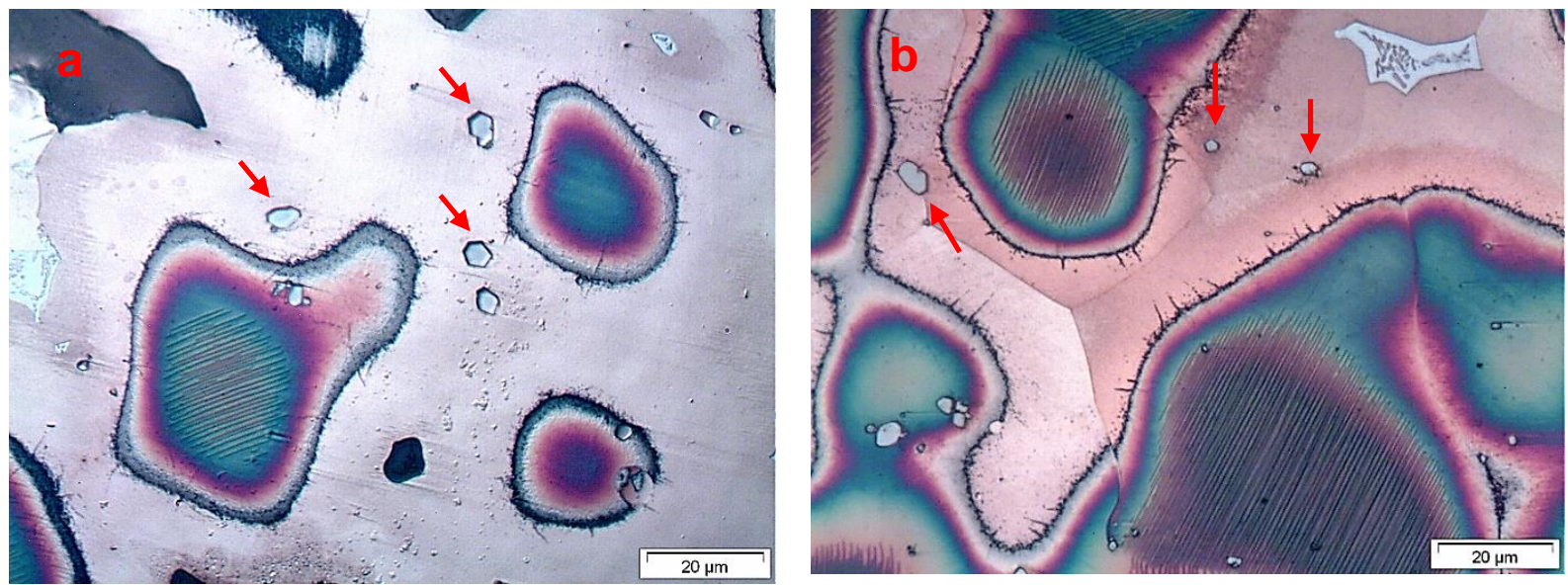

Figura 89- Microestruturas das seções transversais do lingote do experimento Cu8Sn0,16Zr. Cu- $\alpha$ com cor azul, as setas vermelhas marcam a posição dos precipitados facetados nos contornos e na região rica em Sn. Reagentes: Klem III.
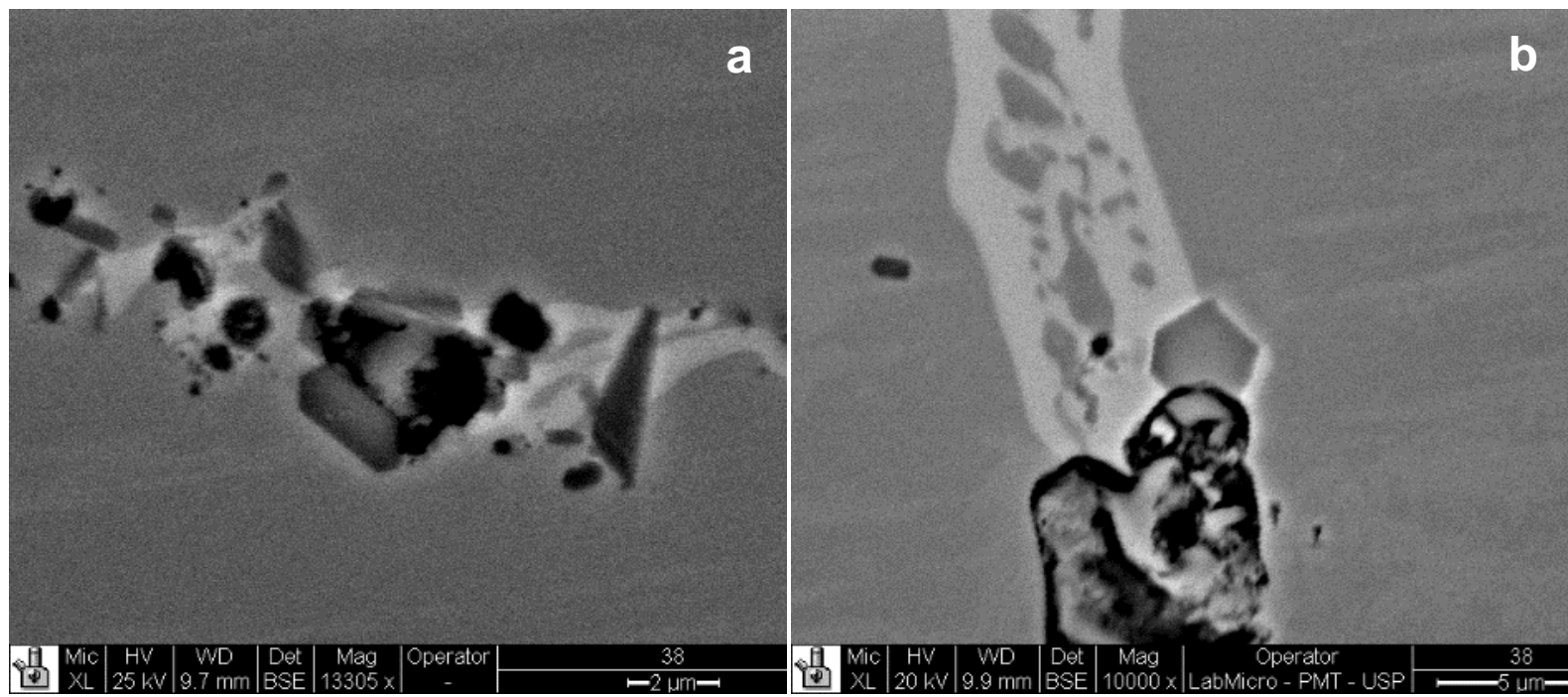

Figura 90 - Microestruturas do experimento Cu8Sn0,08Zr, ambas as imagens (a e b) apresentam partículas hexagonais na região rica em estanho. Imagem obtida no MEV com contraste de elétron retroespalhados. Polimento até $0,05 \mu \mathrm{m}$ com sílica, sem ataque químico.
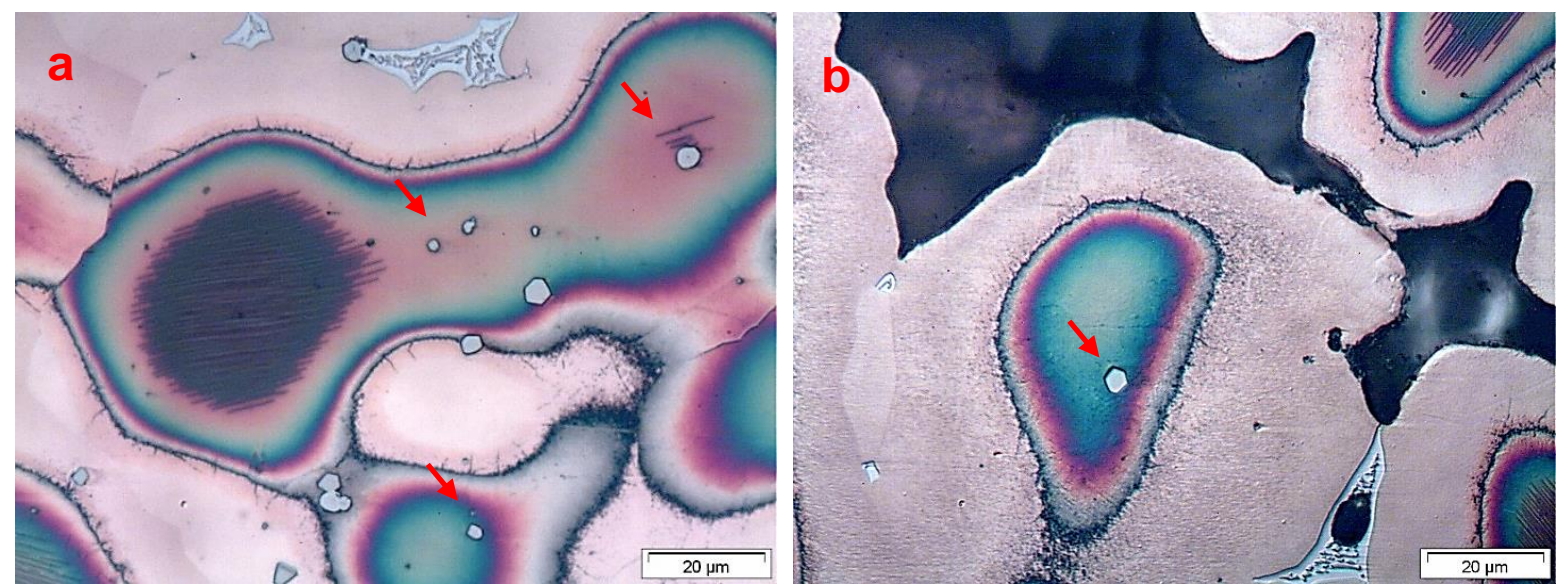

Figura 91- Microestruturas das seções transversais do lingote do experimento Cu8Sn0,16Zr. Cu- $\alpha$ com cor azul, as setas vermelhas marcam a posição dos precipitados facetados no interior da fase primaria. Reagentes: Klem III. 


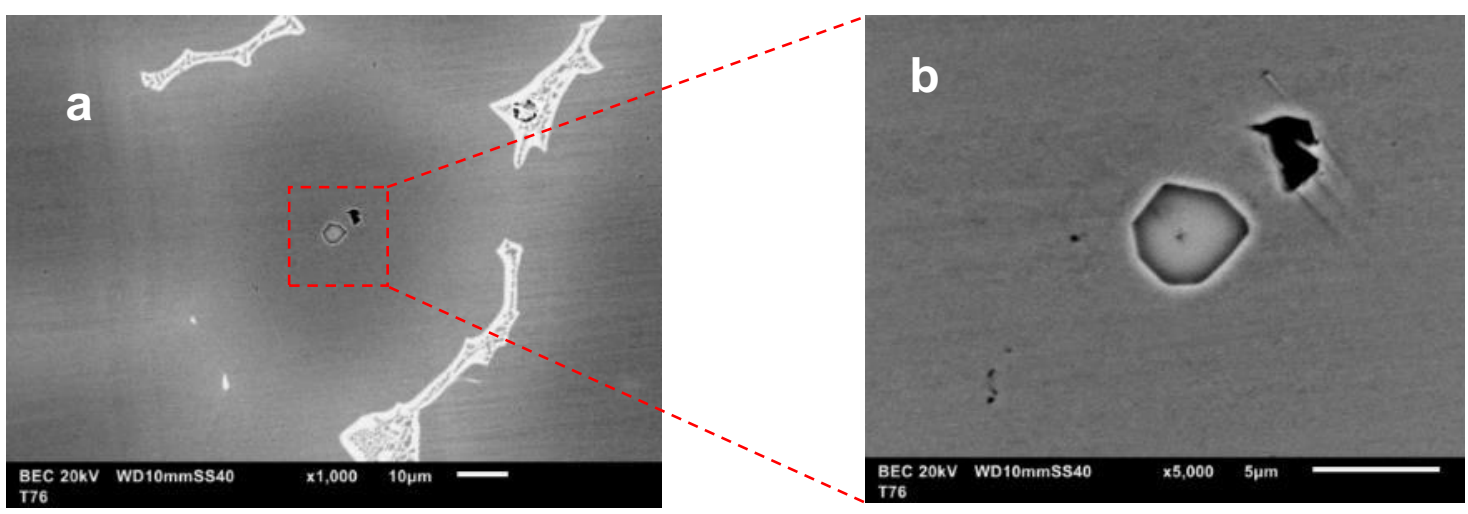

Figura 92 - Imagens obtidas no MEV-FEG de amostras do experimento Cu8Sn0,08Zr mostrando partículas no formato de disco no interior do grão. Polimento até $0,05 \mu \mathrm{m}$ com sílica, sem ataque químico.

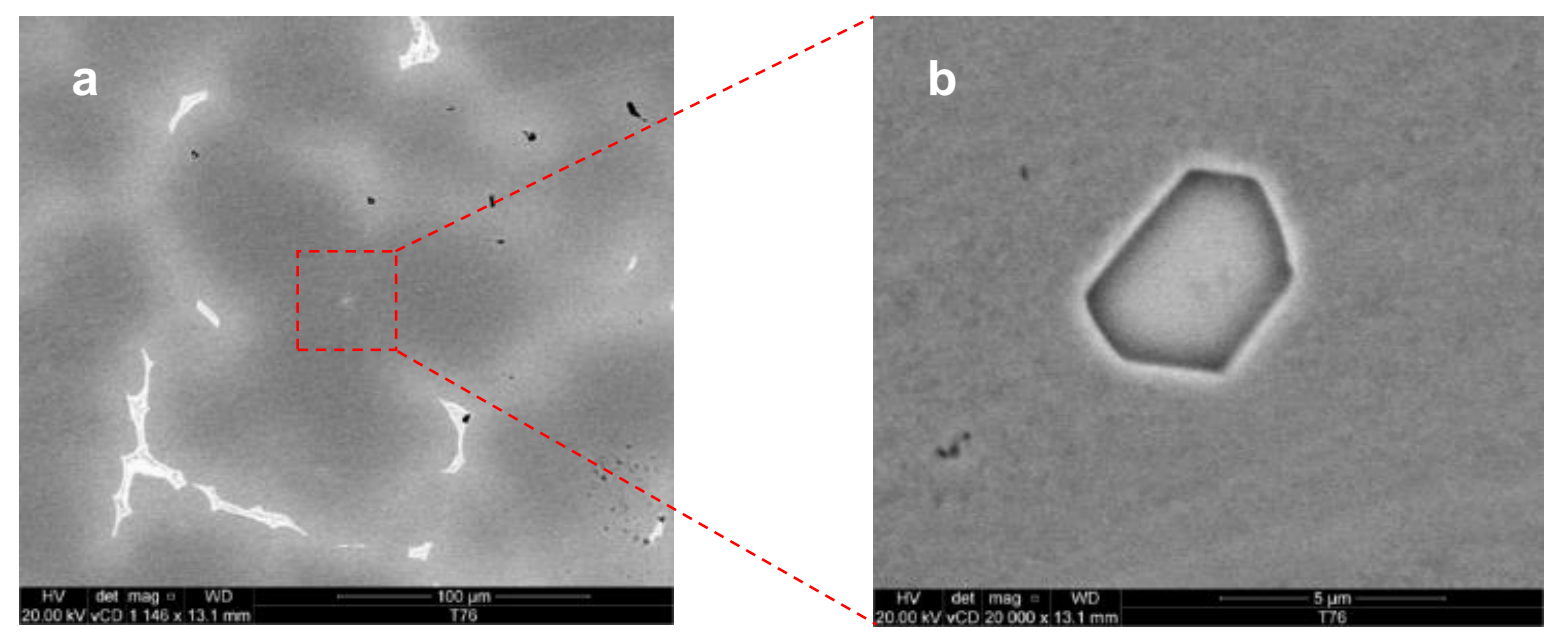

Figura 93 - Microestruturas de grãos do experimento Cu8Sn0,08Zr mostrando uma partícula no interior do grão, longe dos contornos e da região interdendrítica, e uma partícula na região interdendrítica. Imagem obtida no MEV-FEG com elétrons secundários. Reagentes Polimento até $0,05 \mu \mathrm{m}$ com sílica, sem ataque químico. 


\section{CONCLUSÕES}

As seguintes conclusões foram obtidas a partir dos resultados e discussões apresentadas no presente trabalho:

1) Adições de $\mathrm{Zr}$ na faixa entre $0,04 \%$ e $0,4 \%$ na presença de uma cobertura de pó de grafita sobre banhos líquidos de composição nominal Cu-8\%Sn diminui o tamanho médio de grão de até $90 \%$.

2) Adições de $\mathrm{Zr}$ sem a presença de fontes de carbono evidentes sobre banhos líquidos de composição nominal Cu-8\%Sn, desoxidados com adições de $0,025 \% \mathrm{P}$, não diminuem significativamente o tamanho de grão médio.

3) A adição de $Z r$ no teor nominal de $0,16 \% Z r$, correspondente a um teor medido de 0,04\%Zr, representa um bom compromisso para se refinar o tamanho de grão da liga de composição nominal Cu-8\%Sn nas taxas de resfriamento utilizadas ( 8 ${ }^{\circ} \mathrm{C} / \mathrm{s}$ ), resultando em um tamanho médio de $210 \mu \mathrm{m}$. Maiores teores de $\mathrm{Zr}$ não resultam em uma redução significativa no tamanho médio de grão.

4) O aumento do teor de $\mathrm{Sn}$ até $4 \%$ em ligas do sistema $\mathrm{Cu}-\mathrm{Sn}$ desoxidadas com adições de $0,025 \% \mathrm{P}$ causa um aumento no tamanho médio de grão sem ou com uma adição de $0,08 \% Z$ r. No entanto, quando não se adiciona $P$, este aumento do teor de Sn causa tendência a diminuição do tamanho de grão médio.

5) O aumento do teor de $\mathrm{Sn}$ acima de $4 \%$ em ligas do sistema Cu-Sn desoxidadas com adições de 0,025\%P diminui o tamanho de grão médio seja na presença ou ausência de adições de $0,08 \% Z r$.

6) O aumento do teor de $\mathrm{Sn}$ acima de $4 \%$ em ligas do sistema Cu-Sn desoxidadas com adições de $0,025 \% \mathrm{P}$ aumenta o efeito de redução do tamanho médio de grão causado por adições de $0,08 \% Z r$, potencializando o seu efeito inoculante.

7) Um aumento da temperatura mínima da recalescência (Tu) observado nas curvas de resfriamento dos ensaios de adições crescentes de $\mathrm{Zr}$ à liga $\mathrm{Cu}-8 \% \mathrm{Sn}$ indica uma diminuição do tamanho médio de grão.

8) A diminuição do super-resfriamento da recalescência $\left(\Delta T_{R}-U\right)$, do período da recalescência ( $\left.\mathrm{t}_{1}\right)$ e da área do pico da recalescência $(\mathrm{PL})$ indicam uma diminuição do tamanho médio de grão em ligas do sistema Cu-Sn para diferentes teores de 
Sn e adições de $Z r$, indicando uma possibilidade de controle do tamanho médio de grão a partir das curvas de resfriamento.

9) Padrões de difração de elétrons e microanálises de composição química EDS mostram que adições de $\mathrm{Zr}$ a banhos líquidos das ligas do sistema Cu-Sn com cobertura de pó de grafita resultam no aparecimento de um precipitado facetado, geralmente no formato de disco hexagonal, que tem estrutura e composição correspondentes às do $\mathrm{ZrC}$. Este precipitado apresenta uma estrutura cúbica de faces centradas do tipo $\mathrm{NaCl} F m-3 m$, do grupo espacial 225, e corresponde ao sistema cristalino da fase-matriz, Cu- $\alpha$.

10)O parâmetro de desajuste entre os reticulados do Cua e do $\mathrm{ZrC}$ calculados teoricamente para diversas combinações de planos e direções cristalinas dos dois reticulados apresentou um valor mínimo de 1,9\% ((110) [001] do ZrC e (111) [-101] do Cua.), indicando que as partículas de $\mathrm{ZrC}$ podem atuar como centros eficientes de nucleação heterogênea do Cua.

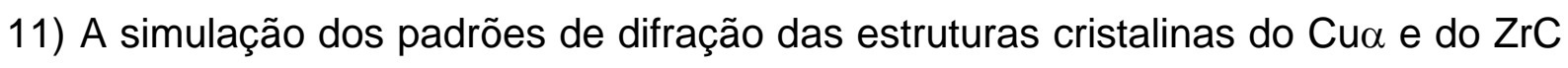
baseadas em padrões de difração de elétrons medidos experimentalmente indica a existência nas amostras do presente trabalho de uma possível relação de orientação entre o Cu- $\alpha$ e o ZrC do tipo (0 2 2) [ 1 - 1 1 1]Cu- $\alpha$ II (2 -2 2) [ 1 1-1-2 ]ZrC com desajuste entre os reticulados de $4,5 \%$.

12) O alinhamento das franjas de rede da matriz $(\mathrm{Cu} \alpha)$ e do precipitado $(\operatorname{ZrC})$ na interface matriz-precipitado, observada nas amostras do presente trabalho em imagens de alta resolução obtidas no microscópio eletrônico de transmissão, indica a existência de um reduzido desajuste entre os reticulados da matriz e precipitado, representando mais uma evidência da eficiência das partículas de $\mathrm{ZrC}$

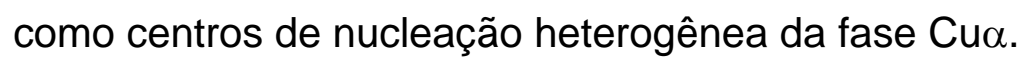




\section{REFERÊNCIAS BIBLIOGRÁFICAS}

ACHARYA, N.N.; MUKUNDA, P.G. Metallography of copper tin alloys. Metallography, v. 21, n. 2, p. 137-150, 1988.

APELIAN, D.; SIGWORTH, G.K.; WHALER, K.R. Assessment of grain refinement and modificationof Al-Si foundry alloys by thermal analysis. AFS Transactions., v. 161, n. p. 297-307, 1984.

ARGYROPOULOS, S.; CLOSSET, B.; GRUZLESKI, J.E.; OGER, H. The quantitative control of modificatiion in Al-Si foundry alloys using a thermal analysis technique. AFS Transactions., v. 91, n. 27, p. 351-358, 1983.

ARIAS, D.; ABRIATA, J.P. Cu-Zr (copper-zirconium). Bulletin of Alloy Phase Diagrams, v. 11, n. 5, p. 452-459, 1990.

ASM-HANDBOOK, 1998. Asm handbook - alloy phase diagrams. In: Asm handbook alloy phase diagrams. American Society for Metals, Metals Park, $\mathrm{OH}$.

BACKERUD, L.; KRÓL, E.; TAMMINEN, J. Solidification characteristics of aluminum alloys vol. 1 Olso, Norway., SkanAluminium, 1986.

BACKERUD, S.L.; SIGWORTH, G.K. Recent developments in thermal analysis of aluminum casting alloys. AFS Transactions., v. 64, n. p. 459-464, 1989.

BARLOW, J.O.; STEFANESCU, D.M. Computer-aided cooling curve analysis revised. AFS Transactions., v. 105, n. 4, p. 349-354, 1997.

BRAMFITT, B.L. Effect of carbide and nitride additions on heterogeneous nucleation behavior of liquid iron. Metallurgical Transactions, v. 1, n. 7, p. 1987-\&, 1970.

CAI, Y.; TAN, M.; SHEN, G.; SU, H. Microstructure and heterogeneous nucleation phenomena in cast SiC particles reinforced magnesium composite. Materials Science and Engineering: A, v. 282, n. 1, p. 232-239, 2000.

CERQUEIRA, E.O.; POPP, R.J.; KUBOTA, L.T. Utilização de filtro de transformada de fourier para a minimização de ruído em sinais analíticos. Química nova, v. 23, n. 5, p. 690-698, 2000.

CHARBONNIER, J. Microprocessor assisted thermal analysis of aluminum alloy structures. AFS Transactions., v. n. 133, p. 907-922, 1984.

CIBULA, $A$. The mechanism of grain refinement of sand castings in aluminium alloys. Journal of the Institute of Metals, v. 76, n. 4, p. 321-360, 1949.

CIBULA, A. Grain-refining additions for cast copper alloys. Journal of the Institute of Metals, v. 82, n. 11, p. 513-524, 1954.

CIBULA, A.; RUDDLE, R.W. The effect of grain-size on the 10-sile properties of high-strength cast aluminium alloys. Journal of the Institute of Metals, v. 76, n. 4, p. 361-376, 1949.

CISSÉ, J.; BOLLING, G.F.; KERR, H.W. Crystallographic orientations between aluminum grown from melt and various titanium compounds. Journal of Crystal Growth, v. 13, n. May, p. 777-781, 1971.

CISSÉ, J.; KERR, H.W.; BOLLING, G.F. The nucleation and solidification of AI-Ti alloys. Metallurgical Transactions, v. 5, n. 3, p. 633-641, 1974.

COUTURE, A.; EDWARDS, J., O. Grain refinement of sand cast bronzes and its influence on their properties. AFS Transactions., v. 82, n. p. 453-461, 1973.

CROSSLEY, F.A.; MONDOLFO, L.F. Mechanism of grain refinement in aluminum alloys. Transactions of the American Institute of Mining and Metallurgical Engineers, v. 191, n. 12, p. 1143-1148, 1951. 
DANTZIG, J.A.; RAPPAZ, M. Solidification. EFPL Press, 2009.

DAVIES, I.G.; DENNIS, J.M.; HELLAWEL.A Nucleation of aluminum grains in alloys of aluminum with titanium and boron. Metallurgical Transactions, $v$. 1, n. 1, p. 275-, 1970.

EASTON, M.; STJOHN, D. Grain refinement of aluminum alloys: Part i. The nucleant and salute paradigms - a review of the literature. Metallurgical and Materials Transactions a-Physical Metallurgy and Materials Science, v. 30, n. 6, p. 1613-1623, 1999.

EVANS, J.W. Physical chemistry of high temperature technology, e. T. Tukdogan, academic press, april 1980. AIChE Journal, v. 28, n. 5, p. 868-868, 1982.

FARINA, M. Uma introdução à microscopia eletrônica de transmissão. São Paulo: Livraria da física, v. n. p. 2010.

FLEMINGS, M.C. Solidification processing. New York, McGraw-Hill, 1974.

GARCIA, A. Solidificação - fundamentos e aplicações. Campinas, Editora da Unicamp, 2001.

GESKIN, E.S.; LING, E.; WEINSTEIN, E. Experimental study of copper deoxidation by charcoal filtration. American Foundrymen's Society, v. 29, n. p. 155-158, 1986.

GOULD, G.C.; FORM, G.W.; WALLACE, J.F. Grain refinement of copper. Modern Casting, v. n. p. 144-153, 1960.

GREER, A.L.; BUNN, A.M.; TRONCHE, A.; EVANS, P.V.; BRISTOW, D.J. Modelling of inoculation of metallic melts: Application to grain refinement of aluminium by Al-Ti-B. Acta Materialia, v. 48, n. 11, p. 2823-2835, 2000.

IBARRA, D.G. Control of grain refinement of Al-Si alloys by thermal analysis. Montreal, Canada., 1999. 165 p. Tese McGill University.

JACKSON, H.F.; LEE, W.E. Comprehensive nuclear materials. Oxford, Elsevier, 2012.

JOAQUIM, M.B.; SARTORI, J.C. Análise de fourier. São Carlos EDUSP, 2003.

JOHNSSON, M.; BACKERUD, L. The influence of composition on equiaxed crystal growth mechanisms and grain size in Al alloys. Zeitschrift Fur Metallkunde, v. 87, n. 3, p. 216-220, 1996.

JONES, G.P.; PEARSON, J. Factors affecting grain refinement of aluminum using titanium and boron additives. Metallurgical Transactions B-Process Metallurgy, v. 7, n. 2, p. 223-234, 1976.

KALPAKJIAN, S. Manufacturing engineering and technology. 5th Upper Saddle River, NJ, Pearson/Prentice Hall, 2006.

KEMPTER, C.P.; FRIES, R.J. Crystallographic data. 189. Zirconium carbide. Analytical Chemistry, v. 32, n. 4, p. 570-570, 1960.

KIM, W.T.; CANTOR, B. Solidification behavior of Pb droplets embedded in a $\mathbf{C u}$ matrix. Acta Metallurgica Et Materialia, v. 40, n. 12, p. 3339-3347, 1992.

KIM, W.T.; CANTOR, B. Heterogeneous nucleation of Al2Cu in Al-Cu eutectic liquid droplets embedded in an al matrix. Acta Metallurgica Et Materialia, v. 42, n. 9, p. 3045-3053, 1994.

KLINGER, M.; JAGER, A. Crystallographic tool box (crystbox): Automated tools for transmission electron microscopists and crystallographers. Journal of Applied Crystallography, v. 48, n. 6, p. 2012-2018, 2015.

KURZ, W.; FISHER, D.J. Fundamentals of solidification. 3rd Aedermannsdorf, Trans Tech Publications, 1989. 
LOU, M.Y.W.; GRANT, N.J. Identification of Cu5Zr phase in $\mathrm{Cu}-\mathrm{Zr}$ alloys. Metallurgical Transactions a-Physical Metallurgy and Materials Science, v. 15, n. 7, p. 1491-1493, 1984.

LU, L.; DAHLE, A.; STJOHN, D. Grain refinement efficiency and mechanism of aluminium carbide in Mg-Al alloys. Scripta Materialia, v. 53, n. 5, p. 517-522, 2005.

MARASLI, N.; HUNT, J.D. The use of measured values of surface energies to test heterogeneous nucleation theory. Journal of Crystal Growth, v. 191, n. 3, p. 558-562, 1998.

MARCANTO, J.A.; MONDOLFO, L.F. Nucleation of aluminium by several intermetallic compounds. Journal of the Institute of Metals, v. 98, n. p. 23-27, 1970.

MARTORANO, M.A.; CAPOCCHI, J.D.T. Dendrite structure control in directionally solidified bronze castings. International Journal of Cast Metals Research, v. 13, n. 1, p. 49-57, 2000.

MAXWELL, I.; HELLAWELL, A. Simple model for grain refinement during solidification. Acta Metallurgica, v. 23, n. 2, p. 229-237, 1975.

MCCARTNEY, D.G. Grain refining of aluminum and its alloys using inoculants. International Materials Reviews, v. 34, n. 5, p. 247-260, 1989.

MOHANTY, P.S.; GRUZLESKI, J.E. Mechanism of grain-refinement in aluminum. Acta Metallurgica Et Materialia, v. 43, n. 5, p. 2001-2012, 1995.

MONDOLFO, L.F. Grain-refinement in the casting on non-ferrous alloys. Journal of Metals, v. 34, n. 8, p. 7-7, 1982.

MORIKAWA, H.; SHIMIZU, K.; RSQUO; ICHI; NISHIYAMA, Z. On the structure of quenched beta phase and its decomopsition products in copper-tin alloy. Transactions of the Japan Institute of Metals, v. 8, n. 3, p. 145-152, 1967.

NEFF, D.V.; SOLON, O. Fluxing, degassiing, and deoxidation of copper'-base alloys. American Foundrymen's Society, v. n. 66, p. 439-450, 1989.

NEFF, V.D. Nonferrous molten metal processes. ASM Handbook - Casting, v. 15, n. 10, p. 44, 1992.

OZGOWICZ, W. Investigation on the deformability of tin bronzes CuSn6 modified with zirconium on the industrial hot rolling of flat ingots. Journal of Achievements in Materials and Manufacturing Engineering, JAMME, v. 24, n. 1, p. 78-83, 2007.

OZGOWICZ, W.; NAWRAT, G. Electrolytic extractions obtained from Cu-Zr and Cu-Ce alloys and their x-ray phase analysis. Journal of Achievements in Materials and Manufacturing Engineering, v. 20, n. 1-2, p. 171-174, 2007.

PATCHETT, J.; ABBASCHIAN, G. Grain refinement of copper by the addition of iron and by electromagnetic stirring. Metallurgical and Materials Transactions B, v. 16, n. 3, p. 505-511, 1985.

PEREPEZKO, J.H., 9th ed., v. 15, ASM Handbook - Casting, American Society for Metals, Metals Park, OH, 1998a.

PEREPEZKO, J.H. Asm handbook - casting, american society for metals. 9th ed. United States of America, Metals Park, OH., 1998b.

REIF, W.; WEBER, G. A new grain refiner for copper-zinc alloys containing 2542-percent zinc. Metall, v. 41, n. 11, p. 1131-1137, 1987a.

REIF, W.; WEBER, G. A new grain refiner for copper-zinc alloys containing 2542\% zinc. Metall, v. 41, n. p. 1131-1137, 1987b. 
SADAYAPPAN, M.; COUSINEAU, D.; ZAVADIL, R.; SAHOO, M.; MICHELS, H.T. Grain refinement of permanent mold cast copper base alloys. AFS Transactions, v. 110, n. p. 505-514, 2002.

SADAYAPPAN, M.; THOMSON, J.P.; ELBOUJDAINI, M.; PING GU, G.; SAHOO, M., 2005. Grain refinement of permanent mold cast copper base alloys. In: Other Information: PBD: 1 Apr 2005, Grain refinement of permanent mold cast copper base alloys. In: Other Information: PBD: 1 Apr 2005, US Department of Energy, pp.1-124.

SAUNDERS, N.; MIODOWNIK, A.P. The Cu-Sn (copper-tin) system. Bulletin of Alloy Phase Diagrams, v. 11, n. 3, p. 278-287, 1990.

SAVITZKY, A.; GOLAY, M.J.E. Smoothing + differentiation of data by simplified least squares procedures. Analytical Chemistry, v. 36, n. 8, p. 1627-1639, 1964.

SCHETKY, L.M.; BACKERUD, L.; LILJENVALL, L.M.; STEEN, H. Microstructure and macrostructure of coper alloys and the use of silidication diagrams. AFS Transactions., v. 158, n. p. 137-144, 1983.

SPARKMAN, D.; KEARNEY, A. Breakthrough in aluminium alloy thermal analysis technology for process control. AFS Transactions., v. 102, n. p. 455-460, 1994.

SPITTLE, J.A. Grain refinement in shape casting of aluminium alloys. International Journal of Cast Metals Research, v. 19, n. 4, p. 210-222, 2006.

STEFANESCU, D. Solidification in the presence of a third phase. In: eds. Science and engineering of casting solidification, second edition, Springer US; 2009. p. 1-33.

TARSHIS, L.A.; WALKER, J.L.; RUTTER, J.W. Experiments on solidification structure of alloy castings. Metallurgical Transactions, v. 2, n. 9, p. 2589-\&, 1971.

THOMPSON-RUSSELL, K.; EDINGTON, J. Practical electron microscopy in materials science. Monographs, Phillips Technical Library, v. n. p. 2, 1977.

TOTH, L. Transition metal carbides and nitrides. Elsevier, 2014.

TRIVEDI, R.; KURZ, W. Dendritic growth. International Materials Reviews, v. 39, n. 2, p. 49-74, 1994.

TURNBULL, D.; FISHER, J.C. Rate of nucleation of condensed systems. The Journal of chemical physics, v. 1, n. p. 71-73, 1949.

TURNBULL, D.; VONNEGUT, B. Nucleation catalysis. Industrial and Engineering Chemistry, v. 44, n. 6, p. 1292-1298, 1952.

UPADHYA, K.G.; STEFANESCU, D.M.; LIEU, K.; YEAGER, D.P. Cmputer-aided cooling curve analysis: Principles ans applications in metal casting. AFS Transactions., v. 47, n. p. 61-66, 1989.

VANDER VOORT, G.F. Metallogrphy: Principles and practice. 1984.

WALLACE, J.F.; KISSLING, R.J. Grain refinement of copper alloy castings. Foundry, v. n. p. 54-57, 1963.

WANG, F.; LIU, Z.; QIU, D.; TAYLOR, J.A.; EASTON, M.A.; ZHANG, M.-X. Revisiting the role of peritectics in grain refinement of al alloys. Acta Materialia, v. 61, n. 1, p. 360-370, 2013.

WANG, Y.; ZENG, X.; DING, W. Effect of Al-4Ti-5B master alloy on the grain refinement of az31 magnesium alloy. Scripta Materialia, v. 54, n. 2, p. 269273, 2006.

WILLIAMS, D.B.; CARTER, C.B. Transmission electron microscopy a textbook for materials science. New York, USA, springer, 2009. 